\title{
Lichtinduzierte Primärprozesse in reversibel photoschaltbaren fluoreszierenden Proteinen: Zeitaufgelöste Spektroskopie von Padron0.9 und rsFastLime
}

\author{
zur Erlangung des \\ mathematisch-naturwissenschaftlichen Doktorgrades \\ "Doctor rerum naturalium" \\ der \\ Georg-August-Universität Göttingen \\ im \\ Promotionsprogramm Chemie \\ der Georg-August-University School of Science (GAUSS)
}

vorgelegt von

\section{Arne Walter}

aus Goslar

\begin{abstract}
angefertigt im
Institut für Physikalische Chemie

der Georg-August-Universität zu Göttingen
\end{abstract}

2014 


\section{Betreuungsausschuss}

Prof. Dr. Jörg Schroeder, Abteilung Wodtke, Institut für Physikalische Chemie, Göttingen

Prof. Dr. Dirk Schwarzer, Abteilung Wodtke, Max-Planck-Institut für biophysikalische Chemie

\section{Mitglieder der Prüfungskommission}

Referent: Prof. Dr. Jörg Schroeder, Abteilung Wodtke, Institut für Physikalische Chemie, Göttingen

Korreferent: Prof. Dr. Dirk Schwarzer, Abteilung Wodtke, Max-PlanckInstitut für biophysikalische Chemie

\section{Weitere Mitglieder der Prüfungskommission}

Prof. Dr. Guido Clever, Arbeitsgruppe Clever, Georg-August-Universität Göttingen

Prof. Dr. Jörg Enderlein, Arbeitsgruppe Enderlein, Georg-AugustUniversität Göttingen

Prof. Dr. Stefan Jakobs, Abteilung Hell, Max-Planck-Institut für biophysikalische Chemie

Prof. Dr. Claudia Steinem, Arbeitsgruppe Steinem, Georg-AugustUniversität Göttingen

Tag der mündlichen Prüfung: 09.07.2014 


\section{Danksagung}

Herrn Prof. Dr. Jörg Schroeder danke ich für die exzellente Betreuung, unzählige Anregungen und die beständige Unterstützung beim Anfertigen dieser Arbeit.

Herrn Prof. Dr. Dirk Schwarzer danke ich für die Übernahme des Korreferats, tatkräftige Unterstützung beim experimentellen Aufbau und intensive fachliche Diskussionen.

Herrn Prof. Dr. Stefan Jakobs danke ich für die Versorgung mit großen Mengen Proteinlösung, fachlicher Unterstützung in der Handhabung derselben und interdisziplinäre Einblicke.

Herrn Prof. Dr. Stefan Hell danke ich für die teilweise Finanzierung meiner Forschungsarbeit, wodurch ich überhaupt erst in Kontakt mit fluoreszierenden Proteinen gekommen bin.

Herrn Prof. Dr. Juergen Troe und Herrn Prof. Dr. Alec Wodtke danke ich für die Aufnahme in die scheidende alte und wachsende neue Arbeitsgruppe, in denen ich mit der Untersuchung von Proteinen nur fachlich ein Sonderling war.

Natürlich gilt auch den Mitgliedern eben jener Arbeitsgruppen mein Dank. Es war und ist eine wirklich tolle Atmosphäre im zweiten Stock der physikalischen Chemie, eine spannende Mischung aus ehrlicher Begeisterung für Forschung und Wissenschaft und ebenso ehrlicher Begeisterung für Tischfußball und Ähnliches. Vielen Dank an meine Bürokollegen, die sich mit großem Langmut immer wieder die gleichen bunten Kurven ansehen und die verworrenen Erklärungsversuche dazu anhören mussten. Danke an Jessica, Inge und Reinhard, ohne deren Infrastrukturen wissenschaftliche Arbeit in den Morgenstunden effektiv nicht und sonst nur schwer möglich gewesen wäre. Ein großer Dank geht auch an die Reste der Arbeitsgruppe Troe, Lars und Elsa, deren Vorrat an Nahrungsmitteln erstaunlich ist und deren sich kaum überschneidende Kenntnisse in Sachen Computer und Orthographie eine große Hilfe waren.

Ein großer Dank auch an Dr. Martin Andresen und Dr. Tanja Brakemann vom MPI, die mich mit Protein, Gerät und Zeit unterstützt haben. 
Meinen sämtlichen Bachelor-, Diplom- und Masterstudenten Harald, Martin, Robert, Marno, Steffen und schließlich Hinrich Hahn, der das Femtogeschäft zuletzt am Leben hielt, danke ich für die gute Zusammenarbeit. Der Popolski Show, Blobby Volley und Dynablaster habt ihr überstanden, ich wünsche alles Gute und dass die Laser laufen!

Ein ebenso großer Dank geht an die fähigen Menschen in den sämtlichen Werkstätten, elektronisch, gläsern, mechanisch, an der Universität wie am MPI, die alle schnell, findig, präzise und auch noch sehr umgänglich sind.

Dank auch allen Mitgliedern und Zuhörern der Country, Western und Weihnachtsband 'Alec Wodtke and the Heartbreakers' und Dr. Tim Schäfer on his never ending mission from god, putting the band back together. Sportlicher Dank für wunderbare Stunden der Rekreation geht an den geschätzten Kollegen Dan Engelhardt, dessen american way of golf eine gekonnte Mischung aus anger, fury, rage und granny ist und in $51 \%$ aller Spiele keine Gefahr für mich darstellte, give or take $1 \%$.

Abseits der Uni gab und gibt es natürlich auch viele Menschen, ohne die es deutlich weniger gut gewesen wäre und die durch geschaffenen Ausgleich ebenfalls zum Gelingen dieser Arbeit beigetragen haben. Meine Eltern: Wo soll man da anfangen? Danke Hanna, danke Dieter. Dora. Und, und hier zitiere ich mich selbst: „dann eigentlich nochmal Dora“. Meine sämtlichen Brüder. TobiDanielHolgerPatziSusiNicolePhilippGordonJohannesundundund. Der 1. Golfklub Goslar e.V. - constant rough. Alle Freunde der 20er und 50er Jahre. Das Team aus KFS und KSF... euch allen vielen Dank, sozusagen als Zwischenbemerkung, denn es geht weiter. 


\section{Abstract}

Within this project, the photodynamics of the reversibly switchable fluorescent proteins Padron0.9 and rsFastLime after photoexcitation were investigated. Cis/trans-isomerization of the chromophore is an essential element of the reversible switching between a fluorescent ON- and a non-fluorescent OFF-state observed on the proteins Padron0.9 and rsFastLime. Both isomers establish an equilibrium between the chromophor's protonated and deprotonated form. The different chromophore species were isolated and selectively excited to elucidate the main reaction pathways by ultrafast pump-probespectroscopy. Intermediate states and the corresponding spectra were identified by extensive spectral and kinetic modelling of the obtained transient data.

For both proteins, the strongly fluorescent $\mathrm{ON}$-state corresponds with the deprotonated cis-species. After excitation, it decays monoexponentially with a lifetime of 1.16 ns and 0.9 ns for Padron0.9 and rsFastLime, respectively. The deprotonated trans-species of Padron 0.9 decays within 1 ps, dominated by internal conversion into a hot ground state. About one third relaxes into a more stable excited state with a lifetime of $7 \mathrm{ps}$. The excited protonated cisrsFastLime has a lifetime of 8 ps, mostly due to internal conversion. About $15 \%$ relax into a more stable exited state with a lifetime of $215 \mathrm{ps}$.

Excitation of protonated cis-Padron0.9 is followed by a fast exited state proton transfer $k_{H}=2.0 \mathrm{ps}^{-1}$ to an exited cis-intermediate, identified by a strong $\mathrm{H} / \mathrm{D}$-isotope effect. This intermediate has a lifetime of $37 \mathrm{ps}$ and relaxes to a corresponding intermediate ground state and the exited fluorescent ONstate with equal probability. The intermediate ground state is subsequently protonated within 2 ps, as shown by pump-dump-probe spectroscopy. In addition, the disturbed ground state protonation equilibrium is reestablished within 45 ps.

Exited state dynamics of protonated trans-rsFastLime are dominated by internal conversion to the ground state within $2.1 \mathrm{ps}$. One third of the excited molecules relax to a intermediate excited state with a lifetime of $14 \mathrm{ps}$ and subsequently to a more stable exited state with a life time of 94 ps with 
subsequent conversion to a cis-groundstate. For protonated cis-rsFastLime, no evidence for an exited state proton transfer was found.

Quantum yields for the photoinduced switching processes found for Padron0.9 are $\Phi_{\text {cis }} \longrightarrow$ trans $(500 \mathrm{~nm})=0.0003$ and $\Phi_{\text {trans }} \longrightarrow$ cis $(400 \mathrm{~nm})=0.02$. The yields are too low to accurately identify the respective products. Neither rsFastLime protonated isomer's spectrum can be distinguished, so product formation may occur but cannot be assigned. For Padron0.9, the excited state proton transfer is proposed to be the first step on the inefficient isomerization path trans $\longrightarrow$ cis. Regardless of the quantum yields for isomerization, it was shown that the different ground state protonation equilibrium for Padron 0.9 and rsFastLime suffice to explain the inverse switching characteristics of these structually very similar proteins. 


\section{Zusammenfassung}

In dieser Arbeit wurde die Dynamik der reversibel schaltbaren fluoreszierenden Proteine Padron0.9 und rsFastLime unmittelbar nach Photoanregung untersucht. Der reversible Schaltprozess zwischen dem fluoreszierenden AN- und nicht fluoreszierenden AUS-Zustand der Proteine Padron0.9 und rsFastLime beinhaltet eine cis/trans-Isomerisierung ihres Chromophors. Beide Isomere befinden sich in einem Gleichgewicht zwischen einer protonierten und einer deprotonierten Form. Durch Femtosekunden-PumpProbe-Spektroskopie wurden die dominanten Reaktionspfade der verschiedenen Spezies des Proteinchromophors durch selektive Anregung aufgeklärt. Durch spektrale und kinetische Modellierung der aufgenommenen transienten Daten wurden intermediäre Zustände und ihre Spektren identifiziert.

Die deprotonierte cis-Spezies beider Proteine wird dem stark fluoreszierenden AN-Zustand zugeordnet. Nach Anregung fällt sie monoexponentiell mit einer Lebensdauer von $1.16 \mathrm{~ns}$ für Padron0.9 bzw. 0.9 ns für rsFastLime in den Grundzustand zurück. Die deprotonierte trans-Spezies von Padron0.9 zerfällt mit einer Lebensdauer von 1 ps. Hier dominiert innere Konversion in einen heißen Grundzustand, etwa ein Drittel geht in einen stabileren angeregten Zustand mit einer Lebensdauer von 7 ps über. Die protonierte cisSpezies von rsFastLime zeigt eine Lebensdauer von 8 ps, innere Konversion in den Grundzustand stellt hier den primären Reaktionsweg dar. Ein Siebtel der angeregten Moleküle wird im angeregten Zustand stabilisiert und fällt nach einer Lebensdauer von 215 ps zurück in einen protonierten Grundzustand. Nach Anregung der cis-Spezies von Padron0.9 erfolgt ein schneller Protonentransfer $k_{H}=2.0 \mathrm{ps}^{-1}$ zu einer angeregten cis-Spezies, der durch einen starken H/D-Isotopeneffekt identifiziert wurde. Diese intermediäre cis-Spezies hat eine Lebensdauer von $37 \mathrm{ps}$ und relaxiert zu etwa gleichen Teilen zu der langlebigen fluoreszierenden Spezies des AN-Zustandes oder geht in einen intermediären Grundzustand über, der innerhalb von 2 ps protoniert wird. Die Geschwindigkeit dieser Protonierung und das Spektrum des intermediären Grundzustandes wurden durch Pump-Dump-Probe Spektroskopie ermittelt. Parallel zu der Reaktionskaskade im angeregten Zustand wurde die Wiederherstellung des gestörten Protonierungsgleichgewichtes im Grundzustand auf einer Zeitskala von 45 ps beobachtet. Bei 
der protonierten trans-Spezies von rsFastLime dominiert nach einer Lebensdauer von 2.1 ps die innere Konversion in den Grundzustand. Etwa ein Drittel der angeregten Moleküle relaxieren in einen intermediären angeregten Zustand mit der Lebensdauer von 14 ps und von dort in einen mit 94 ps langlebigeren angeregten Zustand oder durch innere Konversion in einen cis-Grundzustand. Messungen der protonierten cis-Spezies bei niedrigem $\mathrm{pH}$-Wert zeigten keinen Protonentransferschritt im angeregten Zustand.

Die Quantenausbeuten der photoinduzierten Schaltprozesse für Padron0.9 sind mit $\Phi_{\text {cis }} \longrightarrow$ trans $(500 \mathrm{~nm})=0.0003$ und $\Phi_{\text {trans }} \longrightarrow$ cis $(400 \mathrm{~nm})=0.02 \mathrm{zu}$ niedrig, um Schaltprodukte direkt zu identifizieren. Die protonierten Isomere von rsFastLime sind spektral nahezu identisch, so dass auch hier die Produktbildung nicht eindeutig ist. Für Padron0.9 wird der Protonentransfer im angeregten Zustand als erster Schritt auf dem ineffizienten cis $\longrightarrow$ transIsomerierungspfad vorgeschlagen. Bei der protonierten trans-Spezies von rsFastLime steht innere Konversion in Konkurrenz mit einem sehr effizienten Isomerisierungspfad trans $\longrightarrow$ cis. Unabhängig von den Ausbeuten der einzelnen Pfade wurde gezeigt, dass das unterschiedliche Protonierungsgleichgewicht von Padron0.9 und rsFastLime im Grundzustand genügt, um das hinsichtlich der Anregungswellenlängen umgekehrte Schaltverhalten der beiden strukturell sehr ähnlichen Proteine zu erklären. 


\section{Inhaltsverzeichnis}

1 Grundlagen 1

1.1 Fluoreszierende Proteine . . . . . . . . . . . . . . . 1

1.1 .1 GFP . . . . . . . . . . . . . . . . 1

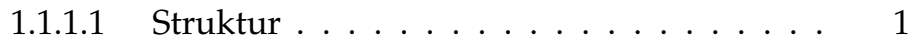

1.1.1.2 Spektren ............. 4

1.1.1.3 Proteindynamik und Zustände .... . . 4

1.1.2 Photoaktivierbare Proteine . . . . . . . . . . 7

1.1.3 Reversibel Schaltbare Fluoreszierende Proteine . . . . 7

1.1.4 Dronpa . . . . . . . . . . . . . . 8

1.1.4.1 Spektren .............. 10

1.1.4.2 Proteindynamik und Zustände . . . . . . . 12

1.1 .5 rsFastLime . . . . . . . . . . . . . . . . . 13

1.1.5.1 Spektren ............ . . . . . . .

1.1.6 Padron . . . . . . . . . . . . . . . . . . 14

1.1.6.1 Spektren .............. 15

1.1.6.2 Proteindynamik und Zustände . . . . . . 16

1.2 Das Chromophor . . . . . . . . . . . . . . . . . . . 19

1.2.1 Grundzustand in Lösung . . . . . . . . . . . . . . . 19

1.2.2 Angeregte Zustände . . . . . . . . . . . . . . . . 20

1.3 Chromophorumgebung ................ 24

1.3.1 Sterische Wechselwirkungen ........... 24

1.3.2 Wasserstoffbrücken und elektrostatische Wechselwirkungen .................... 24

1.3.3 Titrationsverhalten . . . . . . . . . . . . . . . 25

1.4 Kinetischer Isotopeneffekt . . . . . . . . . . . . . . . .

1.4.1 Primärer Isotopeneffekt . . . . . . . . . . . . . . . . 28

1.4.1.1 Theorie des Übergangszustandes . . . . . . $\quad 28$

1.4.1.2 Tunneleffekt . . . . . . . . . . . . 30

2 Experimentelle Technik 31

2.1 Experimenteller Aufbau . . . . . . . . . . . . . . . . . . 31

2.1.1 Clark MXR-CPA $2001 \ldots \ldots \ldots$

2.1 .2 NOPA $\ldots \ldots \ldots \ldots \ldots \ldots$

2.1 .3 SHG und SFG . . . . . . . . . . . . . . \$34 
2.1.4 Weißlichtkontinuum . . . . . . . . . . . . 35

2.1 .5 Interferometer . . . . . . . . . . . . . . . . .

2.1.6 Pumpenkreislauf . . . . . . . . . . . . . . . . . 39

2.2 Messmethode . . . . . . . . . . . . . . . 41

2.2.1 Pump-Probe-Spektroskopie . . . . . . . . . . . 41

2.2.2 Pump-Dump-Probe-Spektroskopie . . . . . . . . . . 42

2.3 Datenverarbeitung . . . . . . . . . . . . . . . 44

2.3.1 Datenaufnahme . . . . . . . . . . . . . . 44

2.3.2 Korrekturen der Daten . . . . . . . . . . . . . . 46

2.3.2.1 Kalibrierung . . . . . . . . . . . . 46

2.3.2.2 Mittelung . . . . . . . . . . . . . 46

2.3.2.3 Zeitlicher Nullpunkt . . . . . . . . . . . 46

2.3.2.4 Offset-Korrektur . . . . . . . . . . . . . . 47

2.3.3 Auswertung der zeitaufgelösten Daten . . . . . . . . 48

2.3.3.1 Anpassung von transienten Signalen . . . . 4 48

2.3.3.2 Zeit- und wellenlängenabhängige Modellierung der Daten . . . . . . . . . . . . . 51

2.4 Probenpräparation . . . . . . . . . . . . 53

3 Ergebnisse und Diskussion

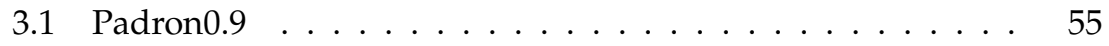

3.1 .1 Grundzustände . . . . . . . . . . . . . 5 55

3.1.2 Angeregte Zustände von $C^{-}$und $T^{-} \ldots \ldots$. . . 60

3.1.2.1 Fluoreszenz . . . . . . . . . . . . . . 60

3.1.2.2 Stimulierte Emission . . . . . . . . . . 60

3.1.2.3 Transiente Spektren . . . . . . . . . . . . . . 61

3.1.2.4 Aufstellen des kinetischen Modells . . . . . 63

3.1.2.5 Anpassung der Daten . . . . . . . . . . . . 66

3.1.2.6 Ergebnisse . . . . . . . . . . . . . . 68

3.1.3 Angeregte Zustände von $C^{H}$ bei hohem $\mathrm{pH}$-Wert . . 71

3.1.3.1 Transiente Spektren . . . . . . . . . . . 71

3.1.3.2 Aufstellen des kinetischen Modells . . . . . 72

3.1.3.3 ESPT: deuterierte Pufferlösung . . . . . . . . 74

3.1.3.4 Anpassung der Daten . . . . . . . . . . . 75

3.1.3.5 Ergebnisse . . . . . . . . . . . 75

3.1.4 Zustand $I \ldots \ldots \ldots \ldots \ldots$. . . . . . . . . . . . .

3.1.4.1 Transiente Pump-Dump-Probe-Spektren . . 78

3.1.4.2 Anpassung der Daten . . . . . . . . . . . 80

3.1.5 Angeregte Zustände von $\mathrm{C}^{H+}$ und $T^{H+}$ bei niedrigem pH-Wert . . . . . . . . . . . . 80

3.1.5.1 Transiente Spektren \& Ergebnis . . . . . . 82 


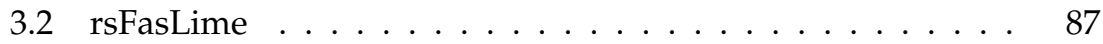

3.2.1 Grundzustände . . . . . . . . . . . . . . . . . 87

3.2.2 Angeregter Zustand von $C^{-} \ldots \ldots \ldots \ldots \ldots$

3.2.2.1 Fluoreszenz und stimulierte Emission . . . 89

3.2.2.2 Transiente Spektren . . . . . . . . . . . . . . . 89

3.2.2.3 Anpassung der Daten . . . . . . . . . . . . 93

3.2.2.4 Ergebnisse . . . . . . . . . . . . . . 93

3.2.3 Angeregte Zustände von $C^{H}$ und $T^{H} \ldots \ldots \ldots$. . . . 94

3.2.3.1 Transiente Spektren . . . . . . . . . . . . . . 95

3.2.3.2 Aufstellen des kinetischen Modells für $C^{H}$. 97

3.2.3.3 Ergebnisse für $C^{H} \ldots \ldots \ldots \ldots$. . . . . 98

3.2.3.4 Kinetisches Modell und Ergebnisse für $T^{H}$. 99

3.3 Photoisomerisierung . . . . . . . . . . . . . . 103

3.4 Ausblick . . . . . . . . . . . . . . . . . . 107

3.4.1 Photoschalten - Ein Photostationäres Gleichgewicht? 107

\section{A Tabellenwerke}





\section{Kapitel 1}

\section{Grundlagen}

\subsection{Fluoreszierende Proteine}

\subsubsection{GFP}

Das grün fluoreszierende Protein (green fluorescent protein, GFP) der Quallenart Aequorea victoria wurde erstmals 1962 beschrieben [1]. In der Qualle überträgt das durch Chemilumineszenz blau emittierende Aequorin über Förster-Energietransfer Energie an GFP, das dann grün fluoresziert [2]. Die Primärstruktur von GFP wurde 1992 von Prasher et al. entschlüsselt [3], zwei Jahre darauf lösten Yang et al [4] und Ormö et al. [5] unabhängig voneinander die Kristallstruktur und ermöglichten damit Untersuchungen zum Einfluss veränderter Proteinumgebungen auf die Chromophoreigenschaften. Durch Mutation vom in der Natur vorkommende Wildtyp-GFP (wild-type, WT) und Verwendung ähnlicher Proteine aus anderen Quellen, wie der Koralle Echinophyllia oder der Seeanemone Anemonia sulcata, wurde seit der Entschlüsselung des GFP-Genoms eine breite Palette von fluoreszierenden Proteinen mit unterschiedlichsten spektralen und photophysikalischen Eigenschaften erstellt. GFP ist sowohl thermisch als auch $\mathrm{pH}$-stabil im Bereich $\mathrm{pH}<4$ oder $>12$ [4], bedarf keines Cofaktors zur Fluoreszenz und ist nicht toxisch, so dass es auch in lebenden Zellen eingesetzt werden kann. Die heute wohl wichtigste Funktion von GFP für die Fluoreszenzmikroskopie als DNA-Marker zur Expression in Pro- und Eukaryotischen Zellen wurde 1994, mehr als 30 Jahre nach seiner Entdeckung, von Chalfie et al. beschrieben |6|.

\subsubsection{Struktur}

WT-GFP besteht aus 238 Aminosäuren mit einer Molekülmasse von 26,9 $\mathrm{kDa}$, die eine kompakte $\beta$-Fassstruktur aus elf $\beta$-Faltblättern ausbilden (siehe Abb.1.1. Das Fass ist $42 \AA$ lang und hat einen Durchmesser von $24 \AA$ [5]. 


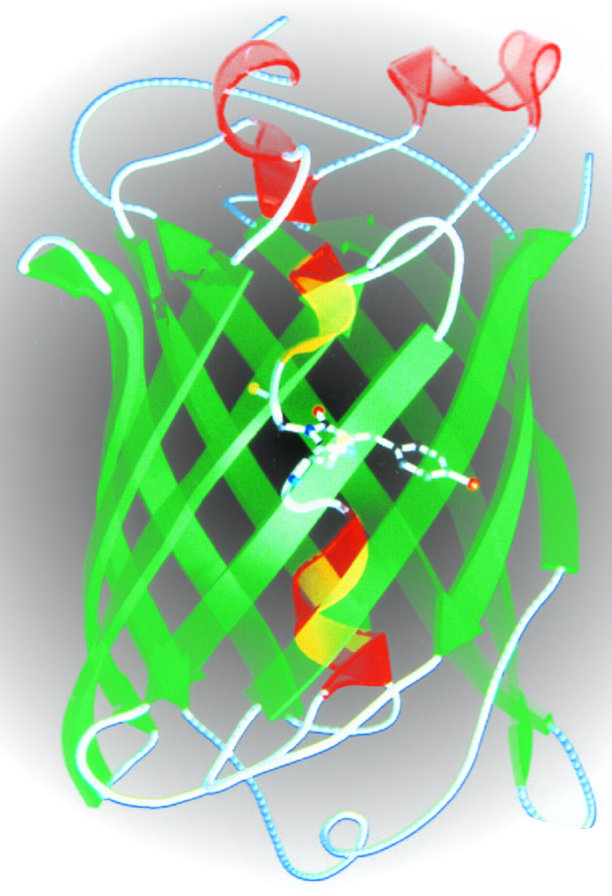

Abb. 1.1: Struktur des GFP nach Brejc et al. |7| grün: $\beta$-Faltblatt, rot: $\alpha$-Helix

Durch das Fass läuft eine einfache $\alpha$-Helix mit partiellem $3{ }_{10}$-Charakter, die in der Mitte ein 4-( $p$-Hydroxybenzyliden)-imidazolin-5-on- Chromophor aus den drei im Proteinstrang aufeinanderfolgenden Aminosäuren, Ser ${ }^{65}$, $T_{y r}{ }^{66}$ und Gly ${ }^{67}$ ausbildet (siehe Abb. 1.2). Das Chromophor steht etwa $60^{\circ}$ zur Längsachse der umgebenden $\beta$-Fassstruktur und wird vollständig umschlossen und von der Umgebung abgeschirmt. In Abb. 1.3 sind Aminosäuren und Wassermoleküle in der näheren Umgebung des Chromophors gezeigt, die das Chromophor in einem Netzwerk von Wasserstoffbrücken stabilisieren: His ${ }^{148}$, Thr $^{203}$ und Ser ${ }^{205}$ sowie ein Wassermolekül bilden Wasserstoffbrücken mit der phenolischen Hydroxylgruppe von Tyr ${ }^{66} ; A^{2} g^{96}$ und $G l n^{94}$ interagieren mit der Carbonylgruppe des Imidazolrings und $G l u^{222}$ schließlich bildet eine Wasserstoffbrücke mit der von $\operatorname{Ser}^{65}$ stammenden Seitenkette des Chromophors. 


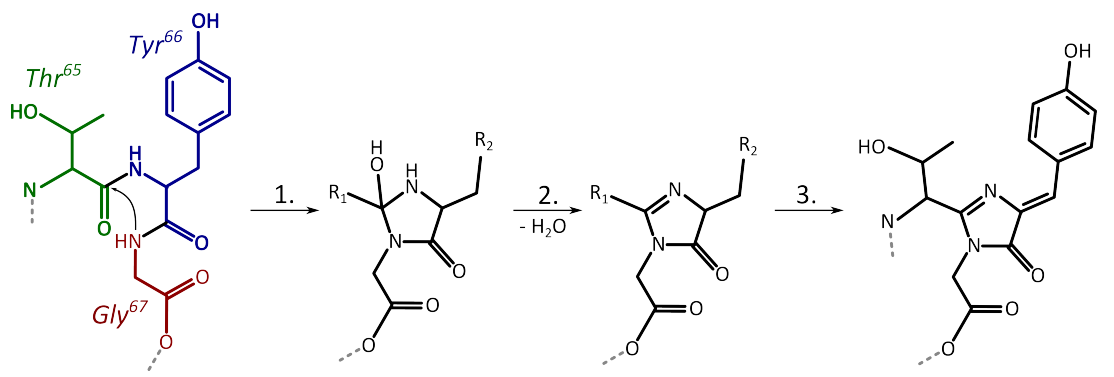

Abb. 1.2: Reaktionspfad zur Bildung des Chromophors von GFP nach Reid et al. |8| Reaktionsschritte: 1. Zyklisierung, 2. Dehydrierung, 3. Oxidation

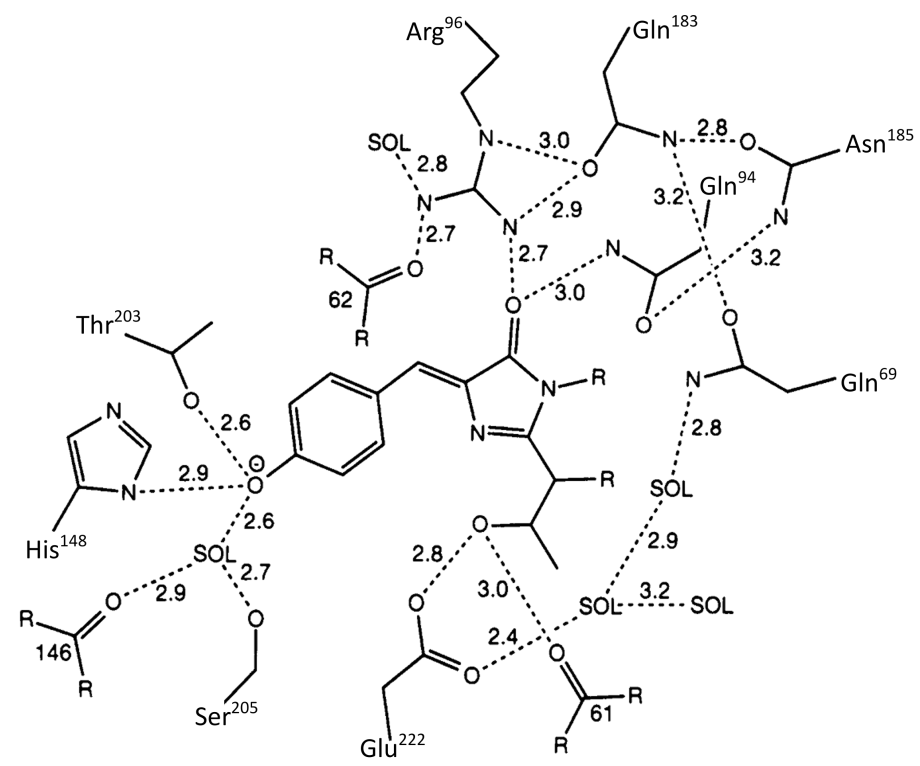

Abb. 1.3: Umgebung und Koordination des GFP-Chromophors nach Ormö et al. |5| gestrichelte Linien: Wasserstoffbrücken, Länge in $\AA$ angegeben 


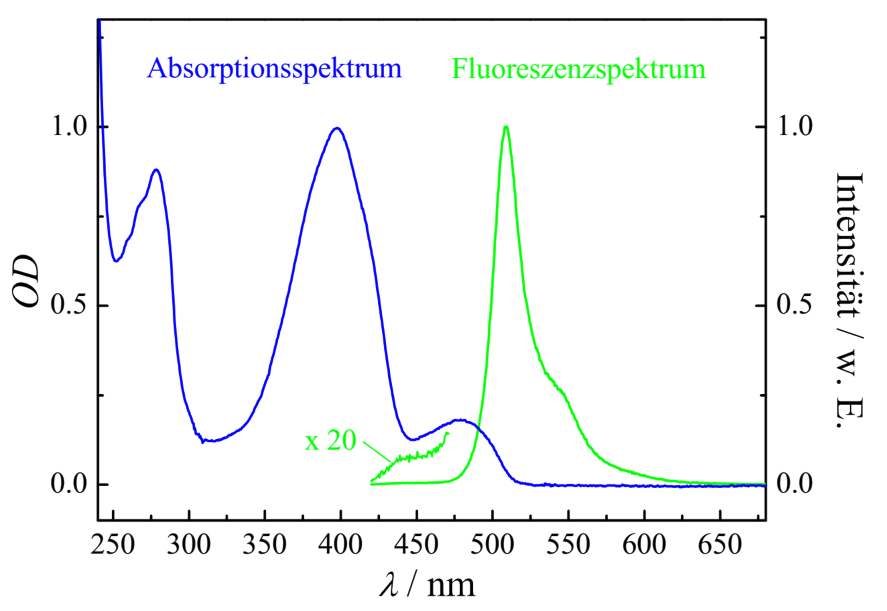

Abb. 1.4: Absorption und Emission des GFP in wässriger Phosphatpufferlösung (pH 7) nach Winkler [9]

\subsubsection{Spektren}

Das Absorptionsspektrum von GFP zeigt im sichtbaren Bereich zwei Absorptionsmaxima $A$ bei 398 und $B$ bei $478 \mathrm{~nm}$ [10], die dem neutralen und dem deprotonierten Chromophor zugeordnet werden, die durch Änderung des pH-Wertes ineinander überführt werden können [11]. Das Emissionsmaximum liegt bei $508 \mathrm{~nm}$ mit einer Schulter bei $545 \mathrm{~nm}$ und hat eine anregungswellenlängenabhängige Fluoreszenzquantenausbeute von 0.720.85 [5] bei einer Fluoreszenzlebensdauer von $3.3 \mathrm{~ns}$ [12].

\subsubsection{Proteindynamik und Zustände}

Chattoraj et al. führten 1996 Fluoreszenz-Hochkonversionsmessungen an GFP bei RT und $77 \mathrm{~K}$ sowie in Deuteriumoxid durch. Bei $77 \mathrm{~K}$ verschiebt sich die $B$-Bande von $478 \mathrm{~nm}$ nach $471 \mathrm{~nm}$, wird schmaler und entwickelt eine deutliche Schwingungsprogression, die mit der $A$-Bande überlagert. Das Maximum der $A$-Bande verschiebt sich nicht wesentlich. Creemers et al. [13] interpretierten das stationäre RT-Absorptionsspektrum bei $478 \mathrm{~nm}$ als Überlagerung von zwei Zuständen $B$ und $I$, wobei $I$ im roten Bereich der Absorptionsbande absorbiert, eine höhere Grundzustandsenergie als $B$ hat und deshalb bei $77 \mathrm{~K}$ nicht populiert ist. Bei $77 \mathrm{~K}$ zeigen die Fluoreszenzspektren 


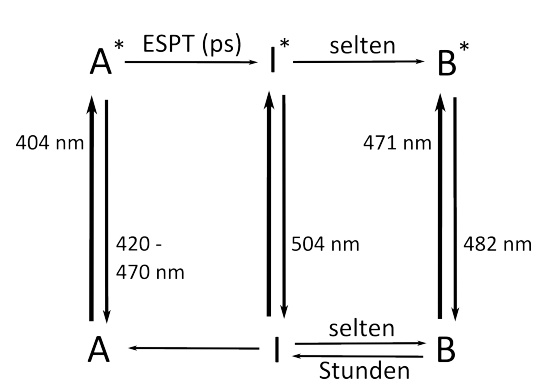

(a) Zustände und Übergänge nach Chattoraj et al. |10|

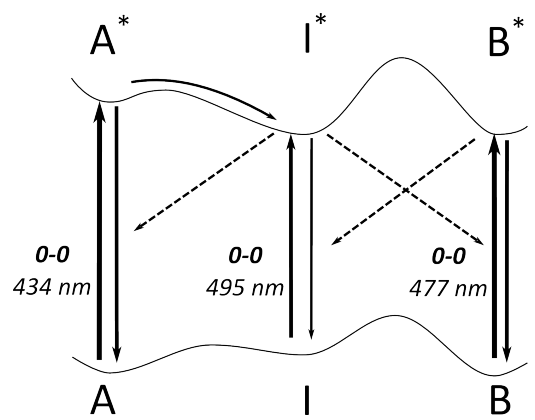

(b) 0-0- Übergänge (kursiv) und strahlungslose Übergänge (gestrichelte Linie) nach Creemers et al. [13]

Abb. 1.5: Zustandsmodell von GFP

eine starke spektrale Abhängigkeit von der Anregungswellenlänge. Anregung von $B$ bei $471 \mathrm{~nm}$ führt zu Emission von $B^{*}$ mit einem Maximum bei $482 \mathrm{~nm}$. Nach Anregung von $A$ bei 404 und $423 \mathrm{~nm}$ zeigt sich ebenfalls Emission mit lokalen Maxima bei $482 \mathrm{~nm}$, zusätzlich tritt aber bei $504 \mathrm{~nm}$ eine weiter Emissionsbande auf, die Chattoraj et al. einem angeregten, $B^{*}$ ähnlichen fluoreszierenden Zwischenzustand $I^{*}$ zuordneten. Wiederholung der Messungen in $\mathrm{D}_{2} \mathrm{O}$ statt $\mathrm{H}_{2} \mathrm{O}$ änderten weder das stationäre Absorptionsnoch Emissionsspektrum bei RT. Bei $77 \mathrm{~K}$ änderte sich das Emissionsspektrum nach Anregung von $B$ bei $471 \mathrm{~nm}$ nicht, bei 404 und $423 \mathrm{~nm}$ allerdings zeigten sich Banden vergleichbarer Intensität bei 482 und $504 \mathrm{~nm}$, sowie eine neue, breite Emission im Bereich $420-470 \mathrm{~nm}$, die $A^{*}$ zugeordnet wurde. Zeitaufgelöste Fluoreszenz-Hochkonversionssmessungen bei RT zeigten den Übergang $A^{*} \longrightarrow I^{*}$ nach Anregung von $A$ bei $398 \mathrm{~nm}$ als einen schnellen Abfall im Bereich von $460 \mathrm{~nm}$ und einen korrespondierenden Anstieg bei $508 \mathrm{~nm}$. In $\mathrm{D}_{2} \mathrm{O}$ verlangsamten sich Abfall und Anstieg deutlich, bei $120 \mathrm{~K}$ verlangsamte sich der Prozess ebenfalls, bei $85 \mathrm{~K}$ verschwand diese Dynamik, was als Beleg für einen Protonentransferprozess mit einer Barriere interpretiert wurde. Mittels Lochbrennspektroskopie wurde gezeigt, dass $A$ in $B$ überführt werden kann und dass die Regeneration langsam vonstatten geht. Nach Anregung von $B$ entsteht sofort das langlebige $B^{*}$ mit einem Emissionsmaximum bei $508 \mathrm{~nm}$ bei RT. Aus diesen Beobachtungen stellten Chattoraj et al. das in Abb. 1.5a gezeigt Zustandsmodell von GFP auf.

Creemers et al. ergänzten dieses Modell, indem sie durch Lochbrennspektroskopie die 0-0-Übergänge der Spezies $A, I$ und $B$ ermittelten und den Über- 


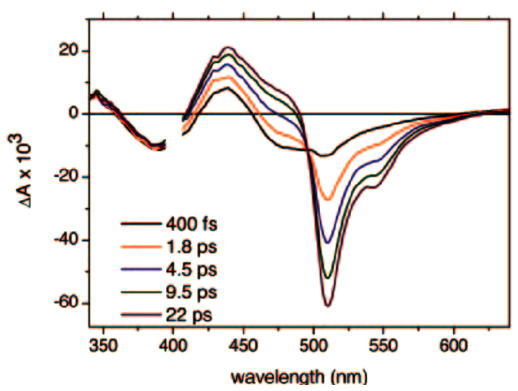

(a) Transiente Spektren von GFP nach Anregung von $A$

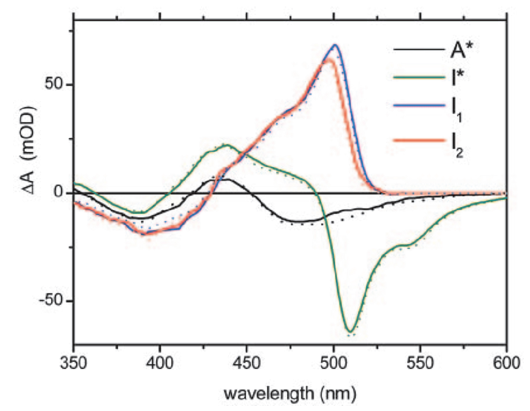

(b) Spektren der Grundzustände $I_{1}$ und $I_{2}$

Abb. 1.6: Pump-Probe und Pump-Dump-Probe Messungen an GFP |17|

gang $I^{*} \longrightarrow B^{*}$ ausschlossen. Stattdessen postulierten sie die Umwandlung von $I^{*} \longrightarrow A, B$ sowie von $B^{*} \longrightarrow I$ durch strahlungslose Prozesse [13]. Qualitative Barrieren, Umwandlung durch einen oder mehrere strahlungslose Prozesse (gestrichelte Pfeile) und die gemessenen Wellenlängen der 0-0-Übergänge (kursiv) sind in Abb. $1.5 \mathrm{~b}$ gezeigt.

Winkler et al. beobachteten mit Pump-Probe Spektroskopie eine initiale $I^{*}$-Emission nach Anregung von $A^{*}$. Sie postulierten eine direkte $A \longrightarrow I^{*}$ Anregung (cross-well exitation). Weiter entwickelten sie ein Modell, das die nicht-monoexponentielle Zeitabhängigkeit der Entwicklung von $A^{*} \longrightarrow I^{*}$ und eine 200 ps-Komponente in der Lebensdauer von $A^{*}$ erklärte, indem sie die Bildung von schwingungsheissem $A_{h}^{*}$ postulierte, das sukzessive mit 2 $k_{r}$ zum kühleren $A_{p}^{*}$ und schließlich mit $k_{r}$ zum kalten $A_{c}^{*}$ abkühlt. Alle drei $A^{*}$-Spezies können über interne Konversion mit $k_{i} c$ in den Grundzustand zurück Fallen. Der heißen Spezies $A_{h}^{*}$ gelingt der Protonentransferprozess über eine Barriere zu $I^{*}$ dank der Überschussenergie mit $k_{h}$ schnell, bei $A_{p}^{*}$ mit $k_{p}$ langsamer während der kalten Spezies $A_{c}^{*}$ dieser Weg verschlossen bleibt [14].

Im Gegensatz dazu assoziierten Thor et al. die $A^{*} \longrightarrow I^{*}$-Entwicklung als eine parallele Deprotonierungsreaktion zweier angeregter Zustände $A_{1}^{*}$ und $A_{2}^{*}$ mit den Lebensdauern 2.2 und 11 ps (12 und 69 ps deuteriert), die sie unterschiedlichen Konfigurationen der Proteinumgebung zuordneten |15] [16].

Kennis et al. [17] nahmen durch Pump-Probe Spektroskopie transiente Ab- 
sorptionsspektren nach Anregung der A-Bande auf. Die Spektren sind in Abb. 1.6a gezeigt. Durch Entvölkerung des $I^{*}$-Zustandes in den korrespondierenden Grundzustand $I_{1}$ mittels stimulierter Emission bestimmten sie das Absorptionsspektrum von $I_{1}$ und zeigten eine Relaxation mit 3 ps (7 ps deuteriert) in einen intermediären Zwischenzustand $I_{2}$, der wiederum mit 400 ps (5 ns deuteriert) zu $A$ relaxiert. Die Lebensdauer von $I^{*}$ wurde auf 3 ns bestimmt. Die Spektren von $I_{1}$ und $I_{2}$ sind in Abb. $1.6 b$ gezeigt.

\subsubsection{Photoaktivierbare Proteine}

In der Klasse der GFP-ähnlichen Proteine gibt es Vertreter, deren Fähigkeit zur Fluoreszenz durch eine induzierte Änderung verändert werden kann. GFP selbst wird durch Bestrahlung der $A$-Bande bei $\sim 400 \mathrm{~nm}$ sehr langsam von der protonierten in die deprotonierte Form überführt, diese Änderung ist über Stunden stabil [10]. Das erste speziell entwickelte photoaktivierbare fluoreszierende Protein war eine Variante des GFP, bei der durch Decarboxylierung von $\mathrm{Glu}^{222}$ das anionische Chromophor stabilisiert wurde; die Bildung des deprotonierten Chromophors durch Anregung der A-Bande war irreversibel, Fluoreszenz nach Anregung der $B$-Bande wurde durch diese Aktivierung um den Faktor 100 verstärkt [18]. Für Kaede, ebenfalls ein GFP-Derivat, wurde eine Rotverschiebung von Absorptions- und Emissionsspektrum durch eine photoinduzierte $\beta$-Eliminierung und anschließender irreversible Vergrößerung des $\pi$-Elektronensystems des Chromophors gezeigt [19].

\subsubsection{Reversibel Schaltbare Fluoreszierende Proteine}

Reversibel (photo-)schaltbare fluoreszierende Proteine (reversibly photoswitchable fluorescent proteins, RSFPs) sind in der Regel GFP-ähnliche Proteine, die wiederholt durch Bestrahlung zwischen einem fluoreszierenden AN- (onstate, oft auch hell (bright)) und einem nicht fluoreszierenden AUS-Zustand (off-state, dunkel (dark)), geschaltet werden können. Bereits 1997 wurde von Dickson et al. bei Einzelmolekülmessungen ein Blinken (blinking), eine zwischen fluoreszierendem und nicht fluoreszierendem Zustand schnell hin- und herwechselnde gelb fluoreszierende GFP-Mutante beobachtet, die nach Emission von $\sim 10^{6}$ Photonen gar nicht mehr fluoreszierte, aber durch Bestrahlung bei $405 \mathrm{~nm}$ teilweise reaktiviert werden konnte. Ohne Lichteinfluss war der dunkle Zustand über mehrere Minuten stabil [20]. Bessere 
Ausbeute zeigte das im Jahr 2000 von Lukyanov et al. beschriebene fluoreszierende Protein asFP595, dessen Fluoreszenzintensität durch Bestrahlung mit grünem Licht verstärkt und durch blaues Licht geschwächt wird [21]. Andresen et al. züchteten 2005 Kristalle von asFP595. Da das Protein auch im Kristall schaltbar war, konnten so durch Röntgendiffraktometrie Kristallstrukturen von AN- und AUS-Zustand ermittelt werden, die den fluoreszierenden Zustand als cis-Isomer und den AUS-Zustand als trans-Isomer des Chromophors identifizierten. Bei den meisten GFP-ähnlichen Proteinen zeigt das cis-Isomer die stärkere Fluoreszenz und die Quantenausbeute bei Anregung des deprotonierten Zustandes ist deutlich höher, allerdings gibt es mit dem rot fluoreszierende Protein eqFP578f auch FPs mit transKonfiguration im AN-Zustand [22]. Es scheint, dass die Isomerisierung ein entscheidender Schritt beim Schaltvorgang ist, die Konformation allein aber nicht der entscheidende Faktor für die Fluoreszenzquantenausbeute sein kann. Beide Isomere eines Proteins erfahren unterschiedliche Stabilisierung und Wechselwirkungen durch die Proteinumgebung, was Einfluss auf das Protonierungsgleichgewicht und die Fluoreszenzlebensdauer haben kann. Die Planarität des $\pi$-Elektronensystems [23], Stabilisierung durch die Proteinumgebung [24] und generelle Flexibilität des Proteins in Chromophornähe [25] werden als Ursachen für hohe oder niedrige Quantenausbeuten diskutiert.

Da Isomer und Protonierungsgrad bei aktuellen Studien mehr und mehr in den Mittelpunkt rücken und die Rolle der phänomenologischen Bezeichnung der $A$ - und $B$ - Banden des GFP immer weiter abnimmt, wird hier eine Nomenklatur zur eindeutigen Beschreibung des Proteinchromophors eingeführt: $C$ beschreibt das cis, $T$ das trans-Isomer. Ein hochgestelltes $H$ oder Minus ( - ) bezeichnet die Ladung als neutral oder anionisch, angeregte Zustände werden mit einem hochgestellten Stern $(*)$ versehen. Für eine bei niedrigem $\mathrm{pH}$-Wert vorkommende protonierte Form wird zusätzlich ein hochgestellte Plus (+) eingeführt, um einen $\mathrm{pH}$-induzierten Effekt auf die Photoeigenschaften zu unterstreichen. Wo es möglich ist, wird im Folgenden neben der jeweiligen Bezeichnung des Autors auch diese Bezeichnung angegeben.

\subsubsection{Dronpa}

Ando et al. [26] beschrieben 2004 das RSFP Dronpa, einer Mutante eines fluoreszierenden Proteins der Koralle Pectiniidae, deren Fluoreszenz sich durch Bestrahlung bei $490 \mathrm{~nm}$ nahezu vollständig ausschalten und durch Bestrahlung bei $400 \mathrm{~nm}$ komplett wieder herstellen lässt. Dieses Verschwinden 


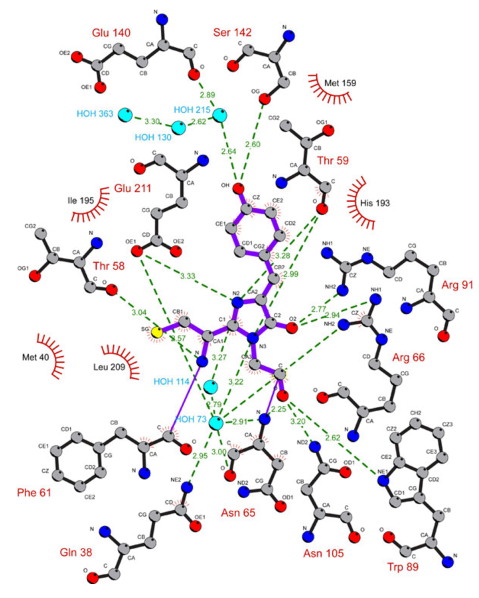

(a) cis-Isomer

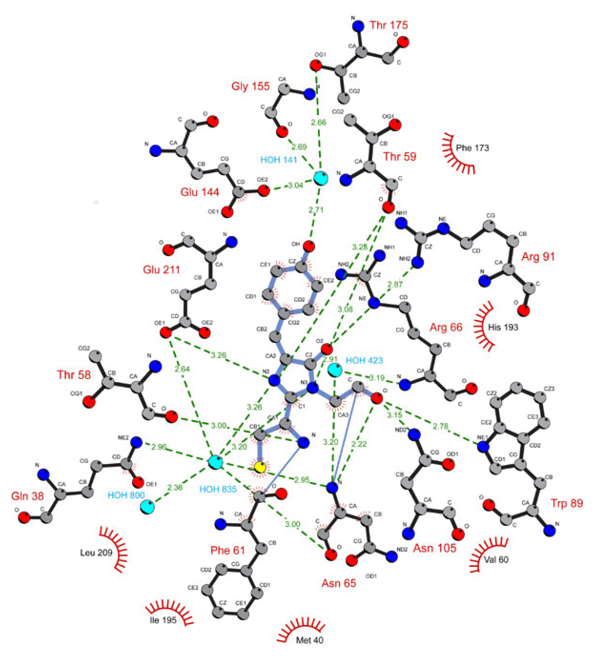

(b) trans-Isomer

Abb. 1.7: Chromophorumgebung von Dronpa nach Andresen et al. [27] Atome und Wasser sind als farbige Kugeln gezeichnet (grau: C, blau: N, rot: $\mathrm{O} / \mathrm{OH}$, türkis: $\mathrm{H}_{2} \mathrm{O}$

Bindungen sind als Striche gezeichnet (grün gestrichelt: Wasserstoffbrücken, schwarze/lila/blau: Atombindung)

und Wiederkehren der Fluoreszenz ist der Grund für den Namen Dronpa, der sich aus „dron", einem Ninja Ausdruck für Verschwinden, und „pa“ für Photoaktivierung, zusammensetzt. Dronpa besteht aus 257 Aminosäuren und hat eine molekulare Masse von $28.8 \mathrm{kD}$. Das Chromophor bildet sich analog zu GFP (siehe Abb. 1.2) autokatalytisch aus den Aminosäuren Cys ${ }^{62}$, $\mathrm{Tyr}^{63}$ und Gly ${ }^{64}$. Der Proteinaufbau mit dem Chromophor in einer $\alpha$-Helix umgeben von einer $\beta$-Fass Struktur gleicht ebenfalls GFP, wobei das Fass in der Mitte zwischen zwei $\beta$-Faltblättern einen Spalt aufweist, der einen Lösungsmittelaustausch mit der Umgebung ermöglicht. Das Chromophor liegt bevorzugt als cis-Isomer vor, wobei die beiden Ringe um $\sim 15^{\circ}$ verdreht sind, und wird in der Proteinumgebung u.a. durch eine Wasserstoffbrücke der p-Hydroxyphenolgruppe zu Ser ${ }^{142}$ und $\pi$ - $\pi$-Wechselwirkungen mit His ${ }^{193}$ stabilisiert.

Andresen et al. [27] identifizierten durch Röntgendiffraktometrie die Kristallstruktur von Dronpa in AN- und AUS-Zustand und zeigten auch hier eine mit dem Schaltvorgang einhergehende cis-trans-Isomerisierung. Das Chromophor ist im trans-Zustand mit $\sim 30^{\circ}$ deutlich stärker verdreht, die 


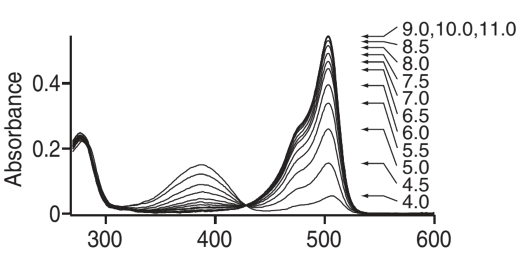

(a) pH-abhängige Absorptionsspektren

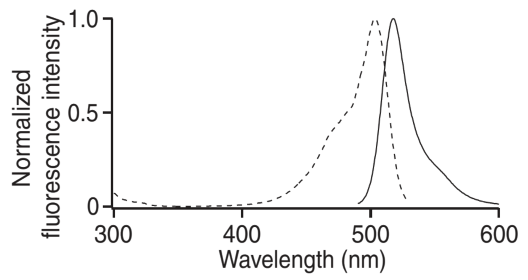

(b) Normalisiertes Anregungs- (gestrichelt) und Fluoreszenzspektrum (durchgezogen)

Abb. 1.8: Spektren von Dronpa nach Ando et al. |26|

$p$-Hydroxyphenolgruppe wird nicht mehr durch die Wasserstoffbrücke zu $\mathrm{Ser}^{142}$ stabilisiert und die $\pi$ - $\pi$-Wechselwirkungen mit $\mathrm{His}^{193}$ wird durch eine $\pi$-Kation-Wechselwirkung zu Arg ${ }^{66}$ ersetzt. Der trans-Zustand ist mit einer Halbwertszeit von $\sim 14$ Stunden sehr stabil.

\subsubsection{Spektren}

Das Absorptionsspektrum des cis-Isomers von Dronpa zeigt im sichtbaren Bereich zwei Absorptionsmaxima bei 390 und bei $503 \mathrm{~nm}$, die durch Titration ineinander überführt werden können (siehe Abb.1.8a). Abb.1.8b zeigt das Fluoreszenzanregungsspektrum sowie das Emissionsspektrum von Dronpa. Das Emissionsmaximum liegt bei $518 \mathrm{~nm}$ mit einer Schulter bei $550 \mathrm{~nm}$ und hat eine Fluoreszenzquantenausbeute von $\Phi_{F, c i s}=0.85\left(\Phi_{F, \text { trans }}=0.02\right) \mathrm{mit}$ einer Fluoreszenzlebensdauer von $3.6 \mathrm{~ns}$ [26] [28]. Das Anregungsspektrum zeigt keinen Beitrag im Bereich $<400 \mathrm{~nm}$.

Die stabile cis-Form liegt bei neutralem $\mathrm{pH}$ fast ausschließlich deprotoniert vor, während die trans-Form fast vollständig protoniert ist. Die Änderung des Absorptionsspektrums durch Bestrahlung bei $488 \mathrm{~nm}$ ist in Abb. 1.9a gezeigt, die korrespondierende Änderung der Fluoreszenzintensität in $\mathrm{Abb} .1 .9 \mathrm{~b}$ Es ist klar zu sehen, dass das Ausschalten, also die cis $\longrightarrow$ transIsomerisierung, deutlich langsamer passiert als das Anschalten. Die Quantenausbeute für die Schaltvorgang wird nach Gl.1.1 berechnet und beträgt $\Phi_{\text {cis } \longrightarrow \text { trans }}(490 \mathrm{~nm})=3 \cdot 10^{-4}$ und $\Phi_{\text {trans }} \longrightarrow$ cis $(400 \mathrm{~nm})=0.36$.

$$
\Phi_{s w}=\frac{h c}{\tau_{\frac{1}{2}} \sigma\left(\lambda_{e x}\right) \lambda_{e x} I}
$$




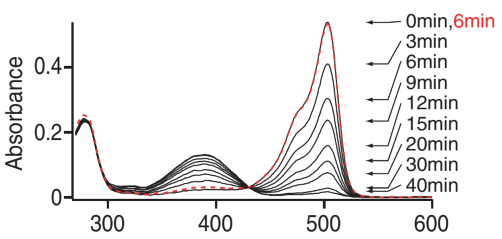

(a) Zeitabhängige Änderung des Absorptionsspektrums durch Bestrahlung mit $488 \mathrm{~nm}$ (schwarz) und $400 \mathrm{~nm}$ (rot)

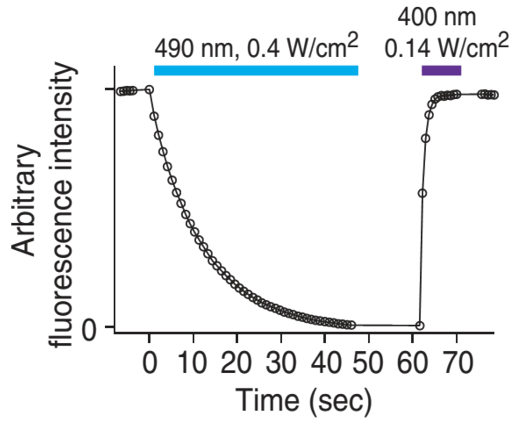

(b) Verlauf der Fluoreszenzintensität bei Bestrahlung

Abb. 1.9: Schaltspektren von Dronpa im Ensemble nach Ando et al. |26|

$\sigma\left(\lambda_{\text {ex }}\right)$ ist der Absorptionsquerschnitt des Chromophors bei Anregungswellenlänge $\lambda_{e x}$, I ist die Intensität des eingestrahlten Lichtes, $\tau_{\frac{1}{2}}$ die gemessene Halbwertszeit des Schaltvorganges und $h$ und $c$ sind Planckkonstante und Lichtgeschwindigkeit.

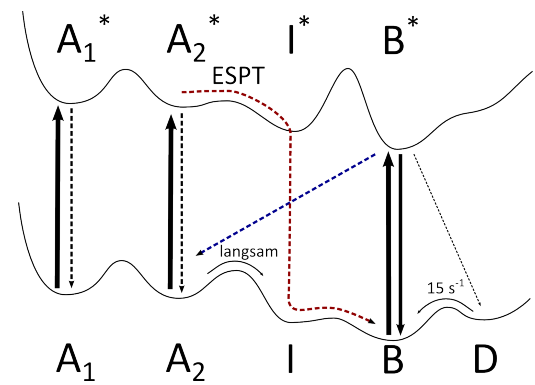

(a) nach Habuchi et al. 2005 28

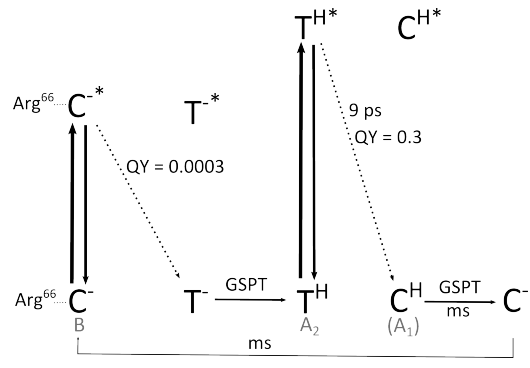

(b) nach Warren et al. 2013 [29]

Abb. 1.10: Zustandsmodelle von Dronpa 


\subsubsection{Proteindynamik und Zustände}

Habuchi et al. [28] zeigten einen Unterschied in der Dynamik der protonierten Form, je nach dem ob sie durch Erniedrigung des $\mathrm{pH}$-Wertes oder durch Bestrahlung der deprotonierten Form bei $488 \mathrm{~nm}$ entstanden war: Die photogeschaltete Form $A_{2}\left(T^{H}\right)$ ließ sich durch Bestrahlung bei $400 \mathrm{~nm}$ wieder zurückschalten, die $\mathrm{pH}$-induzierte protonierte Form $A_{1}\left(\mathrm{C}^{\mathrm{H}+}\right)$ zeigte bei Bestrahlung keine Änderung in den Absorptionsspektren. Obwohl das Fluoreszenzanregungspektrum in Abb. $1.8 \mathrm{~b}$ nach Anregung bei $400 \mathrm{~nm}$ keine Emission zeigt, nahmen Habuchi et al. für den photoaktivierten Weg $A_{2} \longrightarrow B\left(C^{H} \longrightarrow C^{-}\right)$analog zum GFP einen initialen ESPT an, der allerdings nicht in der fluoreszierenden Form $B^{*}\left(C^{-*}\right)$ sondern im nicht fluoreszierenden Zwischenzustand $I^{*}$ endet und von dort aus strahlungslos über $I$ nach $B\left(C^{-}\right)$verläuft. Nach Anregung von $B\left(C^{-}\right)$mit $488 \mathrm{~nm}$ fluoresziert $B^{*}\left(C^{-*}\right)$ mit einer Lebensdauer von $3.6 \mathrm{~ns}$ und fällt zurück in den Grundzustand; ein kleiner Teil endet in der $A_{2}\left(C^{H}\right)$, ein noch kleinerer in Zustand $D$, einem dunklen Zustand der über Sekunden zurück nach $B\left(C^{-}\right)$ konvertiert (siehe Abb.1.10a).

Fron et al. [30] verglichen mittels Pump-Probe Spektroskopie die Dynamik der photoaktivierten Form $A_{2}\left(C^{H}\right)$ nach Anregung bei $405 \mathrm{~nm}$ in $\mathrm{H}_{2} \mathrm{O}$ und $\mathrm{D}_{2} \mathrm{O}$ und schlossen Aufgrund der Verdoppelung einer von ihnen dem ESPT zugeordneten Zeitkonstante von 2 ps auf 4 ps auf einen kinetischen Isotopen Effekt (KIE, siehe Abschn,1.4) und somit auf einen initialen ESPT nach Anregung.

Warren et al. [29] fanden mittels FTIR und VIS-Pump-IR-Probe Spektroskopie keinen Hinweis auf einen ESPT bei Anregung von $T^{H}\left(A_{2}\right)$, dem Schaltprodukt der deprotonierten und von $\mathrm{Arg}^{66}$ stabilisierten cis-Spezies im Grundzustand $C^{-} \cdots \operatorname{Arg}^{66}(B)$. Stattdessen postulierten sie eine schnelle, initiale Isomerisierung aus dem angeregten Zustand in einen protonierten cisGrundzustand $C^{H}$, der anschließend langsam durch einen GrundzustandsProtonentransfer (GSPT) zu einer anionischen cis-Spezies $\mathrm{C}^{-}$deprotoniert wird, die schließlich durch $\mathrm{Arg}^{66}$ stabilisiert wird (siehe Abb. 1.10b. Die Lebensdauer von $T^{H *}$ wurde mit 9 ps bestimmt, die Isomerisierung steht in direkter Konkurrenz zu einer IC zurück nach $T^{H}$ mit einer Ausbeute von $\Phi_{T^{H *} \longrightarrow C^{H}}=0.3$.

Lukacs et al. [31] untersuchten mit VIS-Pump-IR-Probe Spektroskopie und fanden ebenfalls keinen Beleg für einen ESPT bei Anregung der photogeschalteten trans-Spezies bei $400 \mathrm{~nm}$. Da sie aber auch keinen Hinweis auf eine direkte Isomerisierung fanden, schlugen sie eine Umorganisierung 


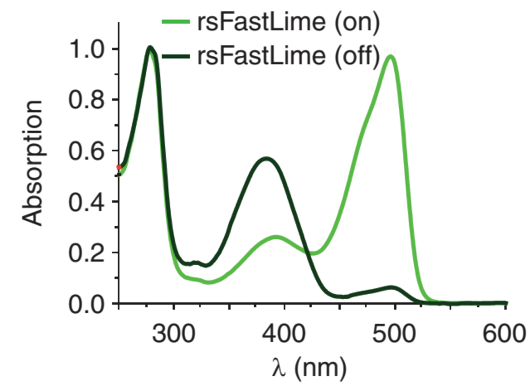

(a) Absorptionsspektrum von rsFastLime pH 7

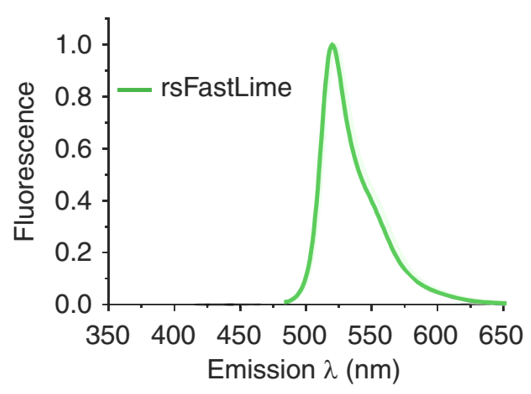

(b) Fluoreszenzspektrum von rsFastLime

Abb. 1.11: Stationäre Spektren von rsFastLime nach Andresen et al. |32|

der das Chromophor stabilisierenden Wasserstoffbrücken vor, die zu einem metastabilen trans-Grundzustand führt, der auf einer ns-Zeitskala zum ursprünglichen trans-Zustand oder zum deprotonierten cis-Isomer $C^{-}$führt.

\subsection{5 rsFastLime}

Ausgehend von den aus Kristallstrukturen bekannten Chromophorumgebungen von Dronpa (siehe Abb. 1.7) und dem schneller isomerisierenden asFP595 vermuteten Stiel et al., dass die cis-trans-Isomerisierung durch die Aminosäure $\mathrm{Val}^{157}$ (nicht abgebildet) sterisch und durch $\mathrm{Arg}^{66}$ wegen der Stabilisierung des cis-Isomers energetisch behindern würde. Durch Ersetzen von Val $^{157}$ mit Glycin wurde eine Beschleunigung der cis $\longrightarrow$ transIsomerisierung um den Faktor 50 im Ensemble im Vergleich zu Dronpa erreicht. Die Fluoreszenzquantenausbeute des Proteins Dronpa-V157G, von Stiel et al. wegen seines schnellen Photoschaltens rsFastLime genannt, ist mit $\Phi_{F}=0.77$ etwas geringer als bei Dronpa, dafür ist es etwa vier mal stabiler gegen Photobleichen. Wie Dronpa liegt rsFastLime im Grunzustand als cis-Isomer vor, die Halbwertszeit des trans-Isomers liegt bei etwa 8 Minuten.

\subsubsection{Spektren}

Das Absorptionsspektrum von rsFastLime zeigt zwei Absorptionsbanden mit einem Maximum bei $392 \mathrm{~nm}$ bzw. $496 \mathrm{~nm}$ als cis- und $384 \mathrm{~nm}$ bzw. $496 \mathrm{~nm}$ als trans-Isomer und ist für beide Isomere in Abb. 1.11 gezeigt. 


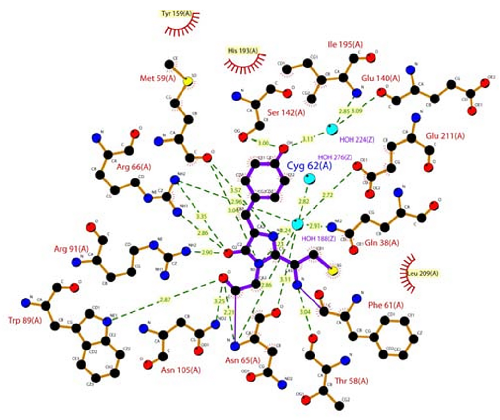

(a) cis-Isomer

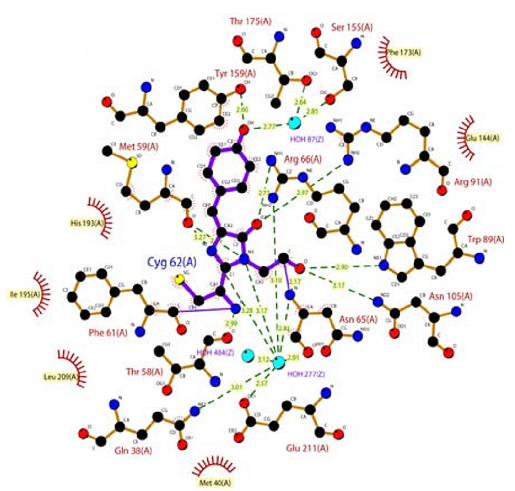

(b) trans-Isomer

Abb. 1.12: Chromophorumgebung von Padron nach Brakemann et al. 23]

Atome und Wasser sind als farbige Kugeln gezeichnet (grau: $\mathrm{C}$, blau: N, rot: $\mathrm{O} / \mathrm{OH}$, türkis: $\mathrm{H}_{2} \mathrm{O}$

Bindungen sind als Striche gezeichnet (grün gestrichelt: Wasserstoffbrücken, schwarze/lila/blau: Atombindung)

Für das cis-Isomer liegt bei neutralem $\mathrm{pH}$ ein Protonierungsgleichgewicht $\mathrm{C}^{H} \rightleftharpoons \mathrm{C}^{-}$vor, das trans-Isomer hingegen ist fast vollständig protoniert als $T^{H}$. Das Emissionsspektrum hat ein Maximum bei $518 \mathrm{~nm}$ und eine Schulter bei $550 \mathrm{~nm}$. Die stationären Spektren sind im Rahmen dieser Arbeit in Abschnitt 3.2.1 und 3.2.2.1 eingehender beschrieben. Zu rsFastlime gibt es bisher keine gesonderten Untersuchungen hinsichtlich der photoinduzierten Prozesse. Die Untersuchung der ultraschnellen photoinduzierten Dynamik ist Gegenstand dieser Arbeit.

\subsubsection{Padron}

Durch Substitution einer einzigen Aminosäure in rsFastLime, Met ${ }^{159}$, durch Tyr (siehe Abb.11.12) gelang es Andresen et al. 2010 ein RSFP mit im Vergleich zu Dronpa umgekehrten Schalteigenschaften zu entwickeln [32]: Dronpa, rsFastlime und alle anderen bis dahin bekannten RSFP fluoreszieren intensiv nach Anregung der $C^{-}$-Spezies mit blauem Licht, gleichzeitig führt Bestrahlung mit dieser Wellenlänge aber mit geringer Ausbeute zum nichtfluoreszierenden trans-Isomer, während Bestrahlung mit UV-Licht mit hoher Ausbeute den umgekehrten Prozess initiiert (negatives Schalten). Bei der neuen Mutante Dronpa-Val ${ }^{159}$ Gly, Met ${ }^{159}$ Tyr schaltet blaues Licht das 


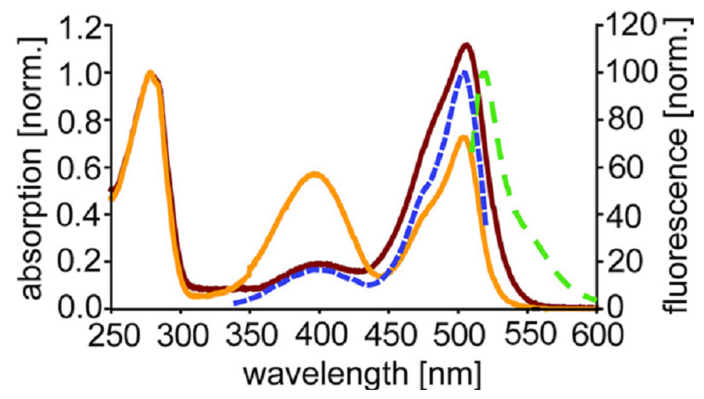

Abb. 1.13: Stationäre Spektren von Padron bei $\mathrm{pH} 7$ nach Brakemann et al. |23| orangene Linie: AN-Zustand, rote Linie: AUS-Zustand, blaue gestrichelte Linie: Fluoreszenzanregungsspektrum, grüne gestrichelte Linie: Fluoreszenzspektrum

Protein mit geringer Ausbeute in den AN-Zustand und regt Proteine im AN-Zustand zur Fluoreszenz an, während UV Licht das Protein ausschaltet (positives Schalten). Da die Fluoreszenzintensität niedrig ist und der Schaltvorgang nur unvollständig führten Andresen et al. eine Reihe weitere Mutationen durch bis sie schließlich, nach sechs weiteren Substitutionen in Chromophornähe, ein positiv schaltendes, im AN-Zustand stark fluoreszierendes photostabiles Protein mit sehr geringer Fluoreszenz im AUS-Zustand (0.7\% des AN-Zustandes) erhielten. Aufgrund der umgekehrten Schalteigenschaften im Vergleich zu Dronpa nannten sie das Protein Padron. Die Fluoreszenzquantenausbeute beträgt $\Phi_{F}=0.64$. Wie auch bei Dronpa entspricht der AN-Zustand dem cis-Isomer [23], das bei RT eine Halbwertszeit von etwa 2 Stunden hat und in das stabilere trans-Isomer übergeht. Da Padron bei niedrigen Temperaturen eine Tendenz zur Dimerisierung zeigte, entwickelten Andresen et al. eine auch bei niedrigen Temperaturen monomere Variante, Padron*, mit sehr ähnlichen Eigenschaften [32]. In dieser Arbeit wird Padron0.9 untersucht, eine weitere Padron-Variante mit hoher Tendenz zur Kristallisation, einem mit einer Halbwertszeit von etwa 4 Stunden etwas stabilerem cis-Zustand, leicht schlechterer Quantenausbeute $\Phi_{F}=$ 0.61 und gegenüber Padron um etwa $1 \mathrm{~nm}$ verschobenen Absorptions- und Emissionsspektren [23].

\subsubsection{Spektren}

Das Absorptionsspektrum von Padron zeigt zwei Absorptionsbanden mit einem Maximum bei 396 nm bzw. 503 nm für das cis- Isomer und eine Ab- 
sorptionsbande bei $505 \mathrm{~nm}$ für das trans-Isomer. Die Absorptionsspektren beider Isomere sind in Abb. 1.13 gezeigt. Für das cis-Isomer liegt bei neutralem $\mathrm{pH}$ wie bei rsFastLime ein Protonierungsgleichgewicht $\mathrm{C}^{H}<0>\mathrm{C}^{-}$ vor, das trans-Isomer hingegen ist vollständig deprotoniert als $T^{-}$. Das Emissionsspektrum hat ein Maximum bei $522 \mathrm{~nm}$ und hat eine Schulter bei $550 \mathrm{~nm}$. Das Fluoreszenzanregungsspektrum in Abb.1.13 zeigt eine deutliche Fluoreszenz nach Anregung der $\mathrm{C}^{H}$-Spezies. Die stationären Spektren sind Gegenstand dieser Arbeit und in Abschnitt 3.1.1 und 3.1.2.1 eingehender beschrieben.

\subsubsection{Proteindynamik und Zustände}

Kristallstrukturanalysen von Brakemann et al. [23] an Padron0.9 zeigten, dass das trans-Isomer durch Tyr ${ }^{159}$ durch eine Wasserstoffbrücke zum $p$ Hydroxyphenylring stabilisiert wird (siehe Abb. 1.12). Die Substitution dieser einen Aminosäure reichte bereits aus, das Schaltverhalten gegenüber rsFastLime umzukehren. Sie machten in direkter Chromophorumgebung drei titrierbare Aminisäurereste von $\mathrm{Glu}^{144}$, $\mathrm{His}^{193}$ und $\mathrm{Glu}^{211}$ aus, die zur Deprotonierung des trans-Isomers bei neutralem $\mathrm{pH}$ beitragen.

Faro et al. [33] isolierten in Tieftemperatur-Röntgenexperimenten zwei fluoreszierende Zwischenzustände auf dem Reaktionsweg vom trans- zum cisIsomer $B_{\text {trans }}\left(T^{-}\right) \longrightarrow I_{c i s} \longrightarrow B_{c i s, L T} \longrightarrow A_{c i s, R T}\left(C^{H}\right) \rightleftharpoons B_{c i s, R T}$ $\left(C^{-}\right)$. Die Absorptions- und Fluoreszenzspektren dieser Zustände sind in Abb. 1.14 gezeigt. Bemerkenswert ist die bei $100 \mathrm{~K}$ stattfindende Isomerisierung der trans-Form durch Bestrahlung bei $523 \mathrm{~nm}$ zu einem metastabilen fluoreszierenden Zwischenzustand $I_{c i s}$, die mit einer Umorganisation von $\mathrm{Met}^{59}$ und geringfügiger Bewegung von $\mathrm{Met}^{93}$ und Ile ${ }^{195}$ einhergeht (siehe Abb.1.12), $\mathrm{Met}^{93}$ ist nicht abgebildet); Faro et al. vermuteten eine leichte Deformation des $\beta$-Fasses bei der Isomerisierung. Die Absorption von $I_{c i s}$ hat ein Maximum bei $481 \mathrm{~nm}$ und zeigt Fluoreszenz bei $524 \mathrm{~nm}$. Innerhalb von Minuten wandelt sich $I_{c i s}$ zu $B_{c i s, L T}$ um, einem cis-Isomer mit Absorptionsmaximum bei $504 \mathrm{~nm}$ aber ähnlicher Fluoreszenz wie $I_{c i s}$, das auch strukturell keine Unterschiede zeigt. Die Änderung des Absorptionsspektrums führten Faro et al. auf nach der Isomerisierung geänderte elektrostatische Wechselwirkungen und Wasserstoffbrücken in $I_{c i s}$ zurück, die sich der geänderten Konformation nur langsam anpassen. Bei Temperaturen über $180 \mathrm{~K}$ verschiebt das Emissionsmaximum blau und es stellt sich ein Protonierungsgleichgewicht zwischen $A_{c i s, R T}\left(C^{H}\right)$ und $B_{c i s, R T}\left(C^{-}\right)$ein. Auch der Übergang von $B_{c i s, L T}$ zu $B_{c i s, R T}$ erfolgte ohne große strukturelle Änderungen. Es zeigte sich, dass auch der $I_{c i s}$-Zustand durch Bestrahlung 

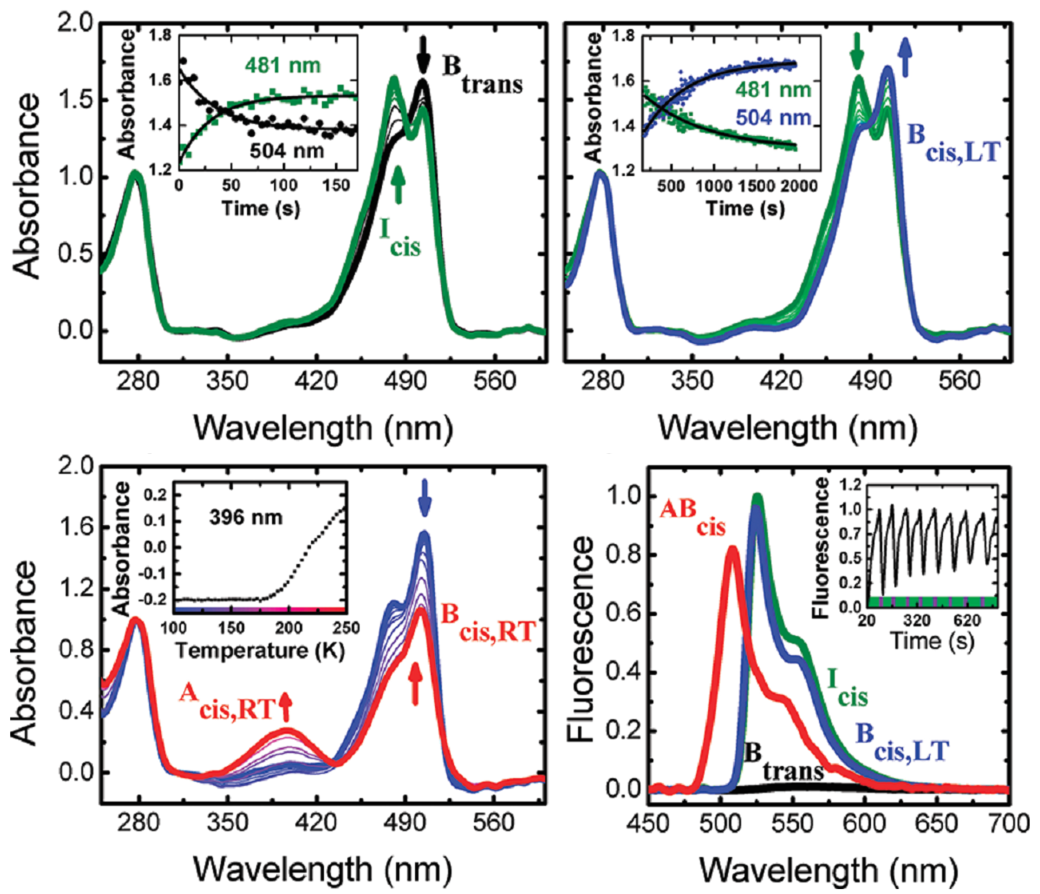

Abb. 1.14: Absorptionszustände im Kryo-Experiment von Faro et al. 33 oben links: Umwandlung von $B_{\text {trans }}$ zu $I_{\text {cis }}$ durch Bestrahlung bei $523 \mathrm{~nm}$ vei $100 \mathrm{~K}$, Insert: zeitabhängige Maxima der Banden

oben rechts: Spontane Umwandlung von $I_{c i s}$ nach $B_{c i s, L T}$ bei $100 \mathrm{~K}$, Insert: zeitabhängige Maxima der Banden

unten links: Bildung des Protonierungsgleichgewichts $A_{c i s, R T} \rightleftharpoons B_{c i s, R T}$ bei $\mathrm{T}>180 \mathrm{~K}$

unten rechts: Emissionsspektren von $B_{\text {trans }}, I_{c i s}, B_{c i s, L T}$ und $B_{c i s, R T}$, Insert: reversible Isomerisierung zwischen $B_{\text {trans }}$ und $I_{c i s}$ durch wechselnde Bestrahlung bei 405 und $523 \mathrm{~nm}$ 
bei $405 \mathrm{~nm}$ effektiv zurück in das $B_{\text {trans }}$-Isomer überführt werden kann (siehe Abb. 1.14.Insert unten rechts). 


\subsection{Das Chromophor}

Das Chromophor von Padron0.9 und rsFastLime, ein $p$-Hydroxybenzylidenimidazolidinon (HBDI) wird, ähnlich wie bei GFP, durch Reaktion dreier benachbarter Aminosäuren $\left(C y s^{62}-T y r^{63}-G l y^{64}\right)$ nach dem Reaktionsschema in Abb.1.2 gebildet [27].

\subsubsection{Grundzustand in Lösung}

HBDI ausserhalb der Proteinumgebung liegt als cis-Isomer vor und isomerisiert durch UV-Bestrahlung. In Wasser hat es die $p K_{S}$-Werte 1.8 für den freien Stickstoff am Imidazolring und 8.2 für die Hydroxylgruppe. Daraus ergeben sich eine kationische, eine neutrale und eine anionische Form mit klar unterscheidbaren Absorptionsspektren mit Maxima bei 391, 368, und $425 \mathrm{~nm}$ in Wasser (siehe Abb. 1.15b] [34], wobei sich die Spektren von cisund trans-Isomer zumindest in Methanol nur durch eine schwache Rotverschiebung von $4 \mathrm{~nm}$ unterscheiden [35]. Die Lage der Absorptionsmaxima ist stark lösungsmittelabhängig, wobei die neutrale Form nur wenig verschiebt, während Kation und stärker noch das Anion erwartungsgemäß eine negative Solvatochromie zeigen. In DMSO liegt das Absorptionsmaximum des Anions sehr weit rotverschoben bei $480 \mathrm{~nm}$. Ein neutrales Zwitterion wurde nicht beobachtet, konnte aber von Dong et al. durch N-Methylierung und Titration isoliert werden; es zeigt ein Absorptionsmaximum bei $486 \mathrm{~nm} \mathrm{[36].}$ Zweiphotonen-Ionisationsmessungen an HDBI in der Gasphase zeigten für das Anion ein Gaussförmiges Spektrum mit einem Maximum bei $479 \mathrm{~nm}$ und 40 nm FWHM, für das Kation ein Absorptionsmaximum bei $406 \mathrm{~nm}$ mit 20 nm FWHM [37]. Für das neutrale Chromophor wurde ein Maximum bei $399 \mathrm{~nm}$ aus dem Absorptionsmaximum eines neutralen Chromophors mit positiver Seitenkette berechnet, das bei $415 \mathrm{~nm}$ lag [38]. Die starke Übereinstimmung der Absorptionsmaxima von HBDI in Gasphase und in GFP speziell beim Anion (vgl. Abb. 1.4) deuteten Andersen et al. als Beweis für den Schutz des Chromophors vor Solvens- und Oxidationseffekten durch die das Chromophor umgebende $\beta$-Fassstruktur [37].

NMR-Studien von He et al. haben einen reversible, $\mathrm{pH}$-induzierte cis trans Isomerisierung aufgrund der Annäherung der freien Energien der Grundzustände bei niedrigen $\mathrm{pH}$-Werten gezeigt. Durch photoinduzierte Überführung der Formen in das trans-Isomer und Messung der Regeneration des cis-Konformers wurden die Aktivierungsenergien für diesen Prozess ermittelt. Der Unterschied der Aktivierungsenergien für die protonierten 


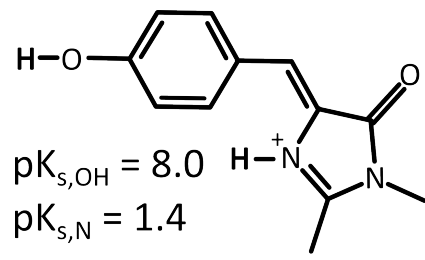

(a) $p$ -

Hydroxybenzylidenimidazolinon (HBDI)

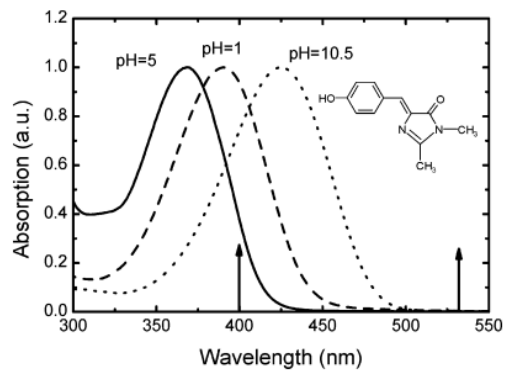

(b) $\mathrm{pH}$-Abhängige Absorptionsspektren [39]

Abb. 1.15: HBDI

Spezies war mit 48.9 (Kation), 54.8 (Neutral) und 54.8 kJ/mol in $\mathrm{D}_{2} \mathrm{O}$ gering. Verwendung anderer Lösungsmittel verlängerte die Regenerationszeit allerdings drastisch von 3-5 Minuten in $\mathrm{D}_{2} \mathrm{O}$ auf 48 Stunden (Methanol, Isopropanol). He et al. schlossen aus diesen Ergebnissen auf einen von jedem Protonierungsgrad aus zugänglichen, nicht planaren Übergangszustand, der eine niedrige Barriere für die Isomerisierung hat und durch Wasser stabilisiert wird [39].

\subsubsection{Angeregte Zustände}

Beide Isomere zeigen quasi keine Fluoreszenz bei Raumtemperatur $\left(\Phi_{F}<\right.$ 0.001), die Quantenausbeute steigt mit sinkender Temperatur nicht linear auf das $10^{3}-10^{4}$-fache [40] [41]. Zeitaufgelöste Fluoreszenzmessungen (Ultrafast Fluorescence Upconversion) von Addison et al. zeigten eine kürzere Lebensdauer für die neutrale im Vergleich zur anionischen Spezies in Methanol, die Konformation machte jeweils keinen Unterschied. Auch die Fluoreszenzspektren beider Isomere in Methanol ähneln sich stark mit leicht geringerer Intensität des trans-Isomers, sie zeigen ein Maximum bei $430 \mathrm{~nm}$. Die Fluoreszenz ist kurz und fällt in Methanol und Acetonitril biexponentiell ab [35]. Mandal et al. bestimmten die Lebensdauern von Anion und neutraler Form Lösungsmittelabhängig (siehe Tab 1.1). Addison et al. schlossen aus dem identischen Verhalten beider Isomere auf eine starke Ähnlichkeit der $S_{1}$-Zustände und ihrer Dynamik. 


\begin{tabular}{l|l|l|l} 
Lösungsmittel & Form & $\tau_{1} / \mathbf{p s}$ & $\tau_{2} / \mathbf{p s}$ \\
\hline Methanol & Neutral & 0.34 & 1.1 \\
& Anion & 0.22 & 1 \\
Acetonitril & Neutral & 0.45 & 1.4 \\
Wasser & Neutral & 0.21 & 1.1 \\
& Anion & $<0.07$ & 0.43
\end{tabular}

Tab. 1.1: Lebensdauern von HBDI in verschiedenen Lösungsmitteln $\mid 42$

Usman et al. bestimmten mit ultraschneller IR-Spektroskopie eine IC-Geschwindigkeit in einen heißen Grundzustand von $(1.2 \pm 0.2 \mathrm{ps})^{-1}$ für die neutrale und die anionische Form und $(0.6 \pm 0.2 \mathrm{ps})^{-1}$ für das Kation, mit anschließender Schwingungskühlung mit (5 - $6 \mathrm{ps})^{-1}$. Durch Polarisationsabhängige Messungen zeigten sie zudem, dass mit elektronischer Anregung der Winkel zwischen dem Übergangsdipolmoment $\mu_{S_{0}} \longrightarrow S_{1}$ und der $\mathrm{C}=\mathrm{O}$-Streckschwingung ändert, was sie einem Twist zuordnen, der zu einer konischen Überschneidung zwischen $S_{1}$ und $S_{0}$ und somit zu einem effektiven IC-Kanal führt [43].

Vengris et al. führten umfangreiche Pump-Probe- und Pump-Dump-ProbeMessungen an cis-HBDI durch und fanden als Hauptprodukt der Photonenabsorption einen angeregten Zustand, der über zwei angerete Zwischenzustände durch innere Konversion in einen heißen Grundzustand übergeht und von dort über einen Zwischengrundzustand in den ursprünglichen Grundzustand relaxiert (siehe Reaktionsschema Abb.11.16). Die Geschwindigkeit der einzelnen Reaktionsschritte war $\mathrm{pH}$-abhängig, erfolgte aber bis auf den letzten Schritt im Grundzustand $k_{G 20}$ im sub-Pikosekundenbereich. Eine multidimensionale strukturelle Umgestaltung von HBDI mit mehr als einer Reaktionskoordinate wurde als Hauptursache für die Dynamik von Grund- und angeregtem Zustand diskutiert, viskositätsabhängige Messungen zeigten einen verlangsamenden Effekt, der jedoch schwächer als erwartet ausfiel und als Hinweis auf einen volumenerhaltenden und deshalb weitgehend viskositätsunabhängigen Hula-Twist-Mechanismus interprätiert wurde [41] [34] [44].

Als Konkurrenzprodukt fanden Vengris et al. für kationische, neutrale und anionische cis-Spezies mit einer Ausbeute von 10-25\% langlebige Photoprodukte (> 4 ns) mit jeweils ähnlichen spektralen Merkmalen: einem negativen 


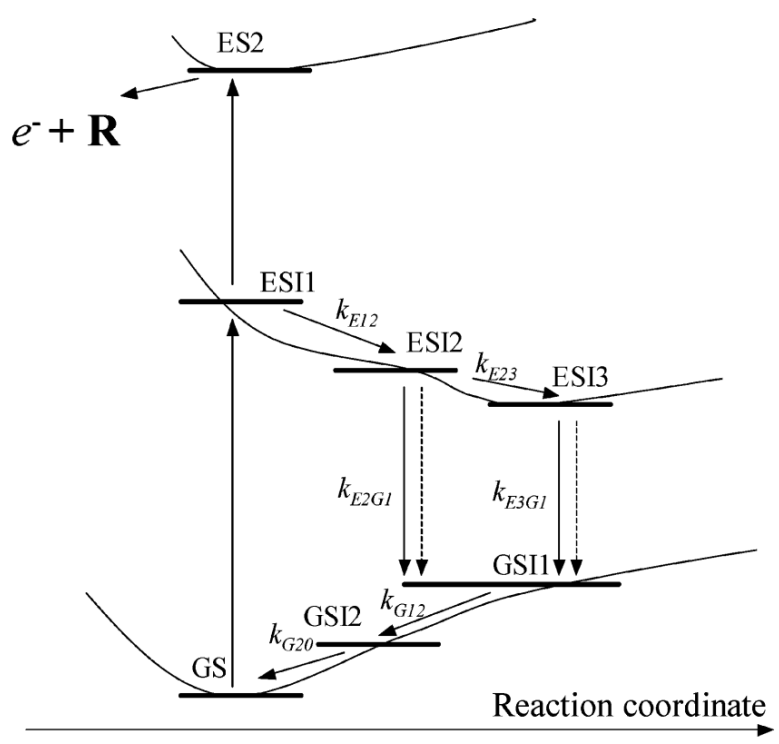

Abb. 1.16: Photodynamik von HBDI nach Vengris et al. |34|

Beitrag im Bereich der Absorption, die sie als Bleichen des Grundzustandes (ground state bleach, GSB) interprätierten, eine schmale positive Bande rotverschoben zum GSB und ein breiter positiver Beitrag mit einem Maximum bei $650 \mathrm{~nm}$. Da die Ausbeute des Photoproduktes durch einen Dumppuls, der die angeregte Spezies abregt, beeinflusst wurde und die relative Ausbeute dieser Photoprodukte von der Pumpintensität abhing, postulierten sie eine Zweiphotonen-Ionisierung. Die schmale Bande wiesen sie einem HBDIRadikal zu, die breite Bande bei $650 \mathrm{~nm}$ dem emittierten und anschließend solvatisierten Elektron. Das Abfallen der dem Elektron zugeschriebenen Bande bei pH 1 (400 ps) interprätierten sie als Kombination des Elektrons mit einem freien Proton; dieser Effekt war auf Radikal- und GSB-Bande nicht $\mathrm{zu}$ sehen und trat nur bei $\mathrm{pH} 1$ auf [34].

Wu et al. zeigten für Varianten des GFP-Tyr ${ }^{66}$ His-Chromophors, in die Imidazolgruppe durch eine Azolgruppe ersetzt ist, drastische Steigerungen der Fluoreszenzquantenausbeuten um drei Größenordnungen durch Einbringen einer $\mathrm{BF}_{2}$-Gruppe, die die Rotation um die Aryl-Alken-Bindung verhindern soll (Abb. 1.17) [45].

Baldridge et al. kapselten verschiedene Benzyliden-3-Methylimidazolidinone (BMI) in „octaacid“ (OA) [46], einem aromatischen Container-Komplex mit 


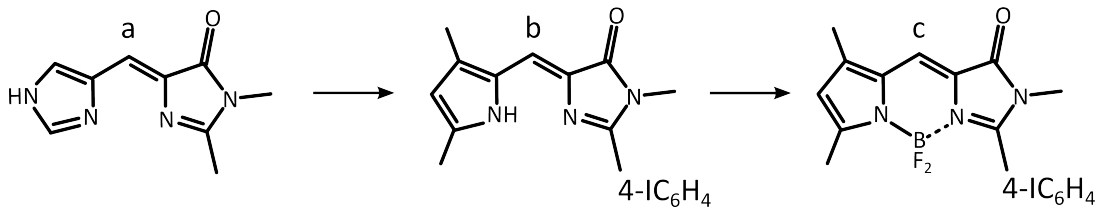

Abb. 1.17: Erhöhung der Fluoreszenzquantenausbeute von GFP-Y66H-ChromophorAnaloga durch Fixierung nach Wu et al. 455

a: GFP-Tyr ${ }^{66}$ His-Chromophor-Analog, b: $\Phi_{F}=0.0005$, c: $\Phi_{F}=0.86 \pm 0.2$

hydophober Kavität. Einige Derivate zeigten einen Anstieg der Fluoreszenzquantenausbeute im Vergleich zu einer Referenzlösung in Benzol um bis zu einer Größenordnung. Bei den meisten Derivaten änderte sich das isomere Gleichgewicht im Grundzustand zugunsten der trans-Spezies. Baldridge et al. begründeten den Anstieg der Fluoreszenzquantenausbeute in dem effizientesten Derivat durch eine Hinderung der $\tau$-Torsion (siehe Abb. 1.18) durch eine Methylgruppe in ortho-Position und folgerten, dass sowohl Isomerisierung, als auch Torsion des Phenylrings, Wege für innere Konversion seien [47]. 


\subsection{Chromophorumgebung}

Das Chromophor liegt nicht isoliert vor, sondern ist in eine Proteinumgebung eingebettet, mit der es vielfältig wechselwirkt (vgl. Abb. 1.3, 1.7, 1.12). Diese Wechselwirkungen können sterischer Natur sein, Wasserstoffbrücken bilden sich zwischen Aminosäureresten und den Donor- bzw. Akzeptorstellen des Chromophors, elektrostatische Wechselwirkungen wie Ladungs-, Diund Quadrupolwechselwirkungen ( $\pi$-stacking) treten auf.

\subsubsection{Sterische Wechselwirkungen}

Den vielleicht wichtigsten Einfluss auf die Eigenschaften des Chromophors in RSFPs sind sterischer Natur. Isomerisierung kann nur stattfinden, wenn genügend Platz vorhanden ist. Das Platzangebot bestimmt maßgeblich die Torsion und die Beweglichkeit des Chromophors, die sich wiederum auf Fluoreszenzlebensdauer und Quantenausbeute auswirken. Die Torsion im Chromophor kann mit Rotationen um die $\mathrm{C}=\mathrm{C}($ tilt $(\tau))$ und $\mathrm{C}-\mathrm{C}$ (twist $(\phi))$ Bindungen zwischen Fünf- und Sechsring beschrieben werden, gezeigt in Abb. 1.18. Brakemann et al. haben den Betrag der Summe dieser beiden Winkel zur Beschreibung der Torsion als einen wichtigen Faktor für die Fluoreszenzquantenausbeute $\Phi_{F}$ vorgeschlagen, wobei die Ausbeute bei planaren $\pi$-Systemen, also kleinen Wertem, höher ist (vgl. Tab 1.2).

\subsubsection{Wasserstoffbrücken und elektrostatische Wechselwirkungen}

Neben der Torsion ist die Beweglichkeit des RSFP-Chromophors eine für die Fluoreszenzquantenausbeute entscheidende Größe. Sterische Hinderungen, Wasserstoffbrückenbindungen und elektrostatische Wechselwirkungen

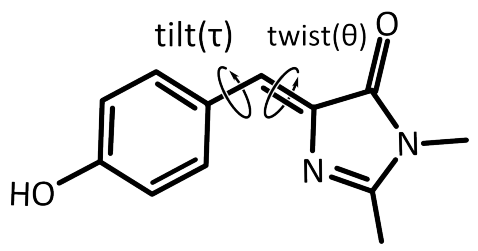

Abb. 1.18: Torsionswinkel des Chromophors von Padron 0.9 


\begin{tabular}{l|l|l|l} 
& Zustand & $|\tau+\phi|$ & $\Phi_{F}$ \\
\hline Dronpa & $C^{-}$ & $3.7 \pm 1.4$ & 0.85 \\
& $T^{-}$ & $20.6 \pm 5.3$ & 0.02 \\
rsFastLime & $C^{-}$ & 1.6 & 0.77 \\
& $T^{-}$ & - & - \\
Padron0.9 & $C^{-}$ & $11.6 \pm 1.1$ & 0.61 \\
asFP595-A143S & $T^{-}$ & $22.3 \pm 2.1$ & 0.002 \\
[48] & $C^{-}$ & $10.3 \pm 1.5$ & keine Angabe \\
& & &
\end{tabular}

Tab. 1.2: Zusammenhang zwischen dem Betrag der Summe der Winkel $\phi$ und $\tau$ und der Fluoreszenzquantenausbeute $\Phi_{F}$ für einige ausgewählte Proteine [23]

mit polaren Gruppen sowie Multipol-Wechselwirkungen wie überlagernde $\pi$-Elektronensysteme ( $\pi$-stacking) können das Chromophor in einer Position fixieren. Eine solche Fixierung bedeutet nicht zwangsläufig eine höhere Fluoreszenzquantenausbeute, verringert aber statistisch die Wahrscheinlichkeit einer effizienten inneren Konversion durch eine Reduzierung der erreichbaren Molekülkonfigurationen.

Speziell elektrostatische Wechselwirkungen protonierbarer Aminosäurereste sind $\mathrm{pH}$-abhängig. Ändert ein stabilisierender Aminosäurerest durch Änderung des pH-Wertes seinen Protonierungszustand, wird die aktuelle Chromophorkonfiguration energetisch ungünstiger. Ist die andere Konfiguratoin energetisch günstiger und die Schwelle der Isomerisierung niedrig, kann das Chromophor reagieren und isomerisieren. Ein solches Verhalten wurde von Pletnev et al. für das rot fluoreszierende Protein mKate beschrieben [49].

\subsubsection{Titrationsverhalten}

Durch die gleichen stabilisierenden Wechselwirkungen können Aminosäurereste Einfluss auf die Protonenaffinität des Chromophors nehmen. Ein direkter Einfluss ist die Stabilisierung des protonierten oder deprotonierten Chromophors, welche sich direkt auf den $p K_{s}$-Wert des Chromophors auswirkt. 
Dieser Effekt ist maßgeblich für die unterschiedlichen Protonierungsgleichgewichte der cis- bzw. trans-Isomere von Padron0.9 im Vergleich zu rsFastLime verantwortlich (vgl. Abb 3.1 und 3.19). Ist der stabilisierende Aminosäurerest selbst protonierbar, wird die Chromophor-Protein-Wechselwirkung komplizierter. Gayda et al. haben das Titrationsverhalten von mIrisGFP durch eine protonierbare Gruppe $C$ in der Umgebung des Chromophors $C$ beschrieben [50]. Die Auswirkungen solch einer titrierbaren Gruppe $X$ auf die $\mathrm{pH}$-Abhängigkeit des protonierbaren Chromophors $C$ sind in Abb 1.19 dargestellt. Abb $1.19 \mathrm{~b}$ zeigt das Protonierungsschema mit den vier möglichen Spezies: $\mathrm{C}^{H} \bar{X}^{H}-$ Chromophor und Aminosäure sind protoniert, $\mathrm{C}^{-} \mathrm{X}^{H}$ $\rightleftharpoons \mathrm{C}^{-} \mathrm{X}^{-}$- Chromophor oder Aminosäure ist protoniert; diese beiden Spezies stehen in einem $\mathrm{pH}$-unabhängigen Gleichgewicht miteinander, und $\mathrm{C}^{-} \mathrm{X}^{-}$- Chromophor und Aminosäure sind deprotoniert. Das System ist durch die drei angegebenen Protonierungsgleichgewichte vollständig bestimmt, $p K_{x 2}$ ergibt sich aus der Gl. 1.2 .

$$
p K_{c 1}+p K_{x 2}=p K_{x 1}+p K_{c 2}
$$

Die bloße Anwesenheit einer titrierbaren Aminosäure in unmittelbarer Umgebung ändert das titrierverhalten des Chromophors zunächst nicht (vgl. $\mathrm{Abb} 1.19 \mathrm{a}$ and $\mathrm{c}$, durchgezogene Linien). Auch ihr pKs-Wert $p K_{x 1}$ hat keinen Einfluss; ein niedriger Wert entvölkert zwar die Spezies $C^{H} X^{H}$ schon bei niedrigerem $\mathrm{pH}$, verschiebt aber das Gleichgewicht $\mathrm{C}^{-} \mathrm{X}^{H} \rightleftharpoons \mathrm{C}^{H} \mathrm{X}^{-}$ zugunsten der Spezies $\mathrm{C}^{H} \mathrm{X}^{-}$(vgl. Abb 1.19d, kurze Striche). Geht man aber davon aus, dass die Aminosäure $X$ einen Einfluss auf die Protonenaffinität $p K_{c}$ des Chromophores $C$ hat und sich dieser Einfluss durch Protonierung von $X$ ändert, also gilt $p K_{c 1} \neq p K_{c 2}$, ändert sich auch das Titrationsverhalten. Erhöht die deprotonierte Aminosäure $X^{-}$die Protonenaffinität von $C$, ist also $p K_{c 1}<p K_{c 2}$, erfolgt der Übergang $C^{H} \longrightarrow C^{-}$in einem ingesamt höheren und schmaleren $\mathrm{pH}$-Bereich (vgl. Abb 1.19e). Umgekehrt wird der Übergangsbereich zu niedrigen $\mathrm{pH}$ hin verbreitert, wenn $\mathrm{X}^{-}$die Protonenaffinität von $C^{H}$ senkt (vgl. Abb1.19f). 


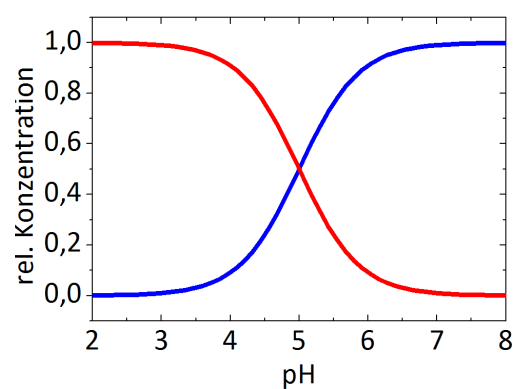

(a) $\mathrm{MWG}, p K_{s}=5$

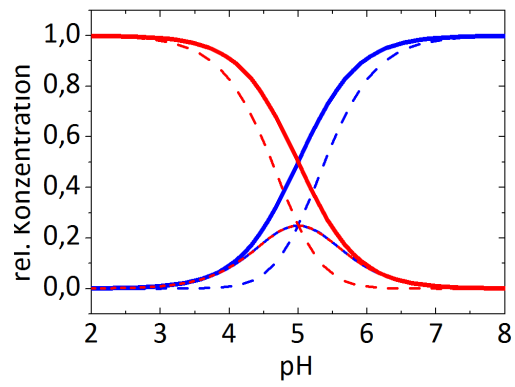

(c) $p K_{x 1}=5, p K_{c 1}=5, p K_{c 2}=5$

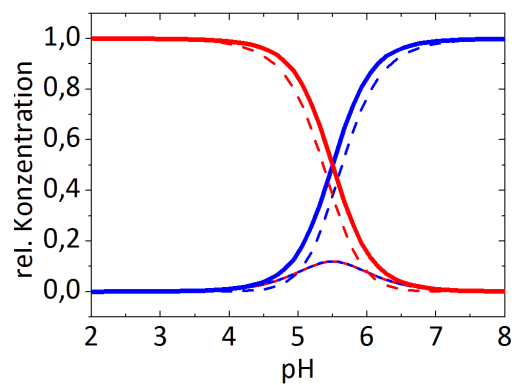

(e) $p K_{x 1}=5, p K_{c 1}=5, p K_{c 2}=6$

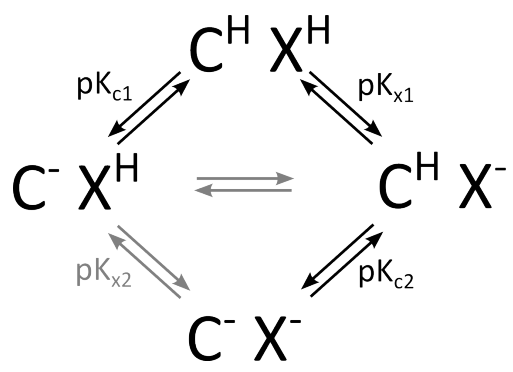

(b)

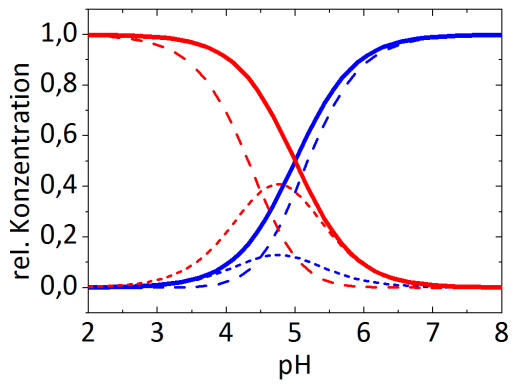

(d) $p K_{x 1}=4, p K_{c 1}=5, p K_{c 2}=5$

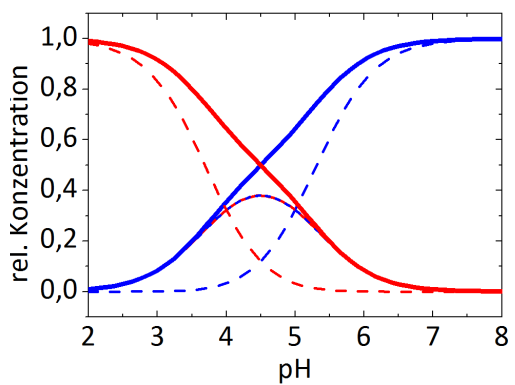

(f) $p K_{x 1}=5, p K_{c 1}=5, p K_{c 2}=4$

Abb. 1.19: Auswirkungen einer protonierenden Gruppe $X$ in der Umgebung des Chromophors $C$. Rote Kurven bezeichnen protonierte, blaue deprotonierte Chromophore. Gestrichelte Linien beschreiben unterschiedliche Subspezies, durchgezogene Linien jeweils die Summe aller protonierter bzw. deprotonierter Spezies. 


\subsection{Kinetischer Isotopeneffekt}

Wenn eine chemische Reaktion durch Austausch eines Atoms durch sein Isotop ihre Reaktionsgeschwindigkeit ändert, spricht man von einem kinetischen Isotopeneffekt (kinetic isotope effect, KIE). Hier soll nur ein grobes Bild im Hinblick auf die Größenordnung des KIEs bei Protonentransferprozesse gezeichnet werden; für eine eingehende Behandlung des Themas sei auf weiterführende Literatur von Bigeleisen (KIE) [51], Westheimer (Primärer H/D KIE) [52] und Krishtalik (Protonentransfer und Lösungsmitteleffekte) [53] verwiesen.

\subsubsection{Primärer Isotopeneffekt}

Wird eine atomare Bindung $\mathrm{zu}$ einem leichten Isotop gebrochen, ist die Geschwindigkeitskonstante $k_{l}$ des geschwindigkeitsbestimmende Schritts meist größer als die Geschwindigkeitskonstante $k_{s}$ des analogen Bindungsbruches zu dem schweren Isotop. Das Verhältnis $\frac{k_{l}}{k_{s}}$ wird als primärer Kinetischer Isotopeneffekt (primary kinetic isotope effect, PKIE) bezeichnet.

\subsubsection{Theorie des Übergangszustandes}

Vereinfacht lässt sich die Dissoziation einer $\mathrm{C}-\mathrm{H}$-Bindung nach Eyrings Theorie des des Übergangszustandes (transition state theory, TST) mit G1 1.3 beschreiben [53] und ist in Abb. 1.20] dargestellt.

$$
\mathrm{C}-\mathrm{H} \stackrel{\mathrm{K}^{\ddagger}}{\rightleftharpoons} \mathrm{C} \cdot \cdots \mathrm{H}^{\ddagger} \stackrel{k^{\ddagger}}{\longrightarrow} \mathrm{C}+\mathrm{H}
$$

Das Edukt $\mathrm{C}-\mathrm{H}$ steht im dynamischen Gleichgewicht $K^{\ddagger}$ mit dem Übergangszustand $\mathrm{C} \cdot \cdots \mathrm{H}^{\ddagger}$. Nachdem ein bestimmter Punkt (point of no return) überschritten wurde, reagiert der Übergangszustand mit der Geschwindigkeit $k^{\ddagger}$ zum Produkt. Die Gesamtgeschwindigkeit $k_{\text {ges }}$ der Dissoziation kann mit Gl. 1.4 beschrieben werden.

$$
k_{g e s}=\kappa \frac{k_{B} T}{h} \exp \left(\frac{-\Delta E^{\ddagger}}{k_{B} T}\right)
$$

Der Transmissionskoeffizient $\kappa$ beschreibt tatsächlich reagierenden Anteil des Übergangszustandes, $\Delta E^{\ddagger}$ ist die Energiedifferenz der Nullpunktsenergien von Edukt und Übergangszustand; $k_{B}$ ist die Boltzmann-, $h$ die Planckkonstante, $T$ beschreibt die Temperatur. 


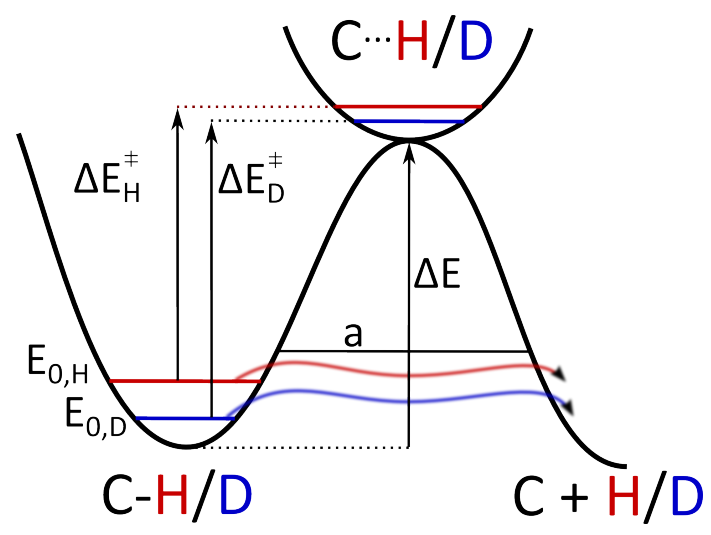

Abb. 1.20: Kinetischer Isotopeneffekt am Beispiel von Wasserstoff und Deuterium

Das Verhältnis der Geschwindigkeiten $k_{H}$ und $k_{D}$ wird mit Gl 1.5 beschrieben.

$$
\frac{k_{H}}{k_{D}}=\exp \left(\frac{\Delta E_{H}^{\ddagger}-\Delta E_{D}^{\ddagger}}{k_{B} T}\right)
$$

Die Nullpunktsenergie der $\mathrm{C}-\mathrm{H}$ - und $\mathrm{C}-\mathrm{D}$-Bindung lässt sich für den Fall eines harmonischen Oszillators nach Gl 1.6 mit $\mathrm{n}=0$ berechnen.

$$
\begin{aligned}
E_{n} & =\hbar \omega\left(n+\frac{1}{2}\right) \\
\omega & =\sqrt{\frac{k}{\mu}}
\end{aligned}
$$

Mit der Annahme, dass die Bindungen $\mathrm{C}-\mathrm{H}$ und $\mathrm{C}-\mathrm{D}$ die gleiche Kraftkonstante $\mathrm{k}$ haben, da unterschiedliche Isotope chemisch nahezu identisch sind, entsteht der Unterschied der Nullpunktsenergien nur aus den unterschiedlichen reduzierten Massen $\mu$.

$$
\begin{aligned}
\Delta E_{0} & =E_{0, H}-E_{0, D} \\
& =\frac{1}{2} \hbar \sqrt{k}\left(\sqrt{\frac{1}{\mu_{H}}}-\sqrt{\frac{1}{\mu_{D}}}\right)
\end{aligned}
$$


Setzt man in Gl.1.9 die reduzierten Massen $\mu_{H}$ und $\mu_{D}$ sowie die Kraftkonstante $\mathrm{k}=485 \mathrm{~N} \mathrm{~kg}^{-1}$ (entspricht einer $\mathrm{C}-\mathrm{H}$-Schwingungsfrequenz von $\tilde{v}=3000 \mathrm{~cm}^{-1}$ ) ein, ergibt sich nach Gl 1.9 für die Edukte ein Nullpunktenergieunterschied von $4.78 \mathrm{~J} \mathrm{~mol}^{-1}$. Mit der Näherung, dass die Nullpunktenergiedifferenz im Übergangszustand zu vernachlässigen ist, da die Kraftkonstante $\mathrm{k}$ der geschwächten $\mathrm{C} \cdot \mathrm{H}$-Bindung sehr viel kleiner ist als für die Edukte, ist $\Delta E_{H}^{\ddagger}-\Delta E_{D}^{\ddagger}=\Delta E_{0}$. Einsetzen in G1 1.5 gibt einen Isotopeneffekt von $\frac{k_{H}}{k_{D}}=6.8$.

\subsubsection{Tunneleffekt}

Für kleine Teilchen wie Protonen kann für Transferprozesse ein TunnelEffekt auftreten. Das Proton durchdringt dabei die Potentialbarriere, anstatt sie klassisch zu überwinden [53]. Dieser Vorgang kann nur quantenmechanisch durch den Wellencharakter des Teilchens beschrieben werden, die Wellenfunktion des Protons hat eine geringe Aufenthaltswahrscheinlichkeit jenseits der Barriere. Dieser Vorgang ist in Abb1.20 durch diffuse Pfeile veranschaulicht. Die Tunnenwahscheinlichkeit ist dabeivon der Barrierenhöhe $\Delta E$, der Barrierenbreite $a$ und von der Masse $m$ des Teilchens abhängig. Für ein rechteckiges Potential kann sie mit Gl. 1.11 beschrieben werden. Entsprechend ist die Tunnelwahrscheinlichkeit für Wasserstoff höher als für das doppelt so schwere Deuterium.

$$
\begin{array}{r}
G=\exp \left(-\beta\left(1-\frac{E}{\Delta E}\right)\right. \\
\beta=\pi^{2} a \sqrt{2 m \Delta E h}
\end{array}
$$




\section{Kapitel 2}

\section{Experimentelle Technik}

Die Photodynamik der untersuchten Proteine läuft auf einer Femto- bis Nanosekundenzeitskala ab. Um diese Prozesse zeitlich auflösen zu können, wurde ein Pump-Probe-Aufbau mit einer zeitlichen Auflösung im Femtosekundenbereich verwendet. Ein bestehender experimenteller Aufbau wurde im Rahmen dieser Arbeit durch die Kontinuumserzeugung und -detektion inklusive Datenaufnahme erweitert.

\subsection{Experimenteller Aufbau}

Der für Pump-Probe- und Pump-Dump-Probe-Messungen verwendete experimentelle Aufbau ist in Abb. 2.1] schematisch dargestellt. Als Laserlichtquelle dient ein Festkörper Titan:Saphir-Laser (Clark MXR-CPA 2001), aus dessen Ausgangspuls durch NOPA und/oder SHG Pump- bzw. Dumppulse verschiedender Wellenlängen erzeugt werden. Durch mechanische Chopper im Strahlengang kann jeder zweite Puls geblockt werden, was durch Photodioden (PD) überprüft wird. Als Probepuls wird in einem $\mathrm{CaF}_{2}-\mathrm{Kristall}$ (SK) ein Weißlichtpuls erzeugt, der mit Pump- und wahlweise Dumppuls in der Messzelle überlagert wird (siehe Abschnitt 2.1.5). Die Pulse aus NOPA, SHG und dem Weißlichtkontinuum können durch Verschiebebühnen (VE) relativ zueinander verzögert werden. Die einzelnen Komponenten sind im Folgenden kurz beschrieben.

\subsubsection{Clark MXR-CPA 2001}

Der als Laserquelle verwendete Clark MXR-CPA 2001 ist ein Festkörperlaser, der ultrakurze Pulse von etwa 120 fs Länge und $900 \mu$ J bei einer Zentralwellenlänge von $773 \mathrm{~nm}$ mit einer Repetitionsrate von $1 \mathrm{kHz}$ erzeugt. Der 


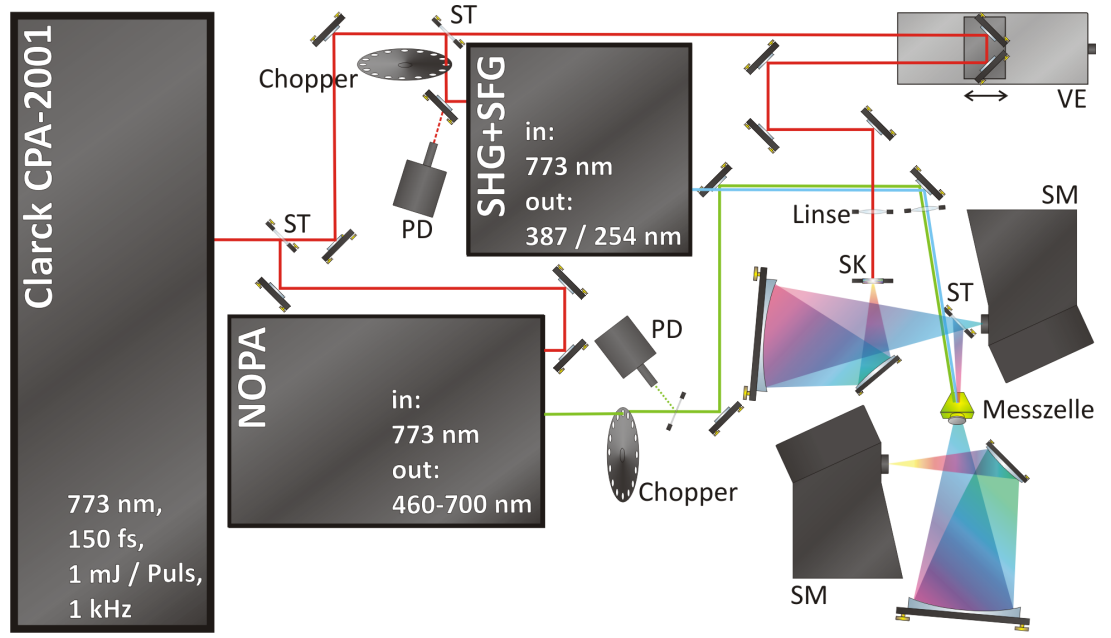

Abb. 2.1: Schematischer Aufbau des verwendeten UV/Vis Lasersystems ST: Strahlteiler, VE: Verschiebeeinheit, PD: Photodiode, SK: Sapphir/ $\mathrm{CaF}_{2}{ }^{-}$ Kristall, SM: Spektrometer

Laser lässt sich in die drei Bereiche Pumpquelle, Seeder und regenerativer Verstärker unterteilen.

Als Pumpquelle dient der Festkörperlaser ORC-1000, ein durch eine Blitzlampe gepumpter frequenzverdoppelter Neodym-dotierter Yttrium-AluminiumGranat Laser (Nd:YAG) mit akkustooptischem Modulator als Güteschaltung.

Als Seeder dient ein passiv modengekoppelter Faserlaser. Aktives Medium ist eine $\mathrm{Er}^{3+}$-dotierte Glasfaser, die bei $1550 \mathrm{~nm}$ emittiert. Die Faser ist ringförmig aufgebaut, die auftretende Gruppengeschwindigkeitsdispersion wird kompensiert. Der Pulsbetrieb wird durch polarisationsrotationsadditive Modenkopplung (APM) erreicht. Polarisations- und Wellenlängenkontrolle, sowie Auskopplung erfolgen hier über ein System aus vier $\lambda / 4$-Verzögerungsplättchen, einem Strahlteilerwürfel und einem doppelbrechenden Filter. Nach Auskopplung aus dem Faserlaser werden die Pulse auf etwa 100 fs komprimiert, in einem Lithiumtriborat-Kristall zu einer Wellenlänge von $775 \mathrm{~nm}$ frequenzverdoppelt und als Seedpuls in den regenerativen Verstärker eingeleitet.

Kern des regenerativen Verstärkers ist ein Titan:Saphir-Kristall (Ti:Sa) als laseraktives Medium. Der Ti:Sa-Laser ist wegen des breitbandigen Laserübergangs und der hohen Besetzungsinversion zur Erzeugung ultrakurzer 
Pulse gut geeignet. Im Resonator wird der eingehende Seedpuls verstärkt. Hierzu wird der spektral recht breite Puls über ein Gitter frequenzabhängig verzögert und der zeitlich breite Puls verstärkt (chirped pulse amplification, CPA), um die Zerstörung des Lasermediums durch Leistungsspitzen zu vermeiden. Anschließend wird der Puls wieder komprimiert. Als Güteschaltung im Resonator dient ein elektrooptischer Schalter (Pockelszelle) mit Polarisator, der auch die Auskopplung des Pulses aus dem Resonator steuert.

\subsubsection{NOPA}

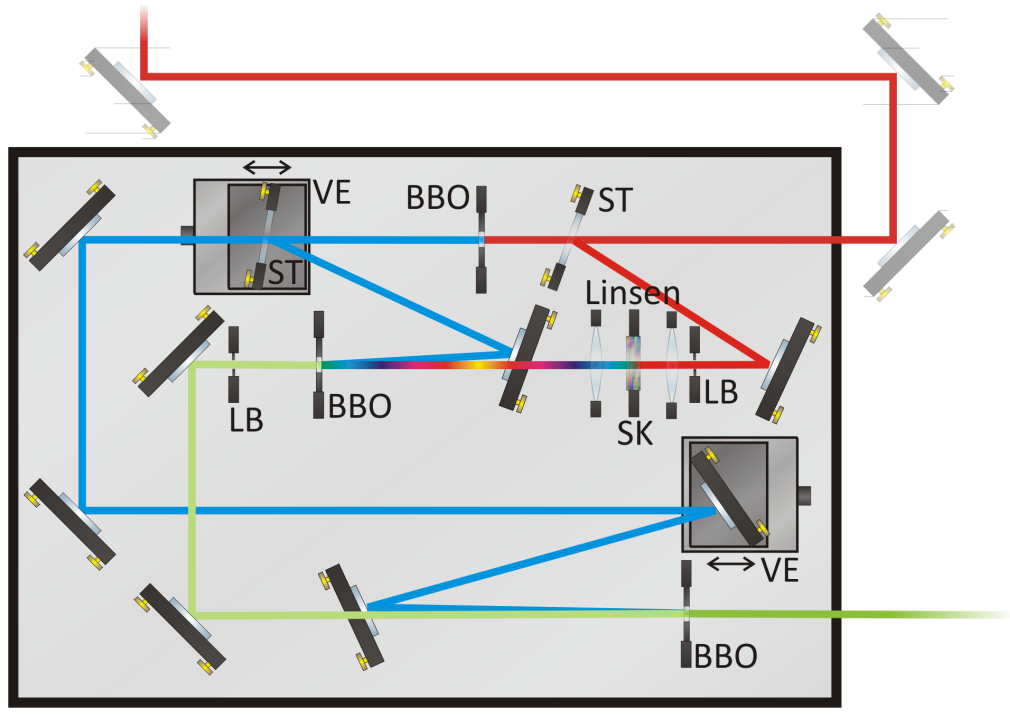

Abb. 2.2: Schematischer Aufbau des nicht-kollinearen optisch-parametrischen Verstärkers (non-collinear optical parametric amplifier, NOPA)

VE: Verschiebeeinheit, BBO: Beta-Bariomboratkristall, ST: Strahlteiler, LB: Lochblende, SK: Sapphirkristall

Der nicht-kollineare optisch parametrische Verstärker (non-collinear optical parammetric amplifier, NOPA) generiert aus monochromem Licht durch einen optisch parametrischen Verstärkungsprozess Licht von durchstimmbarer Wellenlänge im sichtbaren Bereich. Der nicht parallele Verlauf der Strahlen verringert den bei kollinearen Aufbauten auftretenden Gruppengeschwindigkeitsversatz im nichtlinearen Medium und ermöglicht so die 
Generierung kürzerer Pulse [54|. Für eine tiefere Behandlung der zugrundeliegenden optisch nichtlinearen Prozesse sei auf weiterführende Literatur wie Lauterborn [55] oder Diels [56] verwiesen.

Der verwendete NOPA ist ein zweistufiges System, der Aufbau ist in Abb. 2.2 schematisch dargestellt. Ein geringer Teil der Fundamentalen wird durch einen Strahlteiler (ST) abgetrennt und zur Erzeugung eines Weißlichtkontinuums in einen Saphirkristall (SK) fokussiert (siehe 2.1.4). Der Hauptteil der Fundamentalen wird in einem optisch nichtlinearen Kristall (BetaBariumborat, BBO, $8 x 8 x 0.7 \mathrm{~mm}^{3}, \Theta=30^{\circ}$, Typ I Phasenanpassung) zu $387 \mathrm{~nm}$ frequenzverdoppelt und als Pumplicht für die parametrischen Prozesse verwendet. Ein weiterer Strahlteiler (ST) teilt das Pumplicht auf. $20 \%$ betreiben die erste Stufe, die restlichen $80 \%$ die zweite Stufe. Weißlichtkontinuum und Pumppuls werden nun in einem weiteren BBO-Kristall $\left(5 \times 5 \times 2 \mathrm{~mm}^{3}\right.$, $\Theta=32.5^{\circ}$ ) überlagert. Ein Pump-Photon zerfällt in ein Signal- und ein Idler-Photon. Die Geometrie des BBO und der überlagernden Pulse ist so gewählt, dass Weißlicht- und Signalpuls parallel laufen. Da die Frequenzen des Weißlichtkontinuums zeitlich aufgespreizt sind (chirp), kann es über eine Verschiebebühne (VE) spektral durchgestimmt werden. Es wirkt als Seedpuls und stimuliert den Zerfallprozess, in dem die Wellenlängen von Signal- und Seedpuls gleich sind. Der erzeugte Signalpuls wird nun mit den übrigen $80 \%$ Pumppuls in dem $\mathrm{BBO}\left(5 \times 5 \times 2 \mathrm{~mm}^{3}, \Theta=32.5^{\circ}\right)$ der zweiten Verstärkungsstufe überlagert und fungiert hier wiederum als Seedpuls. Der schließlich resultierende Signalpuls liegt im Bereich von 460-700 nm. Die Intensität ist wellenlängenabhängig und liegt typischerweise im Bereich um $15 \mathrm{~mW}$.

\subsubsection{SHG und SFG}

Die Wellenlängen $258 \mathrm{~nm}$ und $387 \mathrm{~nm}$ können separat aus der Fundamentalen erzeugt werden. Der Aufbau ist in Abb. 2.3 schematisch dargestellt. Die Fundamentale wird in einem BBO-Kristall $\left(5 \times 5 \times 0.2 \mathrm{~mm}^{3}, \Theta=29.2^{\circ}, \Phi=90^{\circ}\right.$, Typ I Phasenanpassung) frequenzverdoppelt (second harmonic generation, SHG), was einer Wellenlänge von $387 \mathrm{~nm}$ entspricht. Bei diesem Prozess dreht sich die Polarisationsrichtung der Verdoppelten um $90^{\circ}$ gegenüber der Fundamentalen. Ein dielektrischer Spiegel (DS) leitet die Fundamentale auf eine Verschiebebühne (VE), der verdoppelte Anteil wird transmittiert. Die Polarisationsrichtung der Fundamentalen wird durch ein $\lambda / 2$-Plättchen ebenfalls um $90^{\circ}$ gedreht, anschließend werden die Fundamentale und der abgetrennte verdoppelte Anteil in einem weiteren BBO-Kristall $\left(5 \times 5 \times 0.2 \mathrm{~mm}^{3}\right.$, $\Theta=44.3^{\circ}, \Phi=90^{\circ}$, Typ I) überlagert, wobei die Summenfrequenz der beiden 


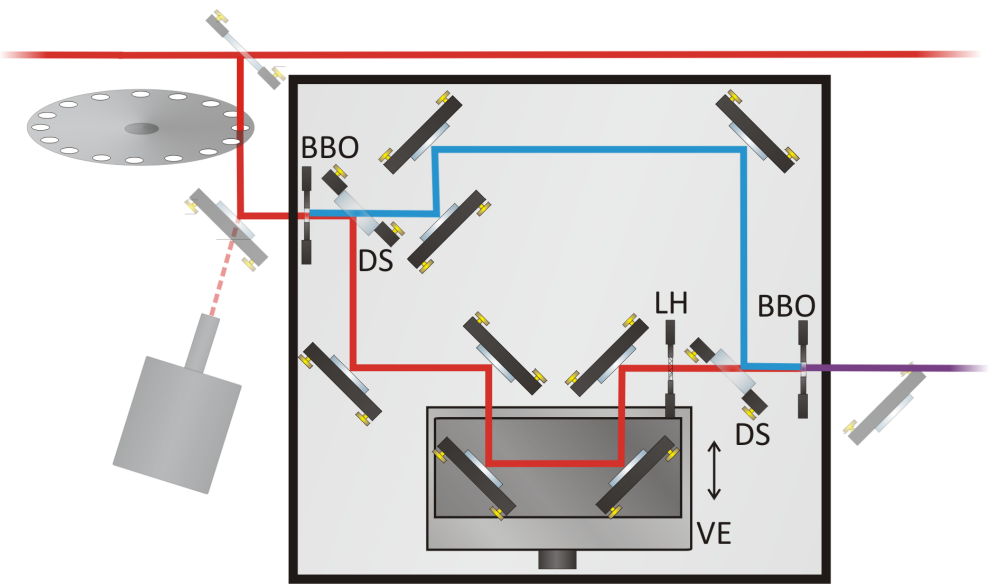

Abb. 2.3: Schematischer Aufbau zur Erzeugung der zweiten Harmonischen (SHG) und Summenfrequenz (SFG)

BBO: Beta-Bariumboratkristall, DS: Dielektrischer Spiegel, LH: $\lambda / 2-P l a t t e$, BE: Verschiebeeinheit

Pulse erzeugt wird (sum frequency generation, SFG), was einer Wellenlänge von $258 \mathrm{~nm}$ entspricht. Über dielektrische Spiegel oder Frequenzfilter können die drei parallel laufenden Pulse getrennt und anschließend separat verwendet werden. Hier wurde ausschließlich die Verdoppelte mit $387 \mathrm{~nm}$ genutzt.

\subsubsection{Weißlichtkontinuum}

Durchläuft ein ausreichend starker, kurzer Laserpuls ein transparentes Medium, kann es zu einer Verbreiterung des Pulsspektrums zu einem Weißlichtkontinuum kommen. Als Ursache wird ein komplexes Zusammenspiel mehrerer optisch nicht linearer Effekte wie Selbstfokussierung, Selbstphasenmodulation, Vier-Wellen-Mischung und die Erzeugung freier Elektronen [57, 58] angenommen. Das erzeugte Kontinuum ist eine kohärente Lichtquelle [59]. Es kann als ein einzelner, stark gechirpter Puls behandelt werden [60] und behält die Polarisation des erzeugenden Laserpulses bei [61]. Der Wellenlängenbereich hängt von der numerischen Apertur [62], Intensität, Pulslänge und Wellenlänge des erzeugenden Lichtes sowie dem verwendeten Material ab [63]. Für eine aktuellen Überblick sei auf vertiefende Literatur von Alfarno [63] und Zheltikov [64] verwiesen. 


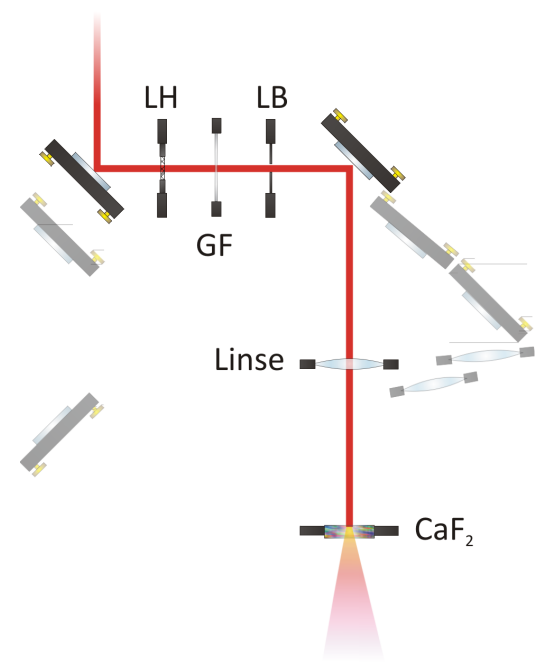

Abb. 2.4: Schematischer Aufbau der Weisslichterzeugung

LH: $\lambda / 2$-Platte, GF: Graufilter, LB: Lochblende, $\mathrm{CaF}_{2}-$ Kristall

Das als Probepuls verwendete Weißlichtkontinuum wird durch Fokussierung der Fundamentalen $(\mathrm{f}=100 \mathrm{~mm})$ in einen Calciumfluoridkristall $\left(\mathrm{CaF}_{2}\right.$, $21 \times 21 \times 4 \mathrm{~mm}^{3}$ ) erzeugt. Der Kristall wird dabei kontinuierlich bewegt, um thermische Beschädigungen zu verhindern. Der schematische Aufbau der Weißlichterzeugung ist in Abb. 2.4 dargestellt. Die Intensität der Fundamentalen wird durch Graufilter (GF) und eine Lochblende (LB) eingestellt. Die Polarisationsrichtung kann über ein $\lambda / 2$-Plättchen (LH) gewählt werden. Es wurde üblicherweise der 'magische Winkel' von $54.7^{\circ}$ zwischen Pump- und Probepuls eingestellt. Das erzeugte Kontinuum ist in Abb. 2.5 gezeigt.

\subsubsection{Interferometer}

Im Interferometer werden Pump- , Probe- und gegebenenfalls ein Dumppuls in der Messzelle überlagert. Der Aufbau ist schematisch in Abb. 2.4 dargestellt. Ein Strahlteiler (ST) teilt den Probepuls in zwei Teilpulse auf. Ein Teil wird als Referenz direkt mit einem Spektrometer (Horiba CP1401825, SM1) mit angeschlossenem Photodiodenarray (Hamamatsu NMOS S3901-256Q, 256 Pixel) detektiert. Der andere Teil wird in der Messzelle mit dem Pump- (blau) und gegebenenfalls dem Dumppuls (grün) überlagert und im Anschluss durch ein weiteres Spektrometer (SM2, baugleich zu SM1) 


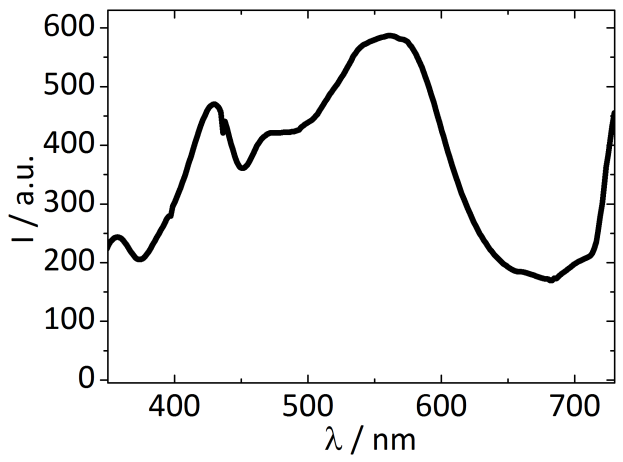

Abb. 2.5: Das erzeugte Weißlichtkontinuum

detektiert. Durch den nicht-kollinearen Aufbau können Pump- und Dumppuls nach Durchlaufen der Messzelle einfach geblockt werden. Reste der Fundamentalen, die nach Kontinuumserzeugung noch übrig sind, werden durch einen Tiefpass Kantenfilter $\left(\lambda_{\text {cutoff }}=750 \mathrm{~nm}(\mathrm{TF})\right)$ gefiltert.

Pump- und Dumppuls werden durch einfache Planspiegel (S1, S2) und bikonvexe Quarzlinsen in die Messzelle gelenkt. Als Probepuls dient das erzeugte Weißlichtkontinuum (siehe 2.1.4). Es ist divergent und spektral sehr breit. Würden hier auch Linsen zur Fokussierung verwendet, käme es wegen der Wellenlängenabhängigkeit des Brechungsindexes des Linsenmediums zu chromatischer Abberation, also unterschiedlichen Foki für verschiedene Wellenlängen (siehe Abb.2.7(a)). Um dies zu vermeiden, wird das Kontinuum durch sphärische Spiegel statt durch Linsen fokussiert. Da der Lichteinfall auf diese Spiegel nicht entlang der optischen Achse erfolgen kann, erfahren die relativ zur Tischebene parallelen (sagittalen) und senkrechten (meridionalen) Anteile des Lichtbündels einfallswinkelabhängig eine unterschiedliche Fokussierung (Astigmatismus, siehe Abb.2.7(b)), wobei die Sagittalebene (S) hier die optische Achse (OA) enthält, die Meridionalebene $(M)$ nicht. In den Punkten $B_{M}$ und $B_{S}$ existieren dann keine Brennpunkte, sondern die Brennlinien der jeweils anderen Ebene. Dieser Abbildungsfehler (Astigmatismus) wird im Interferometer durch die Kombination eines Konvex- (S3, S5) und Konkavspiegels (S5, S6) in geeigneter Anordnung ausgeglichen.

Die verwendeten Spektrometer nutzen auf die 1. Beugungsordnung optimierte holografische Blazegitter, um das einfallende Licht aufzulösen. Der 


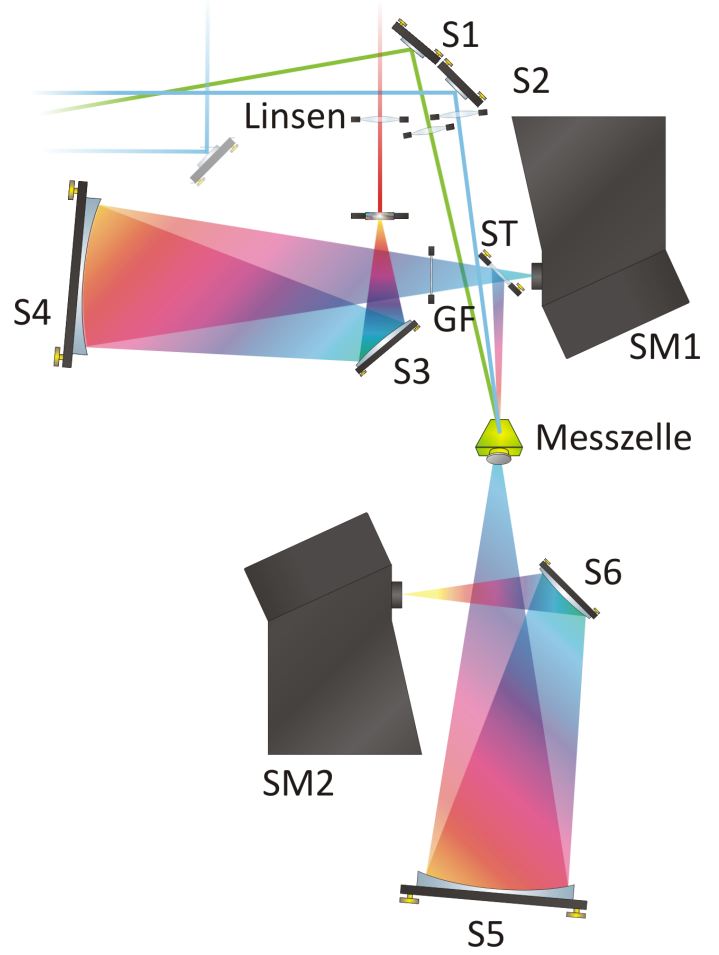

Abb. 2.6: Schematischer Aufbau des Interferometers

S1,2: Planspiegel, S3,6: Konvexspiegel, S4,5: Konkavspiegel, ST: Strahlteiler, SM1,2: Spektrometer mit Diodenzeile, TF: Tiefpass-Kantenfilter

aufgelöste Wellenlängenbereich liegt zwischen 350 und $730 \mathrm{~nm}$. Trotz Blazegitter auftretende Beugung 0. Ordnung wird im Gerät geblockt. Bei der Beugung 2. Ordnung ist dies nicht möglich; ein Bruchteil des Lichts kürzerer Wellenlängen $(\lambda<360 \mathrm{~nm})$ wird so auf die Dioden für höhere Wellenlängen gelenkt $(\approx 650-720 \mathrm{~nm})$. Für Messungen in diesem Bereich kann deshalb ein Hochpass Kantenfilter $\left(\lambda_{\text {cutoff }}=390 \mathrm{~nm}\right)$ vor die Spektrometer gesetzt werden, um dies zu verhindern.

Um unerwünschtes Streu- und Fluoreszenzlicht selektiv zu verringern, wurde zusätzlich ein auf die Polarisationsrichtung des Weißlichts eingestellter Polarisator vor dem Spektrometer SM2 verwendet. 


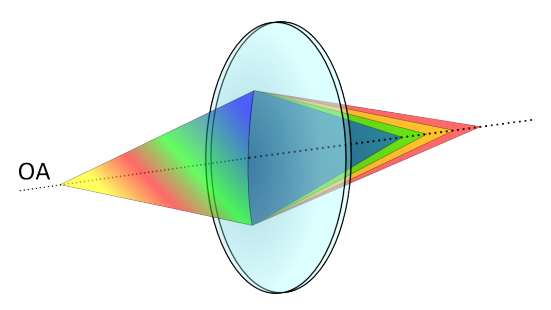

(a) Chromatische Aberration

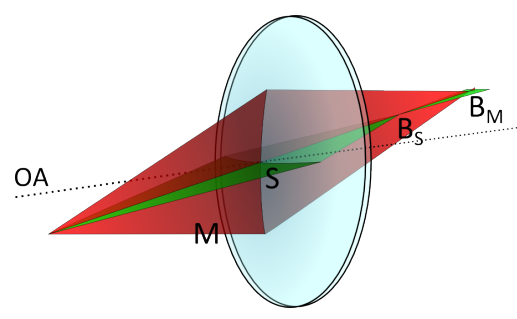

(b) Astigmatismus

Abb. 2.7: Auftretende Abbildungsfehler

\subsubsection{Pumpenkreislauf}

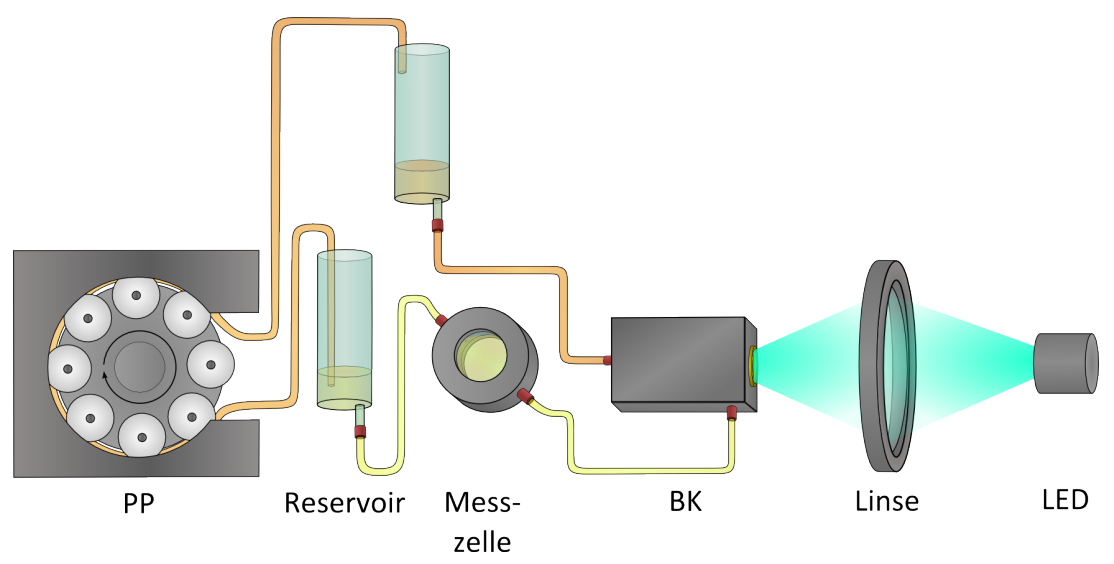

Abb. 2.8: Schematischer Aufbau des Probekreislaufs

PP: Peristaltikpumpe, BK: Bestrahlungskammer, LED: Lichtemittierende Diode

Um Ausbleichen und eine Akkumulation von Photoprodukten im Verlauf der Messung zu verhindern, wurde ein Volumen der Probelösung $(\approx 6 \mathrm{~mL})$ in einem Kreislauf so schnell durch die Messzelle gepumpt, dass die Lösung im Bereich der Überlagerung von Pump- und Probestrahl zwischen zwei Pulsen vollständig ausgetauscht wurde. Die verwendeten Proteine sind gegenüber mechanischem Stress anfällig und denaturieren leicht. Durch den verwendeten Pumpkreislauf, schematisch in Abb.2.8 dargestellt, konnte ein konstanter Fluss mit hoher Geschwindigkeit bei minimaler mechanischer Belastung erreicht werden. Eine Peristaltikpumpe (PP) transportierte die 
Proteinlösung von einem Reservoir in ein zweites Reservoir auf etwa $60 \mathrm{~cm}$ über der Tischebene. Die Lösung floss durch eine Bestrahlungskammer (BK) und die Messzelle zurück in das erste Reservoir. Die Flussgeschwindigkeit konnte durch die Höhe des zweiten Reservoirs eingestellt werden. Innerhalb der Bestrahlungskammer war die Flussgeschwindigkeit wegen des größeren Innendurchmessers reduziert. Durch ein Glasfenster wurde die Lösung hier mit einer LED (1 W, 390 bzw. $490 \mathrm{~nm}$ ) bestrahlt, um das Protein möglichst vollständig in das jeweils gewünschte Isomer zu überführen. 


\subsection{Messmethode}

\subsubsection{Pump-Probe-Spektroskopie}

Pump-Probe-Spektroskopie ist eine Methode zur zeitaufgelösten Untersuchung intra- wie intermolekularer Phänomene. Eine Materialprobe wird durch einen kurzen Pumppuls der Intensität $I_{p}$ angeregt. Nach einer einstellbaren Zeit $\Delta t$ wird ihr Zustand durch einen Probepuls abgefragt. Durch Interaktion mit dem angeregten Probegut ändert der Probepuls seine Intensität, diese Änderung wird aufgenommen. Schwankungen in Intensität und spektraler Beschaffenheit des Probepulses werden durch eine Referenzmessung der Intensität $I_{0}$ vor Interaktion mit dem Probegut kompensiert. Aus Probe- und Referenzstrahl ergibt sich die optische Dichte $O D$ der Lösung, siehe G1.2.1.

$$
O D=\log \frac{I}{I_{0}}
$$

Den größten Beitrag zur optischen Dichte werden in der Regel nicht angeregte Moleküle im Grundzustand liefern. Ihr Signal ändert sich zeitlich nicht und entspricht ihrem stationären Absorptionsspektrum. Dieser Beitrag wird vom Gesamtsignal abgezogen. Betrachtet wird die durch den Pumppuls hervorgerufene Änderung der optischen Dichte der Probe $\triangle O D$, siehe G1.2.2 Die Zeitauflösung ergibt sich aus der Faltung der zeitabhängigen Intensitätsprofile von Pump- und Probepuls.

$$
\Delta O D=\log \left(\frac{I}{I_{0}}\right)_{\text {gepumpt }}-\log \left(\frac{I}{I_{0}}\right)_{\text {ungepumpt }}
$$

In dieser Arbeit wurden transparente Lösungen von fluoreszierenden Proteinen hinsichtlich ihrer Dynamik nach Anregung untersucht. Die Menge der angeregten Proteine im Probevolumen und somit die Stärke des Signals ist abhängig von der Proteinkonzentration $c$ und der Intensität $I_{p}$. Bei isotroper Orientierung der Proteine kann durch den polarisierten Pumppuls zudem nur der Teil der Proteinchromophore im Probevolumen angeregt werden, dessen Übergangsdipolmoment eine Komponente parallel zur Polarisationsrichtung aufweist.

Ein aufgenommenes $\triangle O D$-Spektrum ist eine Superposition der Beiträge des Grund- und aller angeregten Zustände. Positive Beiträge zu $\triangle \mathrm{OD}$, für die gelten muss $I_{\text {gepumpt }}<I_{\text {ungepumpt }}$, können ausschließlich von der Absorption 
eines angeregten Zustandes kommen (exited state absorption). Negative Beiträge hingegen, für die gelten muss $I_{\text {gepumpt }}>I_{\text {ungepumpt }}$, können einerseits von stimulierter Emission des angeregten Zustandes kommen, andererseits von einer geringeren Absorption durch Moleküle im Grundzustand, der nach Anregung niedriger populiert ist (Grundzustandsbleichen, ground state bleach). Sofern durch die Anregung keine permanenten Produkte gebildet werden, wird $\Delta \mathrm{OD}(\mathrm{t})$ für $t \longrightarrow \infty$ gegen Null laufen.

Die Intensität des $\Delta \mathrm{OD}$-Signals (G1.2.3) hängt bei Einphotonenabsorption von der Menge des initial angeregten Proteins $c_{e x}$ und dessen spektralen Eigenschaften im Grundzustand $\epsilon_{g}(\lambda)$ und den beteiligten Zuständen $\epsilon_{i}(\lambda)$, deren zeitabhängiger Konzentration $c_{i}(t)$ sowie dem Überlapp zwischen Pump- und Probepuls $\sigma_{p p}$ ab. Die Menge des angeregten Proteins wiederum hängt mit der Proteinkonzentration $c_{0}$, Pumpintensität $I_{p}$ und der Absorption bei der Pumpwellenlänge $\epsilon_{g}\left(\lambda_{p}\right)$ zusammen.

$$
\begin{aligned}
\Delta O D(t, \lambda) & =c_{\text {ex }} \cdot\left(c_{g}(t) \epsilon_{g}(\lambda)+\sum_{i}\left(c_{i}(t) \epsilon_{i}(\lambda)\right) \cdot \sigma_{p p}\right) \\
c_{\text {ex }} & =I_{\text {pump }} c_{0} \epsilon_{g}\left(\lambda_{\text {pump }}\right)
\end{aligned}
$$

\subsubsection{Pump-Dump-Probe-Spektroskopie}

Die Pump-Dump-Probe-Spektroskopie ist ein der Pump-Probe-Spektroskopie ähnliches Dreipulsexperiment. Eine Materialprobe wird durch einen Pumppuls angeregt. Nach einer Verzögerungszeit $\Delta \mathrm{t}_{\text {dump }}$ wird ein zweiter intensiver Laserpuls eingestrahlt, der mit der angeregten Materialprobe interagiert, also entweder absorbiert wird, oder Emission stimuliert. So können sonst nicht oder nur schwach populierte Zustände und ihre Dynamik innerhalb einer Reaktionskaskade zugänglich gemacht werden, wie z.B. Zustand $B$ im Reaktionsschema in Abb.2.9b. Gilt $k_{1}>k_{2}$ « $k_{3}$ ist Zustand $B$ nie nennenswert populiert (siehe Abb. 2.9b), sein Spektrum und die Reaktionsrate $k_{3}$ kann nicht gemessen werden. Wird $B^{*}$ durch einen verzögerten Puls (hier: $\Delta \mathrm{t}_{\text {dump }}=4 \mathrm{ps}$ ) durch stimulierte Emission nach $B$ überführt, also geleert (engl.: dumped), gibt es direkt nach dem Puls eine messbare Konzentration von $B$ (siehe Abb. 2.9c) und das Spektrum sowie Dynamik dieses Zustandes können aufgenommen werden.

Analog zur Pump-Probe-Spektroskopie kann das Pump-Dump-Spektrum nun als Differenzspektrum zwischen gedumpter und nicht-gedumpter PumpProbe-Messung aufgetragen werden. In Abb.2.9d ist ein Doppeldifferenzkonzentrationsspektrum für die Reaktion aus Abb. 2.9a aufgetragen. Die 
durch den Dumppuls induzierte Änderung der optischen Dichte wird, ähnlich wie bei dem Pump-Probe Messungen, mit mit Gl 2.4 beschrieben.

$$
\Delta \triangle O D=\Delta O D_{\text {gedumpt }}-\Delta O D_{\text {ungedumpt }}
$$

Auch ein Pump-Dump-Probe-Spektrum ist eine Superposition der Beiträge aller durch den Dumppuls direkt oder indirekt beeinflussten Zustände. Positive Signale werden durch eine Dumppuls-induzierte Bevölkerung einer absorbierenden Spezies oder Entvölkerung einer angeregten Spezies im Bereich ihrer stimulierten Emission erzeugt, negative Signale durch Bleichen einer angeregten absorbierenden Spezies. Bleibende Signale werden nur generiert, wenn der Dumppuls direkt Einfluss auf die Erzeugung stabiler Spezies hat, entweder durch Unterstützung oder Behinderung eines durch den Pumppuls induzierten Bildungsprozesses oder durch einen durch den Dumppuls selbst induzierten Bildungsprozess, sonst wird $\Delta \Delta \mathrm{OD}(\mathrm{t})$ für $t \rightarrow \infty$ gegen Null laufen. 


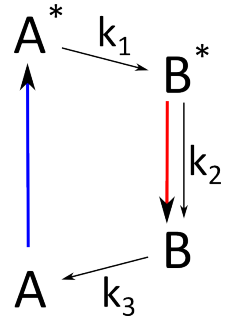

(a) Reaktionsschema

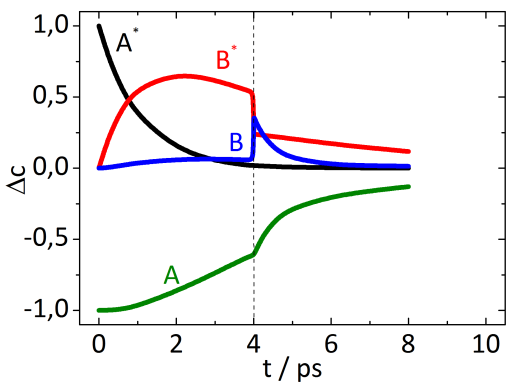

(c) $\Delta \mathrm{c}$-Spektrum

$$
t_{\text {pump }}=0 \mathrm{ps}, t_{\text {dump }}=4 \mathrm{ps}
$$

Abb. 2.9: Reaktionsschema und

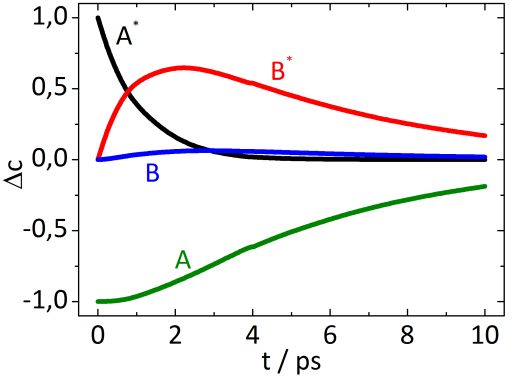

(b) $\Delta c$-Spektrum

$$
t_{\text {pump }}=0 \text { ps }
$$

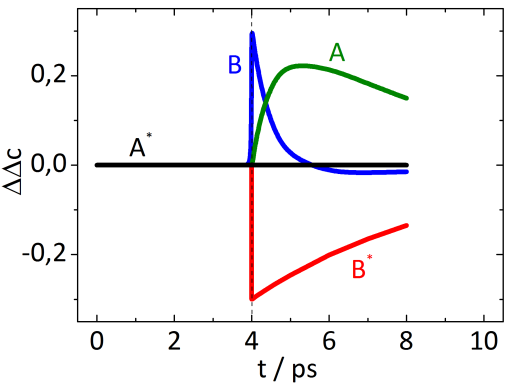

(d) $\Delta \Delta \mathrm{c}$-Spektrum von

$$
t_{\text {pump }}=0 \mathrm{ps}, t_{\text {dump }}=4 \mathrm{ps}
$$

korrespondierende

Differenz-

Konzentrationsspektren der beteiligten Spezies mit und ohne Dumppuls nach Anregung durch einen Pumppuls

\subsection{Datenverarbeitung}

\subsubsection{Datenaufnahme}

Den grundlegenden Takt des Experiments gibt der modengekoppelte Faserlaser im Clark MXR an (siehe 2.1.1). Der zeitliche Abstand der einzelnen Moden taktet die Steuerelektronik der Pockelszelle (DT, Hochfrequenztreiber DT-505), die als Güteschaltung im Resonator fungiert und die Pulse in Abständen von $1 \mathrm{~ms}$ auskoppelt. Dabei gibt die Steuerung ein TTL-Signal ab, das als Startsignal für alle weiteren Geräte im Experiment dient. Der elektrische Aufbau ist in Abb. 2.10 schematisch dargestellt. Das Signal aus 


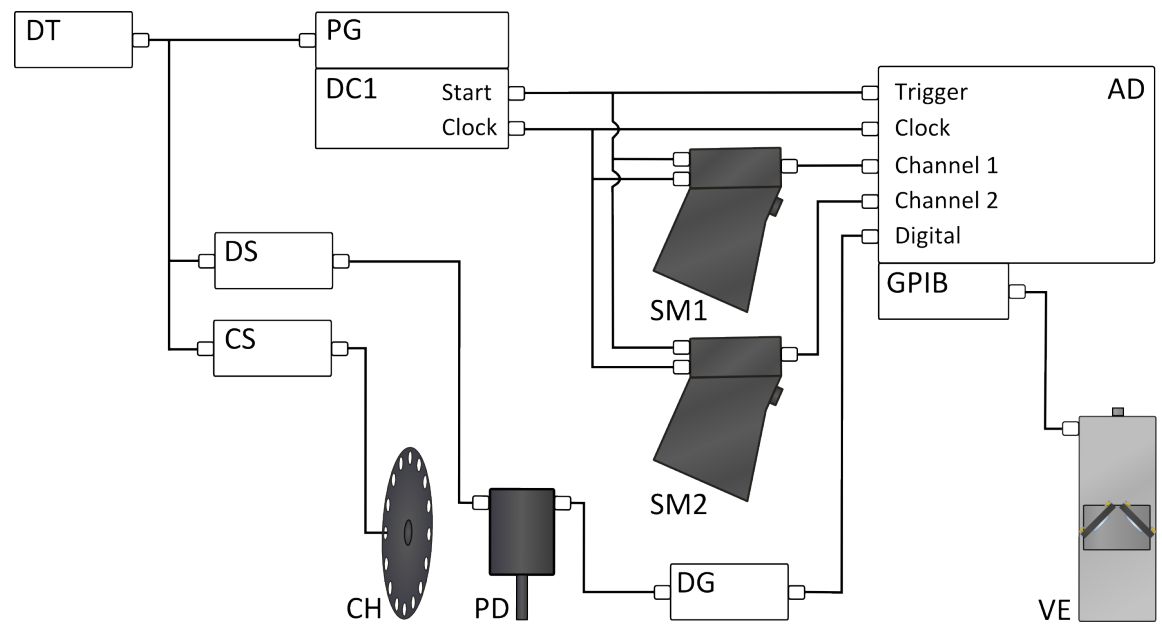

Abb. 2.10: Elektrische Steuerung und Datenaufnahme. Signaleingang: links, Signalausgang: rechts

DT: Steuerelektronik Pockelszelle, DS: Diodensteuerung, CS: Choppersteuerung, CH: Chopper, PD: Photodiode, DG: Delay-Generator, PG: Pulsgenerator, DC1: Diodentreiber, SM1,2: Spektrometer mit Diodenzeile, AD: Analog/Digitalwandler, GPIB: GPIB-Karte, PVE: Verschiebeeinheit

dem Pockelszellentreiber startet den Pulsgenerator (PG, Hamamatsu C822501) sowie die Diodensteuerung (DS) für eine integrierende Photodiode (PD, Hamamatsu 1226-8BQ) und gibt der Choppersteuerung (CS) den Takt für den Schrittmotor im Chopper $(\mathrm{CH})$ vor. Der Pulsgenerator generiert einen Startpuls, der das sequentielle Auslesen der Diodenzeile durch den Treiberschaltkreis (DC, Hamamatsu C7884) initiiert und ein Clocksignal, das den Wechsel von Pixel zu Pixel steuert. Start-, Clock- und beide Diodensignale werden von einem Analog/Digital-Wandler (AD) ausgelesen. Die Photodiode (PD) nimmt das Signal des Pumppulses hinter dem Chopper auf und speist es in einen Delaygenerator (DG, Stanford Research Systems Inc. DG535), der bei Überschreiten einer Intensitätsschwelle ein Signal an einen Digitalkanal der Messkarte sendet. Ein selbstgeschriebenes Messprogramm nimmt die Daten auf und steuert über eine GPIB-Karte (GPIB) auch die Position der Verschiebebühne (VE). Start- und das Clocksignal ermöglichen ein exaktes Auslesen und die Zuordnung der eingehenden Signale. Das Digitalsignal gibt an, ob die jeweilige Messung mit oder ohne Pumppuls erfolgte. Gespeichert wird der Mittelwert mehrerer, üblicherweise einiger hundert, aus den aufgenommenen Intensitäten berechneten $\Delta \mathrm{OD}$-Signale 
für jeden der 256 Pixel der Diodenzeile für einen Verzögerungszeitpunkt. Je nach Messung wird eine Reihe von Verzögerungszeiten abgefahren, wobei ein Datensatz immer mindestens aus einem Hin- und Rückweg bestehen muss, um eventuelles Photobleichen der Probe zu kompensieren.

\subsubsection{Korrekturen der Daten}

Der Datensatz einer Messung besteht aus $256 \Delta$ OD-Werten pro Verzögerungszeit $\Delta t$. Jeder der 256 Werte ist ein Mittelwert aus üblicherweise einigen hundert Einzelmessungen und direkt einem Pixel der Diodenzeile und somit einer Wellenlänge im Bereich $\lambda_{\text {probe }}=350-730 \mathrm{~nm}$ zugeordnet. Jede Verzögerungszeit wird in der Regel mehrfach angefahren.

\subsubsection{Kalibrierung}

Der Aufbau der Spektrometer SM1 und SM2 (siehe 2.1.5) ist identisch. Beim Einbau der Diodenzeilen wurde anhand der charakteristischen Linien einer Quecksilberdampflampe darauf geachtet, dass beide Zeilen das Spektrum identisch abbilden. Die Zuordnung der einzelnen Pixel zu Wellenlängen erfolgte nachträglich, indem aus mehreren, eindeutig zuzuordnenden Quecksilberlinien eine lineare Kalibrierungsfunktion erstellt wurde.

\subsubsection{Mittelung}

Aus allen aufgenommenen Daten einer Wellenlänge $\lambda$ bei einem Verzögerungszeitpunkt $\Delta t$ wurde der Mittelwert gebildet. Einzelne, stark vom Mittelwert abweichende Messpunkte wurden dabei nicht berücksichtigt. Die Schwelle zu dieser Diskriminierung wurde mit dem Dreifachen der Standardabweichung vom Mittelwert sehr hoch gewählt, dass möglichst nur Störsignale von Ereignissen, wie sich im Messfokus befindliche Partikel oder Luftblasen, entfernt wurden.

\subsubsection{Zeitlicher Nullpunkt}

Das als Probepuls verwendete Weisslichtkontinuum (siehe Abschnitt 2.1.4) zeigt einen negativen Chirp. Der blaue Anteil um $350 \mathrm{~nm}$ interagiert mit dem Pumppuls etwa eine Pikosekunde vor dem roten Anteil um 730 nm. Um 


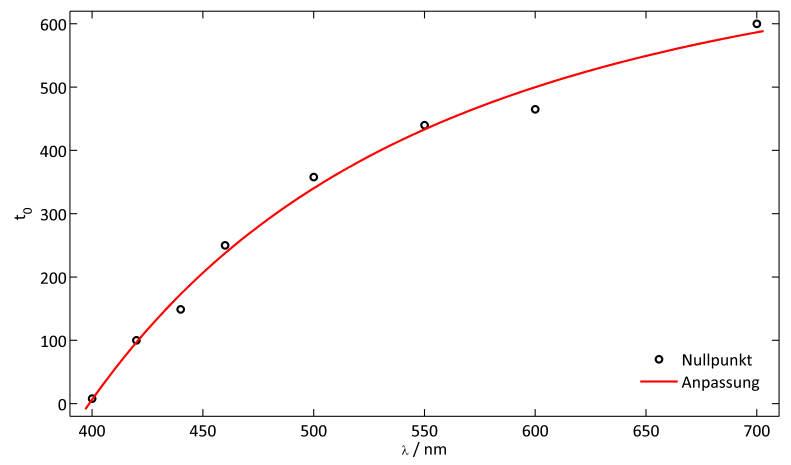

Abb. 2.11: Anpassung der wellenlängenabhängigen Nullpunkte

diese zeitliche Verschiebung zu kompensieren, wurden die Zeitprofile verschiedener Wellenlängen mit einer multiexponentiellen Funktion angepasst (siehe Abschnitt2.3.3.1) und die ermittelten Nullpunkte gegen die Wellenlänge aufgetragen. Diese Punkte wurden dann mit der Potenzfunktion in Gl. 2.5 angepasst.

$$
t_{0}(\lambda)=a \lambda^{b}+c
$$

\subsubsection{Offset-Korrektur}

Da bei der Pump-Probe-Spektroskopie nur pumpstrahlinduzierte Änderungen aufgenommen werden, muss $\triangle O D$ vor Eintreffen des Pumppulses in der Probe zur Zeit $t_{0}$ gleich Null sein. Aufbaubedingt können aber durchaus Signale vor $t_{0}$ aufgenommen werden: Die Diodenzeilen der Spektrometer SM1 und SM2 nehmen einfallendes Licht im gesamten Zeitraum zwischen zwei Auslesevorgängen auf. Sie unterscheiden dabei nicht, ob das Licht vor oder nach $t_{0}$ einfällt. Streulicht des Pumpstrahls und Fluoreszenzlicht der zu untersuchenden Probe, das den Spalt eines Spektrometers bevorzugt trifft, erzeugt somit einen Beitrag zum Signal, der unabhängig von der Verzögerungszeit $\Delta t$ konstant ist. Die großen konkaven Spiegel S4 und S5 (siehe Abb. 2.6 sammeln Streu- und Fluoreszenzlicht und lenken es auf den Spalt der Spektrometer. Zur Unterdrückung wurde ein Polarisator in Durchlassrichtung für den Probestrahl verwendet, der weite Teile des im magischen Winkel polarisierten Pumpstrahls und des isotropen Fluoreszenzlichtes abblockte. Das verbleibende Signal für $t<t_{0}$ wurde gemittelt und 
als konstantes Spektrum von dem gesamten Datensatz abgezogen.

\subsubsection{Auswertung der zeitaufgelösten Daten}

\subsubsection{Anpassung von transienten Signalen}

Die Zeitauflösung des Pump-Probe-Systems ergibt sich aus der Faltung der Zeitprofile von Pump- und Probepuls. Beide Pulse können annähernd mit einem Gaußprofil beschrieben werden, das Resultat der Faltung ist wieder ein Gaußprofil (Gl.2.6. Abb.2.12a). Die Zeitauflösung wird mit der Pulsbreite bei halber Intensität (full width half maximum, FWHM) in G1. 2.7 beschrieben.

$$
\begin{aligned}
g(t) & =\frac{1}{\sigma \sqrt{2 \pi}} \exp \left(-\frac{1}{2}\left(\frac{t-t_{0}}{\sigma}\right)^{2}\right) \\
F W H M & =2 \sqrt{2 \ln (2)} \sigma \approx 2.3548 \sigma
\end{aligned}
$$

Die Dynamik eines einzelnen, unimolekularen Zerfalls- oder Abregungsprozesses kann mit einer exponentiellen Zerfallsfunktion $e(t)$ mit der Lebensdauer $\tau$ beschrieben werden (G1.2.8. Abb. 2.12b).

$$
e(t)=\exp \left(-\frac{t-t_{0}}{\tau}\right)
$$

Ist dieser Prozess durch ein Ereignis (Pumppuls) zur Zeit $t_{0}$ induziert, kann es vor diesem Zeitpunkt kein Signal geben. Durch Multiplikation der Funktion $e(t)$ mit einer Step-Funktion $\Theta(t)$ (Gl. 2.9. Abb. 2.12c), die vor dem Zeitpunkt $t_{0}$ den Wert 0 und ab $t_{0}$ den Wert 1 annimmt, entsteht als Signalfunktion eine exponentielle Zerfallsfunktion $e_{p}(t)$, deren Wert vor $t_{0}$ gleich 0 ist (Gl.2.10, Abb. 2.12d).

$$
\begin{gathered}
\Theta(t)=\mathbb{R} \rightarrow(0,1) \\
t \mapsto\left(\begin{array}{cc}
0: & t<t_{0} \\
1: & t \geq t_{0}
\end{array}\right) \\
e_{p}(t)=e(t) \cdot \Theta(t)
\end{gathered}
$$


Durch Faltung der Signalfunktion $e_{p}(t)$ mit der Zeitauflösung des Systems $g(t)$ entsteht die Modellfunktion $f(t)$ (Gl.2.11, Abb.2.12e), die eine monoexponentielle Dynamik mit der Lebensdauer $\tau$ beschreibt.

$$
\begin{aligned}
f(t)= & g(t) * e_{p}(t) \\
= & \frac{1}{2} \exp \frac{\sigma^{2}-2 t \tau+4 t_{0} \tau}{2 \tau^{2}} \\
& \left(-1+\sqrt{\frac{1}{\sigma^{2}}} \sigma+\operatorname{erfc}\left[\frac{\sigma^{2}-t \tau+2 t_{0} \tau}{\sqrt{2} \sigma \tau}\right]\right)
\end{aligned}
$$

Das aufgenommene Signal besteht meist aus einer Summe oder einer Folge von Einzelprozessen, die aufgenommenen Daten werden dann mit einer Summe $f_{M}(t)$ einzelner Funktionen der Form $f(t)$ mit unterschiedlichen Amplituden $A_{n}$ und Lebensdauern $\tau_{n}$ angepasst (Gl. 2.12 Abb. 2.12f). $I_{1}$ beschreibt einen Gesamtoffset und ist nach der in Abschnitt 2.3.2.4 erfolgten Korrektur in der Regel obsolet.

$$
f_{M}(t)=\sum_{n}\left(A_{n} f_{n}\left(\tau_{n}, t\right)\right)+I_{1}
$$




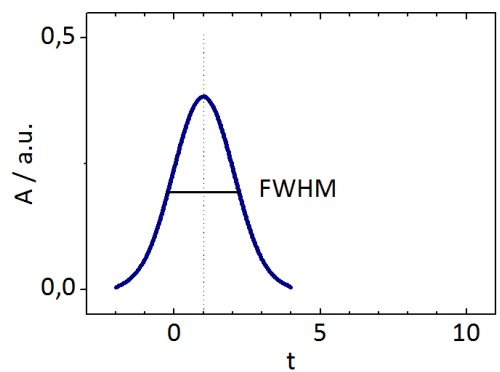

(a) Gl. 2.6

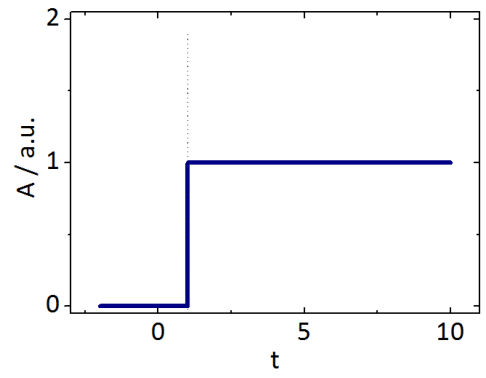

(c) G1. 2.9

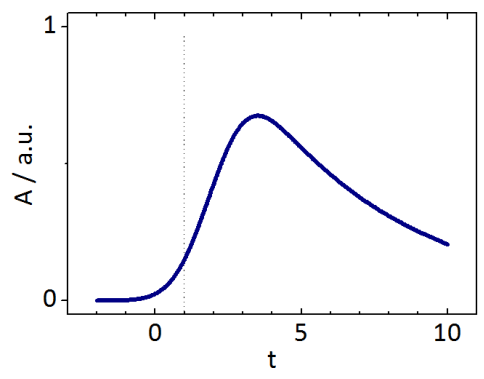

(e) Gl. 2.11

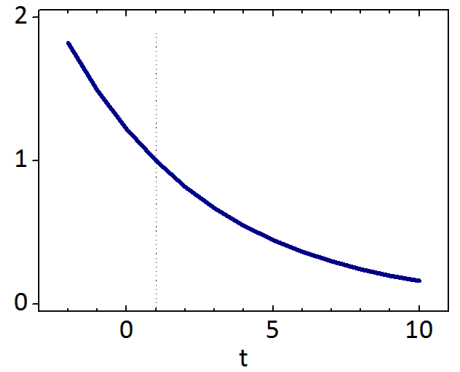

(b) Gl. 2.8

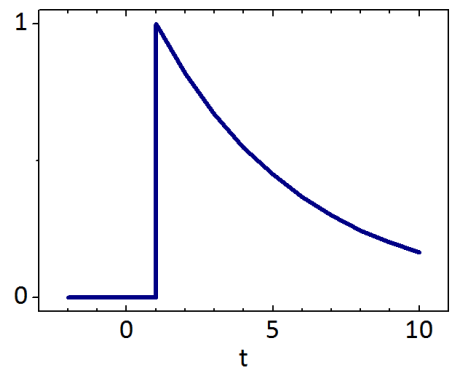

(d) G1. 2.10

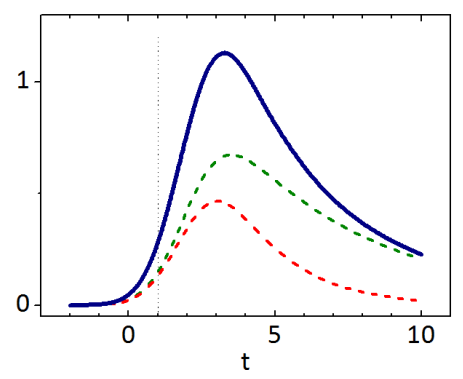

(f) Gl. 2.12

Abb. 2.12: Darstellung der einzelnen Schritte bei der Erstellung der Funktion zur Anpassung transienter Daten. Die gepunktete Linie markiert $t_{0}$. 


\subsubsection{Zeit- und wellenlängenabhängige Modellierung der Daten}

Die Zusammensetzung des Signals $\triangle O D(\lambda, t)$ ist in Gl. 2.3 beschrieben. Die Gleichung zeigt ein Problem der Modellierung: Das Signal einer Spezies $i$ entspricht dem Produkt aus Konzentration $c_{i}(t)$ und Absorption $\epsilon_{i}(\lambda)$, das System ist unterbestimmt und bietet eine beliebige Kombination der beiden Parameter als Lösung. Um eine exakte Lösung zu erhalten, müssen die Freiheitsgrade einer Anpassung reduziert werden, indem bekannte Speziesspektren, Amplitudenverhältnisse zwischen diesen Spektren und Ausbeuten bestimmter Reaktionswege festgelegt werden.

Um die Konzentration $c_{i}(t)$ einer Spezies $i$ zu ermitteln, wurde ein kinetisches Reaktionsmodell erstellt und zeitabhängig gelöst. Als Beispiel ist hier die Anregung eines Fluorophors $A$ das mit $k_{F}$ fluoresziert und mit $k_{I C}$ interne Konversion in den Grundzustand erfährt.

$$
\begin{gathered}
A^{*} \stackrel{k_{F}}{\longrightarrow} A \\
A^{*} \stackrel{k_{I C}}{\longrightarrow} A \\
c\left(A^{*}(0)\right)=-c(A(0))=c_{e x} \\
c\left(A^{*}(t)\right)=\frac{\delta c\left(A^{*}(t)\right)}{\delta t}=c_{e x} \exp \left(-\left(k_{F}+k_{I C}\right) t\right) \\
c(A(t))=\frac{\delta c(A(t))}{\delta t}=-c_{e x} \exp \left(-\left(k_{F}+k_{I C}\right) t\right)
\end{gathered}
$$

Die beiden Geschwindigkeitskonstanten $k_{F}$ und $k_{I C}$ können nicht getrennt voneinander beobachtet werden. Die Depopulation von $A^{*}$ und Repopulation von $A$ erfolgen mit $k_{e f f}=k_{F}+k_{I C}$. Ist die Fluoreszenzquantenausbeute $\Phi_{F}$ bekannt, kann das Verhältnis von $k_{F}$ zu $k_{I C}$ nach Gl. 2.14 bestimmt werden.

$$
\Phi_{F}=\frac{k_{F}}{k_{F}+k_{I C}}
$$

Jeder kinetischen Spezies wurde ein Spektrum zugeordnet, das mit einer Summe von Gauß-Funktionen (Gl.2.15) beschrieben wurde.

$$
S_{i}(\lambda)=\sum_{j=1}^{k} \frac{A_{j}}{\sigma_{j} \sqrt{2 \pi}} \exp \left(-\frac{1}{2}\left(\frac{\lambda-\lambda_{c, j}}{\sigma_{j}}\right)\right)
$$

$A$ ist ein Amplitudenfaktor, $\sigma$ die Standardabweichung und $\lambda_{c}$ die Zentralwellenlänge der Gauß-Funktion. Die Halbwertsbreite FWHM lässt sich mit 
G1. 2.16 aus $\sigma$ berechnen. Die Integral der einzelnen Gauss-Funktionen ist ohne den Amplitudenfaktor $A$ auf 1 normiert.

$$
F W H M=2 \sqrt{2 \ln (2)} \sigma \approx 2.3548 \sigma
$$




\subsection{Probenpräparation}

Alle verwendeten Lösungen wurden aus einer $5 \mathrm{mM}$ Protein-Stammlösung in PBS Puffer hergestellt. Jeweils $50 \mu \mathrm{L}$ dieser konzentrierten Proteinlösung wurden in $6 \mathrm{~mL} 5 \mathrm{mM}$ wässriger Pufferlösung nach Tabelle 2.1 verdünnt und sofort verwendet. Für die Messungen in deuteriertem Puffer wurde ein Carbonat-Puffer mit einer geringen Menge $\mathrm{H}^{+}$-Ionen angesetzt. Die Verdünnung von $50 \mu \mathrm{L}$ wässriger Proteinlösung in $6 \mathrm{~mL} \mathrm{D}_{2} \mathrm{O}$ sollte $\mathrm{zu}$ einem D/H-Verhältnis von 100:1 führen, Protein und Pufferanteil der Stammlösung sind zu vernachlässigen. Der H/D-Austausch im Protein wurde durch Lagerung über Nacht erreicht. Die gewünschte Isomerisierung wurde durch Bestrahlung des Proteins im Pumpenkreislauf (siehe Abschnit2.1.6 erzeugt. Die Bestrahlung erfolgte vor jeder Messung für eine halbe Stunde und wurde während der Messung fortgeführt.

\begin{tabular}{|c|c|c|c|}
\hline $\mathrm{pH}$ & Puffer & Ansatz & Anmerkung \\
\hline 3.5 & Acetat & $0.030 \mathrm{~g} \mathrm{CH}_{3} \mathrm{COOH}$ & $1 \mathrm{M} \mathrm{HCl}$ auf $\mathrm{pH} 3.5$ \\
\hline 4 & Citrat & $0.105 \mathrm{~g} \mathrm{C}_{6} \mathrm{H}_{8} \mathrm{O}_{7} \cdot \mathrm{H}_{2} \mathrm{O}$ & $\begin{array}{l}1 \mathrm{M} \mathrm{NaOH} \text { auf } \mathrm{pH} \\
4\end{array}$ \\
\hline 7 & PBS & $\begin{array}{l}0.8 \mathrm{~g} \mathrm{NaCl}, 0.02 \mathrm{~g} \mathrm{KCl} \\
0.178 \mathrm{~g} \mathrm{Na}_{2} \mathrm{HPO}_{4} \cdot \mathrm{H}_{2} \mathrm{O} \\
0.027 \mathrm{~g} \mathrm{KH}_{2} \mathrm{PO}_{4}\end{array}$ & nicht selbst erstellt \\
\hline 7 & Tris & $0.121 \mathrm{~g} \mathrm{C}_{4} \mathrm{H}_{11} \mathrm{NO}_{3}$ & nicht selbst erstellt \\
\hline 10 & Tricin & $0.089 \mathrm{~g} \mathrm{C}_{6} \mathrm{H}_{13} \mathrm{NO}_{5}$ & $1 \mathrm{M} \mathrm{HCl}$ auf $\mathrm{pH} 10$ \\
\hline 10.5 & Phosphat & $0.134 \mathrm{~g} \mathrm{Na}_{2} \mathrm{HPO}_{4} \cdot 7 \mathrm{H}_{2} \mathrm{O}$ & $\begin{array}{l}1 \mathrm{M} \mathrm{HCl} \text { auf } \mathrm{pH} \\
10.5\end{array}$ \\
\hline 10.3 & Carbonat & $0.0053 \mathrm{~g} \mathrm{Na}_{2} \mathrm{CO}_{3}$ & in $10 \mathrm{~mL} \mathrm{D}_{2} \mathrm{O}$ \\
\hline
\end{tabular}

Tab. 2.1: Verwendete Puffer-Lösungen für verschiedene $\mathrm{pH}-$ Werte und Messungen. Die Angaben beziehen sich auf jeweils $100 \mathrm{~mL}$ Pufferlösung in zweifach destilliertem Wasser (Aqua bidest) 



\section{Kapitel 3}

\section{Ergebnisse und Diskussion}

\subsection{Padron0.9}

\subsubsection{Grundzustände}

Das Chromophor von Padron0.9 kann cis- wie auch trans-Konfiguration annehmen, wobei das trans-Isomer die energetisch günstigere Form darstellt und das cis-Isomer bei Raumtemperatur innerhalb von Stunden in die trans-Form isomerisiert [32]. Die Absorptionsspektren der beiden Isomere, dargestellt in Abb. 3.1. sind stark pH-abhängig. Die Spektren zeigen jeweils zwei deutlich unterscheidbare Banden, deren Maxima für das cis-Isomer bei 397 und $503 \mathrm{~nm}$ und für das trans-Isomer bei 387 und $506 \mathrm{~nm}$ liegen und dem protonierten $\left(C^{H}, T^{H}\right)$ bzw. dem deprotonierten $\left(C^{-}, T^{-}\right)$Chromophor zugeordnet werden können. Das pH-abhängige Verhalten der beiden Banden im cis-Spektrum (Abb. 3.1a, offene Kreise) mit einem isosbestischen Punkt bei 428 nm im Bereich pH 5-10 legt ein Protonierungsgleichgewicht zwischen $C^{H}$ und $C^{-}$nahe. Bei näherer Betrachtung wird klar, dass es sich hier nicht um ein einfaches Gleichgewicht der Form $C^{H} \rightleftharpoons C^{-}$handeln kann: Bei $\mathrm{pH} 4$ ist die $\mathrm{C}^{-}$-Bande bei $503 \mathrm{~nm}$ praktisch nicht existent und wächst bei Erhöhung des pH-Wertes bis pH 8 an, während die $C^{H}$-Bande bei $397 \mathrm{~nm}$ zwar abnimmt, aber auch bei pH 10 noch etwa mit halber Intensität präsent ist. Das Maximum der $\mathrm{C}^{\mathrm{H}}$-Absorptionsbande ist bei $\mathrm{pH}<6$ signifikant blau verschoben und liegt bei pH 4 bei $385 \mathrm{~nm}$. Das Absorptionsspektrum bei diesem $\mathrm{pH}$ durchläuft nicht den isosbestischen Punkt. Bei hohem $\mathrm{pH}-W e r t$ $>9$ verbreitert sich das $C^{-}$-Absorptionsspektrum, während die maximale Amplitude geringfügig nachlässt.

Das trans-Isomer (Abb. $3.1 \mathrm{~b})$ zeigt von $\mathrm{pH} 4$ nach 6 eine schnelle und nahezu vollständige Umwandlung von $T^{H}$ nach $T^{-}$. Dieser Übergang geschieht allerdings abrupter, als es bei einem einfachen Gleichgewicht $T^{H} \rightleftharpoons T^{-}$ möglich wäre. Bei hohen $\mathrm{pH}-W e r t e n ~>6$ ist zudem, wie beim cis-Isomer, eine 


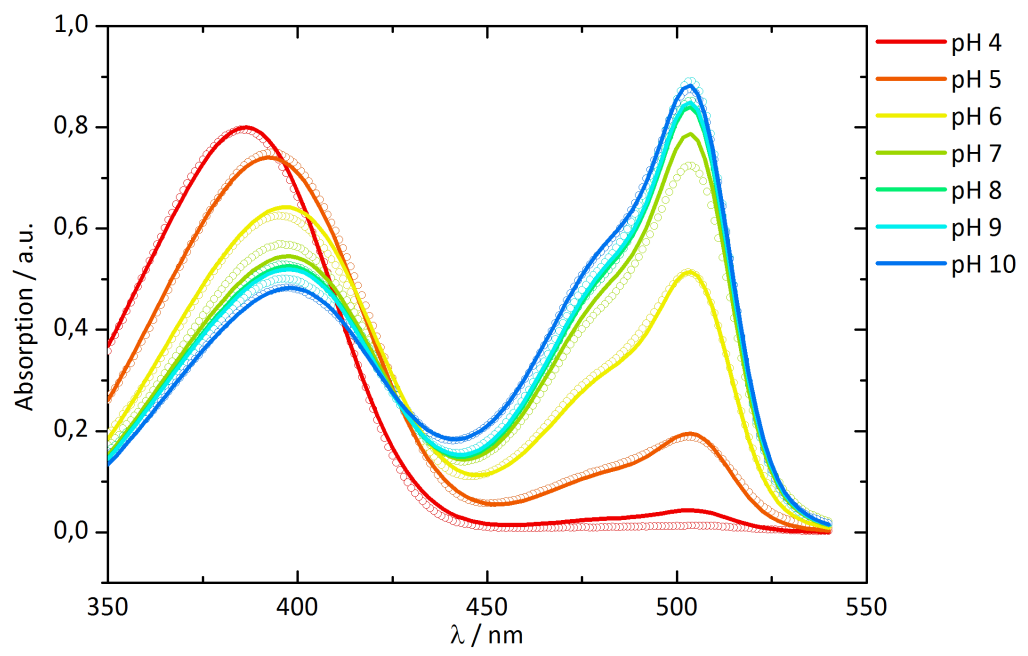

(a) cis-Isomer

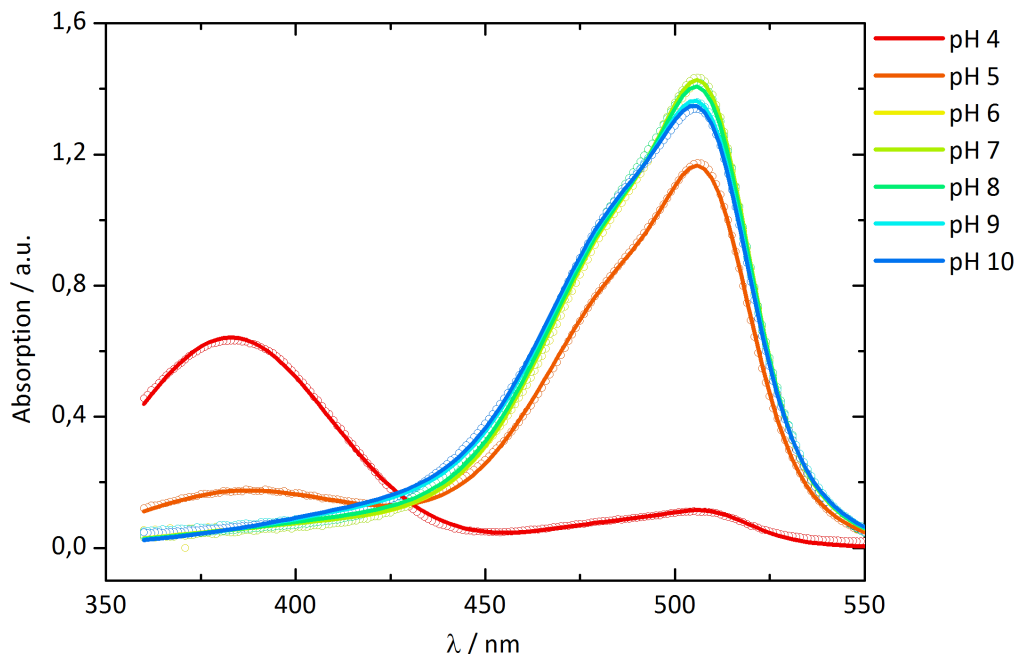

(b) trans-Isomer

Abb. 3.1: pH-Abhängige Absorptionsspektren des cis- (a) und trans-Isomers (b) von Padron0.9. Gemessene Spektren sind als offene Kreise dargestellt, die durchgezogenen Linien sind Anpassungen der gemessenen Spektren nach dem Modell 3.9a Die Spektren sind auf einen Absorptionspeak der Proteinumgebung bei $290 \mathrm{~nm}$ normiert. 
Verbreiterung der Absorptionsbande auf Kosten der Intensität zu beobachten.

Die Koexistenz von $C^{H}$ und $C^{-}$in dem weiten $\mathrm{pH}$-Bereich von $\mathrm{pH}$ 5-10 kann mit einer protonierenden Gruppe $X$ in der Umgebung des Chromophors erklärt werden, die die Protonenaffinität des Chromophors beeinflusst (vgl. 1.3. Die Verbreiterung des $C^{-}$-Spektrums bei $\mathrm{pH}>9$ kann dabei auf den Einfluss der $X^{-}$-Gruppe auf die spektralen Eigenschaften des Chromophor zurückgeführt werden. Dieses Modell reicht jedoch nicht aus, um auch die spektrale Blauverschiebung der $C^{H}$-Absorptionsbande bei $\mathrm{pH}$-Werten $<5 \mathrm{zu}$ erklären. Die Ursache dieser spektralen Verschiebung kann mehrere Gründe haben. Eine Möglichkeit wäre die Existenz einer weiteren protonierenden Gruppe $Y$, deren Protonierung eine Stabilisierung des Grundzustands und somit eine Blauverschiebung in der Absorption des protonierten Chromophors bewirkt. Die Ähnlichkeit der $C^{H}$ - und $T^{H}$-Absorptionsbanden (vgl. Abb.3.1, die sich nur um etwa $20 \%$ in der Amplitude unterscheiden und spektral fast identisch sind, lassen vermuten, es handele sich hier um identische Spezies, die durch eine $\mathrm{pH}$-induzierte Isomerisierung gebildet wurde. Bei pH 4 läge dann, unabhängig von der Bestrahlung, das gleiche Isomer vor.

Um diese zu untersuchen, wurden zwei Proben einer Protein Pufferlösung pH 4 durch LED-Bestrahlung vollständig zum cis- bzw. zum trans-Isomer überführt (Abb. 3.2, rote Linien). Anschließend wurden die Lösungen durch Zugabe einer äquivalenten Menge einer Pufferlösung mit pH 11 neutralisiert. Die Absorptionsspektren nach Neutralisierung (Abb. 3.2, grüne Linien) haben wieder die Form des jeweiligen Isomers bei $\mathrm{pH} \approx 7$. Diese Reversibilität der $\mathrm{pH}$-induzierten Blauverschiebung des Absorptionsspektrums schließt eine Isomerisierung aus, nach der sich beide Spektren bei Neutralisierung hätten gleich verhalten müssen. Die Ursache für die beobachtete Blauverschiebung wird daher eine weitere protonierende Gruppe $Y$ in der Chromophorumgebung sein. Auch die $\mathrm{pH}$-abhängigen Absorptionsspektren des trans-Isomer kann das Modell mit nur einer protonierenden Gruppe $X$ nicht hinreichend erklären. Der steile Übergang von $T^{H}$ nach $T^{-}$zwischen $\mathrm{pH} 4$ und 6 wird abgedeckt, die spektrale Verbreiterung für $\mathrm{pH}>9$ verlangt nach dem Einfluss einer weiteren protonierenden Gruppe.

Eine Erweiterung des Modells in Abb. $1.19 \mathrm{~b}$ um die Gruppe $Y$ führt zu 8 verschiedenen Spezies (siehe Abb. 3.3). Zur Beschreibung der spektralen Entwicklung des cis-Isomers genügen vier verschiedene Spektren, die der Spezies $C^{H} X^{H} Y^{H}, C^{-} X^{-} Y^{-}$und der spektral jeweils ununterscheidbaren deprotonierten Spezies $C^{-} X^{H} Y^{H} / C^{-} X^{-} Y^{H} / C^{-} X^{H} Y^{-}$und der protonierten Spezies $C^{H} X^{-} Y^{H} / C^{H} X^{H} Y^{-} / C^{H} X^{-} Y^{-}$. Für das trans-Isomer, das 


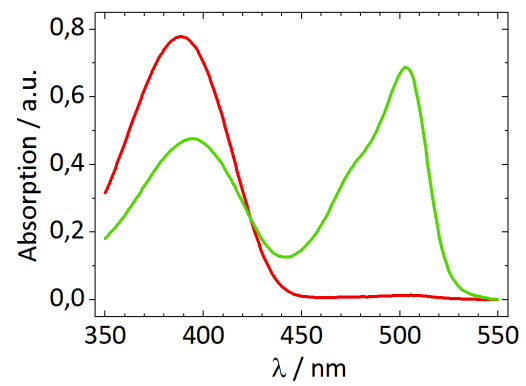

(a) cis-Isomer

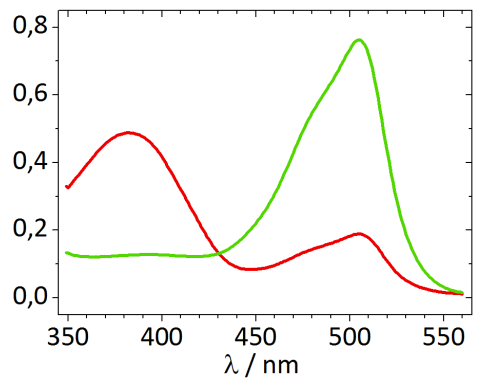

(b) trans-Isomer

Abb. 3.2: Absorptionsspektren der Isomere von Padron 0.9 bei $\mathrm{pH} 4$ (rote Linien) und nach anschließender Änderung des $\mathrm{pH}$-Wertes auf $\approx 7$ (grüne Linien)

keine spektrale Verschiebung zeigt, genügen drei Spektren, die den spektral jeweils ununterscheidbaren protonierten Spezies $T^{H} X^{H} Y^{H} / T^{H} X^{-} Y^{H} /$ $T^{H} X^{H} Y^{-} / T^{H} X^{-} Y^{-}$und den deprotonieren Spezies $T^{-} X^{H} Y^{H} / T^{-} X^{-} Y^{H}$ / $T^{-} X^{H} Y^{-}$sowie $T^{-} X^{-} Y^{-}$zugeordnet wurden. Das Modell mit den durch Anpassung ermittelten Gleichgewichtskonstanten ist in Abb. 3.3 gezeigt, Spezies mit gleichen Spektren sind mit der gleichen Farbe unterlegt. Das Spektrum jeder Spezies wurde mit einer Summe von Gauß-Funktionen beschrieben. Die Spektren sind in Abb. 3.4c und d gezeigt, die relativen Konzentrationen der Spezies sind in $\mathrm{Abb}$. $3.4 \mathrm{a}$ und $\mathrm{b}$ pH-abhängig aufgetragen. Die modellierten $\mathrm{pH}$-abhängigen Absorptionsspektren sind als durchgezogene Linien in Abb. 3.1a und bezeigt. Die bei niedrigem $\mathrm{pH}$ Wert vorkommenden protonierten Spezies $C^{H} X^{H} Y^{H}$ und $T^{H} X^{H} Y^{H}$ werden in dieser Arbeit mit $C^{H+}$ bzw. $T^{H+}$ bezeichnet, die protonierten Spezies mit teilprotonierter Umgebung werden unter dem Kürzel $C^{H}$ bzw. $T^{H}$ zusammengefasst, alle deprotonierten Spezies mit $C^{-}$und $T^{-}$. 


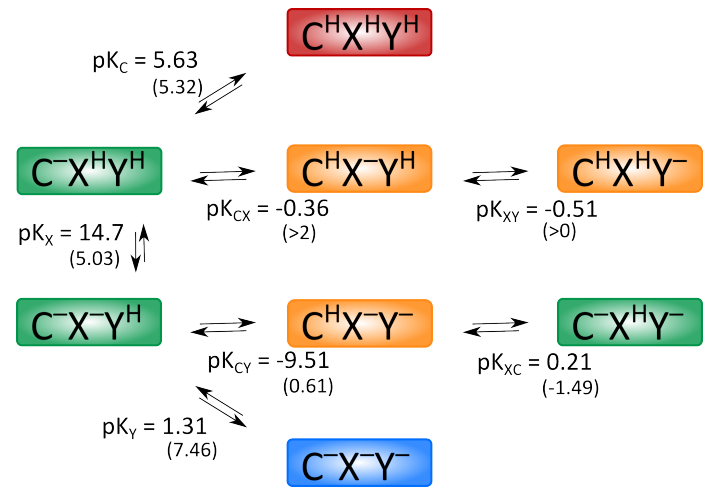

Abb. 3.3: Modell der Protonierung des Chromophors $C$ (respektive $T$ ) von Padron 0.9 mit zwei protonierenden Gruppen $X$ und $Y$ in unmittelbarer Umgebung. Spezies mit identischen Absorptionsspektren sind mit der gleichen Farbe unterlegt. Die pK-Werte aus der Anpassung der Absorptionsspektren für cis- und trans-Isomer (in Klammern) sind angegeben.

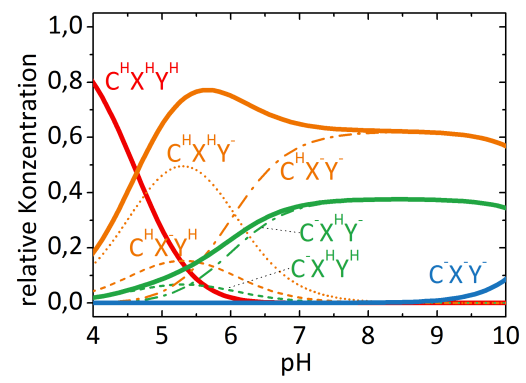

(a) Spezies cis-Isomer

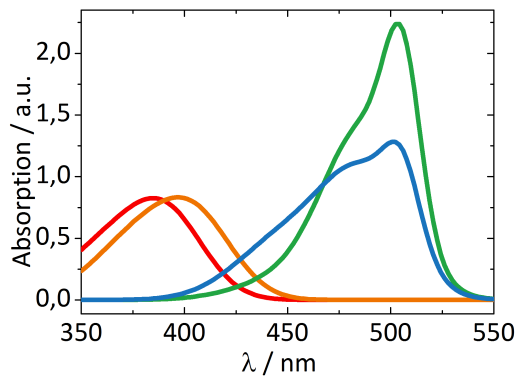

(c) Speziesspektren cis-Isomer

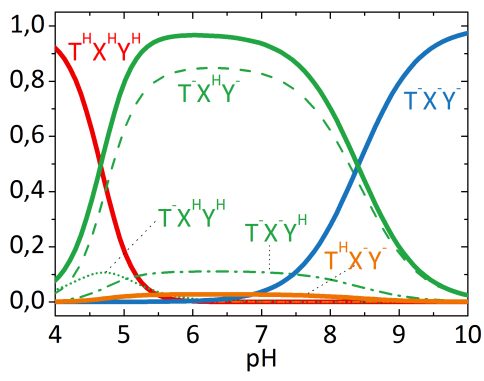

(b) Spezies trans-Isomer

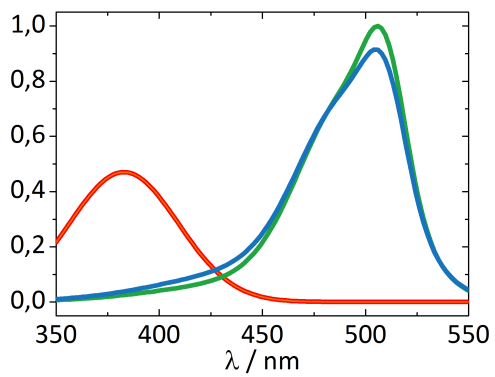

(d) Speziesspektren trans-Isomer

Abb. 3.4: Modell des Protonierungsgleichgewichtes von Padron0.9, $\mathrm{pH}$-abhängige Konzentrationen und ihre Absorptionsspektren 


\subsubsection{Angeregte Zustände von $C^{-}$und $T^{-}$}

\subsubsection{Fluoreszenz}

Nach Anregung durch Licht fluoresziert Padron0.9 grün. Die Intensität der Fluoreszenz hängt von Anregungswellenlänge, pH-Wert und der Konfiguration des Chromophors ab. Das trans-Isomer zeigt nahezu keine Fluoreszenz. Die $\mathrm{pH}$-abhängigen Fluoreszenzspektren des cis-Isomers nach Anregung bei 503 (offene Kreise) und $397 \mathrm{~nm}$ (volle Quadrate) sind in Abb. 3.5a gezeigt. Maximale Fluoreszenzintensität wird nach Anregung bei $503 \mathrm{~nm}$ bei $\mathrm{pH} \approx 9$ erreicht. Bei niedrigerem $\mathrm{pH}$-Wert sinkt die Fluoreszenzintensität. Dieser Effekt ist tendenziell mit einer geringeren relativen Konzentration $\operatorname{der} C^{-}$-Spezies bei niedrigem $\mathrm{pH}$ zu erklären. Nach Anregung bei $397 \mathrm{~nm}$ ist die Fluoreszenzintensität insgesamt deutlich niedriger als bei $503 \mathrm{~nm}$, die $\mathrm{pH}$-Abhängigkeit ist jedoch ähnlich. Die Fluoreszenzausbeute sinkt ebenfalls bei niedrigerem $\mathrm{pH}$, wobei die Konzentration der Spezies mit protoniertem Chromophor bei sinkendem $\mathrm{pH}$ tendenziell ansteigt. Abb. 3.4a zeigt jedoch für pH 7 und 9 eine ähnliche Konzentration an Spezies mit deprotoniertem und protoniertem Chromophor. Die $\mathrm{pH}$-Abhängigkeit der Fluoreszenzquantenausbeute muss auf andere Effekte zurückzuführen sein, wird hier aber nicht näher untersucht.

Unabhängig von der Anregungswellenlänge und dem pH-Wert, ist die Form der aufgenommenen Fluoreszenzspektren bis auf einen Amplitudenfaktor gleich und kann mit der Summe von drei Gaußkurven beschrieben werden, die Anpassung ist in Abb. 3.5a als durchgezogene Linie hinter den aufgenommenen Datenpunkten zu sehen. Die Fluoreszenzlebensdauer wurde als triexponentieller Abfall mit 39 ps, 500 ps und 3.6 ns bestimmt [65]. Die Fluoreszenzquantenausbeute ist $\Phi_{F}=0.61[23]$.

\subsubsection{Stimulierte Emission}

Da die Emission bei Pump-Probe-Messungen als durch den Probestrahl stimulierte und nicht als spontane Emission aufgenommen wird, wurde das stationäre Fluoreszenzspektrum $S_{v}(\lambda)$ zur Anpassung nach Gl. 3.1 in das stimulierte Emissionsspektrum $\sigma_{e m, v}(\lambda)$ umgerechnet [66].

$$
\sigma_{e m, v}(\lambda)=\frac{\lambda^{4} E_{v}(\lambda)}{8 \pi n_{v, F} c_{0} \tau_{r a d, v} q_{v}}
$$




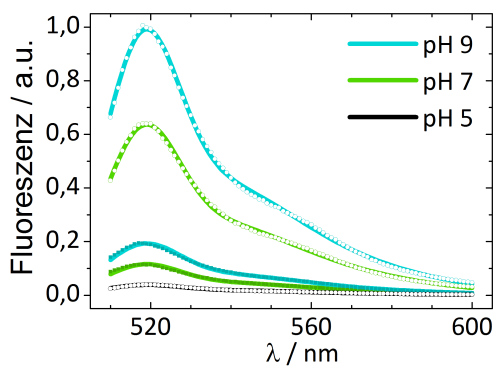

(a) Fluoreszensspektren cis-Isomer. $\circ: \lambda_{p}=503 \mathrm{~nm}, \mathbf{\square}: \lambda_{p}=397 \mathrm{~nm}$

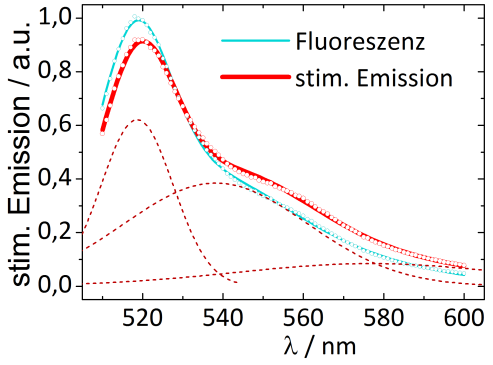

(b) Stimuliertes Emissionsspektrum

Abb. 3.5: Emissionsspektren von Padron0.9. Punkte: gemessene Daten, durchgezogene Linie: Anpassung der Daten mit einer Summe von Gaußfunktionen, gestrichelte Linie: einzelne Gaußfunktionen

$E_{v}$ ist die Fluoreszenzquantenverteilung und bis auf einen Amplitudenfaktor identisch mit dem stationären Fluoreszenzspektrum $S_{v}(\lambda)$. Der Brechungsindex $n_{v, F}$ im Bereich der Fluoreszenz wird als wellenlängenunabhängig angenommen und die Lichtgeschwindigkeit im Vakuum $c_{0}$, Strahlungslebensdauer $\tau_{r a d, v}$ und die Fluoreszenzquanteneffizienz $q_{v}$ sind Konstanten. Es ergibt sich G1. 3.2 als qualitative Beschreibung der stimulierten Emission aus Gl. 3.1.

$$
\sigma_{e m, v}(\lambda) \propto \lambda^{4} E_{v}(\lambda) \propto \frac{\lambda^{4}}{\lambda_{0}^{4}} S_{v}(\lambda)
$$

Das gemessene Fluoreszenz- und das daraus berechnete stimulierte Emissionsspektrum $\left(\lambda_{0}=530 \mathrm{~nm}\right)$ sind in Abb. $3.5 \mathrm{~b}$ als offene Kreise und durchgezogene Linie gezeigt. Das stimulierte Emissionsspektrum wurde analog zum Fluoreszenzspektrum mit drei Gaußfunktionen angepasst. Das resultierende Emissionsspektrum der deprotonierten cis-Spezie ist in Tab A.1 beschrieben und wird im Weiteren $C_{e m}^{-*}$ genannt.

\subsubsection{Transiente Spektren}

Die transiente Dynamik der Zustände $\mathrm{C}^{-}$und $T^{-}$wurde mittels PumpProbe-Spektroskopie (siehe Abschnitt 2.2.1) bei pH 7 und 10 untersucht. Die Absorptionsspektren der einzelnen Chromophorspezies in Abb. 3.4c und dzeigen, dass bei der gewählten Anregungswellenlänge $\lambda_{p}=505 \mathrm{~nm}$ 


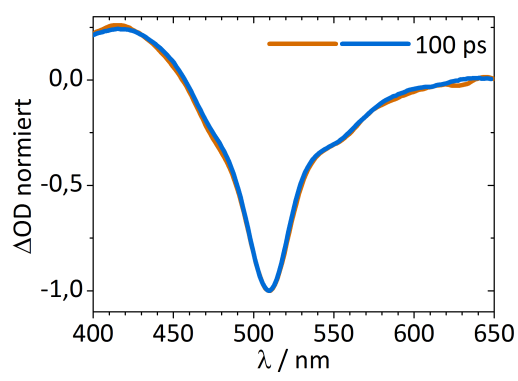

(a) cis-Isomer

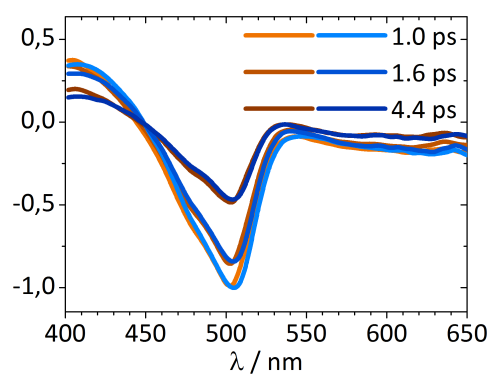

(b) trans-Isomer

Abb. 3.6: Vergleich der transienten Spektren von Padron $0.9, \lambda_{p}=505 \mathrm{~nm}$, bei pH 7 (orange) und pH 10 (blau) zu verschiedenen Verzögerungszeiten

ausschließlich deprotonierte Spezies angeregt werden. Nach Abb. 3.4a und b ändert sich die Chromophorumgebung von $\mathrm{pH} 7 \mathrm{zu} 10$, so dass bei $\mathrm{pH}$ 7 die einfach protonierte Umgebung $C^{-} X^{H} Y^{-} / C^{-} X^{-} Y^{H}$ bzw. $T^{-} X^{H} Y^{-}$ / $T^{-} X^{-} Y^{H}$ populiert ist, bei pH 10 aber zusätzlich etwa $10 \%$ der deprotonierte Spezies $C^{-} X^{-} Y^{-}$vorliegt. Im Falle des trans-Isomers liegt das Gleichgewicht bei $\mathrm{pH} 10$ sogar ausschließlich bei der vollständig deprotonierten Spezies $T^{-} X^{-} Y^{-}$.

Die zeitaufgelösten Signale bei pH 7 und 10 unterscheiden sich dennoch weder für das cis- noch das trans-Isomer nennenswert. Zur Verdeutlichung sind die transienten Spektren für einige Verzögerungszeiten in Abb. 3.6 aufeinander skaliert dargestellt. Das Spektrum von $C^{-} X^{-} Y^{-}$variiert zwar deutlich von $C^{-} X^{H} Y^{-} / C^{-} X^{-} Y^{H}$, jedoch ist der Anteil $C^{-} X^{-} Y^{-}$bei $\mathrm{pH}$ 10 recht gering. Das trans-Isomer liegt bei $\mathrm{pH} 10$ ausschließlich als $T^{-} X^{-} Y^{-}$ vor, die spektralen Unterschiede zu $T^{-} X^{H} Y^{-} / T^{-} X^{-} Y^{H}$ sind hingegen nicht sehr stark. Die Ähnlichkeit der transienten Spektren bei pH 7 und 10 ist so groß, dass die Kinetik der deprotonierten Spezies der Isomere im Weiteren als identisch erachtet und nur die Messungen bei pH 10 betrachtet werden.

Die aufgenommenen transienten Spektren von $C^{-}$und $T^{-}$bei $\mathrm{pH} 10$ und 505 nm Anregungswellenlänge sind in Abb. 3.7 als offene Kreise gezeigt. Die Messungen von $C^{-}$und $T^{-}$erfolgten direkt hintereinander ohne Änderung der experimentellen Parameter mit derselben Proteinlösung. Zur Überführung in das jeweilige Isomer wurde die Lösung vor und während der ersten Messung mit einer LED bei $495 \mathrm{~nm}$ und vor und während der zweiten Messung mit $400 \mathrm{~nm}$ bestrahlt. Durch dieses Vorgehen sind die 
Signale der beiden Messungen direkt vergleichbar, da der Überlapp von Pump- und Probestrahl $\sigma_{p p}$, die Proteinkonzentration $c_{0}$ und die Pumpintensität $I_{p}$ gleich sind (siehe Gl. 2.3). Zu frühen Zeiten ähneln sich die Spektren der beiden Isomere. Zwischen 400 und $450 \mathrm{~nm}$ ist das Signal positiv, hier absorbiert ein angeregter Zustand (exited state absorption, ESA). Im Bereich $\operatorname{der} C^{-}$- und $T^{-}$-Absorption zwischen 450 und $520 \mathrm{~nm}$ ist das Signal negativ und rührt vom gebleichten Grundzustand (ground state bleach, GSB) her. Für Wellenlängen > $520 \mathrm{~nm}$ ist das Signal ebenfalls negativ und stimulierter Emission zuzuschreiben.

Hier zeigt das cis-Isomer eine deutliche Bandenstruktur, während das Signal des trans-Isomers sehr breit und strukturlos ist und auf der roten Flanke des GSB um $530 \mathrm{~nm}$ schnell abfällt, während die Emission für $\lambda>550 \mathrm{~nm}$ keinen entsprechend schnellen Abfall zeigt. Wie für den AN-Zustand erwartet, führt die Anregung von $C^{-}$zu einem langlebigen angeregten Zustand $C^{-*}$, während das Signal des AUS-Zustands $T^{-}$nach einigen Pikosekunden fast verschwunden ist. Eine langlebige Komponente bleibt allerdings auch in dieser Messung bestehen, die dem transienten $C^{-}$-Signal bei $\Delta t>100$ ps sehr ähnelt. Zur Verdeutlichung ist das entsprechende $C^{-}$-Signal skaliert als grüne Kurve auf die transienten Spektren von $T^{-}$in Abb. $3.7 \mathrm{~b}$ gelegt. Das transiente Spektrum von $C^{-}$fällt nicht monoexponentiell ab, sondern zeigt zu frühen Zeiten hauptsächlich im Bereich von 400 - 520 nm eine schnelle Komponente, ähnlich wie $T^{-}$.

Beide Spektren wurden wellenlängenabhängig mit einem triexponentiellen Abfall mit den Zeitkonstanten $\tau_{1}=(1.1 \pm 0.2) \mathrm{ps}, \tau_{2}=(6.5 \pm 0.7) \mathrm{ps}$ und $\tau_{3}=(1.16 \pm 0.3) \mathrm{ns}$ angepasst. Die wellenlängenabhängigen Amplituden der Anpassung sind in Abb. 3.8 gezeigt. Es fällt auf, dass die schnellen Beiträge in Abb. 3.8b, die die $\mathrm{T}^{-}$-Messung dominieren, mit ähnlicher Form und Verhältnis zueinander auch in Abb. 3.8a zu sehen sind, während die langlebige Komponente, die die $C^{-}$-Messung dominiert, wie erwartet zu einem geringen Teil in Abb. 3.8b auftaucht. Diese Verteilung deutet darauf hin, dass der Isomerisierungsprozess durch die LED-Einstrahlung nicht vollständig war und jede Messung noch einen kleinen Beitrag des jeweils anderen, unerwünschten, Isomers enthält.

\subsubsection{Aufstellen des kinetischen Modells}

Das der cis-Spezies zugeordnete Signal fällt monoexponentiell mit $\tau_{3}=$ $1.16 \mathrm{~ns}$ ab. Diese Zeitkonstante kann direkt dem angeregten Zustand $C^{-*} \mathrm{zu}$ geordnet werden, der monoexponentiell mit $k_{C}=\tau_{3}^{-1}$ in den Grundzustand 


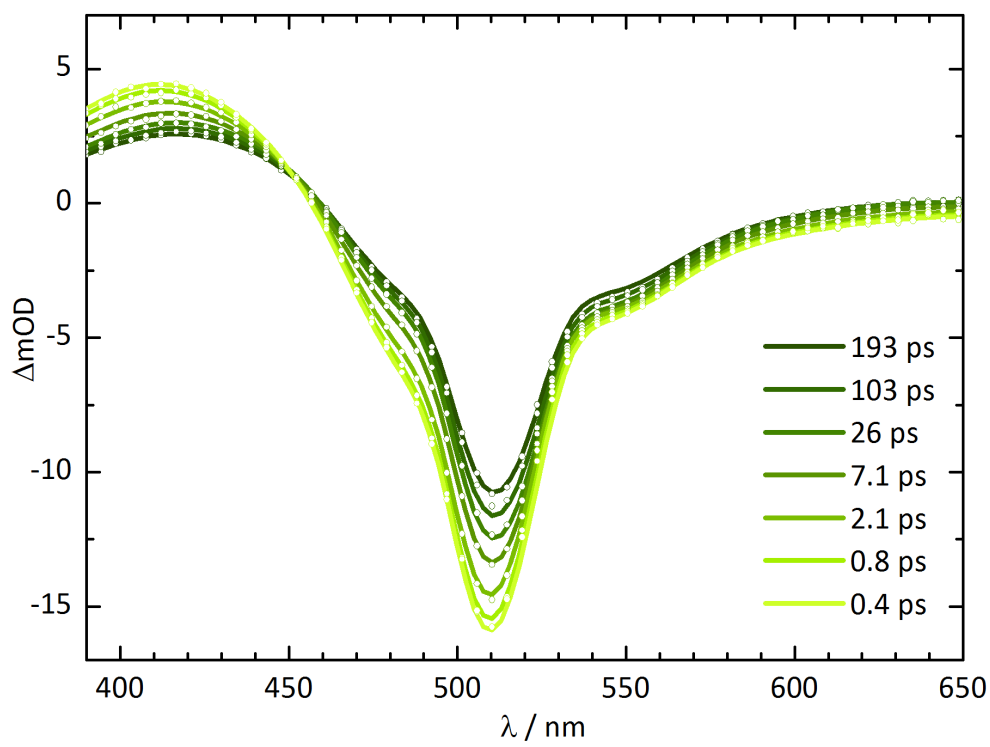

(a) cis-Isomer Padron0.9

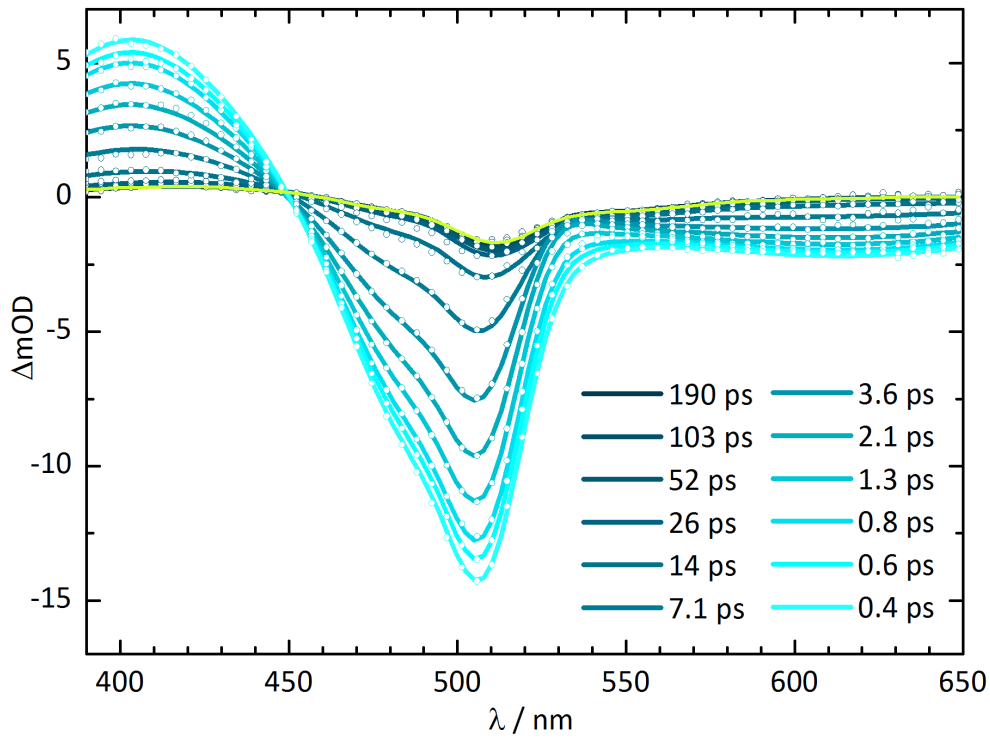

(b) trans-Isomer Padron0.9. Die grüne Linie zeigt das skalierte Spektrum aus a bei $\Delta \mathrm{t}=193 \mathrm{ps}$.

Abb. 3.7: Transiente Spektren von Padron 0.9 bei $\mathrm{pH} 10$ nach Anregung bei $505 \mathrm{~nm}$ bei verschiedenen Verzögerungszeiten. ○ : aufgenommenen Daten, $/$ : Anpassung durch das kinetische Modell in Fig 3.9a. 


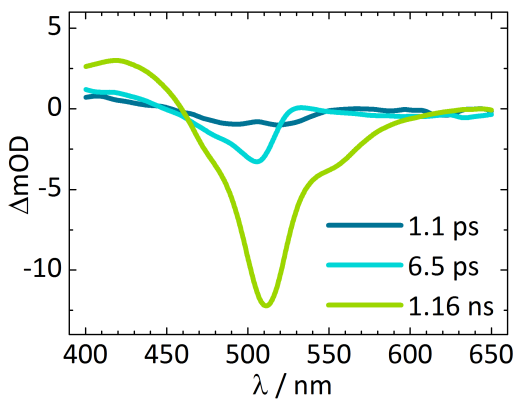

(a) cis-Isomer

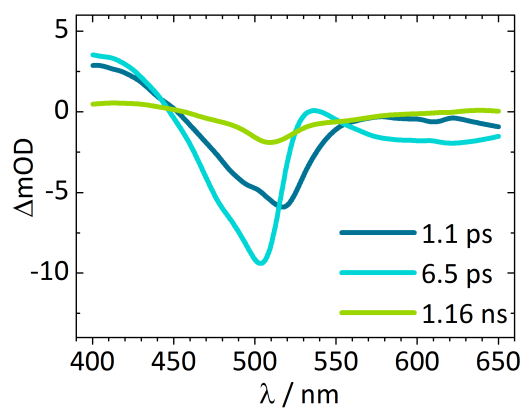

(b) trans-Isomer

Abb. 3.8: Amplitudenspektren der exponentiellen Anpassung der transienten Daten von Padron0.9 bei pH 10 nach Anregung bei $505 \mathrm{~nm}$.

$C^{-}$zurückfällt. Die Zeitkonstanten $\tau_{1}$ und $\tau_{2}$ beschreiben die Dynamik des trans-Isomers nach Anregung von $T^{-}$. Die Fluoreszenzensdauer von Padron0.9 wurde von Fron et al. [65] durch TCSPC als triexponentiell mit den Zeitkonstanten 39 ps, 500 ps und $3.6 \mathrm{~ns}$ bestimmt. Die längste Zeitkonstante wurde der Lebensdauer des initial angeregten Zustandes $C^{-*}$ zugeschrieben, die schnelleren nicht näher definierten Relaxationsprozessen im angeregten Zustand. Die Pump-Probe Messungen zeigen weder eine schnelle 39 psKomponente, noch 500 ps oder 3.6 ns, sondern fallen monoexponentiell ab. Da das betrachtete Zeitfenster allerdings auf $\sim 200$ ps beschränkt ist, kann sich die gemessene Lebensdauer von $\tau_{3}=1.16 \mathrm{~ns}$ aus etwa $30 \%$ einer $500 \mathrm{ps}$ und $70 \%$ einer 3.6 ns-Komponente zusammensetzen.

Das Signal der trans-Spezies fällt biexponentiell mit $\tau_{1}=1.1 \mathrm{ps}$ und $\tau_{2}=$ $6.5 \mathrm{ps}$ ab. Die Emission für $\lambda>550 \mathrm{~nm}$ fällt weitestgehend monoexponentiell mit $\tau_{2}$ ab, während die Absorption des angeregten Zustandes und das Bleichen des Grundzustands biexponentiell mit $\tau_{1}$ und $\tau_{2}$ abfallen. Für große Verzögerungen $\Delta \mathrm{t}>20 \mathrm{ps}$ verschwindet das transiente Signal vollständig. Das Amplitudenspektrum von $\tau_{2}$ in Abb. $3.8 \mathrm{~b}$ im Bereich von 450 - 520 $\mathrm{nm}$ ähnelt dem Absorptionsspektrum von $T^{-}$(vgl. Abb. 3.4d. Das Amplitudenspektrum von $\tau_{1}$ zeigt eine ähnliche Struktur, ist aber breiter und $\sim 20 \mathrm{~nm}$ rotverschoben, mit dem Maximum an der Kante des $T^{-}$-Spektrums bei $520 \mathrm{~nm}$. Fron et al. haben in Pump-Probe Messungen für das trans-Isomer ebenfalls eine biexponentielle Dynamik mit ähnlichen Zeitkonstanten von 0.7 und 5.2 ps festgestellt. In einem Fluoreszenz-Hochkonversionsexperiment konnten sie die 5.2 ps, nicht aber die 0.7 ps Komponente messen, was die Bildung eines emittierenden Zustandes auf dieser Zeitskala ausschließt. Fron 
et al. schlugen stattdessen die Bildung eines heißen Grundzustandes oder eines anderen angeregten Zustandes vor.

Ein heisser Grundzustand $T_{h}^{-}$würde entsprechend rotverschoben zum Spektrum vom relaxierten Grundzustand $T^{-}$absorbieren, die Population von $T_{h}^{-}$ aus $T^{-*}$ mit $k_{I C_{1}}$ ist ausserdem konsistent mit dem Amplitudenspektrum der Zeitkonstante $\tau_{1}$ in Abb. $3.8 \mathrm{~b}$ und beschreibt den schmalbandigen Abfall des Signals bei $520 \mathrm{~nm}$ gut. Da das gesamte Signal letztlich komplett verschwindet, muss $T_{h}^{-}$mit $k_{c_{2}}$ zu $T^{-}$abkühlen. Diese Abkühlung muss langsamer stattfinden als die Population durch die interne Konversion, da $T_{h}^{-}$sonst nie nennenswert populiert wäre. Die innere Konversion $k_{I C_{1}}$ kann nicht der einzige Reaktionskanal für $T^{-*}$ sein. Die transiente Absorption bei $400 \mathrm{~nm}$ zeigt beide Zeitkonstanten $\tau_{1}$ und $\tau_{2}$, die Emission nur das langsamere $\tau_{2}$. Ein Teil der angeregten Moleküle muss also in Konkurrenz mit der internen Konversion $k_{I C_{1}}$ von $T^{-*}$ mit $k_{c_{1}}$ in einen anderen, langlebigeren angeregten Zustand $T_{r}^{-*}$ relaxieren, der sich spektral im Bereich der transienten Absorption, nicht aber im Bereich der Emission von $T^{-*}$ unterscheidet und die Lebensdauer $\tau_{2}$ hat. Die Reaktion von $T_{r}^{-*}$ nach $T^{-}$erfordert die Reorganisation der mit $k_{c_{1}}$ erfolgten Änderung im angeregten Zustand, weshalb eine Reaktionskaskade mit initialer Entvölkerung durch interne Konversion mit $k_{I C_{2}}$ nach $T_{r, h}^{-}$oder $T_{r}^{-}$und anschließender Relaxation $\mathrm{zu} T^{-}$anzunehmen ist. Da der gebleichte Grundzustand $T^{-}$ebenfalls mit $\tau_{2}$ repopuliert wird, muss die Depopulation von $T_{r}^{-*}$ hier der geschwindigkeitsbestimmende Schritt sein, was dazu führt, dass $T_{r, h}^{-}$und $T_{r}^{-}$nie nennenswert populiert werden.

Diese Überlegungen sind in dem kinetischen Modell in Abb. 3.9a zusammengefasst. Die farbig unterlegten Zustände repräsentieren die tatsächlich populierten Zustände, die dicken Pfeile die relevanten Reaktionswege. Die grau unterlegten Zustände und gestrichelten Reaktionswege sind nur der Vollständigkeit halber angegeben und werden in dem Modell nicht berücksichtigt. Die Abkühlung des heißen Grundzustandes wurde zur Reduzierung der Anpassungsparameter stark vereinfacht durch den Übergang eines heißen in einen kalten Zustand beschrieben.

\subsubsection{Anpassung der Daten}

Die transienten Spektren des cis- und trans-Isomers (Abb. 3.7a und b) wurden simultan global mit dem kinetischen Modell in Abb. 3.9a angepasst. Beide Datensätze wurden als Mischung aus dem jeweils erwünschten und einem geringen Anteil unerwünschten Isomer behandelt. Die gemessenen Signale 
sind die Summe der Beiträge beider Isomere nach G1 2.3 Überlapp $\sigma_{p p}$ und Pumpintensität $I_{\text {pump }}$ und die Proteinkonzentration $c_{\text {Prot }}$ sind bei beiden Messungen identisch, was zu Gl 3.3 führt.

$$
\Delta O D(\lambda, t)=I_{\text {pump }} \sigma_{\text {pp }} c_{\text {Protein }} \sum_{i} c_{i} \epsilon_{i}\left(\lambda_{p}\right) \sum_{j}\left(c_{i, j}(t) S_{i, j}(\lambda)\right)
$$

Jede Grundzustandspezies mit der anteiligen Konzentration $c_{i}, \sum_{i} c_{i}=1$, die bei $\lambda_{p}=505 \mathrm{~nm}$ absorbiert $\left(\epsilon_{i}(505 \mathrm{~nm}) \neq 0\right)$, trägt mit den an ihrer Reaktionsdynamik beteiligten Spezies $j$ mit den relativen Konzentrationen $c_{i, j}$ und den Spektren $S_{i, j}$ zum Signal bei, wobei gilt $\sum_{j} c_{i, j}=1$. Die beteiligten Grundzustandspezies bei $\mathrm{pH} 10$ und der Anregungswellenlänge $\lambda_{p}=$ $505 \mathrm{~nm}$ sind für das trans-Isomer $T^{-} X^{-} Y^{-}$, die Spezies des cis-Isomer liegen im Gleichgewicht (G1. 3.4) vor.

$$
\left.\left(C^{H} X^{-} Y^{-} \rightleftharpoons C^{-} X^{H} Y^{-}\right) \stackrel{H^{+}}{\rightleftharpoons} C^{-} X^{-} Y^{-}\right)
$$

Die Gesamtkonzentration aller beteiligten Spezies ist konstant (G1. 3.5). Mit der Annahme, dass sich die beiden cis-Spezies kinetisch identisch verhalten, können sie für diesen $\mathrm{pH}$-Wert als eine Spezies $C_{p H 10}^{-}$beschrieben werden. Analog wird $T^{-} X^{-} Y^{-}$als $T_{p H 10}^{-}$und $C^{H} X^{-} Y^{-}$als $C_{p H 10}^{H}$ bezeichnet. Da die Isomere reversibel ineinander umgewandelt werden, gilt für die Konzentration G13.9.

$$
\begin{aligned}
\sum_{i} c_{i} & =c_{T^{-} X^{-} Y^{-}}+c_{C^{H} X^{-} Y^{-}}+c_{C^{-} X^{H} Y^{-}}+c_{C^{-} X^{-} Y^{-}}=1 \\
c_{c i s} & =c_{C^{H} X^{-} Y^{-}}+c_{C^{-} X^{H} Y^{-}}+c_{C^{-} X^{-} Y^{-}} \\
c_{\text {trans }} & =c_{T^{-} X^{-} Y^{-}} \\
c_{C_{p H 10}^{-}} & =c_{c i s}-c_{C_{p H 10}^{H}} \\
c_{T_{p H 10}^{-}} & =1-c_{c i s}
\end{aligned}
$$

Da der $\mathrm{pH}$-Wert während der Messung konstant ist, sind die Konzentrationsverhältnisse der Spezies $C_{p H 10}^{-}$und $C_{p H 10}^{H}$ zueinander ebenfalls konstant und aus der Anpassung der cis-Absorptionsspektren bekannt (siehe Abb. 3.4a. Das Verhältnis der Absorptionskoeffizienten $C_{p H 10}^{H}$ und $T_{p H 10}^{-}$bei $\lambda_{p}=505$ $\mathrm{nm}$ kann aus den Speziesspektren in $\mathrm{Abb}$. 3.4c und d berechnet werden. Aus diesen Überlegungen ergibt sich Gl. 3.10. die zur gemeinsamen Anpassung beider Datensätze verwendet wurde. Die relativen Konzentrationen $c_{i}(t)$ der nach Anregung bevölkerten Spezies entstammen dem kinetischen Modell aus Abb. 3.9a Alle konstanten Parameter wurden zu einem gemeinsamen 
Amplitudenfaktor $A$ zusammengefasst.

$$
\begin{aligned}
\Delta O D(\lambda, t)=A & \cdot\left(\frac{\epsilon_{T_{p H 10}^{-}}(505 n m)}{\epsilon_{C_{p H 10}^{-}}(505 n m)} \sum_{i}\left(c_{i}(t) S_{i}(\lambda)\right)\right. \\
& \left.+c_{c i s} \cdot\left(1-\frac{{ }^{c_{C_{p H 10}^{H}}}}{{ }^{c_{C_{p H 10}^{-}}}}\right) \sum_{j}\left(c_{j}(t) S_{j}(\lambda)\right)\right)
\end{aligned}
$$

Zur spektralen Beschreibung der Grundzustände wurden die bekannten Spektren der Spezies $C_{p H 10}^{-}$und $T_{p H 10}^{-}$verwendet. Der angeregte Zustand $\mathrm{C}^{-*}$ wurde als Überlagerung des bekannten stimulierten Emissionsspektrums $C_{e}^{-*} m$ mit Absorptionsbanden beschrieben, die mit drei Gaußfunktionen modelliert wurden. Die angeregten Zustände $T^{-*}$ und $T_{r}^{-*}$ wurden mit jeweils drei Gaußfunktionen beschrieben, jeweils zwei Absorptions- und eine breite Emissionsbande. Der heiße Grundzustand $T_{h}^{-}$wurde aus drei Absorptionsbanden modelliert.

\subsubsection{Ergebnisse}

Die resultierenden Geschwindigkeitskoeffizienten sind im Modell in Abb. 3.9a angegeben. Die Entwicklung der Konzentrationen der einzelnen Spezies ist in Abb. 3.9b gezeigt. Die Spektren der einzelnen Spezies sind in Abb. 3.9c zu sehen.

Die Relaxation im angeregten Zustand erfolgt schnell und hat nur geringe spektrale Auswirkungen. Der Grundzustand ist nach $\sim 20$ ps wieder repopuliert. Größere strukturelle Änderungen des Chromophors und der Umgebung, wie Isomerisierung oder ein ESPT, können daher ausgeschlossen werden. Im beobachteten Zeitrahmen ist eine Umorganisierung der stabilisierenden Wasserstoffbrücken oder eine geringfügige Umlagerung des Chromophors wahrscheinlich.

Die Proteinlösung in Abb. 3.7abestand nach Gl. $3.10 \mathrm{zu} 76 \%$ aus dem cisund zu $24 \%$ aus dem trans-Isomer, in Abb. $3.7 \mathrm{~b}$ zu $12 \%$ aus dem cis- und zu $88 \%$ aus dem trans-Isomer.

Im Rahmen der Messungen wurde keine Isomerisierung $T^{-} \longrightarrow C^{-}$durch Anregung beobachtet. Dieses Ergebnis steht im Widerspruch zu der Interpretation von Fron et al., die eine schnelle und quantitative Isomerisierung nach Anregung der $T^{-}$-Spezie vorgeschlagen haben [65], deckt sich aber mit 
der aus den Schaltzyklen von Padron0.9 ermittelten Quantenausbeute des Schaltvorgangs $\Phi_{\text {trans }} \longrightarrow$ cis $(503 \mathrm{~nm})=0.0003$. 


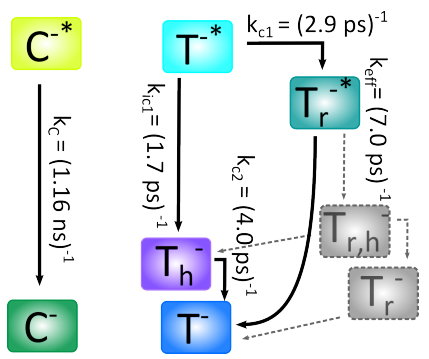

(a) Kinetisches Modell zur Anpassung der Daten in Fig 3.7

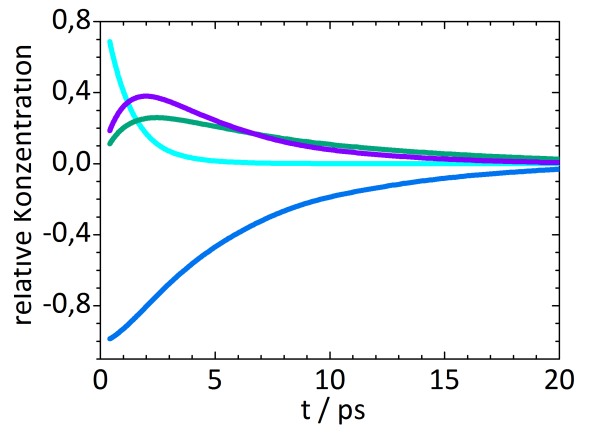

(b) Konzentrationsverlauf der Spezies aus a

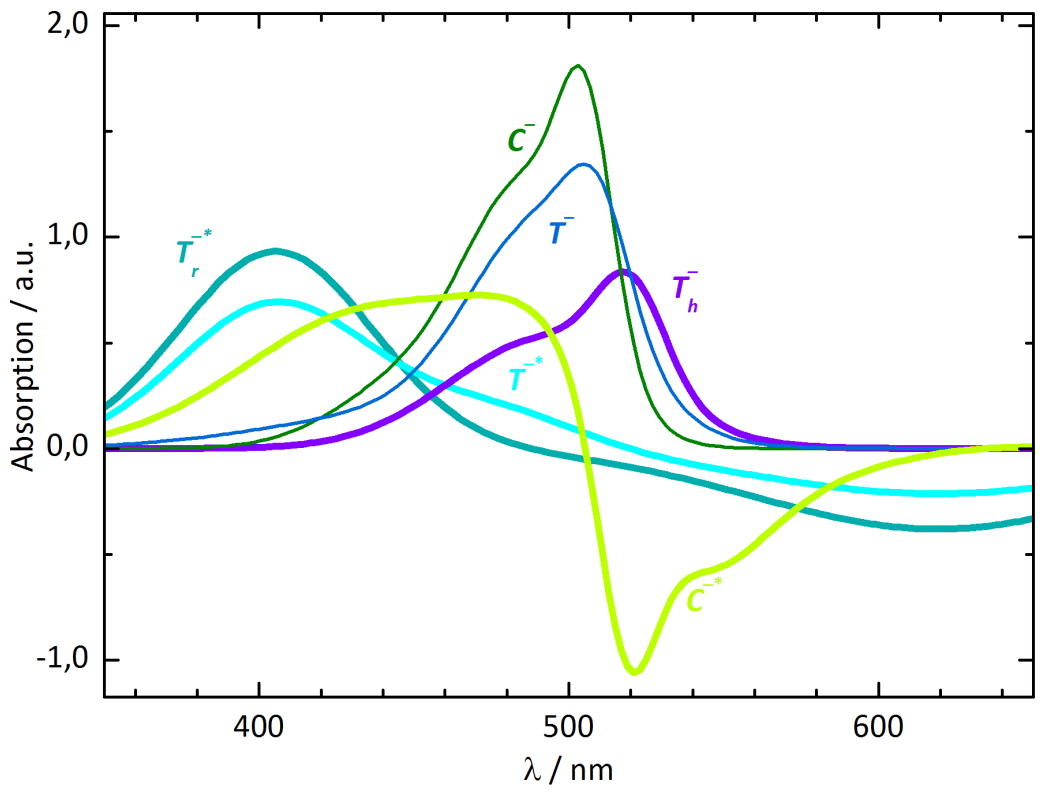

(c) Spektren der beteiligten Spezies

Abb. 3.9: Modell der photoinduzierten Dynamik von Padron0.9 nach Anregung der $C^{-}$- und $T^{-}$-Spezies bei $\lambda_{p}=505 \mathrm{~nm}$, zeitabhängige Konzentrationen der beteiligten Spezies und ihre Absorptionsspektren 


\subsubsection{Angeregte Zustände von $C^{H}$ bei hohem pH-Wert}

Die transiente Dynamik des Zustands $C^{H}$ wurde mittels Pump-Probe Spektroskopie durch Anregung bei $\lambda_{p}=387 \mathrm{~nm}$ bei $\mathrm{pH} 7$ und 10 untersucht. Das trans-Isomer wurde in diesem $\mathrm{pH}$-Bereich nicht weiter berücksichtigt, da sein Protonierungsgleichgewicht so stark nach $T^{-}$verschoben ist, dass keine Spezies $T^{H}$ existiert (vgl. Abb. 3.1b und 3.4d und entsprechend keine Daten aufgenommen werden konnten. Nach Abb. 3.4aliegt bei $\mathrm{pH} 10$ ausschließlich die Spezies $C^{H} X^{-} Y^{-}$vor, bei pH 7 zu $90 \%$, die übrigen $10 \%$ sind den doppelt protonierten Spezies $C^{H} X^{H} Y^{-}$und $C^{H} X^{-} Y^{H}$ zugeordnet. Die transienten Spektren in Abb. 3.10 bei $\mathrm{pH} 7$ und 10 zeigen nur geringe Abweichungen, die aus der geringfügig anderen Zusammensetzung stammen können. Im weiteren Verlauf der Auswertung wurden nur die Messung bei $\mathrm{pH} 10$ betrachtet.

\subsubsection{Transiente Spektren}

Die aufgenommenen transienten Spektren von $C^{H}$ bei $\mathrm{pH} 10$ und $387 \mathrm{~nm}$ Anregungswellenlänge sind in $\mathrm{Abb}$. 3.11a als offene Kreise gezeigt. Das frühe Spektrum 0.5 ps nach Anregung zeigt ein ausgeprägtes Grundzustandsbleichen im Bereich der $C^{H}$-Absorption, überlagert mit Absorption des angeregten Zustands mit einem Maximum bei $445 \mathrm{~nm}$. Das breite negative Signal für Wellenlängen $\lambda>490 \mathrm{~nm}$ kann stimulierter Emission des angeregten Zustands zugeordnet werden. Diese Emission ist zunächst breit, flach und ohne ausgeprägte Struktur, entwickelt sich aber innerhalb von einigen Pikosekunden zu einem schmalen, markanten Spektrum mit klar erkennbarer Bandenstruktur, die ein Maximum bei $515 \mathrm{~nm}$ und eine Schulter bei $550 \mathrm{~nm}$ zeigt. Das späte Spektrum bei $\Delta \mathrm{t}>100$ ps ähnelt stark dem transienten Spektrum der $C^{-}$-Spezies, das zum Vergleich als grüne, gestrichelte Linie skaliert und um -3 mOD verschoben in Abb. 3.11a gezeigt ist.

Die Spektren in Abb. 3.11a wurde wellenlängenabhängig mit einem triexponentiellen Abfall mit den Zeitkonstanten $\tau_{1}=(1.6 \pm 0.3) \mathrm{ps}, \tau_{2}=$ $(26 \pm 5)$ ps und $\tau_{3}=1.16$ ns angepasst. Die wellenlängenabhängigen Amplituden der Anpassung sind in Abb. 3.12a dargestellt. $\tau_{3}$ wurde fixiert und entspricht der Lebensdauer von $C^{-*}$ (siehe 3.1.3.2. 


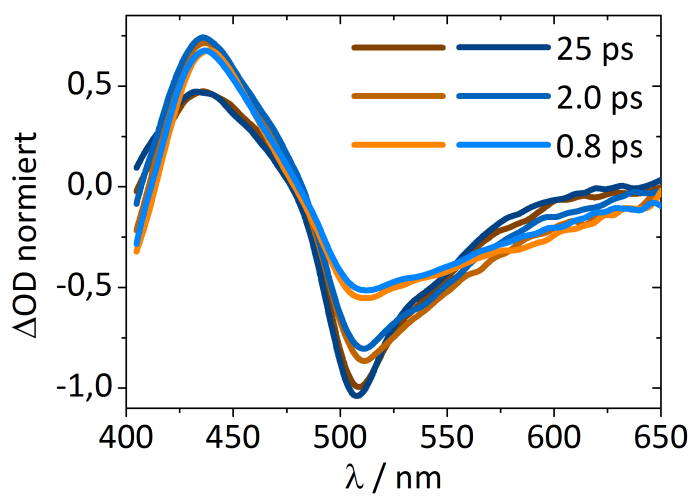

Abb. 3.10: Vergleich der transienten Spektren von Padron0.9, cis-Isomer, $\lambda_{p}=387 \mathrm{~nm}$, bei pH 7 (orange) und pH 10 (blau) zu verschiedenen Verzögerungszeiten

\subsubsection{Aufstellen des kinetischen Modells}

Die starke Ähnlichkeit der transienten Spektren von $C^{H}$ und $C^{-}$bei großer Verzögerung lässt vermuten, dass sich $C^{H}$ nach Anregung in Richtung $C^{-*}$ verändert. Auch die Fluoreszenzspektren für Anregung von $C^{H}$ und $C^{-}$ sind identisch, mit einer deutlich geringeren Fluoreszenzquantenausbeute für $C^{H}$. Dies ist ein starker Beleg dafür, dass der emittierende Zustand in beiden Fällen $C^{-*}$ sein wird. Nach Anregung der $C^{H}$-Spezies muss also ein Protonentransfer im angeregten Zustand (exited state proton transfer, ESPT) $C^{H *} \longrightarrow C^{-*}$ erfolgen. Zur Verifizierung des ESPT wurde eine weitere Messung in deuterierter Pufferlösung durchgeführt, siehe Abschnitt3.1.3.3.

Die spektrale Evolution der stimulierten Emission passiert biexponentiell mit $\tau_{1}$ und $\tau_{2}$ (vgl. Abb. 3.12a). $\tau_{1}$ entspricht dem initialen schnellen Anwachsen der Emission mit einem Maximum bei $510 \mathrm{~nm}, \tau_{2}$ einer langsameren Modulation auf der roten Flanke des schnell gewachsenen Spektrums, die zu dem finalen Emissionsspektrum führt. Diese Modulation wird durch ein Intermediat im Reaktionsweg $C^{H *} \longrightarrow C_{i}^{-*} \longrightarrow C^{-*}$ des ESPT dargestellt, das schon stark den Charakter von $\mathrm{C}^{-*}$ hat.

Die Lebensdauer $\tau_{1}$ dominiert darüber hinaus die Grundzustandsrepopulation von $\mathrm{C}^{\mathrm{H}}$. Dies deutet auf eine mit dem ESPT konkurrierende innere Konversion des initial angeregten Zustandes $C^{H *} \longrightarrow C^{H}$ in den Grundzustand hin. Fron et al. haben nach Anregung der $C^{H}$-Spezies eine Zeitkonstante von 1 ps beobachtet, die sie ebenfalls einem mit interner Konversion 


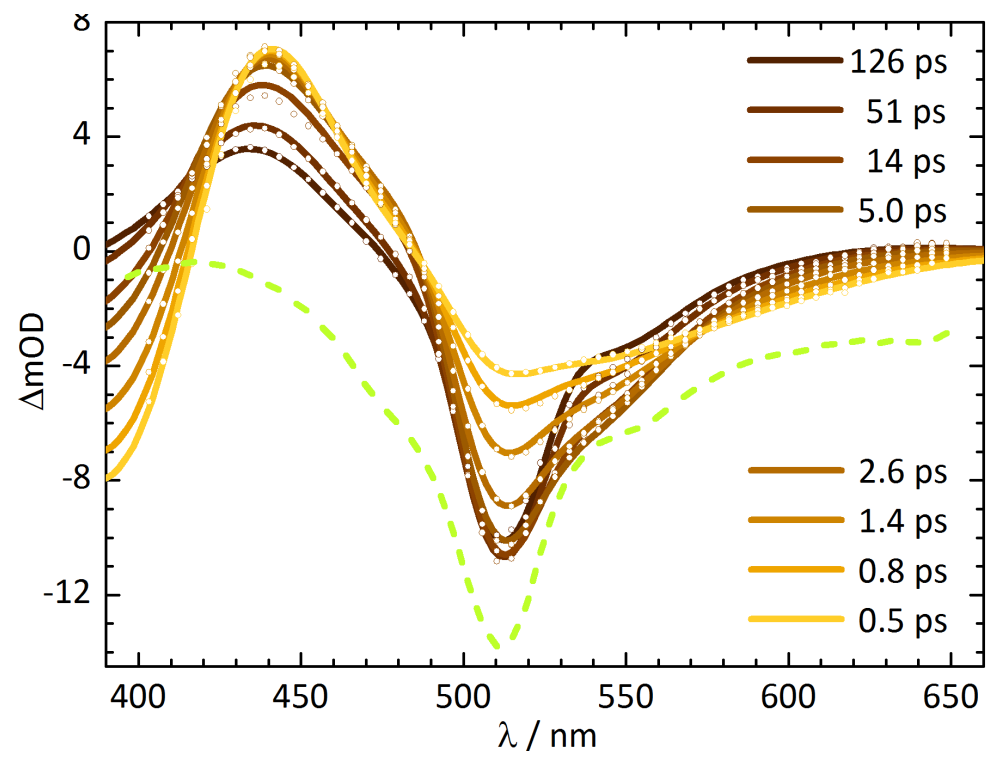

(a) $\mathrm{H}_{2} \mathrm{O}$-Puffer

Die grüne Linie zeigt das skalierte Spektrum aus 3.7abei $\Delta t=193$ ps.

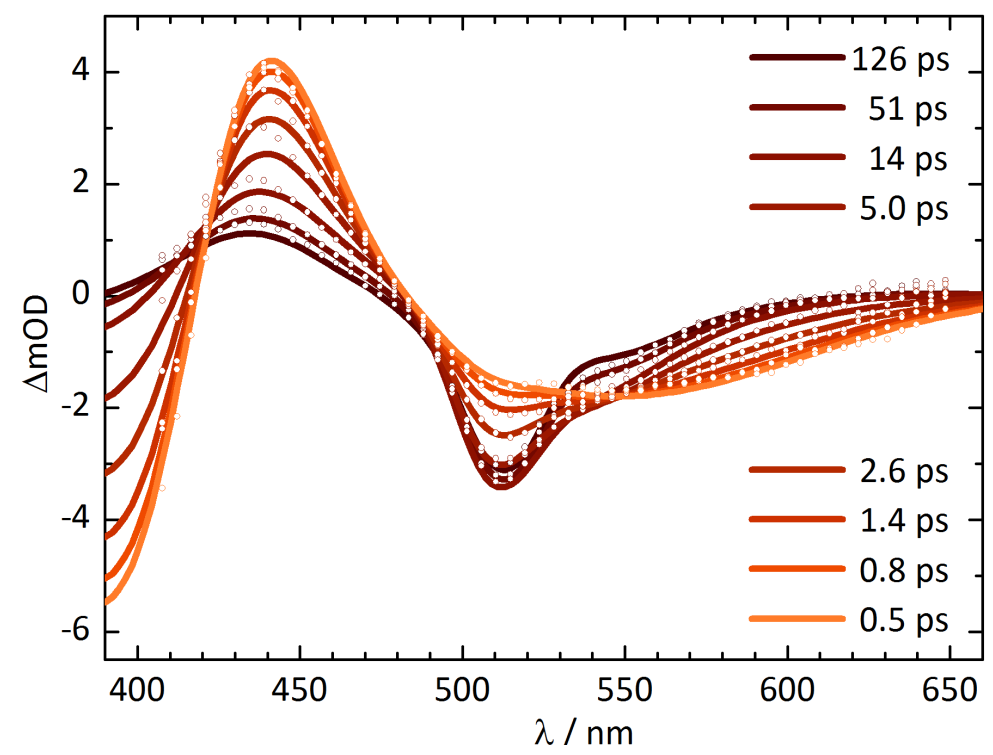

(b) $\mathrm{D}_{2} \mathrm{O}$-Puffer

Abb. 3.11: Transiente Spektren des cis-Isomers von Padron 0.9 bei $\mathrm{pH} 10$ nach Anregung bei $387 \mathrm{~nm}$ bei verschiedenen Verzögerungszeiten. $\circ$ : aufgenommenen Daten, / : Anpassung durch das kinetische Modell in Fig 3.13a 


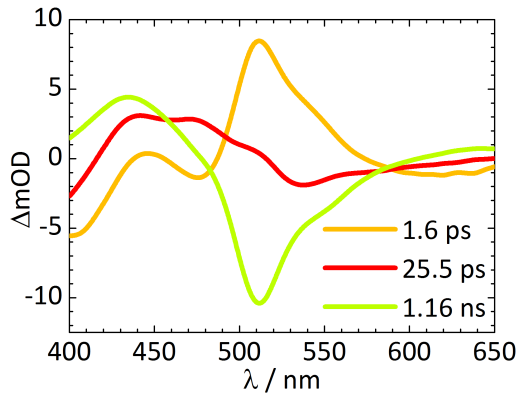

(a) $\mathrm{H}_{2} \mathrm{O}$-Puffer

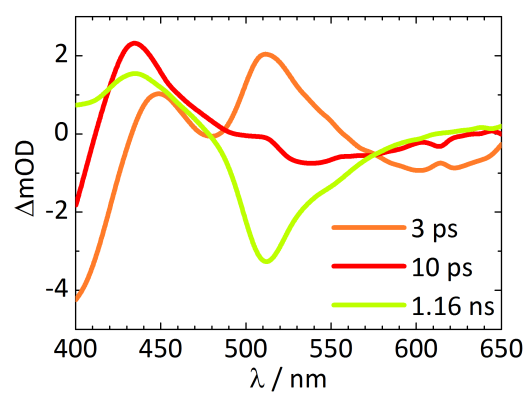

(b) $\mathrm{D}_{2} \mathrm{O}$-Puffer

Abb. 3.12: Amplitudenspektren der exponentiellen Anpassung der transienten Daten des cis-Isomers von Padron0.9 bei pH 10 nach Anregung bei $387 \mathrm{~nm}$.

konkurrierenden ESPT zugeschrieben haben [65]. Auch für GFP wurde eine analoge Konkurrenzreaktion beobachtet [14].

Die Tatsache, dass das transiente $C^{H}$-Spektrum für $\Delta t>100$ ps weniger dem Spektrum der $C^{-*}$-Spezies als dem transienten $C^{-}$-Spektrum ähnelt, das sich aus dem Spektrum von $C^{-*}$ und dem Grundzustandsbleichen von $C^{-}$zusammensetzt, deutet auf einen weiteren Protonentransfer im Grundzustand $C^{-} \longrightarrow C^{H}$ hin, der zu einem Bleichen der $C^{-}$Spezies führt. Emission in diesem Bereich kann wegen der gleichen Fluoreszenzspektren bei Anregung von $C^{H}$ und $C^{-}$für späte Zeiten ausgeschlossen werden. Die Amplitudenspektren der der Spezies $C^{-*}$ zugeordneten Lebensdauer $\tau_{3}=1.16 \mathrm{~ns}$ in Abb. 3.12a und Abb. 3.8a ähneln sich ebenfalls stark. Die jeweils negative Amplitude im Bereich der $C^{-}$-Absorption lässt auf eine Repopulation des Grundzustandes $C^{-*} \longrightarrow C^{-}$mit $k_{C}=\tau_{3}^{-1}$ schließen. Diese Überlegungen sind in dem kinetischen Modell in Abb. 3.13a zusammengefasst.

\subsubsection{ESPT: deuterierte Pufferlösung}

Um den postulierten initialen ESPT zu verifizieren, wurde die Messung noch einmal in deuterierter Pufferlösung wiederholt. Durch H/D-Austausch konnte eine Deuterierung des Proteinchromophors von > $98 \%$ erreicht werden. Aufgrund des kinetischen H/D-Isotopeneffektes verlangsamen sich Protonentransferprozesse signifikant (siehe Abschnitt 1.4). Die transienten Spektren sind in Abb. $3.11 \mathrm{~b}$ dargestellt. Der Vergleich mit den nicht deuterierten Spektren in Abb. 3.11a zeigt deutliche Unterschiede. Kurz nach 
Anregung ist das Verhältnis des Signals des gebleichten Grundzustands bei $400 \mathrm{~nm}$ zu der Absorption des angeregten Zustands bei $445 \mathrm{~nm}$ in beiden Messungen beinahe identisch. In deuterierter Pufferlösung entwickelt sich in der Folge aber deutlich weniger stimulierte Emission.

Die spektrale Evolution wurde triexponentiell mit $\tau_{3}=1.16 \mathrm{~ns}$, der Lebensdauer der $C^{-}$-Spezies, angepasst und ergab die Zeitkonstanten $\tau_{1}=$ $(3.0 \pm 0.5)$ ps und $\tau_{2}=(15 \pm 5)$ ps. Die wellenlängenabhängigen Amplituden dieser Zeitkonstanten sind in Abb. $3.12 \mathrm{~b}$ dargestellt. Auch hier dominiert die Zeitkonstante $\tau_{1}$ das Anwachsen der stimulierten Emission und die Grundzustandsrepopulation. Allerdings ist $\tau_{1}$ fast doppelt so groß wie in der undeuterierten Messung und im Verhältnis stärker im Bereich der Repopulation des Grunzustandes vertreten. Diese Beobachtungen unterstützen die Annahme einer Konkurrenzreaktion zwischen ESPT und IC bei der Depopulation von $\mathrm{C}^{\mathrm{H}}$; die Deuterierung des Chromophors verlangsamt den Protonen- (bzw. Deuteronen-)transfer, während die Geschwindigkeit der internen Konversion nicht beeinflusst wird. Entsprechend wird durch Deuterierung die Quantenausbeute der Fluoreszenz nach Anregung bei $400 \mathrm{~nm}$ verringert.

\subsubsection{Anpassung der Daten}

Die transienten Spektren in wässriger und deuterierter Pufferlösung (Abb. 3.11a und b wurden global mit dem kinetischen Modell in Abb. 3.13aangepasst. Dabei wurden die bereits in 3.1.1 und 3.1.2 bestimmten Spektren der Spezies $C^{H}, C^{-}$und $C^{-*}$ sowie die in 3.1.3.2 postulierten Zustände $C^{H *}$ und $C_{i}^{-*}$ verwendet. Zusätzlich wurde der Zustand I (siehe Abb. 3.13a eingeführt. Spektren, Amplituden und Geschwindigkeitskonstanten, die keinen Protonentransfer beschreiben, wurden als nicht deuterierungsabhängig angesehen und für beide Messungen simultan angepasst. Ein Amplitudenfaktor in der Anpassung korrigierte die unterschiedlichen Konzentrationen der beiden Proteinlösungen. Der Faktor $x=0.75$ in Abb. 3.13a setzt mit dem vereinfachten Grundzustandsgleichgewicht $C^{H} \rightleftharpoons C^{-}$das korrekte Verhältnis zwischen protoniertem und deprotoniertem Chromophor bei $\mathrm{pH}$ 10, wobei $k_{g}$ die Geschwindigkeit der Gleichgewichtseinstellung beschreibt.

\subsubsection{Ergebnisse}

Die resultierenden Geschwindigkeitskoeffizienten aus der Anpassung sind im Modell in Abb. 3.13a angegeben. Die Entwicklung der Konzentratio- 
nen der einzelnen Spezies ist in Abb. 3.13b dargestellt, die Spektren der einzelnen Spezies schließlich sind in Abb. 3.13c zu sehen. Der KIE für den ESPT ist $k_{H} / k_{D}=4.5$. Nach Anregung der $C^{H}$-Spezies erfolgt für $70 \%$ der Moleküle in $C^{H *}$ ein ESPT nach $C_{i}^{-*}$ (deuteriert: $35 \%$ ). Insgesamt $36 \%$ aller Moleküle enden im fluoreszierenden $C^{-}$-Zustand (deuteriert: $18 \%$ ), während $34 \%$ im I-Zustand enden (deuteriert: $17 \%$ ). Von Brakemann et al. aufgenommene Fluoreszenzanregungsspektren zeigen bei $\mathrm{pH} 7$ relative Fluoreszenzintensität von $\frac{I_{F, C^{-}}}{I_{F, C H}}=17 \%$ [23]. Unter Berücksichtigung der Absorptionskoeffizienten und der relativen Konzentration der Spezies ergibt G1 3.11 mit $\frac{\epsilon_{C^{H}}}{\epsilon_{C^{-}}}=0.4$ aus Abb. $3.4 \mathrm{c}$ und $\frac{{ }^{C} H}{c_{C^{-}}}=1.54$ aus Abb. $3.4 \mathrm{a}$ die relative Fluoreszenzquantenausbeute $\frac{\Phi_{C^{-}}}{\Phi_{C^{H}}}=28 \%$, was im Hinblick auf die unterschiedlichen $\mathrm{pH}-$ Werte der Messungen und der Komplexität des Modells eine gute Übereinstimmung mit den aus dem Modell ermittelten $36 \%$ ist.

$$
\frac{\Phi_{C^{-}}}{\Phi_{C^{H}}}=\frac{\frac{I_{F, C^{-}}}{\epsilon_{C^{-}} c_{C^{-}}(p H 7)}}{\frac{I_{F, C^{H}}}{\epsilon_{C^{H} c_{C} c^{H}}(p H 7)}}
$$

Die Anregung der $C^{H}$-Spezies bei $387 \mathrm{~nm}$ führt bei Padron0.9 zu einer im Vergleich zur Bestrahlung mit $500 \mathrm{~nm}$ recht effizienten cis $\longrightarrow$ transIsomerisierung. Die Quantenausbeute dieses Schaltprozesses wurde mit $\Phi_{\text {cis } \longrightarrow \text { trans }}(387)=0.02$ bestimmt. Innerhalb der betrachteten Zeitskala gibt es keine Hinweise auf die Bildung der $T^{-}$-Spezies nach Anregung von $C^{H}$. Da die Spektren von $T^{-}$und $C^{-}$sich ähneln und nur $2 \%$ trans-Isomer als Ausbeute erwartet werden, kann keine Aussage darüber getroffen werden, ob das Signal des trans-Isomers einfach überlagert wird oder tatsächlich noch keine Isomerisierung stattgefunden hat. Ist sie noch nicht erfolgt, sind nach dem verwendeten Modell die einzigen Zustände, aus denen $T^{-}$gebildet werden kann, $C^{H *}, C_{i}^{-*}$ und $I$; für den angeregten Zustand $C^{-*}$ ist keine so effiziente Isomerisierung bekannt.

\subsubsection{Zustand $I$}

Zustand I wurde eingeführt, weil die transienten Spektren bei langen Verzögerungszeiten um $430 \mathrm{~nm}$ eine deutlich höhere transiente Absorption zeigten, als durch den bekannten, zu dieser Zeit hauptsächlich populierten, Zustand $C^{-*}$ zu erklären gewesen wäre. Das aus der Anpassung erhaltene Absorptionsspektrum von I in Abb. 3.13c zeigt eine starke Absorptionsbande mit einem Maximum bei $402 \mathrm{~nm}$ sowie eine äußerst schwache Bande um 


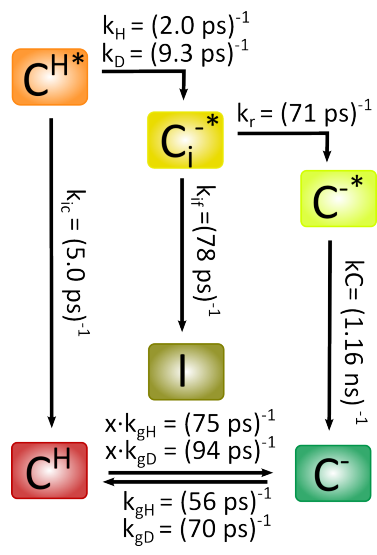

(a) Kinetisches Modell zur Anpassung der Daten in Fig 3.11

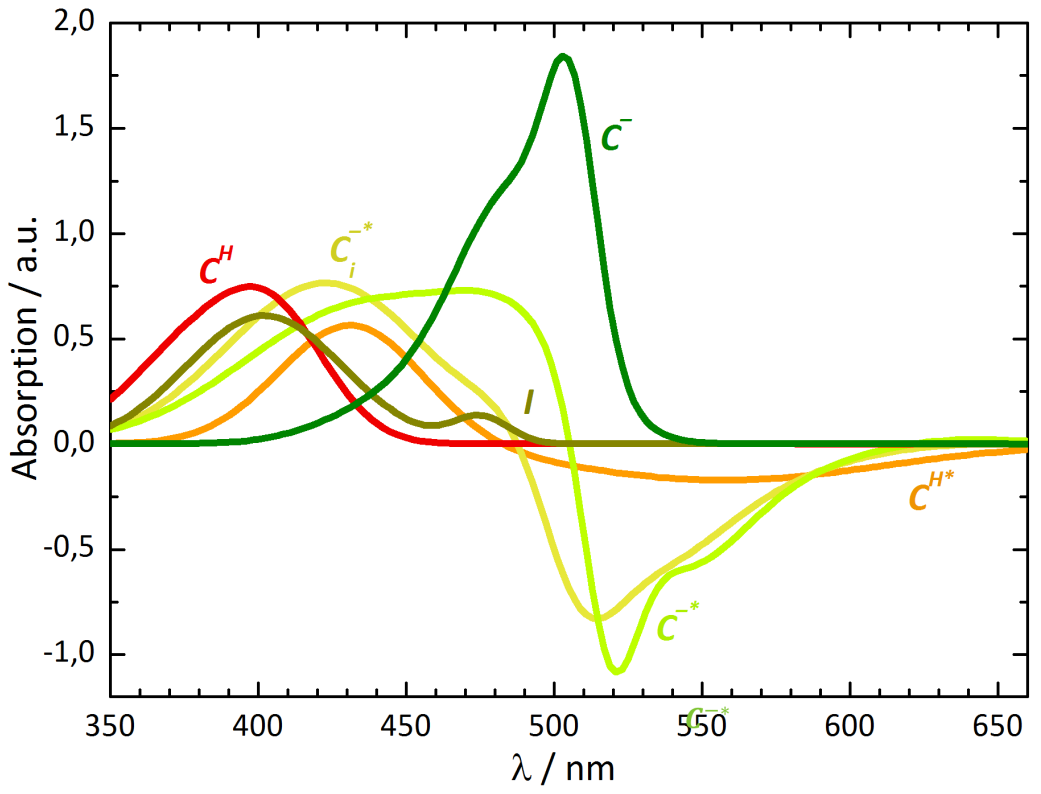

(c) Spektren der Spezies ausa

Abb. 3.13: Modell der photoinduzierten Dynamik von Padron0.9 nach Anregung der $C^{H}$-Spezies durch $\lambda_{p}=387 \mathrm{~nm}$, zeitabhängige Konzentrationen der beteiligten Spezies und ihre Absorptionsspektren 
$475 \mathrm{~nm}$ und ähnelt so stark einem Grundzustandsspektrum mit größtenteils protoniertem Chromophor. Die Bevölkerung einer Spezies im Grundzustand deckt sich auch mit den Fluoreszenz-Hochkonversionsuntersuchungen von Fron et al., die nach dem ESPT keine anwachsende stimulierte Emission bei Entvölkerung von $C_{i}^{*}$ zeigten [65]. Nach dem kinetischen Modell enden etwa $34 \%$ der angeregten $C^{H}$ Moleküle in dem Zustand I. Angesichts der niedrigen Quantenausbeute für den Schaltprozess von $\Phi_{\text {cis }} \longrightarrow$ trans $=0.02$ hat $I$, ebenso wie $C_{i}^{-*}$, vermutlich noch cis-Konformation. Ein protonierter Grundzustand kann nicht direkt durch IC aus der nach dem ESPT populierten deprotonieren Spezies $C_{i}^{-*}$ gebildet werden, sondern bedarf eines Protonierungsschrittes $C_{i}^{-} \longrightarrow I$. Für GFP wurde von Kennis et al. nach Anregung der $A$-Bande $\left(C^{H}\right)$ und erfolgtem ESPT ein intermediärer Grundzustand beschrieben, dessen Spektrum dem der deprotonierten $B$-Spezies $\left(C^{-}\right)$ähnelte (siehe Abb.1.6b), innerhalb von Pikosekunden relaxierte und dann mit einer Lebensdauer von 400 ps protoniert wurde [17]. Da I für Padron0.9 mit gutem Ergebnis als direktes Reaktionsprodukt von $C_{i}^{-*}$ beschrieben werden kann, muss ein solcher Protonierungsschritt deutlich schneller als der Übergang von $C_{i}^{-*}$ nach $C_{i}^{-}$sein.

Um den vermuteten elektronischen Grundzustand $C_{i}^{-}$der angeregten Spezies $C_{i}^{-*}$ zu untersuchen, wurde eine Pump-Dump-Probe-Messung durchgeführt. Angeregt wurde bei $\lambda_{p}=387 \mathrm{~nm}$, mit 40 ps Verzögerung erfolgte die Einstrahlung eines Dumppulses bei $\lambda_{d}=560 \mathrm{~nm}$ mit hoher Intensität $\left(\mathrm{I}_{d} \approx\right.$ $4 \mathrm{I}_{p}$ ), um die Population des angeregten Zustands $C_{i}^{-*}$ mittels stimulierter Emission möglichst effektiv in den Grundzustand zu überführen. AnschlieBend wurde mit variabler Verzögerung das transiente Spektrum mit dem Weißlicht-Probespektrum aufgenommen (siehe Abschnitt 2.2.2). Die Verzögerung von $40 \mathrm{ps}$ nach Anregung ist ein Kompromiss; $C^{H *}$ sollte vollständig depopuliert, das Protonierungsgleichgewicht $\mathrm{C}^{H} \rightleftharpoons \mathrm{C}^{-}$im Grundzustand weitestgehend eingestellt aber $C_{i}^{-*}$ immer noch ausreichend bevölkert sein. Dem kinetischen Modell nach verteilen sich die Konzentrationen der vorliegenden Spezies nach 40 ps wie folgt: $c_{C^{H}}(40 \mathrm{ps})=0, c_{C_{i}^{-*}}(40 \mathrm{ps})=0.25$, $c_{C^{-*}}(40 p s)=0.24, c_{C^{H}}(40 p s)=-0.49, c_{I}(40 p s)=0.22$ und $c_{C^{-}}(40 p s)=-0.21$. Abb. 3.14a zeigt die gemessenen transienten Pump-Dump-Probe-Spektren als offene Kreise.

\subsubsection{Transiente Pump-Dump-Probe-Spektren}

Die Daten wurden triexponentiell mit $\tau_{1}=(2.1 \pm 0.2) \mathrm{ps}, \tau_{2}=(570 \pm$ 200) ps und $\tau_{3}=1.16 \mathrm{~ns}$ angepasst, wobei die letzte Zeitkonstante als Le- 


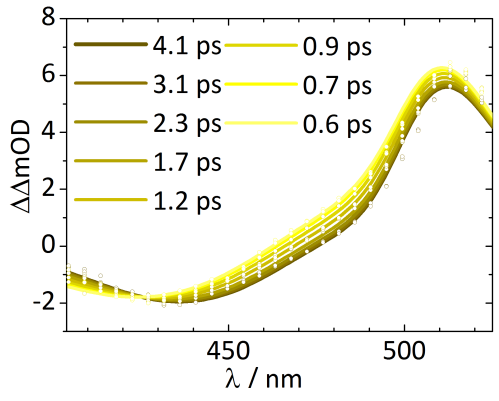

(a) transiente Spektren, Dumppuls bei $\mathrm{t}=0 \mathrm{ps}, \mathrm{o}:$ aufgenommene Daten, $\zeta$ : Anpassung durch das kinetische Modell in Fig $3.15 a$

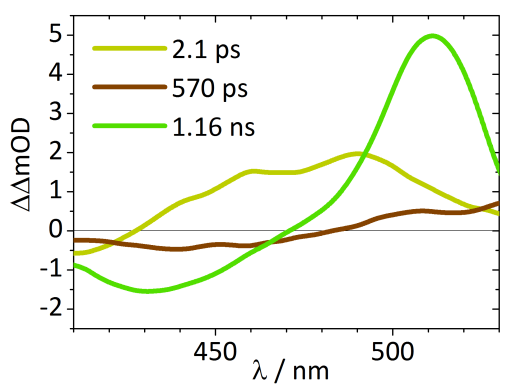

(b) Amplitudenspektrum der triexponentiellen Anpassung von a

Abb. 3.14: Pump-Dump-Probe-Spektroskopie an Padron 0.9 mit $\lambda_{p}=387 \mathrm{~nm}$ und $\lambda_{d}$ $=560 \mathrm{~nm}, \Delta \mathrm{t}_{d}=40 \mathrm{ps}$

bensdauer des angeregten Zustandes $C^{-*}$ festgesetzt wurde. Die wellenlängenabhängigen Amplituden der einzelnen Zeitkonstanten sind in Abb. $3.14 b$ dargestellt. Das transiente Spektrum wird von $\tau_{3}$ dominiert. Das Amplitudenspektrum zeigt eine breite negative Komponente von 410 bis $470 \mathrm{~nm}$ mit einem Minimum bei $430 \mathrm{~nm}$ und eine positive Komponente für $\lambda>470 \mathrm{~nm}$. Das Spektrum der Zeitkonstanten $\tau_{3}$ ist eine Superposition aller langlebigen, durch den Dumppuls veränderten, Zustände. Durch Einstrahlung bei $560 \mathrm{~nm}$ sollen die Zustände $C_{i}^{-*}$ und $C^{-*}$ in ihre korrespondierenden Grundzustände $C_{i}^{-}$und $C^{-}$überführt werden, wobei für $C_{i}^{-}$ein schneller GSPT vermutet und für $C^{-}$ein langsames Protonierungsgleichgewicht mit $C^{H}$ postuliert wurde. Die 570 ps Komponente hat eine vergleichsweise geringe Amplitude. Sie hat einen negativen Beitrag für $\lambda<480 \mathrm{~nm}$ und ist für größere Wellenlängen positiv. Eine entsprechende Zeitkonstante wurde in den bisherigen Messungen nicht beobachtet. Da sich das Spektrum über den gesamten gemessenen Wellenlängenbereich inklusive der Emission erstreckt, kann es sich hier um einen Relaxationsprozess im angeregten Zustand handeln. Fron et al. berichteten von einer schwachen 500 ps Komponente der Fluoreszenzlebensdauer [65], die hier bisher nicht bestätigt werden konnte (siehe Abschn. 3.1.2.1). Die schnelle Zeitkonstante $\tau_{1}$ zeigt ein breites, im Bereich von $430-530 \mathrm{~nm}$ positives Spektrum mit einem Maximum bei $490 \mathrm{~nm}$ und einer Schulter bei $460 \mathrm{~nm}$. Für $\lambda<430 \mathrm{~nm}$ ist der Beitrag negativ, das Minimum ist bis $410 \mathrm{~nm}$ noch nicht erreicht. Da der GSPT für $C^{H} \rightleftharpoons C^{-}$ deutlich langsamer ist, kann diese schnelle Komponente entweder ein GSPT 
bzw. die Einstellung eines Protonierungsgleichgewichtes $I \rightleftharpoons C_{i}^{-}$, oder eine schnelle Relaxation einer der Grundzustandsspezies sein. Der negative Beitrag im Amplitudenspektrum von $\tau_{1}$ im Bereich um $400 \mathrm{~nm}$, also dort, wo I absorbiert, deutet stark auf den GSPT zu I hin. Die Relaxation einer deprotonierten Spezies im Grundzustand sollte das Spektrum in diesem Bereich nicht verändern.

\subsubsection{Anpassung der Daten}

Das Aufstellen eines kinetischen Modells für ein Pump-Dump-Probe-Experiment ist deutlich komplexer als für ein vergleichbares Pump-Probe-Experiment. Deshalb werden nur die ersten 4 ps $\left(2 \tau_{1}\right)$ betrachtet und die langsameren Prozesse, wie die Entvölkerung von $C_{i}^{-*}\left(\tau_{C_{i}^{-*}}=\left(k_{r}+k_{i f}\right)^{-1}=37 \mathrm{ps}\right)$ und $C^{-*}\left(\tau_{C_{i}^{-}}=\left(k_{C}\right)^{-1}=1.16 \mathrm{~ns}\right)$ sowie die Einstellung des Grundzustandsgleichgewichts $\left(\tau_{\mathrm{C}^{H}} \rightleftharpoons_{\mathrm{C}^{-}}=\left(x k_{g H}+k_{g H}\right)^{-1}=32\right.$ ps) nicht berücksichtigt. Für die schnelle Komponente wurde ein Protonierungsgleichgewicht

$$
I \underset{k_{g i H}}{\stackrel{y k_{g i H}}{\rightleftharpoons}} C_{i}^{-}
$$

angenommen. Die Anpassung ergab ein extrem zur protonierten Seite verschobenes Gleichgewicht mit $\mathrm{y} \approx 0$.

Mit diesen Annahmen ergibt sich das kinetische Modell in Abb. 3.15a, mit dem die Daten in Abb. 3.14a angepasst wurden. Die bekannten Spektren und Amplitudenverhältnisse von $C_{i}^{-*}, C^{-*}, C^{-}$und $I$ wurden verwendet. Der Konzentrationsverlauf von $I$ und $C_{i}^{-}$sowie die Spektren, insbesondere das angepasste Spektrum von $C_{i}^{-}$, ist in Abb. 3.15b und c dargestellt, wobei $C^{-*}$ und $C_{i}^{-*}$ negative Vorzeichen haben.

\subsubsection{Angeregte Zustände von $C^{H+}$ und $T^{H+}$ bei niedrigem $\mathrm{pH}-$ Wert}

Die transiente Dynamik der Zustände $C^{H+}$ und $T^{H+}$ wurden mittels PumpProbe-Spektroskopie durch Anregung bei $\lambda_{p}=387 \mathrm{~nm}$ bei $\mathrm{pH} 4$ untersucht. Nach Abb. 3.4a und b liegt für das cis-Isomer bei $\mathrm{pH} 4$ eine Mischung von $80 \% C^{H} X^{H} Y^{H}, 15 \% C^{H} X^{H} Y^{-}$und $5 \% C^{H} X^{-} Y^{H}$ vor, während das transIsomer in der protonierten Form ausschließlich als $T^{H} X^{H} Y^{H}$ vorliegt. Beide Messungen wurden direkt nacheinander mit der gleichen Proteinlösung 


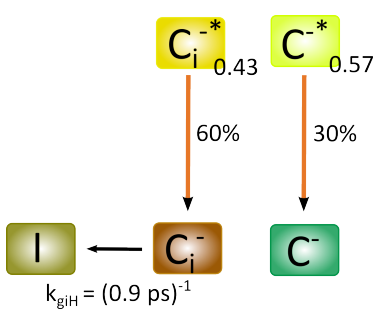

(a) Kinetisches Modell zur Anpassung der Daten in Fig $3.14 \mathrm{a}$

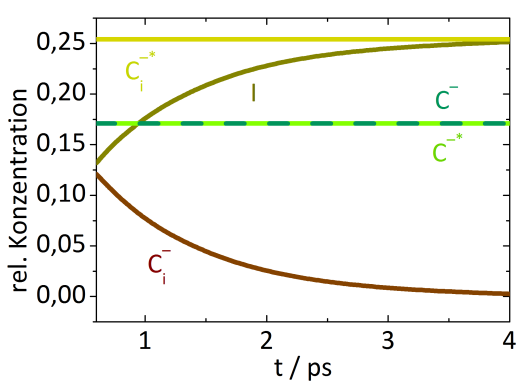

(b) Konzentrationsverlauf der Spezies ausa

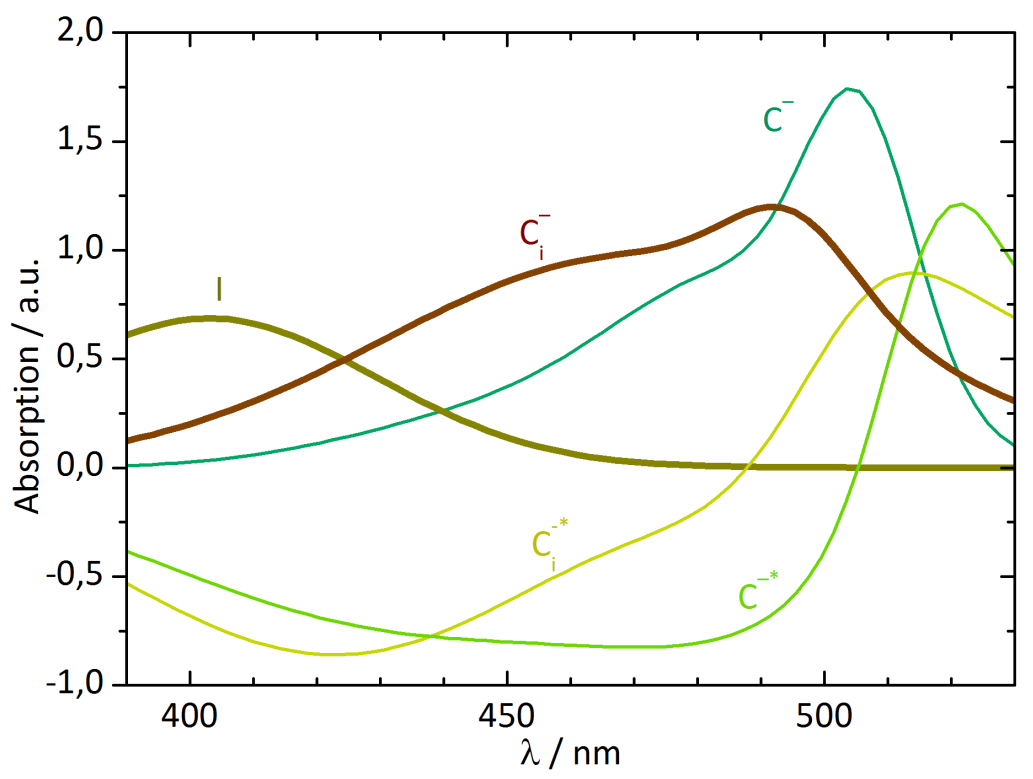

(c) Spektren der Spezies aus a

Abb. 3.15: Modell der photoinduzierten Dynamik von Padron0.9 nach Anregung der $C^{H}$-Spezies durch $\lambda_{p}=387 \mathrm{~nm}$ und Dumpen durch $\lambda_{d}=560 \mathrm{~nm} 40$ ps nach Anregung, zeitabhängige Konzentrationen der beteiligten Spezies und ihre Absorptionsspektren 
und ohne Variation der experimentellen Parameter durchgeführt. Zwischen den Messungen wurde die LED-Bestrahlung von 490 nach $400 \mathrm{~nm}$ geändert.

\subsubsection{Transiente Spektren \& Ergebnis}

Die aufgenommenen transienten Spektren von $\mathrm{C}^{\mathrm{H}+}$ und $\mathrm{T}^{\mathrm{H}+}$ bei $\mathrm{pH} 4$ und $387 \mathrm{~nm}$ Anregungswellenlänge sind in Abb. 3.16a und b gezeigt. Die Ähnlichkeit beider Spektren ist bemerkenswert, wobei das Signal des cisIsomers um den Faktor 1.3 intensiver ist. Die frühen Spektren 0.6 ps nach Anregung zeigen ein ausgeprägtes Grundzustandsbleichen im Bereich der $C^{H} X^{H} Y^{H}$ - bzw. $T^{H} X^{H} Y^{H}$-Absorption, überlagert mit Absorption des angeregten Zustands mit einem Maximum bei $430 \mathrm{~nm}$. Das breite negative Signal für Wellenlängen $\lambda>480 \mathrm{~nm}$ kann stimulierter Emission des angeregten Zustands zugeordnet werden und fällt innerhalb weniger Pikosekunden ab. Für Verzögerungszeiten $\Delta t>7 \mathrm{ps}$ zeigt das gesamte transiente Spektrum $\Delta \mathrm{OD}>0$, abgesehen vom gebleichten Grundzustand, der auch nach $109 \mathrm{ps}$ noch nicht vollständig repopuliert ist.

Die zeitliche Entwicklung der beiden Spektren kann für jede Wellenlänge mit einem triexponentiellen Abfall mit den Zeitkonstanten $\tau_{1}=(0.9 \pm 0.1) \mathrm{ps,}$ $\tau_{2}=(8.7 \pm 1.5)$ ps und $\tau_{3}=(240 \pm 50)$ ps angepasst werden. Die wellenlängenabhängigen Amplituden dieser Anpassung sind in Abb. 3.17a und 3.17b gezeigt. Bemerkenswert ist, dass es im Vergleich zu den transienten Spektren der $C^{H}$-Spezies bei $\mathrm{pH} 7$ oder 10 keinen ESPT zu geben scheint. Während die Spektren zu frühen Zeiten der $C^{H *}$-Spezies aus Abb. 3.13c ähneln, entwickelt sich hier kein definiertes Emissionsspektrum. Die anfängliche, breite Emission verschwindet und geht in einen oder mehrere Zustände mit sehr breiter Absorption über. Das gesamte Spektrum entwickelt sich triexponentiell, auch der Grundzustand wird mit drei Zeitkonstanten repopuliert, was zusammen mit der relativ geringen spektralen Änderung auf eine Abfolge von Umorganisationen der Chromophorumgebung hindeutet, die letztlich wieder zum Ausgangszustand führt. Während bei $C^{H+}$ eine Mischung verschiedener Zustände vorliegt, gibt es bei den herrschenden Bedingungen nur eine trans-Spezies. Die Interprätation der gemessenen Spektren als Summe der Beiträge von Spezies mit unterschiedlichen Umgebungen nach Abb. 3.3 scheidet demnach aufgrund der starken Ähnlichkeit der transienten Spektren der cis- und trans-Spezies aus.

Winkler et al. [14] berichteten nach Anregung der A-Bande von GFP mit UV-Licht von einem schnellen, multiexponentiellen Abfall, aber auch einer langlebigen Komponente mit einer Lebensdauer um 200 ps. Sie postulierten 


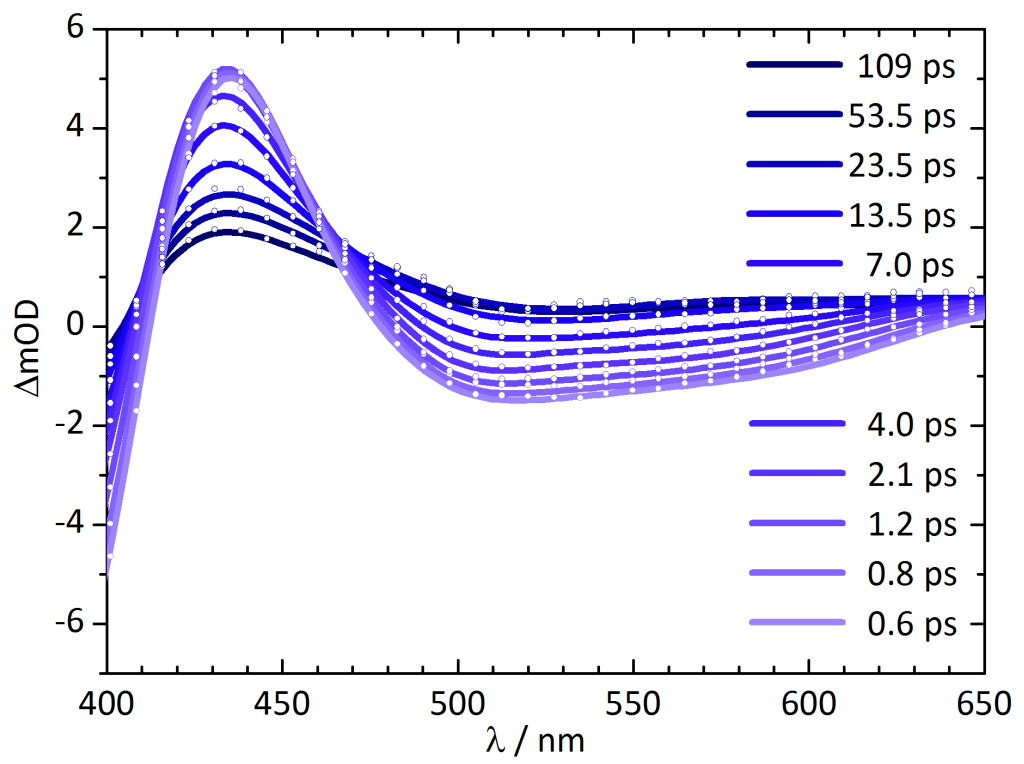

(a) cis-Isomer. $\circ$ : aufgenommene Daten, / : Anpassung durch das kinetische Modell in Fig $3.18 \mathrm{a}$

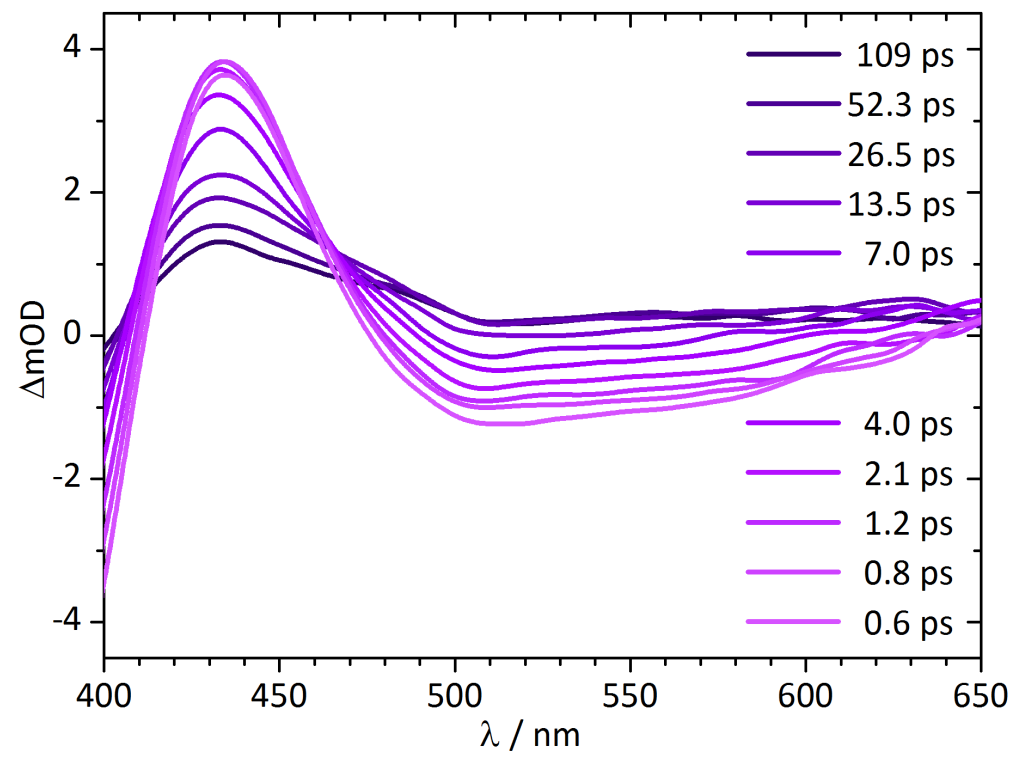

(b) trans-Isomer, aufgenommene Daten

Abb. 3.16: Transiente Spektren von Padron 0.9 bei $\mathrm{pH} 4$ nach Anregung bei $387 \mathrm{~nm}$ bei verschiedenen Verzögerungszeiten 
einen ESPT über eine Barriere in Konkurrenz mit IC aus einem schwingungsheißen angeregten Zustand. Nach Abkühlen sollte die Barriere für den ESPT zu hoch sein und der kalte angeregte Zustand langsam via IC in den Grunzustand übergehen. Ein ähnliches Modell eines schwingungsheißen Zustandes $C^{H+*}$, der allerdings nie die Barriere für einen ESPT überwindet, abkühlt und in einem langlebigen angeregten Zustand verbleibt, könnte die hier gezeigten Spezies ebenso erklären wie ein Modell mehrerer konsekutiver angeregter Spezies. Auf eine entsprechende Modellierung wurde hier jedoch verzichtet, da es keine weiteren Hinweise gibt, das Modell sehr komplex und eine Anpassung vermutlich nicht belastbar wäre.

Für das isolierte GFP-Chromophor $p$-HBDI (siehe Abschnitt 1.2) postulierten Vengris et al. die Bildung eines langlebigen Radikals und solvatisierten Elektrons durch Zweiphotonen-Absorption mit ähnlichen spektralen Eigenschaften [34]; einer zum GSB rotverschobenen Absorptionsbande, die sie dem Radikal zuordneten, sowie einer breiten Absorptionsbande des Elektrons im Bereich von $650 \mathrm{~nm}$. Die im betrachteten Zeitfenster von $100 \mathrm{ps}$ nicht abklingende, schmale Absorptionsbande bei $430 \mathrm{~nm}$, sowie die breite Absorptionsbande auf dem gesamten Wellenlängenbereich $\lambda>500 \mathrm{~nm}$, die bis $650 \mathrm{~nm}$ ansteigt, können also zu einem Radikal und einem freien Elektron gehören. Das gesamte Spektrum wäre dann eine Überlagerung der Anregungsprodukte von Ein- und Zweiphotonenabsorption.

Die Ähnlichkeit der hier gezeigten Spektren für späte Zeiten und den Befunden von Vengris et al. ist groß, so dass eine Anpassung der Daten an ein entsprechendes Modell versucht wurde. Wird durch einen ZweiphotonenProzess ein Radikal und ein freies Elektron erzeugt, können sie entweder mit $k_{\text {rek }}$ rekombinieren oder das Elektron diffundiert mit $k_{\text {diff }}$ vom Radikal weg. Der Kehrwert der Summe der Geschwindigkeiten wird der langen Lebensdauer $\tau_{3}=\left(k_{\text {diff }}+k_{\text {rek }}\right)^{-1}$ zugeordnet. Die schnelle Zeitkonstante $\tau_{1}$ wird die Depopulation der initial angeregten Spezies $C^{H+*}$ durch innere Konversion nach $\mathrm{C}^{H+}$ mit $k_{i} c$ und einer Relaxation im angeregten Zustand mit $k_{r}$ nach $C_{r}^{H+*}$ beschreiben, $\tau_{2}$ schließlich wird dem geschwindigkeitsbestimmenden Schritt $k_{i c 2}=\tau_{2}^{-1}$ der Depopulation von $C_{r}^{H+*}$ und Repopulation von $C^{H+}$ zugeordnet. Das entsprechende kinetische Modell mit den ermittelten Geschwindigkeitskonstanten ist in Abb. 3.18a dargestellt. Der zeitliche Verlauf der Konzentration der beteiligten Spezies, sowie ihre Spektren sind in Abb. 3.18b und 3.18c abgebildet. Die Anpassung der Daten für Abb. 3.16a sind dort als durchgezogene Linien enthalten.

Unabhängig vom gewählten Modell lassen die starke Ähnlichkeit der transienten Spektren und auch die spektrale Ähnlichkeit der Grundzustände $C^{H+}$ 


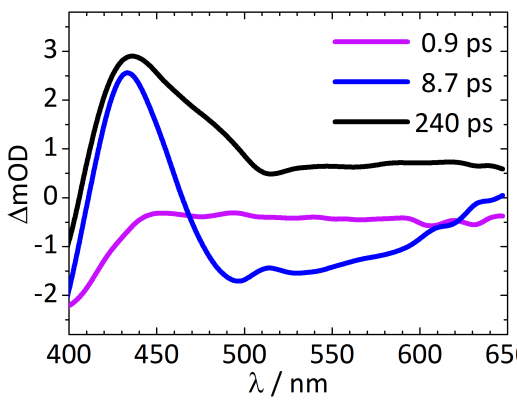

(a) cis-Isomer

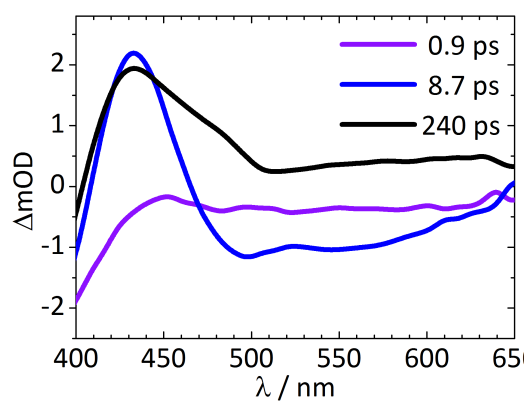

(b) trans-isomer

Abb. 3.17: Amplitudenspektren der exponentiellen Anpassung der transienten Daten von Padron0.9 bei $\mathrm{pH} 4$ nach Anregung bei $387 \mathrm{~nm}$.

und $T^{H+}$ (siehe Abb. $3.4 \mathrm{c}$ und d vermuten, dass sich die Strukturen des cis- und trans-Chromophors bei niedrigen $\mathrm{pH}-W e r t e n$ annähern. Allerdings bleiben geringe spektrale Unterschiede, namentlich die unterschiedlichen Amplituden sowohl der Grundzustand- als auch der transienten Spektren, sowie die in Abb. 3.2 gezeigte Tatsache, dass sich die beiden Isomere durch Absenken und erneutes anheben des $\mathrm{pH}$-Wertes nicht ineinander überführen lassen. Dies belegt eindeutig, dass es sich bei $C^{H+}$ und $T^{H+}$ um verschiedene Spezies handelt. 


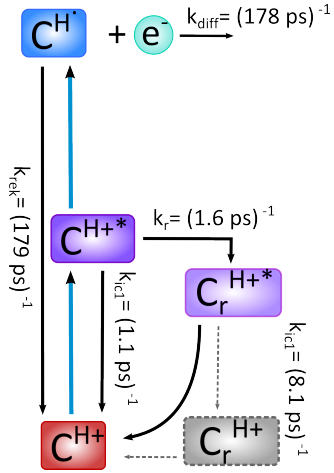

(a) Kinetisches Modell zur Anpassung der Daten in Fig 3.16

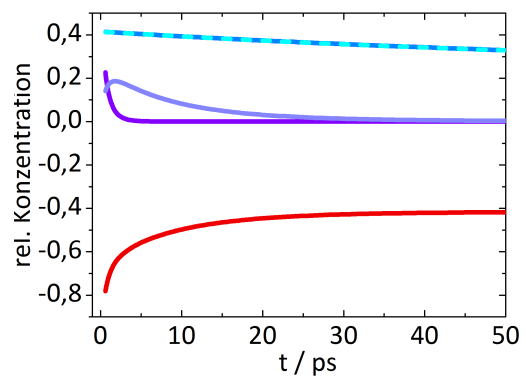

(b) Konzentrationsverlauf der Spezies ausa

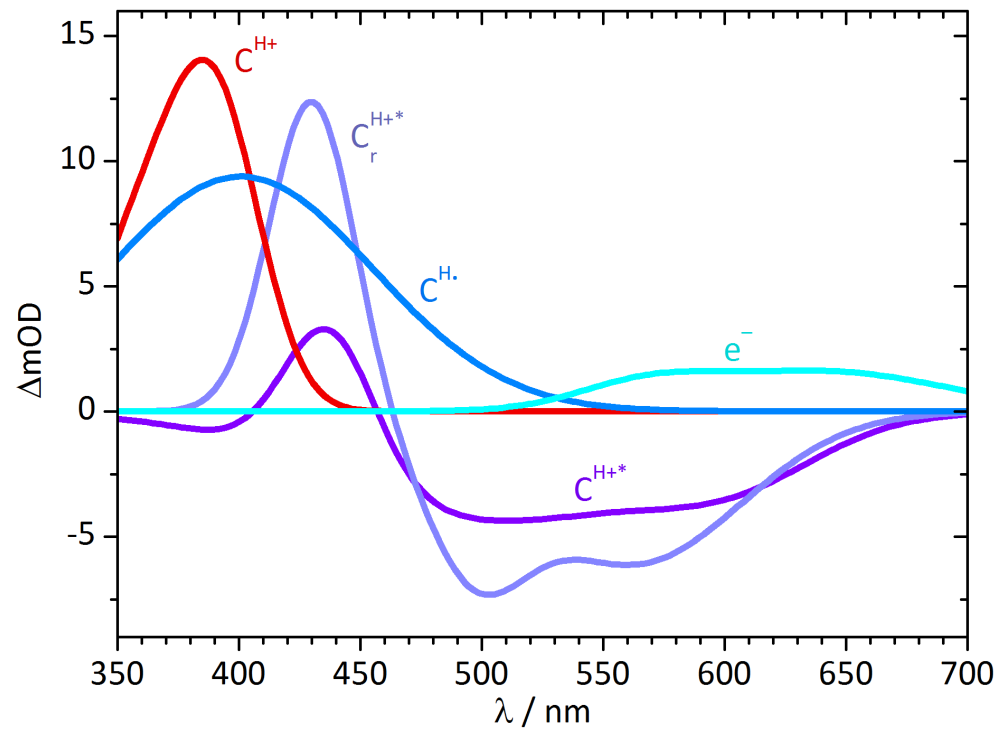

(c) Spektren der Spezies aus a

Abb. 3.18: Modell der photoinduzierten Dynamik von Padron0.9 nach Anregung der $C^{H+}$-Spezies durch $\lambda_{p}=387 \mathrm{~nm}$, zeitabhängige Konzentrationen der beteiligten Spezies und ihre Absorptionsspektren 


\section{2 rsFastLime}

\subsubsection{Grundzustände}

Das Chromophor von rsFastlime ist identisch mit dem von Padron0.9 und kann entsprechend cis- unnd trans-Kofiguration annehmen, wobei hier das cis-Isomer die stabilere Konfiguration darstellt und das trans-Isomer innerhalb von Minuten in die cis-Form isomerisiert. Analog zu Padron0.9 sind die Absorptionsspektren, dargestellt in Abb. 3.19, stark $\mathrm{pH}$-abhängig und zeigen die typischen Banden des protonierten $\left(\mathrm{C}^{\mathrm{H}}\right)$ und deprotonierten $\left(\mathrm{C}^{-}\right)$ Chromophors, deren Maxima für das cis-Isomer bei 391 und $496 \mathrm{~nm}$ liegen. Das Maximum des protonierten trans-Isomer liegt bei $384 \mathrm{~nm}$. Ob die in Abb. $3.19 \mathrm{~b}$ gezeigte Absorption mit dem Maximum bei $496 \mathrm{~nm}$ tatsächlich vom trans- oder von verbleibendem cis-Isomer stammt, ist unklar. Die $\mathrm{pH}-$ abhängigen Absorptionsspektren des cis-Isomers zeigen im Bereich von $\mathrm{pH}$ 5-10 ein Protonierungsgleichgewicht zwischen $C^{H}$ und $C^{-}$mit einem isosbestischen Punkt bei $430 \mathrm{~nm}$. Wie bei Padron0.9 bleibt die $C^{H}$-Bande auch bei hohen $\mathrm{pH}$-Werten bestehen und das Absorptionsmaximum verschiebt bei $\mathrm{pH}<5$ blau.

Für das trans-Isomer wurde nur ein Absorptionsspektrum bei $\mathrm{pH} 10$ (siehe Abb. 3.19b aufgenommen, da die Messung aufgrund der schnellen Rückisomerisierung schwierig ist und weitere Spektren für die folgende Auswertung nicht relevant sind. Selbst bei pH 10 existiert vornehmlich die protonierte Spezies $T^{H}$.

Die pH-abhängigen Absorptionsspektren des cis-Isomers in Abb. 3.19a wurden analog zu Padron0.9 mit zwei protonierenden Gruppen $X$ und $Y$ in unmittelbarer Chromophorumgebung angepasst. Das Modell mit den ermittelten Gleichgewichtskonstanten ist in Abb. 3.20 dargestellt. Spezies mit gleichen Spektren sind mit der gleichen Farbe unterlegt. Die Spektren der einzelnen Spezies wurden mit einer Summe von Gauß-Funktionen angepasst und sind in Abb. 3.21b dargestellt, die relativen Konzentrationen der Spezies sind in $\mathrm{Abb}$. $3.21 \mathrm{a} \mathrm{pH}$-abhängig aufgetragen. Die modellierten $\mathrm{pH}$ abhängigen Absorptionsspektren sind als durchgezogene Linien in Abb. 3.19a gezeigt. Das trans-Absorptionsspektrum wurde mit einer Summe von Gauß-Funktionen angepasst (Abb. 3.19b, durchgezogene Linie). Mit den Annahmen, dass die Isomerisierung vollständig war und die Absorptionsbande bei $496 \mathrm{~nm}$ tatsächlich der $T^{-}$-Spezies zuzuordnen ist und dass die Verhältnisse der Absorptionsmaxima von protonierter und unprotonierter Spezies bei beiden Isomeren gleich sind (Gl. 3.12), wurde das Spektrum der 


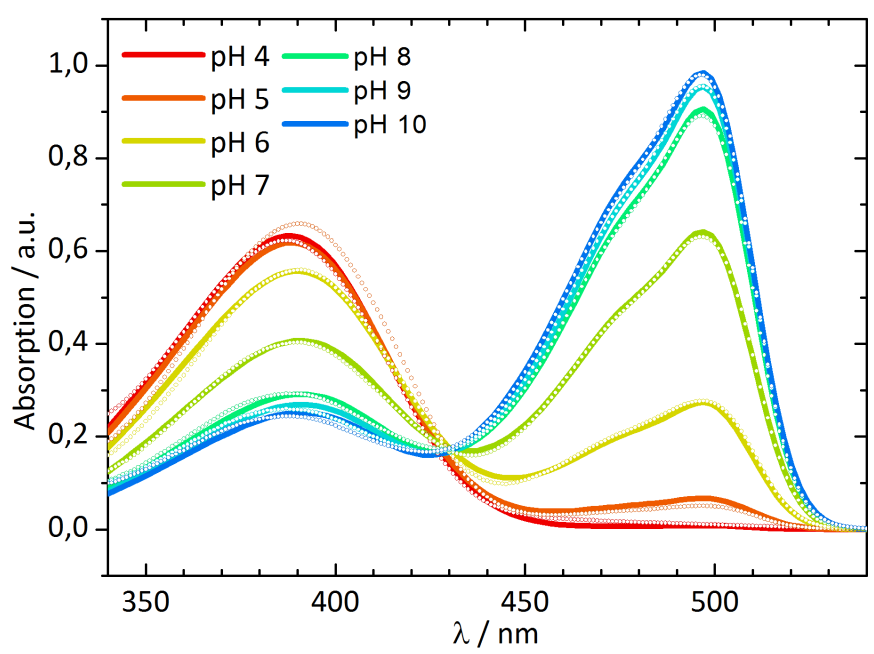

(a) cis-Isomer

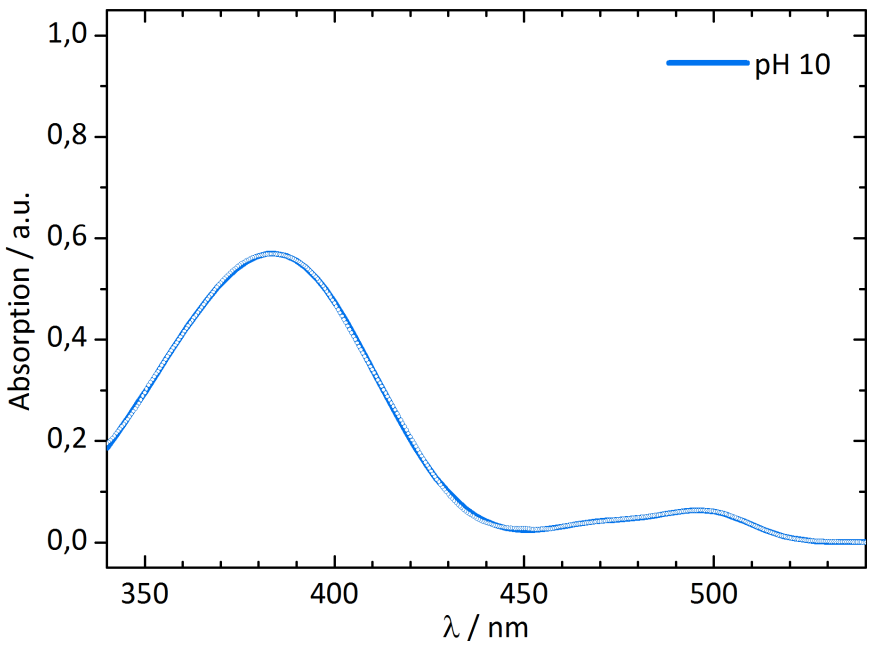

(b) trans-Isomer

Abb. 3.19: $\mathrm{pH}$-abhängige Absorptionsspektren von rsFastlime. Gemessene Spektren sind als offene Kreise dargestellt, die durchgezogenen Linien sind Anpassungen der gemessenen Spektren nach dem Modell 3.9a Die Spektren sind auf einen Absorptionspeak der Proteinumgebung bei $290 \mathrm{~nm}$ normiert. 
$T^{H}$-Spezies errechnet, es wird in Abb $3.21 \mathrm{c}$ gezeigt.

$$
\frac{\epsilon_{\max }\left(T^{-}\right)}{\epsilon_{\max }\left(C^{-}\right)}=\frac{\epsilon_{\max }\left(T^{H)}\right.}{\epsilon_{\max }\left(C^{H)}\right.}
$$

Bei pH 10 liegt trans-rsFastlime demnach immer noch zu 95\% in der protonierten Form vor.

\subsubsection{Angeregter Zustand von $C^{-}$}

\subsubsection{Fluoreszenz und stimulierte Emission}

Im Gegensatz zu Padron0.9 emittiert rsFastlime nahezu ausschließlich nach Anregung der deprotonierten cis-Spezies $C^{-}$. Das Fluoreszenzspektrum bei pH 7 und Anregung bei $500 \mathrm{~nm}$ ist in Abb. 3.22 als blaue Kreise dargestellt und kann durch die Summe dreier Gaußkurven beschrieben werden (blaue Linie). Aus dem Fluoreszenzspektrum wurde nach G1. 3.2 das stimulierte Emissionsspektrum berechnet. Es ist in Abb. 3.22 als rote Kreise dargestellt und wurde ebenfalls mit drei Gaußkurven angepasst (rote Linie). Das resultierende Emissionsspektrum der deprotonierten cis-Spezies ist in Tab A.6 beschrieben und wird im Weiteren $C_{e m}^{-*}$ genannt.

\subsubsection{Transiente Spektren}

Die transiente Dynamik des Zustands $C^{-}$wurde mittels Pump-Probe-Spektroskopie bei pH 7 untersucht. Nach Abb. 3.21b und 3.21c werden bei der gewählten Anregungswellenlänge von $\lambda_{p}=500 \mathrm{~nm}$ ausschließlich deprotonierte Spezies angeregt. Nach Abb. 3.21a handelt es sich bei dem cis-Isomer um eine Mischung von $80 \% C^{-} X^{H} Y^{-}$und $20 \% C^{-} X^{H} Y^{H}$. Das Absorptionsspektrum des trans-Isomers in Abb. $3.19 \mathrm{~b}$ zeigt selbst bei hohem $\mathrm{pH}$-Wert nur eine geringe Absorption im Bereich um $500 \mathrm{~nm}$. Ob es sich dabei tatsächlich um $T^{-}$oder Reste von $C^{-}$im dynamischen Gleichgewicht handelt, ist unklar.

Die transienten Spektren für $C^{-}$und $T^{-}$zu verschiedenen Verzögerungszeiten bei pH 7 und $\lambda_{p}=500 \mathrm{~nm}$ sind in $\mathrm{Abb}$. 3.23a und bals offene Kreise dargestell. Die beiden Messungen erfolgten direkt hintereinander ohne Änderung der experimentellen Parameter mit derselben Proteinlösung. Zur Überführung in das jeweils erwünschte Isomer wurde die Lösung vor und während der ersten Messungen mit einer LED bei $400 \mathrm{~nm}$ und vor und 


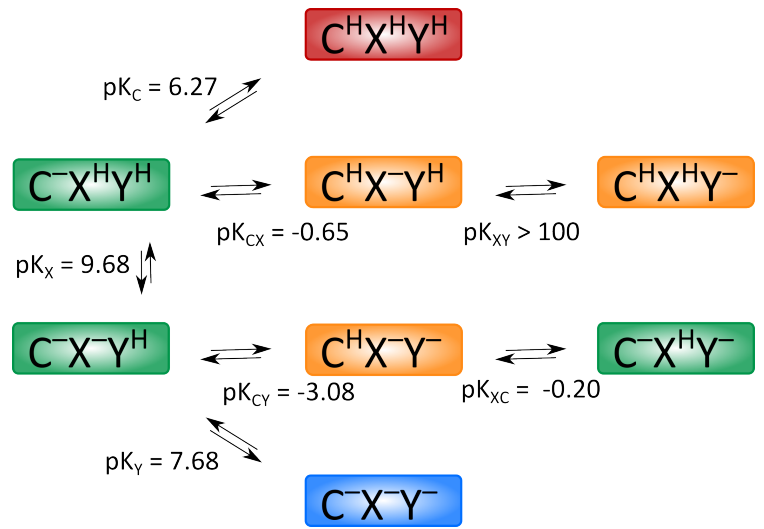

Abb. 3.20: Modell der Protonierung des Chromophors $C$ von rsFastlime mit zwei protonierenden Gruppen $X$ und $Y$ in unmittelbarer Umgebung. Spezies mit identischen Absorptionsspektren sind mit der gleichen Farbe unterlegt. Die pK-Werte aus der Anpassung der Absorptionsspektren für das cis-Isomer sind angegeben.

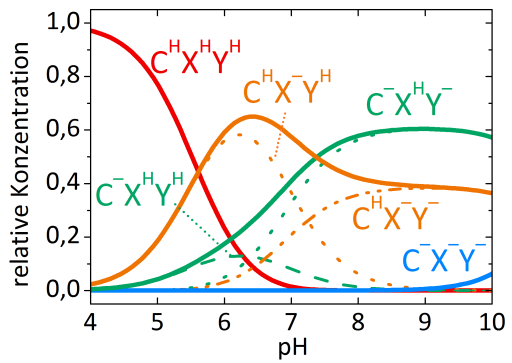

(a) Spezies cis-Isomer

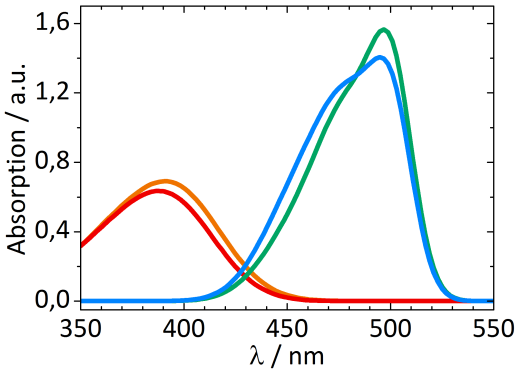

(b) Speziesspektren cis-Isomer

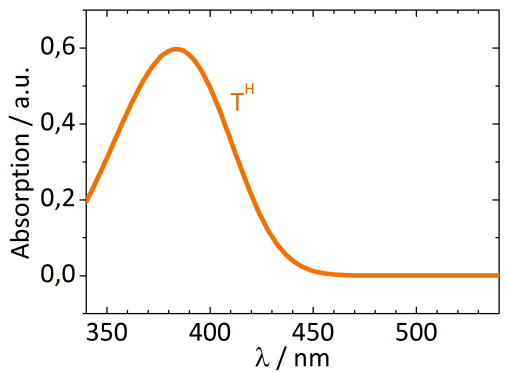

(c) Speziesspektren trans-Isomer

Abb. 3.21: Modell des Protonierungsgleichgewichtes von rsFastlime, $\mathrm{pH}$-abhängige Konzentrationen und ihre Absorptionsspektren 


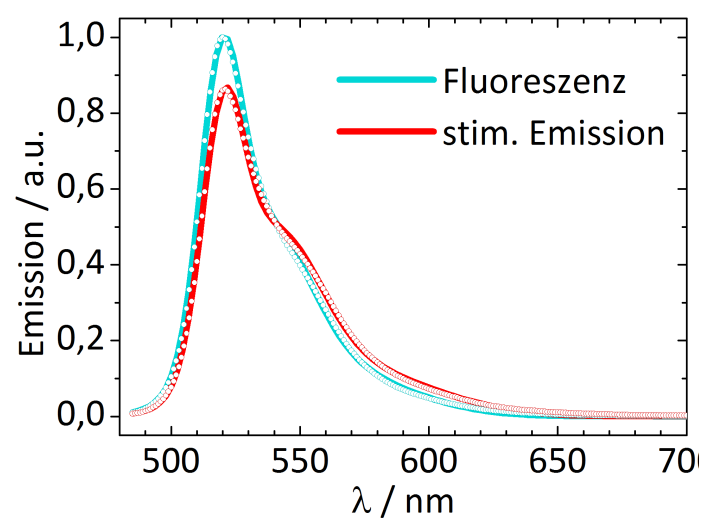

Abb. 3.22: Fluoreszenz- und stimuliertes Emisssionsspektrum nach Gl. $3.2, \lambda_{p}=$ $500 \mathrm{~nm}, \mathrm{pH} 7$

während der zweiten Messung bei $495 \mathrm{~nm}$ bestrahlt. Die Spektren sind also bezüglich Pumpintensität, Konzentration und Überlapp direkt vergleichbar (siehe 2.3.

Es fällt auf, dass beide Messungen nahezu identische Signale zeigen, die zweite Messung in Abb. 3.23a gegenüber der ersten in Abb. 3.23b aber etwa $45 \%$ an Intensität eingebüßt hat. Die Spektren zeigen transiente Absorption im Bereich 390 - 460 nm, überlagert von einem gebleichten Grundzustand im Bereich der $C^{-}$-Absorption und einer ausgeprägten stimulierten Emission im Bereich 520 - $630 \mathrm{~nm}$ mit deutlicher Schulter bei $550 \mathrm{~nm}$. Die Signale beider Messungen fallen monoexponentiell mit $\tau=(0.9 \pm 0.1) \mathrm{ns}$ ab, die wellenlängenabhängigen Amplituden der exponentiellen Anpassung sind in Abb. 3.24a und b gezeigt. Die praktisch identischen Spektren und der Abfall der Intensität durch Bestrahlung bei $495 \mathrm{~nm}$ zeigen, dass beide aufgenommenen Datensätze der $C^{-}$-Spezies zugeordnet werden müssen. Es ist mit dem verwendeten Aufbau nicht gelungen, das cis-Isomer vollständig in die instabile trans-Form zu überführen. Die Daten legen vielmehr eine Umwandlung von 45 \% nahe. Die 45 \% Protein in trans-Konformation liegen hauptsächlich protoniert vor und tragen offenbar nicht zum Signal bei. Die gemessene Zeitkonstante für den monoexponentiellen Abfall der Spektrenintensität kann somit direkt dem angeregten Zustand $C^{-*}$ zugeordnet werden, der mit $k_{C}=\tau^{-1}$ in den Grundzustand $C^{-}$zurückfällt. 


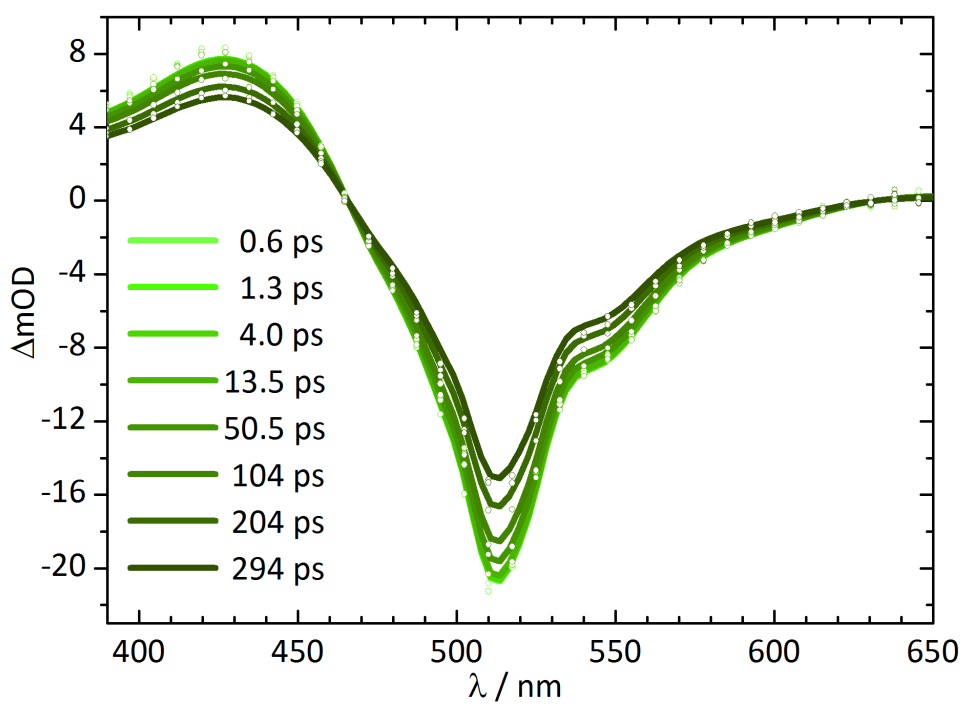

(a) cis-Isomer rsFastlime

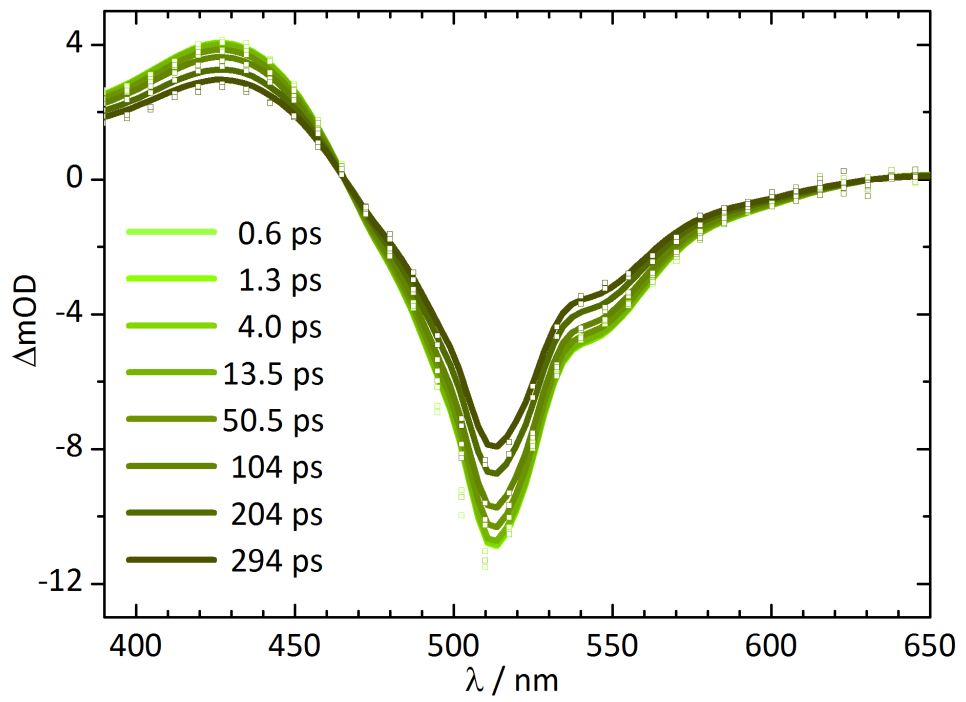

(b) trans-Isomer rsFastlime

Abb. 3.23: Transiente Spektren von rsFastlime bei $\mathrm{pH} 7$ nach Anregung bei $505 \mathrm{~nm}$ bei verschiedenen Verzögerungszeiten. $\circ$ : aufgenommene Daten, / : Anpassung durch 2-Zustandsmodell. 


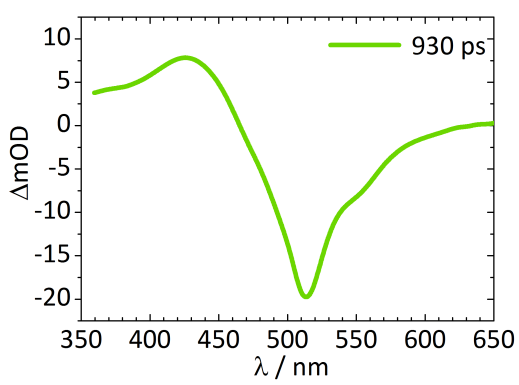

(a) cis-Isomer

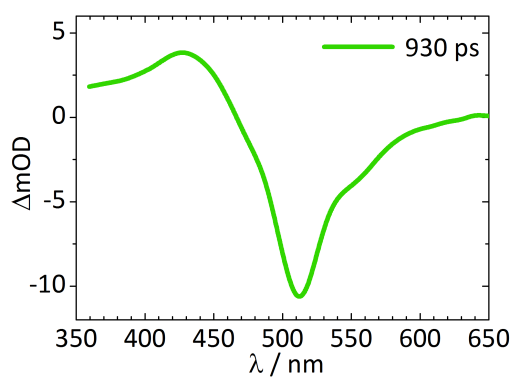

(b) trans-Isomer

Abb. 3.24: Amplitudenspektren der exponentiellen Anpassung der transienten Daten von rsFastlime bei pH 7 nach Anregung bei 505 nm.

\subsubsection{Anpassung der Daten}

Die transienten Daten in Abb. 3.23a und b w w wrden simultan global mit einem einfachen kinetischen Modell mit zwei Zuständen, $C^{-*}$ und $C^{-}$, und der Übergangsrate $k_{C}$ angepasst. Für die Daten der partiell zum trans-Isomer überführten Lösung in Abb. $3.23 \mathrm{~b}$ wurde ein Konzentrationsfaktor verwendet, der den Anteil des cis-Isomers und somit die Schalteffizienz in der Lösung angibt. Zur Beschreibung der Zustände wurde das aus Abb. 3.21b bekannte Spektrum der Grundzustandsspezies $C^{-}$verwendet. $C^{-*}$ wurde als Überlagerung je dreier gaussförmiger Absorptionsbanden und des bekannten stimulierten Emissionsspektrums $C_{e m}^{-*}$ angepasst. Zusätzlich wurde im Überlappbereich des Absorptions- und Emissionsspektrums eine weitere Bande angepasst, die die Emission um Reabsorption des emittierten Lichtes durch Grundzustandsmoleküle bei der Messung des Fluoreszenzspektrums korrigiert.

\subsubsection{Ergebnisse}

Der aus der Anpassung der Daten von Abb 3.23a mit einem Modell aus zwei Zuständen resultierende Geschwindigkeitskoeffizient ist $k_{C}=(0.9 \mathrm{~ns})^{-1}$. Die Spektren der einzelnen Spezies, einschließlich der Korrekturbande zur Reabsorption (hellblau), sind in Abb. $3.25 \mathrm{zu}$ sehen. Mit der Annahme, dass die Proteinlösung in Abb. 3.23a vollständig aus cis-Isomeren bestand, wurde der Anteil des cis-Isomers nach LED-Bestrahlung bei $490 \mathrm{~nm}$ auf $47 \%$ bestimmt; 53 \%der Chromophore konnten in die trans-Form überführt werden. Abb. 


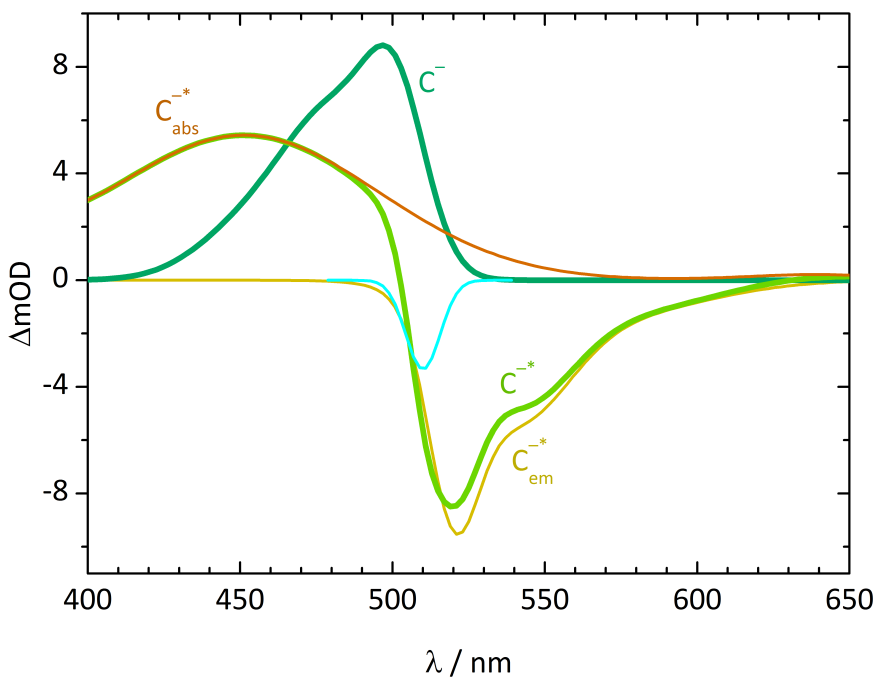

Abb. 3.25: Spektren der an der photoinduzierten Dynamik von rsFastlime nach Anregung der $C^{-}$-Spezies bei $\lambda_{p}=505 \mathrm{~nm}$ beteiligten Spezies

3.23 zeigt das Signal des deprotonierten Anteils der verbleibenden $53 \%$ des cis-Isomers.

Im Rahmen der Messungen wurde keine Isomerisierung $C^{-} \longrightarrow T^{-}$durch Anregung beobachtet. Die Schalteffizienz von Dronpa ist nach Anregung bei $505 \mathrm{~nm}$ mit $\Phi_{\text {cis }} \longrightarrow$ trans $(505 \mathrm{~nm})=0.0003$ äusserst niedrig [28]. Die Quantenausbeute des entsprechenden Prozesses von rsFastLime wurde bisher nicht bestimmt. Die von Andresen et al. gezeigte, um Faktor 50 schnellere Schaltzeit [32] lässt einen entsprechend effizienteren Prozess vermuten, was immer noch einer Quantenausbeute von $\Phi_{\text {cis }} \longrightarrow$ trans $<0.02$ entspricht. Ein Beitrag von $2 \% T^{H}$ als Schaltprodukt, das spektral von dem ohnehin vorhandenen $C^{H}$ praktisch nicht zu unterscheiden ist und aus einem so langlebigen Zustand wie $C^{-*}$ stammt, ist mit diesem Experiment nicht aufzulösen.

\subsubsection{Angeregte Zustände von $C^{H}$ und $T^{H}$}

Die transiente Dynamik der Zustände $C^{H}$ und $T^{H}$ wurden mittels PumpProbe-Spektroskopie durch Anregung bei $\lambda_{p}=387 \mathrm{~nm}$ bei $\mathrm{pH} 7$ untersucht. 
Das trans-Isomer liegt bei diesem pH-Wert vollständig protoniert vor, während das cis-Isomer nach $\mathrm{Abb}$. 3.21a im Gleichgewicht aus $40 \% \mathrm{C}^{H} \mathrm{X}^{-} Y^{H}$, $20 \% C^{H} X^{-} Y^{-}, 35 \% C^{-} X^{H} Y^{-}$und $5 \% C^{-} X^{H} Y^{H}$ vorliegt. Nach den $\mathrm{Ab}$ sorptionsspektren der einzelnen Spezies in Abb. $3.21 \mathrm{~b}$ werden bei $\lambda_{p}=$ $387 \mathrm{~nm}$ nur die protonierten $\mathrm{C}^{\mathrm{H}}$-Spezies angeregt.

\subsubsection{Transiente Spektren}

Die aufgenommenen transienten Spektren von $C^{H}$ und $T^{H}$ bei pH 7 und $387 \mathrm{~nm}$ Anregungswellenlänge sind in Abb. 3.26a und bals offene Kreise dargestellt. Die Messung von $C^{H}$ und $T^{H}$ erfolgte direkt nacheinander ohne Änderung der experimentellen Parameter mit derselben Proteinlösung. Zur Überführung in das jeweilige Isomer wurde die Lösung vor und während der ersten Messung mit einer LED bei $400 \mathrm{~nm}$ und vor und während der zweiten Messung mit $495 \mathrm{~nm}$ bestrahlt.

Kurz nach Anregung zeigt das transiente $C^{H}$-Spektrum ein schwach negatives Signal für Wellenlängen $<410 \mathrm{~nm}$, das dem GSB zugeordnet werden kann. Im Bereich von 410 - $460 \mathrm{~nm}$ ist das Signal positiv mit einem Maximum bei $430 \mathrm{~nm}$, für $\lambda>460 \mathrm{~nm}$ wird es wieder negativ mit einem Minimum bei $500 \mathrm{~nm}$ und einer leichten Schulter bei $550 \mathrm{~nm}$. Während der GSB und die transiente Absorption bei $430 \mathrm{~nm}$ im beobachteten Zeitraum stark abfallen, ändert sich die Intensität im Bereich der Emission kaum. Hier erfährt das Maximum eine Rotverschiebung um etwa $10 \mathrm{~nm}$ und das Signal wird insgesamt etwas schmaler, wodurch die Schulter bei $540 \mathrm{~nm}$ deutlicher hervortritt.

Das Spektrum wurde wellenlängenabhängig mit einem biexponentiellen Abfall mit den Zeitkonstanten $\tau_{c 1}=(6.6 \pm 0.6)$ ps und $\tau_{c 2}=(187 \pm 30) \mathrm{ps}$ angepasst, die wellenlängenabhängigen Amplituden sind in Abb. 3.27a dargestellt. $\tau_{c 1}$ hat einen negativen Beitrag im Bereich $\lambda<420 \mathrm{~nm}$, was der Repopulation des gebleichten Grundzustandes zugeschrieben werden kann und zeigt positive Amplituden im Bereich der transienten Absorption um $430 \mathrm{~nm}$. Außerdem ist ein negativer Beitrag bei 480 und ein positiver bei $510 \mathrm{~nm}$ zu sehen, was die Rotverschiebung und das Anwachsen des Emissionsmaximums beschreibt. Der Beitrag der langsamen Komponente $\tau_{c 2}$ ist positiv im Bereich $\lambda<460 \mathrm{~nm}$, für größere Wellenlängen ist er negativ mit einem Minimum bei $507 \mathrm{~nm}$ und einer Schulter bei $540 \mathrm{~nm}$.

Das transiente Spektrum von $T^{H}$ in Abb. 3.26 zeigt einen im Vergleich zu $C^{H}$ deutlich ausgeprägteren GSB unter $410 \mathrm{~nm}$, der im beobachteten Zeitbereich nicht vollständig wieder aufgefüllt wird. Im Bereich von 410 $470 \mathrm{~nm}$ zeigt das Spektrum eine schnell abfallende transiente Absorption, für 


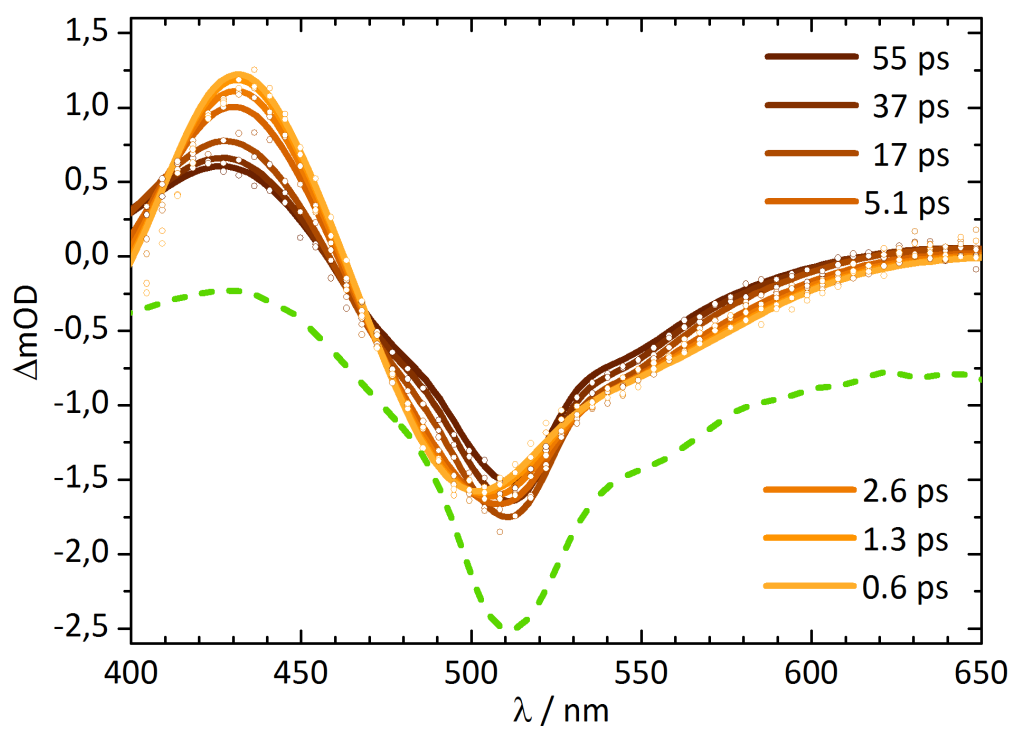

(a) cis-Isomer rsFastlime

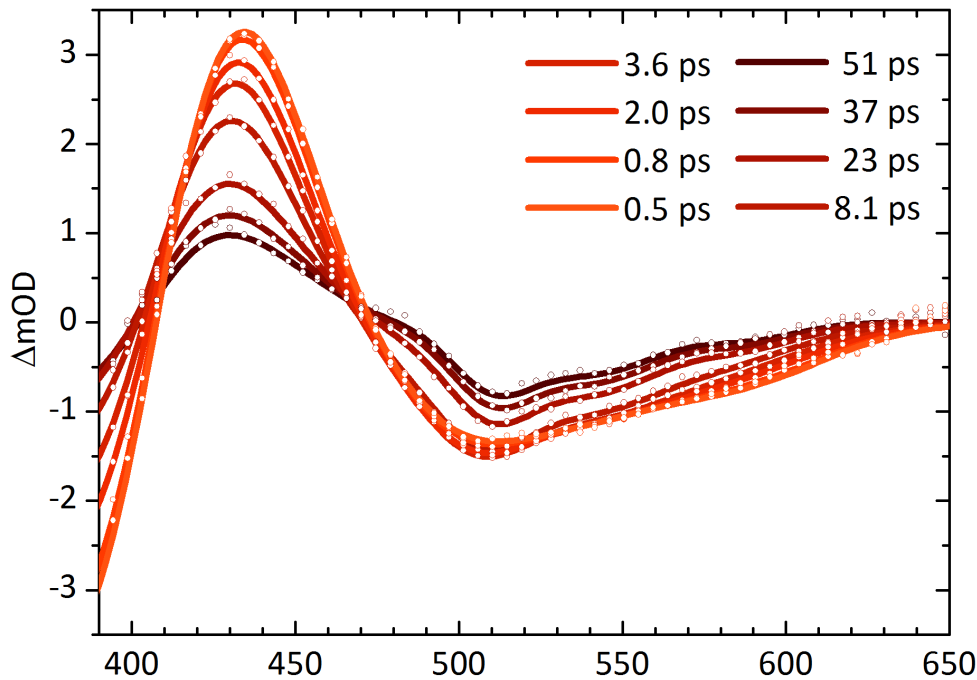

(b) trans-Isomer rsFastlime

Abb. 3.26: Transiente Spektren von rsFastlime bei $\mathrm{pH} 7$ nach Anregung bei $387 \mathrm{~nm}$ bei verschiedenen Verzögerungszeiten. $\circ$ : aufgenommenen Daten, / : Anpassung durch die kinetischen Modelle in Abb. 3.28a und 3.29a 


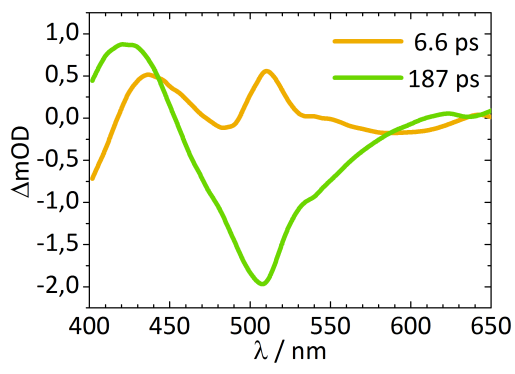

(a) cis-Isomer rsFastlime

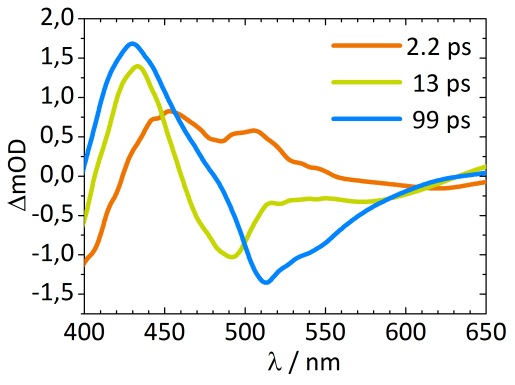

(b) trans-Isomer rsFastlime

Abb. 3.27: Amplitudenspektren

Wellenlängen über $470 \mathrm{~nm}$ ist ist eine breite, langsam abfallende Emission zu sehen, die zu späteren Zeiten eine schwache Bandenstruktur entwickelt. Fron et al. beschrieben zur Anpassung der Dynamik des Photoschaltprodukts von Dronpa bei pH 8, der $T^{H}$-Spezies, fünf Zeitkonstanten: 2, 13, 90 sowie zusätzlich 4 und 700 ps [30]. Die 4 ps ordneten sie einem ESPT zu. Die transienten Spektren der $T^{\bar{H}}$-Spezies von rsFastLime wurden mit sehr gutem Ergebnis mit einem triexponentiellen Abfall mit den Zeitkonstanten $\tau_{t 1}=$ $(2.2 \pm 0.2) \mathrm{ps}, \tau_{t 2}=(13 \pm 1)$ ps und $\tau_{t 3}=(99 \pm 9)$ ps angepasst, die wellenlängenabhängigen Amplituden dieser Anpassung sind in Abb. $3.27 b$ dargestellt. Der GSB wird biexponentiell mit den schnellen Zeitkonstanten $\tau_{t 1}$ und $\tau_{t 2}$ aufgefüllt, die transiente Absorption fällt triexponentiell ab. Die zunächst breite Emission wächst mit $\tau_{t 1}$, fällt dann hauptsächlich auf der blauen Flanke mit $\tau_{t 2}$ ab, um schließlich mit $\tau_{t 3}$ langsam zu verschwinden.

\subsubsection{Aufstellen des kinetischen Modells für $C^{H}$}

Die frühe Dynamik nach Anregung von $C^{H}$ wird durch die schnelle Depopulation des initial angeregten Zustandes $C^{H *}$ bei gleichzeitiger Repopulation des Grundzustandes beschrieben, während sich das Emissionsspektrum mit der gleichen Zeitkonstante ändert. Neben dieser schnellen Dynamik existiert eine langlebige Komponente. Es kann von zwei konkurrierenden Prozessen aus dem angeregten Zustand $C^{H *}$ ausgegangen werden, von denen einer innere Konversion mit $k_{i c}$ in den Grundzustand ist, während der andere mit $k_{H}$ in einen anderen angeregten Zustand führt, der dann langsam depopuliert wird. Die parallele Reaktion zweier initial angeregter Spezies, von denen eine kurz- und die andere langlebig ist, wie von Thor et al. für GFP 
postuliert [15], kann die spektrale Entwicklung im Bereich der Emission nicht erklären, deren Intensität nur wenig abfällt und im Maximum sogar ansteigt.

Die Ähnlichkeit des transienten Spektrums von $C^{H}$ nach 50 ps mit dem transienten Spektrum von $C^{-}$lässt eine Reaktion in Richtung $C^{-*}$ vermuten. Der negative Beitrag zwischen 460 und $500 \mathrm{~nm}$, der im transienten $C^{-}$-Spektrum von einem $C^{-}$GSB kommt, kann in diesem Fall durch ein Protonierungsgleichgewicht $\mathrm{C}^{-} \rightleftharpoons \mathrm{C}^{H}$ im Grundzustand, also effektiv eine Depopulation von $C^{-}$, entstehen. Da in diesem Bereich die Lebensdauer $\tau_{c 2}$ eine negative Amplitude zeigt, wird der angeregte Zustand, der im Bereich $\lambda>500 \mathrm{~nm}$ für den negativen Beitrag verantwortlich ist, in den cis-Grundzustand übergehen und ihn repopulieren. Die vorangegangenen Überlegungen wurden in dem kinetischen Modell in Abb. 3.28a zusammengefasst. Allerdings wird die spektrale Entwicklung hinreichend mit zwei Zeitkonstanten beschrieben, die der Depopulation von $C^{H *}$ und der Depopulation des zweiten angeregten Zustandes zugeordnet werden können. Eine eigene Zeitkonstante auf eine solche Gleichgewichtseinstellung existiert nicht. Alternativ zu dem Modell mit dem Grundzustandsgleichgewicht ist eine angeregte Spezies mit breitem, gegenüber der $C^{-}$-Spezies blauverschobenem, Emissionsspektrum denkbar, das mit $\tau_{2}$ in den Grundzustand übergeht.

\subsubsection{Ergebnisse für $C^{H}$}

Das beste Ergebnis für die Anpassung von $C^{H}$ wurde mit nur vier Zuständen erzielt; einem angeregten Zustand $C_{i}^{-*}$, der $C^{-*}$ ähnelt, aber eine sehr viel kürzere Lebensdauer hat, und einem Grundzustands-Protonierungsgleichgewicht. Ein direkter Übergang von $C_{i}^{-*}$ zu den bekannten, deprotonierten cis-Spezies $C^{-*}$ oder $C^{-}$ist in diesem Modell nicht nötig, um die Daten anzupassen. Die Gleichgewichtseinstellung im Grundzustand ist hier fast genau so schnell wie die Depopulierung von $C_{i}^{-*}$. Eine Modellierung mit drei Zuständen ohne $C^{-*}$ und Grundzustandsgleichgewicht mit $C^{-}$, bei dem der angeregte Zustand $C_{i}^{-*}$ auch unterhalb von $500 \mathrm{~nm}$ Emission zeigt, lieferte allerdings nur geringfügig schlechtere Übereinstimmung mit den Daten. $\mathrm{Ob} C_{i}^{-*}$ zunächst in einen intermediären Grundzustand konvertiert, kann nicht ermittelt werden. Die Depopulation von $C_{i}^{-*}$ scheint der geschwindigkeitsbestimmende Schritt zu sein. Bei der Modellierung ohne Grundzustandsgleichgewicht geht die Population von $C_{i}^{-*}$ ausschließlich in $C^{H}$ über. 
Die Modellierung der Daten von $C^{H}$ kommt zu keinem eindeutigen Ergebnis; beide Modelle beschreiben die Daten ähnlich gut. Die Spektren des in $\mathrm{Abb} 3.28 \mathrm{a}$ gezeigten Modells sind in Abb. 3.28c gezeigt, die relativen Konzentrationen in $\mathrm{Abb} 3.28 \mathrm{~b}$. Zweifelsfrei kann festgestellt werden, dass der primäre Prozess nach Anregung von $C^{H}$ bei beiden Modellen die innere Konversion nach $C^{H}$ ist. Etwa $14 \%$ der angeregten Moleküle gehen in den angeregten Zustand $C_{i}^{-*}$ mit einer Lebensdauer von über 200 ps über, der Emission im Bereich $\lambda>500 \mathrm{~nm}$ zeigt und damit vermutlich ein intermediärer, deprotonierter cis-Zustand ist. Das Fluoreszenzanregungsspektrum von Dronpa zeigt keinen Beitrag im Bereich der Absorption von $C^{H}|26|$, was gegen einen ESPT spricht. Allerdings führt eine Quantenausbeute von $14 \%$ mit einer Lebensdauer von 215 ps auch nur zu etwa $1 \%$ Emission, verglichen mit der berichteten Fluoreszenzlebensdauer von 3.6 ns für Dronpa.

\subsubsection{Kinetisches Modell und Ergebnisse für $T^{H}$}

Die Quantenausbeute für den Schaltprozess $\Phi_{\text {trans }} \longrightarrow$ cis $(400 \mathrm{~nm})$ ist bei Dronpa sehr hoch; Ando et al. berichteten eine Quantenausbeute von 0.37 [26]. Die Quantenausbeute des entsprechenden Prozesses von rsFastLime ist unbekannt; Aufgrund der fast identischen Schaltzeit [67] wird sie ähnlich groß sein. In einer frühen Studie schlugen Fron et al., basierend auf der Verlangsamung einer der angepassten Zeitkonstanten bei Deuterierung, einen ESPT als initialen Schritt des Photoschaltprozesses vor [30]. Warren et al. beschrieben nach der Anregung von $T^{H}$ eine angeregte Spezies $T^{H *}$, die eine Lebensdauer von 9 ps hat und mit einer Quantenausbeute von 0.3 in einen protonierten Grundzustand $C^{H}$ isomerisiert [29].

Die hier beobachtete, den GSB dominierende, kurze Zeitkonstante $\tau_{t 1}=$ 2.2 ps, die als Abfall auch im Bereich der transienten Absorption und als Anstieg im Bereich der Emission bei 500 - 550 nm liegt, deutet auf einen Konkurrenzprozess bei der Depopulation aus dem angeregten Zustand $\mathrm{C}^{H *}$ zwischen einer inneren Konversion in den Grundzustand und einem Übergang in einen anderen angeregten Zustand $I^{*}$ hin, der ebenfalls im Bereich von $430 \mathrm{~nm}$ absorbiert und im Bereich $\lambda>470 \mathrm{~nm}$ emittiert. Die Zeitkonstante $\tau_{t 2}=13$ ps beschreibt die Depopulation von $I^{*}$, der negative Beitrag von $\tau_{2}$ im Bereich des GSB deutet auf eine Konversion aus $I$ in den Grundzustand $T^{H}$ oder die Population des entsprechenden protonierten cis-Isomers $C^{H}$, die beide spektral kaum voneinander zu unterscheiden sind, hin. Hier steht der Übergang in einen Grundzustand in Konkurrenz mit einem Prozess, der in einen angeregten Zustand $I_{2}^{*}$ führt, der schließlich mit $\tau_{t 3}$ depopuliert wird. 


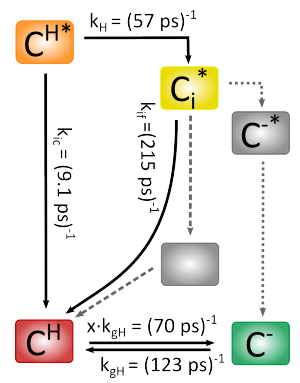

(a) Kinetisches Modell zur Anpassung der Daten in Fig 3.26 a

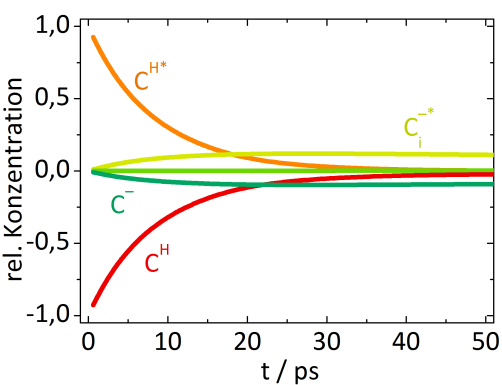

(b) Konzentrationsverlauf der Spezies ausa

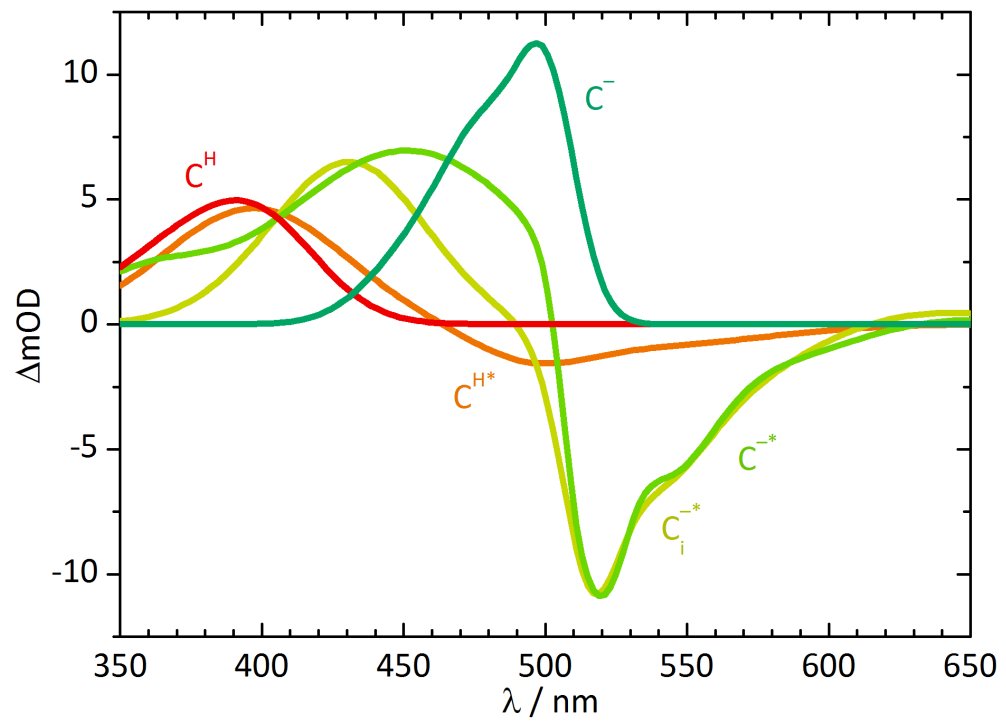

(c) Spektren der Spezies ausa

Abb. 3.28: Modell der an der photoinduzierten Dynamik von rsFastLime nach Anregung der $C^{H}$-Spezies durch $\lambda_{p}=387 \mathrm{~nm}$, zeitabhängige Konzentrationen der beteiligten Spezies und ihre Absorptionsspektren 
Der negative Beitrag von $\tau_{t 2}$ um $490 \mathrm{~nm}$ kann der Form nach entweder der Population einer intermediären deprotonierten Grundzustandsspezies mit Absorptionsmaximum bei $490 \mathrm{~nm}$ zugeordnet werden, oder der Rotverschiebung der Emission beim Übergang von $I$ nach $I_{2}^{*}$. Das aus diesen Überlegungen entstandene Modell ist in Abb. 3.29a dargestellt. In einem ersten Modellierungsversuch wurde die Depopulation von $I_{2}^{*}$, der im beobachteten Zeitrahmen nur einige Prozent des Gesamtsignals ausmacht, vernachlässigt, da der Zielzustand unbekannt war. Letztlich wurde ein Übergang nach $C^{H}$ angenommen. Die Konzentrationsverläufe und die Spektren der im Modell beschriebenen Spezies sind in den Abb. 3.29b und 3.29 dargestellt. Die bei der Anpassung ermittelten Geschwindigkeitskonstanten für die einzelnen Schritte sind in Abb. 3.29a angegeben.

Es zeigte sich, dass die Depopulation von $T^{H *}$ mit $\left(k_{1}+k_{i c}\right)^{-1}=2.1 \mathrm{ps} \mathrm{zu}$ $64 \%$ durch die IC in den Grundzustand dominiert wird. Die übrigen $36 \%$ gehen in den angeregten Zustand $I^{*}$ über. Diese Ausbeute, die etwa der Quantenausbeute des Schaltprozesses entspricht, legt die Vermutung nahe, dass der Übergang $T^{H *} \longrightarrow I^{*}$ entscheidend für die Isomerisierung ist und $I^{*}$ somit entweder selbst bereits cis-Konformation besitzt, oder durch IC in einen cis-Grundzustand übergeht. Spektral erinnert $I^{*}$ mit der Emission oberhalb von $500 \mathrm{~nm}$ bereits an eine deprotonierte cis-Spezies. Dieser Eindruck verstärkt sich für $I_{2}^{*}$ mit der schmaleren Emissionsbande mit einem Maximum bei $518 \mathrm{~nm}$ und deutlichen Schultern noch, allerdings ist die Lebensdauer mit 94 ps deutlich kürzer als von $C^{-*}$. Ausgehend von der Annahme, dass die Schwelle zur Isomerisierung bereits im ersten Schritt überschritten war, wurde die Depopulation der $I_{2}^{-*}$-Spezies schließlich mit den Grundzuständen $C^{H}$ und $C^{-}$gekoppelt. Die Anpassung ergab, dass nur der Weg $C_{i}^{-*} \longrightarrow C^{H}$ genutzt wird. 


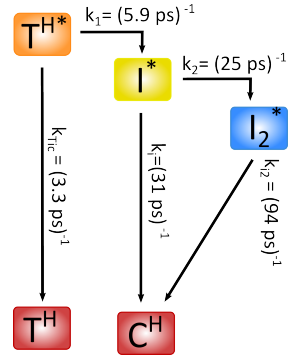

(a) Kinetisches Modell zur Anpassung der Daten in Fig $3.26 \mathrm{~b}$

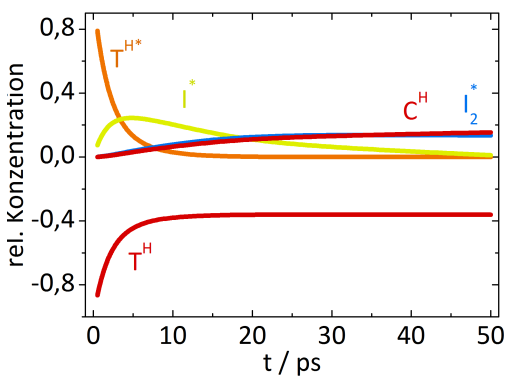

(b) Konzentrationsverlauf der Spezies ausa

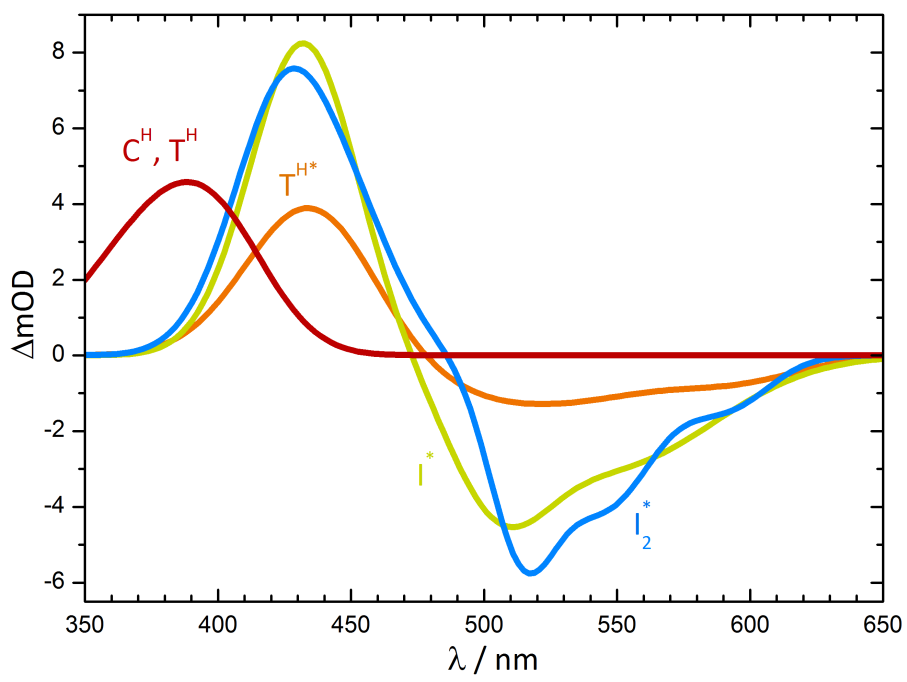

Abb. 3.29: Spektren der Spezies aus a

Abb. 3.30: Modell der photoinduzierten Dynamik von rsFastLime nach Anregung der $T^{H}$-Spezies durch $\lambda_{p}=387 \mathrm{~nm}$, zeitabhängige Konzentrationen der beteiligten Spezies und ihre Absorptionsspektren 


\subsection{Photoisomerisierung}

Bisher wurden die initialen Prozesse nach Anregung der einzelnen Grundzustands-spezies von Padron0.9 und rsFastLime dargestellt und durch kinetische Modelle interpretiert. Die aufgestellten Modelle sind noch einmal in Abb. 3.31 gezeigt. Die Reaktionswege, über die die Photoisomerisation abläuft, sind allerdings nach wie vor weitestgehend ungeklärt. Die Isomerisierungsausbeuten bei Padron 0.9 sind mit $2 \%$ und $0.02 \%$ zu gering, um auftretende Produkte mit den hier verwendeten Methoden zu identifizieren.

Es ist plausibel, dass der effiziente ESPT, der nach Anregung $\operatorname{der} C^{H}$-Spezies belegt werden konnte, den ersten Schritt auf dem Isomerisierungsweg darstellt, da dieser bei der bei niedrigem $\mathrm{pH}$ vorliegenden, nicht schaltenden Spezies $C^{H+}$ nicht erfolgt. Die intermediäre Spezies $C_{i}^{-*}$ führt zu den Produkten $C^{-*}$ und über $C_{i}^{-}$zu I. Eine photoinduzierte Isomerisierung erfolg in der Regel aus einem elektronisch angeregten Zustand heraus und die Effizienz der Isomerisiserung aus dem fluoreszierenden $C^{-*}$ ist, wenn sie überhaupt auftritt, extrem gering. Vermutlich wird also innere Konversion über eine konische Durchschneidung mit geringer Ausbeute von $C_{i}^{-*}$ in einen trans-Grundzustand führen.

Die trans $\longrightarrow$ cis-Isomerisierung nach Anregung von $T^{-}$konnte durch die im Rahmen dieser Arbeit durchgeführten Experimente nicht beobachtet werden. Faro et al. [33] akkumulierten durch Bestrahlung von $T^{-}$bei $80 \mathrm{~K}$ ein Grundzustandsintermediat mit cis-Konfiguration, wobei die Umwandlung nur zu etwa $20 \%$ erfolgte, was auf die Bildung eines photostationären Gleichgewichts hindeutet. Die intermediäre Spezies konnte durch Bestrahlung bei $405 \mathrm{~nm}$ wieder zu $T^{-}$umgewandelt werden. Das cis-Intermediat zeigte ein Absorptionsmaximum bei $481 \mathrm{~nm}$ und ging bei $100 \mathrm{~K}$ vollständig in den $C^{-}$-Grundzustand über, für den sich oberhalb von $180 \mathrm{~K}$ ein Protonierungsgleichgewicht mit $C^{H}$ einstellte. Der hier gezeigte Zustand $C_{i}^{-}$zeigt spektral mit einem Absorptionsmaximum um $490 \mathrm{~nm}$ eine gewisse Ähnlichkeit mit dem von Faro gefundenen cis-Intermediat und ist bei RT ebenfalls nicht populiert. Vermutlich wird also innere Konversion über konische Durchschneidung mit geringer Ausbeute aus einem angeregten trans-Zustand $\mathrm{zu} \mathrm{C}_{i}^{-}$oder einem ähnlichen cis-Intermediat führen und von dort in den cis-Grundzustand. Diese Wege sind in Abb 3.31a als gestrichelte Linien dargestellt.

Bei rsFastLime ist die trans $\longrightarrow$ cis-Isomerisierung deutlich effizienter, das wahrscheinliche Produkt, $C^{H}$, ist aber spektral nicht vom Edukt $T^{H}$ zu unterscheiden. Der Befund der schnellen Isomerisierung nach Anregung 
der $T^{H}$-Spezies deckt sich mit den Messungen von Warren et al. an Dronpa [29]. Die Quantenausbeute der cis $\longrightarrow$ trans-Isomerisierung nach Anregung von $C^{-}$ist mit $0.03 \%$ sehr niedrig, entsprechend gibt es keine spektralen Hinweise auf Produkte. Wie bei Padron0.9 lässt sich die Entwicklung der transienten Spektren mit nur zwei Zuständen beschreiben, es scheint keine nennenswerten Umorientierungen im angeregten Zustand zu geben. Es muss also einen Reaktionsweg aus $C^{-*}$ geben, der entweder direkt oder über Intermediate zu einem trans-Produkt führt. Dieser Weg ist in Abb 3.31b als gestrichelte Linien dargestellt.

Für Padron0.9 sind nach Photoanregung die Isomerisierungswege $C^{H *} \longrightarrow T$ und $T^{-*} \longrightarrow C$ notwendig, für rsFastLime müssen die Wege $C^{-*} \longrightarrow T$ und $T^{H *} \longrightarrow C$ existieren, um das beobachtete Schaltverhalten der Proteine zu erklären. Die bisherigen Untersuchungen schließen aber die jeweils anderen Reaktionswege keineswegs aus. Bekannt ist nur das Resultat: Padron0.9 wird durch Bestrahlung bei $500 \mathrm{~nm}$ an- und bei $400 \mathrm{~nm}$ ausgeschaltet, bei rsFastLime ist es umgekehrt. Bei Faros Kryoexperimenten gelang nur eine teilweise Umwandlung von $T^{-}$zu dem cis-Intermediat, die Bildung erfolgte im Zeitraum von einigen zehn Sekunden. Da die Absorptionsspektren der beiden Spezies ähnlich sind (das Intermediat erscheint als Schulter bei $481 \mathrm{~nm}$ auf der blauen Flanke der $T^{-}$-Absorption), kann die nur teilweise Umwandlung, analog zu Stilben, durch Bildung eines photostationären Gleichgewichts zwischen cis-Intermediat und $T^{-}$interpretiert werden, deren Anregung zumindest z.T. die Bildung der jeweils anderen Spezies zur Folge hat. 


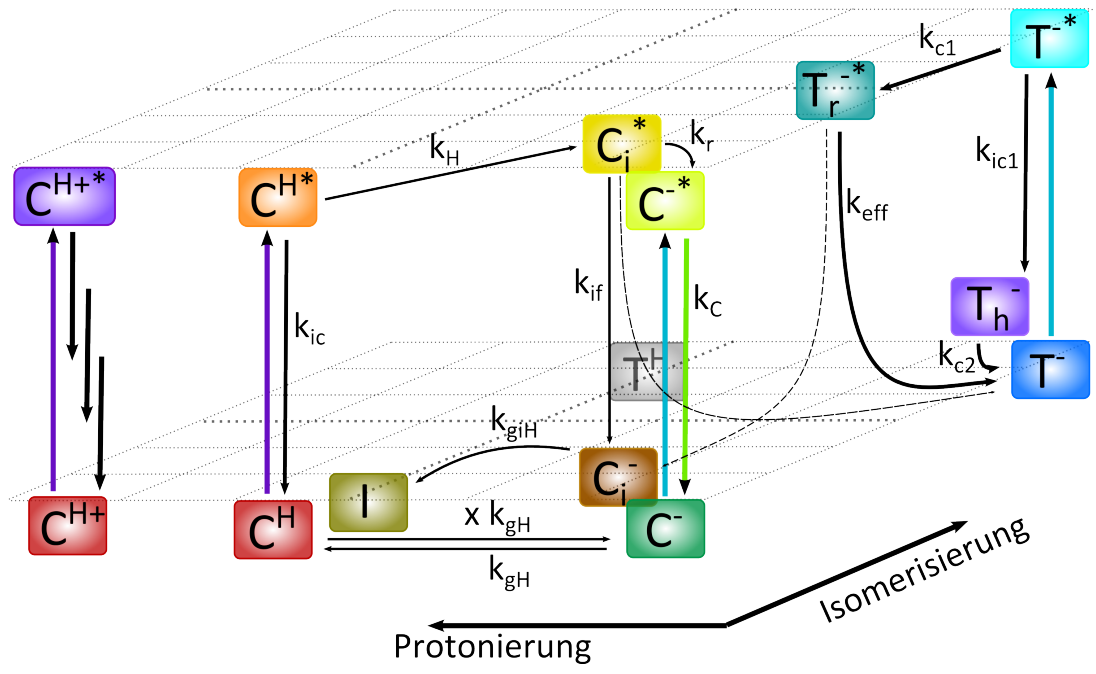

(a) Padron0.9

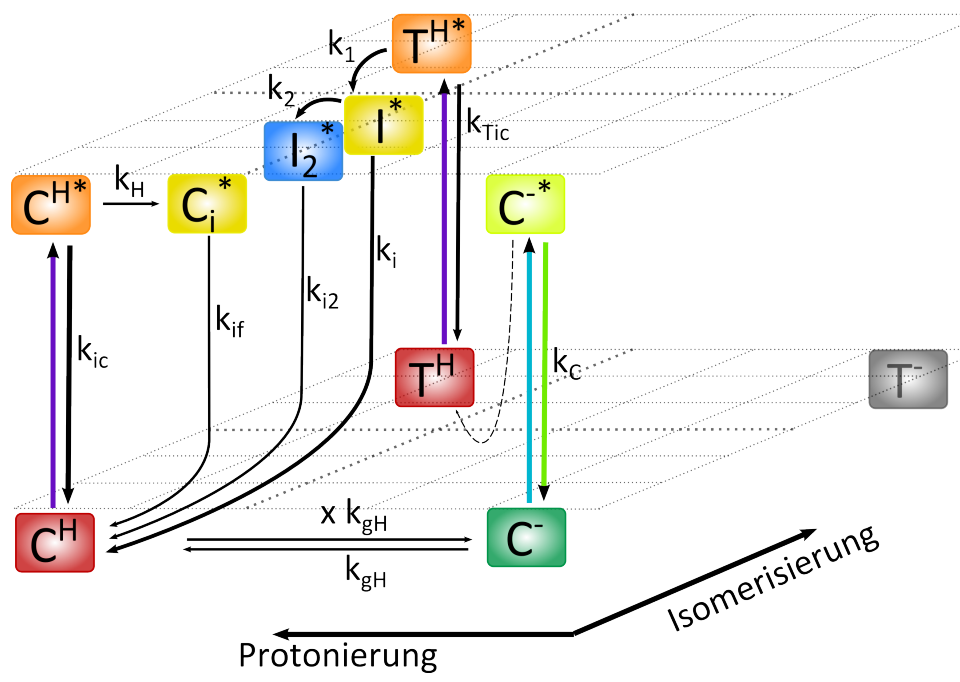

(b) rsFastLime

Abb. 3.31: Zusammenfassung der kinetischen Modelle zur Beschreibung der Dynamik nach Photoanregung der einzelnen Spezies. Vermutete Wege der Isomerisierung sind als gestrichelte Linien dargestellt. 


\begin{tabular}{l|l} 
& $k / \mathbf{p s}^{-1}$ \\
\hline$k_{C}$ & 1160 \\
$k_{c 1}$ & 2.9 \\
$k_{i c 1}$ & 1.7 \\
$k_{e f f}$ & 7.0 \\
$k_{c 2}$ & 4.0 \\
$k_{H}$ & 2.0 \\
$k_{i c}$ & 5.0 \\
$k_{r}$ & 71 \\
$k_{i f}$ & 78 \\
$k_{g H}$ & 56 \\
$x k_{g H}$ & 75
\end{tabular}

\begin{tabular}{l|l} 
& $k / \mathbf{p s}^{-1}$ \\
\hline$k_{C}$ & 900 \\
$k_{1}$ & 5.9 \\
$k_{\text {Tic }}$ & 3.3 \\
$k_{2}$ & 25 \\
$k_{i}$ & 31 \\
$k_{i 2}$ & 94 \\
$k_{H}$ & 57 \\
$k_{i c}$ & 9.1 \\
$k_{i f}$ & 215 \\
$k_{g H}$ & 123 \\
$k_{g H}$ & 70
\end{tabular}

(a) Padron0.9 (Abb. 3.31a)

(b) rsFastLime (Abb. 3.31b

Abb. 3.32: Geschwindigkeitskoeffizienten der kinetischen Modelle zur Beschreibung der Dynamik nach Photoanregung der einzelnen Grundzustandsspezies 


\subsection{Ausblick}

Der Austausch einer einzigen Aminosäure, Met ${ }^{159}$, durch Tyr kehrte die Schalteigenschaften von rsFastLime um und führte nach einigen weiteren Optimierungen schließlich zu Padron0.9. Über seine $p$-Hydroxyphenylgruppe stabilisiert Tyr ${ }^{159}$ das deprotonierte trans-Isomer (siehe Abb 1.12). Anders als bei rsFastLime ist trans-Padron das stabilere Isomer, außerdem ist das Protonierungsgleichgewicht im Grundzustand komplett verschoben: Während das cis-Isomer für beide Proteine in einem recht ausgewogenen Gleichgewicht vorliegt, ist das Gleichgewicht bei rsFastLime weit $\mathrm{zu} T^{H}$, bei Padron hingegen weit nach $T^{-}$verschoben (vgl. Abb. 3.1 und 3.19).

\subsubsection{Photoschalten - Ein Photostationäres Gleichgewicht?}

In einem Versuch zur qualitativen Beschreibung der Schalteigenschaften des deprotonierbaren Proteinchromophors wurde das Modell der direkten Photoisomerisierung von Stilben von Siebrand/Orlandi [68] um eine Protonierungskoordinate erweitert. Protonierte und deprotonierte Form des jeweiligen Isomers stehen in einem Gleichgewicht $K$ zueinander, das in Gl. 3.13 für das cis-Isomer beschrieben wird.

$$
K_{C g}=\frac{C^{-}}{C^{H}}=\frac{\frac{k_{g} x}{x+1}}{\frac{k_{g}}{x+1}}
$$

Das die Geschwindigkeit der Einstellung des Gleichgewichtes $K_{C g}$ wird mit $k_{g}$ beschrieben, $x$ definiert die Lage des Gleichgewichtes. Alle initial angeregten Spezies laufen in einem angeregten Zustand zusammen, der durch innere Konversion in den Grundzustand übergeht und teils in einem Grundzustand mit cis- und teils mit trans-Konfiguration endet.

Das resultierende Modell ist in Abb. 3.33a dargestellt. Die Geschwindigkeitskonstanten wurden alle gleich und um den Faktor 100 schneller als die Pumprate gewählt. Ausnahmen bildeten die Reaktionen der deprotonierten Spezies: Um den im Vergleich zur Anregung bei $\lambda_{\text {ex }}=400 \mathrm{~nm}$ langsamen Schaltprozess bei $500 \mathrm{~nm}$ nachzubilden, wurden die Prozesse $k_{C 2}$ und $k_{T 2}$ im Vergleich zu den anderen Prozessen um den Faktor 10 verlangsamt und mit $k_{C}$ und $k_{T}$ jeweils ein Konkurrenzprozess in den Grundzustand eingeführt. Für die Schaltkurven beider Proteine wurden die gleichen Parameter verwendet. Der einzige Unterschied sind die Protonierungsgleichgewichte $K_{C g}$ und $K_{T g}$, die für das Padron mit $K_{C g}=0.75$ und $K_{T g}=100$ und 


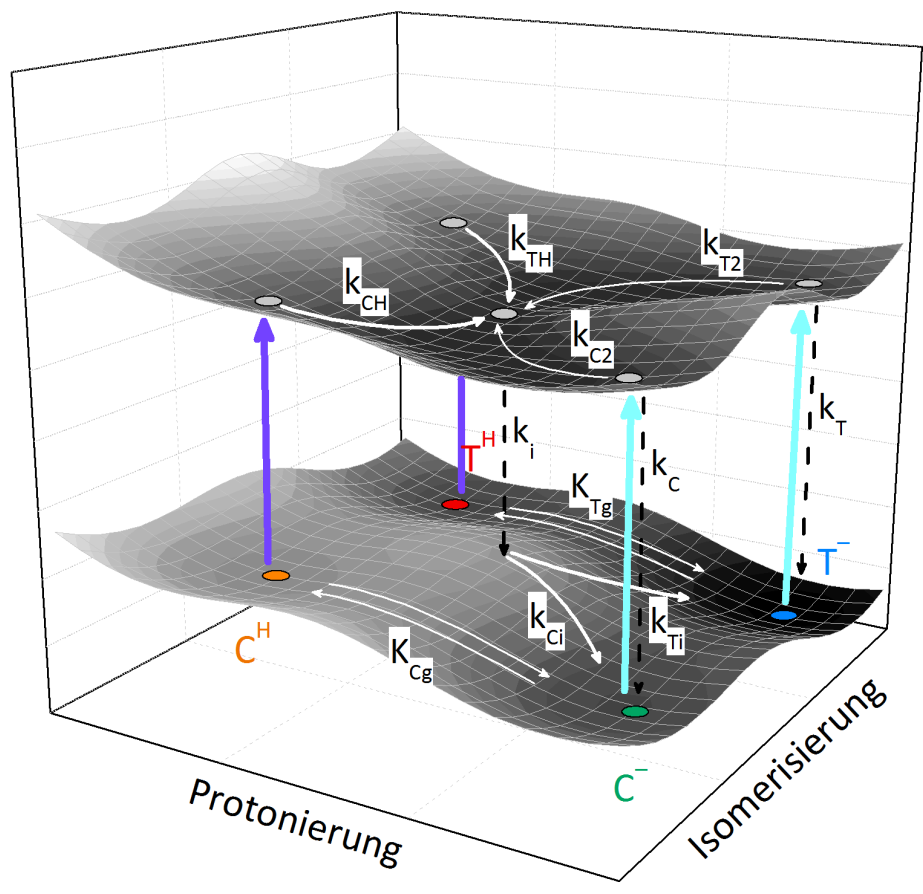

(a) Modell zum Schaltvorgang von Padron0.9 und rsFastLime

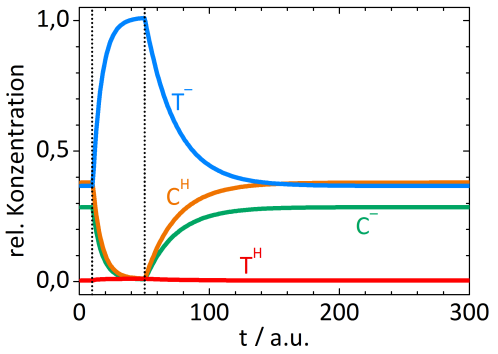

(b) Padron0.9

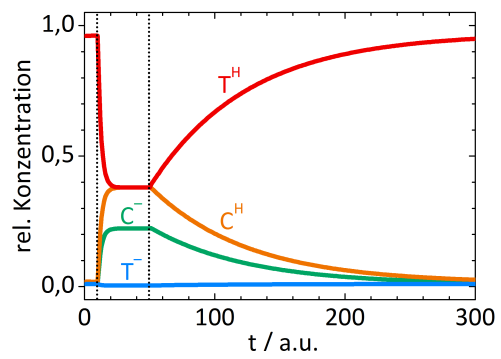

(c) rsFastLime

Abb. 3.33: Allgemeines Schaltmodell und Konzentrationsverlauf der Grundzustandspezies. $10<\mathrm{t}<50: \lambda_{\text {ex }}=400 \mathrm{~nm}, \mathrm{t}>=50: \lambda_{\text {ex }}=500 \mathrm{~nm}$ 
für rsFastLime mit $K_{C g}=0.59$ und $K_{T g}=0.01$ angepasst wurden, um die tatsächlichen Protonierungsgleichgewichte bei neutralem $\mathrm{pH}$ zu beschreiben. Die Absorptionsquerschnitte der einzelnen Spezies bei den jeweiligen Anregungswellenlängen wurden als gleich angenommen.

Die Einstellung der photostationären Gleichgewichte durch Bestrahlung bei verschiedenen Wellenlängen nach dem Modell in Abb. 3.33a ist für Padron0.9 in Abb. 3.33b und für rsFastLime in Abb. 3.33c dargestellt. Wie die Schaltzyklen zeigen, reicht dieses einfache Modell in Verbindung mit der Verschiebung des Protonierungsgleichgewichtes im trans-Isomer von rsFastLime zu Padron0.9 bereits aus, um qualitativ die Umkehr der Schaltrichtung $\mathrm{zu}$ beschreiben.

Tabelle 3.1 zeigt die Absorptionsmaxima der AN- und AUS-Zustände einiger anderer RSFPs sowie die schaltinduzierenden Wellenlängen. Es ist ein deutlicher Trend erkennbar: Bei den meisten RSFPs bestimmt die dominierende Absorptionsbande auch die Schaltrichtung. Die Ausnahmen stellen Padron, cerFP505 und rsCherry bzw. rsCherryRev dar, wo die Absorptionsmaxima für AN- und AUS-Zustand gleich sind. Padron, bzw. das sehr ähnliche Padron0.9, wurde hier bereits diskutiert. Das Protein cerFP505 zeigt beim Übergang vom AN in den AUS-Zustand einen geringfügigen Abfall in der Absorptionsbande um $494 \mathrm{~nm}$ und einen korrespondierenden Anstieg bei $390 \mathrm{~nm}$. Der AUS-Zustand zeigt immer noch etwa 80\% der Fluoreszenz des AN-Zustandes, was für ein zum fluoreszierenden Zustand verschobenes photostationäres Gleichgewicht spricht. Die beiden Proteine rsCherry und rsCherryRev zeigen, ähnlich wie die hier untersuchten Padron0.9 und rsFastLime, ein inverses Schaltverhalten hinsichtlich der Anregungswellenlängen. Da die Absorptionsspektren der AUS-Zustände von rsCherry nicht bekannt sind, kann ihr Schaltverhalten bezüglich der Protonierung nicht weiter diskutiert werden.

Das einfache Schaltmodell in $\mathrm{Abb} 3.33$ würde ohne weitere Modifikationen qualitativ das Schaltverhalten der meisten in Tab. 3.1 dargestellten RSFPs reproduzieren. Zur quantitativen Beschreibung der übrigen Schaltvorgänge muss das Schaltmodell allerdings bezüglich der tatsächlichen Reaktionswege, ihrer Geschwindigkeiten und Quantenausbeuten erweitert werden.

Es scheint, als ob das Protonierungsgleichgewicht der Isomere eine entscheidende Rolle bei den Schaltprozessen der RSFPs spielt, der bisher zu wenig Beachtung geschenkt wurde. Durch pH-abhängige Messungen der Quantenausbeuten der Schaltvorgänge der einzelnen Proteine könnte der Einfluss der Protonierungsgleichgewichte geklärt werden. 


\begin{tabular}{|c|c|c|c|c|}
\hline Protein & $\begin{array}{l}\lambda\left(A b s_{\max , A N}\right) \\
/ \mathrm{nm}\end{array}$ & $\begin{array}{l}\lambda\left(A b s_{\max }, A U S\right. \\
/ \mathrm{nm}\end{array}$ & $\begin{array}{l}\text { Schaltet bei } \\
\lambda\left(A b s_{\max }, A N\right)\end{array}$ & $\begin{array}{l}\text { Schaltet bei } \\
\lambda\left(A b s_{\max }, A U S\right)\end{array}$ \\
\hline asFP595 |69| & 445 & 568 & AUS & $\mathrm{AN}$ \\
\hline bsDronpa |32| & 460 & 385 & AUS & $\mathrm{AN}$ \\
\hline cerFP505 [70| & 494 & $494(390)^{*}$ & AUS & $\mathrm{AN}^{*}$ \\
\hline Dronpa |26| & 503 & 390 & AUS & $\mathrm{AN}$ \\
\hline mGeos-M [71] & 500 & 390 & AUS & $\mathrm{AN}$ \\
\hline mTFP0.7 |72] & 453 & 370 & AUS & AN \\
\hline Padron [32] & $503(396)^{*}$ & 505 & $\mathrm{AN}^{*}$ & AUS \\
\hline rsCherry |73| & 572 & $572(450)^{* *}$ & AN & $\mathrm{AUS}^{* *}$ \\
\hline $\begin{array}{l}\text { rsCherryRev } \\
{[73 \mid}\end{array}$ & 572 & $572(450)^{* *}$ & AUS & $\mathrm{AN}^{* *}$ \\
\hline rsEGFP |74| & 493 & 396 & AUS & $\mathrm{AN}$ \\
\hline rsEGFP2 |75] & 478 & 408 & AUS & $\mathrm{AN}$ \\
\hline $\begin{array}{l}\text { rsFastLime } \\
{[32]}\end{array}$ & $496(392)$ & $384(496)$ & AUS & $\mathrm{AN}$ \\
\hline rsTagRFP |76] & $567(440)$ & $440(567)$ & AUS & $\mathrm{AN}$ \\
\hline
\end{tabular}

Tab. 3.1: Absorptionsmaxima $A b s_{\max }$ der AN- und AUS-Zustände einiger RSFPs und Schaltrichtung bei Bestrahlung derselben. Weitere wichtige Absorptionsbanden sind in Klammern angegeben.

* Bestrahlung bei der angegebenen Wellenlänge schaltet das Protein ** die genaue Lage der Absorptionsbanden von rsCherry und rsCherryRev sind nicht angegeben, Bestrahlung bei der angegebenen Wellenlänge schaltet das Protein 
Anhang 

Anhang A

\section{Tabellenwerke}




\begin{tabular}{|c|c|c|c|}
\hline & $\lambda_{c} / n m$ & $\sigma / n m$ & A / a.u. \\
\hline \multirow[t]{2}{*}{$C^{H} X^{H} Y^{H}$} & 367.5 & 23.8 & 29.8 \\
\hline & 393.1 & 17.6 & 21.8 \\
\hline \multirow[t]{2}{*}{$C^{H} X^{H} Y^{-}, C^{H} X^{-} Y^{H}$} & 382.0 & 23.8 & 34.3 \\
\hline & 407.6 & 17.6 & 19.1 \\
\hline \multirow[t]{3}{*}{$C^{-} X^{H} Y^{H}, C^{-} X^{-} Y^{H}, C^{-} X^{H} Y^{-}$} & 449.2 & 23.6 & 9.43 \\
\hline & 487.1 & 19.8 & 66.9 \\
\hline & 505.8 & 8.7 & 28.8 \\
\hline \multirow[t]{3}{*}{$C^{-} X^{-} Y^{-}$} & 449.2 & 23.6 & 20.3 \\
\hline & 487.1 & 19.8 & 56.0 \\
\hline & 505.8 & 8.7 & 12.2 \\
\hline$T^{H} X^{H} Y^{H}, T^{H} X^{H} Y^{-}, T^{H} X^{-} Y^{H}$ & 382.8 & 26.4 & 45.8 \\
\hline \multirow[t]{3}{*}{$T^{-} X^{H} Y^{H}, T^{-} X^{-} Y^{H}, T^{-} X^{H} Y^{-}$} & 452.7 & 46.6 & 13.3 \\
\hline & 491.9 & 23.5 & 59.2 \\
\hline & 509.7 & 9.9 & 15.2 \\
\hline \multirow[t]{3}{*}{$T^{-} X^{-} Y^{-}$} & 452.7 & 46.6 & 20.3 \\
\hline & 491.9 & 23.5 & 56.0 \\
\hline & 509.7 & 9.9 & 12.2 \\
\hline \multirow[t]{3}{*}{$C_{e m, p H 10}^{-*}$} & 518.6 & 9.0 & 27.6 \\
\hline & 538.2 & 22.8 & 43.2 \\
\hline & 576.8 & 33.9 & 14.1 \\
\hline
\end{tabular}

Tab. A.1: Parameter zur Beschreibung der Speziesspektren von Padron0.9 im Grundzustand (Abb. 3.4 durch Gaussfunktionen (Gl.2.15 


\begin{tabular}{|c|c|c|c|}
\hline & $\lambda_{c} / n m$ & $\sigma / n m$ & A / a.u. \\
\hline \multirow[t]{3}{*}{$T^{-}$} & 452.7 & 46.6 & 0.263 \\
\hline & 491.9 & 23.5 & 0.727 \\
\hline & 509.7 & 9.9 & 0.158 \\
\hline \multirow[t]{3}{*}{$T^{-*}$} & 405.3 & 31.3 & 0.698 \\
\hline & 475.2 & 27.7 & 0.163 \\
\hline & 619.1 & 58.3 & -0.406 \\
\hline \multirow[t]{3}{*}{$T_{r}^{-*}$} & 405.3 & 31.3 & 0.948 \\
\hline & 475.2 & 27.7 & 0.002 \\
\hline & 619.1 & 58.3 & -0.722 \\
\hline \multirow[t]{2}{*}{$T_{h}^{-}$} & 492.6 & 31 & 0.532 \\
\hline & 520.1 & 11.1 & 0.17 \\
\hline \multirow[t]{3}{*}{$C^{-}$} & 449.2 & 23.6 & 0.236 \\
\hline & 487.1 & 19.8 & 0.750 \\
\hline & 505.8 & 8.7 & 0.282 \\
\hline \multirow[t]{6}{*}{$C^{-*}$} & 436.1 & 40.4 & 0.850 \\
\hline & 493.2 & 24.7 & 0.346 \\
\hline & 518.6 & 9.0 & -0.272 \\
\hline & 538.2 & 22.8 & -0.426 \\
\hline & 576.8 & 33.0 & -0.139 \\
\hline & 616.4 & 28.7 & 0.032 \\
\hline
\end{tabular}

Tab. A.2: Parameter zur Beschreibung der Speziesspektren von Padron0.9 nach Anregung von $C^{-}$und $T^{-}$durch $\lambda_{p}=505 \mathrm{~nm}$ bei $\mathrm{pH} 10$ (Abb. 3.9c) durch Gaussfunktionen (Gl.2.15 


\begin{tabular}{|c|c|c|c|}
\hline & $\lambda_{c} / n m$ & $\sigma / n m$ & A / a.u. \\
\hline \multirow[t]{3}{*}{$C^{-}$} & 449.2 & 23.6 & 0.206 \\
\hline & 487.1 & 19.8 & 0.948 \\
\hline & 505.8 & 8.7 & 0.386 \\
\hline \multirow[t]{2}{*}{$C^{H}$} & 382.0 & 23.9 & 0.518 \\
\hline & 407.6 & 17.6 & 0.289 \\
\hline \multirow[t]{6}{*}{$C^{-*}$} & 436.1 & 40.4 & 1.116 \\
\hline & 493.2 & 24.7 & 0.446 \\
\hline & 518.6 & 9.0 & -0.358 \\
\hline & 538.2 & 22.8 & -0.561 \\
\hline & 576.8 & 33.0 & -0.183 \\
\hline & 616.4 & 28.7 & 0.042 \\
\hline \multirow[t]{6}{*}{$C_{i}^{-*}$} & 422.8 & 33.4 & 1.08 \\
\hline & 499.5 & 17.1 & 0.256 \\
\hline & 507.3 & 13.1 & -0.373 \\
\hline & 527.0 & 26.5 & -0.585 \\
\hline & 565.6 & 33.9 & -0.191 \\
\hline & 619.4 & 28.7 & 0.016 \\
\hline \multirow[t]{2}{*}{$I$} & 402.1 & 26.4 & 0.678 \\
\hline & 475.3 & 9.7 & 0.050 \\
\hline
\end{tabular}

Tab. A.3: Parameter zur Beschreibung der Speziesspektren von Padron0.9 nach Anregung von $C^{H}$ durch $\lambda_{p}=387 \mathrm{~nm}$ bei $\mathrm{pH} 10$ (Abb. 3.13c durch Gaussfunktionen (G1.2.15 


\begin{tabular}{l|c|c|c} 
& $\lambda_{c} / n m$ & $\sigma / n m$ & A / a.u. \\
\hline$C^{-}$ & 449.1 & 23.55 & 0.117 \\
& 487.1 & 19.8 & 0.344 \\
& 505.8 & 8.7 & 0.219 \\
$C_{i}^{-}$ & 470.0 & 39.4 & 0.791 \\
& 493.0 & 10.0 & 0.0791 \\
$I$ & 403.0 & 26.3 & 0.385 \\
$C^{-*}$ & 436.1 & 40.4 & -0.633 \\
& 493.2 & 24.7 & -0.147 \\
& 518.6 & 9.0 & 0.203 \\
& 538.2 & 22.8 & 0.318 \\
& 576.8 & 33.0 & 0.104 \\
$C_{i}^{-*}$ & 422.8 & 33.4 & -0.612 \\
& 499.5 & 17.1 & -0.147 \\
& 507.3 & 13.1 & 0.212 \\
& 527.0 & 26.5 & 0.332 \\
& 565.6 & 33.9 & 0.108
\end{tabular}

Tab. A.4: Parameter zur Beschreibung der Speziesspektren von Padron0.9 nach Anregung von $C^{H}$ durch $\lambda_{p}=387 \mathrm{~nm}$ und Dumpen nach 40 ps durch $\lambda_{d}=$ $560 \mathrm{~nm}$ bei pH 10 (Abb. 3.15c) durch Gaussfunktionen (Gl.2.15) 


\begin{tabular}{l|c|c|c} 
& $\lambda_{c} / n m$ & $\sigma / n m$ & $\mathrm{~A} / \mathrm{a} . \mathrm{u}$. \\
\hline$C^{H+}$ & 367.5 & 23.8 & 0.509 \\
& 393.1 & 17.6 & 0.370 \\
$C^{H+*}$ & 437.1 & 18.7 & 0.272 \\
& 506.0 & 66.9 & -0.724 \\
& 604.6 & 35.3 & -0.171 \\
$C_{r}^{H+*}$ & 429.9 & 17.4 & 0.543 \\
& 496.2 & 20.8 & -0.266 \\
& 562.2 & 44.4 & -0.677 \\
$C^{H \cdot}$ & 400.8 & 54.6 & 1.28 \\
$e^{-}$ & 566.9 & 28.0 & 0.0636 \\
& 641.2 & 50.7 & 0.203
\end{tabular}

Tab. A.5: Parameter zur Beschreibung der Speziesspektren von Padron0.9 nach Anregung von $C^{H}+$ durch $\lambda_{p}=387 \mathrm{~nm}$ bei $\mathrm{pH} 4$ (Abb. 3.16 durch Gaussfunktionen (G1.2.15) 


\begin{tabular}{|c|c|c|c|}
\hline & $\lambda_{c} / n m$ & $\sigma / n m$ & A / a.u. \\
\hline \multirow[t]{2}{*}{$C^{H} X^{H} Y^{H}$} & 371.6 & 28.6 & 28.0 \\
\hline & 397.0 & 20.5 & 17.1 \\
\hline \multirow[t]{2}{*}{$C^{H} X^{H} Y^{-}, C^{H} X^{-} Y^{H}$} & 375.7 & 28.6 & 32.5 \\
\hline & 401.1 & 20.5 & 17.2 \\
\hline \multirow[t]{3}{*}{$C^{-} X^{H} Y^{H}, C^{-} X^{-} Y^{H}, C^{-} X^{H} Y^{-}$} & 455.9 & 17.9 & 18.0 \\
\hline & 481.9 & 15.6 & 38.2 \\
\hline & 501.3 & 10.0 & 25.5 \\
\hline \multirow[t]{3}{*}{$C^{-} X^{-} Y^{-}$} & 455.9 & 17.9 & 26.3 \\
\hline & 481.9 & 15.6 & 37.5 \\
\hline & 501.3 & 10.0 & 20.8 \\
\hline \multirow[t]{2}{*}{$T^{H}$} & 372.7 & 25.3 & 28.1 \\
\hline & 397.9 & 20.0 & 12.5 \\
\hline \multirow[t]{3}{*}{$C_{e m, p H 10}^{-*}$} & 519.7 & 8.1 & 12.0 \\
\hline & 539.1 & 18.0 & 18.6 \\
\hline & 569.9 & 31.9 & 9.33 \\
\hline
\end{tabular}

Tab. A.6: Parameter zur Beschreibung der Speziesspektren von rsFasLime im Grundzustand (Abb. 3.21) durch Gaussfunktionen (Gl. 2.15) 


\begin{tabular}{l|c|c|c} 
& $\lambda_{c} / n m$ & $\sigma / n m$ & A / a.u. \\
\hline$C^{-}$ & 455.9 & 17.9 & 0.101 \\
& 481.9 & 15.6 & 0.215 \\
$C^{-*}$ & 501.3 & 10.0 & 0.144 \\
& 357.7 & 22.1 & 0.0732 \\
& 451.3 & 44.3 & 0.604 \\
& 519.7 & 8.1 & -0.131 \\
& 539.1 & 18.0 & -0.204 \\
Korrektur & 510.0 & 5.65 & -0.0474
\end{tabular}

Tab. A.7: Parameter zur Beschreibung der Speziesspektren von rsFasLime nach Anregung von $\mathrm{C}^{-}$durch $\lambda_{p}=505 \mathrm{~nm}$ bei pH 10 (Abb. 3.25) durch Gaussfunktionen (Gl. 2.15) 


\begin{tabular}{l|c|c|c} 
& $\lambda_{c} / n m$ & $\sigma / n m$ & A / a.u. \\
\hline$C^{-}$ & 455.9 & 17.9 & 0.130 \\
& 481.9 & 15.6 & 0.274 \\
& 501.3 & 10.0 & 0.184 \\
$C^{H}$ & 375.7 & 28.6 & 0.234 \\
& 401.1 & 20.5 & 0.124 \\
$C^{H *}$ & 397.1 & 31.8 & 0.370 \\
& 494.5 & 20.9 & -0.0581 \\
& 537.6 & 39.9 & -0.0816 \\
$C_{i}^{*}$ & 425.7 & 28.0 & 0.322 \\
& 438.9 & 23.8 & 0.126 \\
& 515.5 & 9.6 & -0.169 \\
& 534.8 & 19.5 & -0.262 \\
& 565.6 & 25.9 & -0.132 \\
& 639.1 & 29.7 & 0.0360
\end{tabular}

Tab. A.8: Parameter zur Beschreibung der Speziesspektren von rsFasLime nach Anregung von $C^{H}$ durch $\lambda_{p}=387 \mathrm{~nm}$ bei $\mathrm{pH} 10$ (Abb. 3.28c) durch Gaussfunktionen (G1.2.15) 


\begin{tabular}{l|c|c|c} 
& $\lambda_{c} / n m$ & $\sigma / n m$ & A / a.u. \\
\hline$T^{H}, C^{H}$ & 372.7 & 25.3 & 0.206 \\
$T^{H *}$ & 397.9 & 20.0 & 0.109 \\
& 435.0 & 24.9 & 0.262 \\
& 517.1 & 48.5 & -0.156 \\
$I^{*}$ & 597.2 & 24.32 & -0.0248 \\
& 432.4 & 20.38 & 0.407 \\
$I_{2}^{*}$ & 506.0 & 16.0 & -0.0843 \\
& 540.0 & 42.7 & -0.320 \\
& 427.4 & 21.8 & 0.465 \\
& 460.8 & 14.2 & 0.0381 \\
& 513.9 & 12.1 & -0.148 \\
& 544.6 & 20.0 & -0.220
\end{tabular}

Tab. A.9: Parameter zur Beschreibung der Speziesspektren von rsFasLime nach Anregung von $T^{H}$ durch $\lambda_{p}=387 \mathrm{~nm}$ bei $\mathrm{pH} 10$ (Abb. 3.28c) durch Gaussfunktionen (G1.2.15) 


\section{Literaturverzeichnis}

[1] O. Shimomura, F. H. Johnson, Y. Saiga, Journal of Cellular and Comparative Physiology 1962, 59, 223-239.

[2] H. Morise, O. Shimomura, F. H. Johnson, J. Winant, Biochemistry 1974, $13,2656-2662$.

[3] D. Prasher, V. Eckenrode, W. W. Ward, F. G. Prendergast, M. J. Cormier, Gene 1992, 111, 229-233.

[4] F. Yang, L. Moss, G. N. J. Phillips, Nature Biotechnology 1996, 14, 12461251.

[5] M. Ormö, A. Cubitt, K. Kallio, L. Gross, R. Tsien, S. J. Remington, Science 1996, 273, 1392-1395.

[6] M. Chalfie, Y. Tu, G. Euskirchen, W. Ward, D. Prasher, Science 1994, 263, 802-805.

[7] K. Brejc, T. Sixma, P. Kitts, S. Kain, R. Tsien, M. Ormö, S. J. Remington, Proc. Natl. Acad. Sci. USA 1997, 94, 2306-2311.

[8] B. G. Reid, G. C. Flynn, Biochemistry 1997, 36, 6789-6791.

[9] K. Winkler, Dissertation, Georg-August-Universität Göttingen, 2002.

[10] M. Chattoraj, B. King, G. Bublitz, S. Boxer, Proc. Natl. Acad. Sci. USA 1996, 93, 8362-8367.

[11] M. Kneen, J. Farinas, Y. Li, A. Verkman, Biophysical Journal 1998, 74, 1591-1599.

[12] M. Perpzzo, K. Ward, R. Thompson, W. Ward, The Journal of Biological Chemistry 1988, 263, 7713-7716.

[13] T. Creemers, A. Lock, V. Subramaniam, T. M. Jovin, S. Völker, Nature structural biology 1999, 6, 557-560.

[14] K. Winkler, J. Lindner, V. Subramaniam, T. M. Jovin, P. Vöhringer, Physical Chemistry Chemical Physics 2002, 4(6), 1072-1081, DOI 10.1039/ b108843b. 
[15] J. J. van Thor, G. Zanetti, K. Ronayne, M. Towrie, J. Phys. Chem. B 2005, 109, 16099-16108.

[16] J. J. van Thor, K. L. Ronayne, M. Towrie, J. T. Sage, Biophysical Journal 2008, 95(4), 1902-1912, DOI 10.1529/biophysj.108.129957.

[17] J. T. M. Kennis, D. S. Larsen, I. H. M. van Stokkum, M. Vengris, J. J. van Thor, PNAS 2004, 101, 17988-17993, DOI '10.1073'pnas.0404262102.

[18] G. H. Patterson, Science 2002, 297(5588), 1873-1877, DOI 10.1126/ science.1074952.

[19] I. Hayashi, H. Mizuno, K. I. Tong, T. Furuta, F. Tanaka, M. Yoshimura, A. Miyawaki, M. Ikura, Journal of Molecular Biology 2007, 372(4), 918-926, DOI 10.1016/j.jmb.2007.06.037.

[20] R. M. Dickson, A. B. Cubitt, R. Y. Tsien, W. E. Moerner, Nature 1997, 388, 355-358.

[21] K. A. Lukyanov, Journal of Biological Chemistry 2000, 275(34), 25879 25882, DOI 10.1074/jbc.c000338200.

[22] N. V. Pletneva, V. Z. Pletnev, I. I. Shemiakina, D. M. Chudakov, I. Artemyev, A. Wlodawer, Z. Dauter, S. Pletnev, Protein Science 2011, 20(7), 1265-1274, DOI 10.1002/pro.654.

[23] T. Brakemann, G. Weber, M. Andresen, G. Groenhof, A. C. Stiel, S. Trowitzsch, C. Eggeling, H. Grubmuller, S. W. Hell, M. C. Wahl, S. Jakobs, Journal of Biological Chemistry 2010, 285(19), 14603-14609, DOI 10.1074/jbc.M109.086314.

[24] H. Mizuno, T. K. Mal, M. Wälchli, A. Kikuchi, T. Fukano, R. Ando, J. Jeyakanthan, J. Taka, Y. Shiro, I. Mitsuhiko, A. Miyawaki, Proceedings of the National Academy of Sciences of the United States of America 2008, 105(27), 9227-9232, DOI 10.1073/pnas.0709599105.

[25] H. Mizuno, T. K. Mal, M. Wälchli, T. Fukano, M. Ikura, A. Miyawaki, Journal of Biomolecular NMR 2010, 48(4), 237-246, DOI 10.1007/ s10858-010-9453-5.

[26] R. Ando, Science 2004, 306(5700), 1370-1373, DOI 10.1126/science. 1102506.

[27] M. Andresen, A. C. Stiel, S. Trowitzsch, G. Weber, C. Eggeling, M. C. Wahl, S. W. Hell, S. Jakobs, PNAS 2007, 104, 13005-13009, DOI ^10. 1073pnas.0700629104. 
[28] S. Habuchi, R. Ando, P. Dedecker, W. Verheijen, H. Mizuno, A. Miyawaki, J. Hofkens, Proceedings of the National Academy of Sciences of the United States of America 2005, 102(27), 9511-9516, DOI 10.1073/pnas. 0500489102.

[29] M. M. Warren, M. Kaucikas, A. Fitzpatrick, P. Champion, J. Timothy Sage, J. J. van Thor, Nature Communications 2013, 4, 1461, DOI $10.1038 /$ ncomms 2460 .

[30] E. Fron, C. Flors, G. Schweitzer, S. Habuchi, H. Mizuno, R. Ando, F. C. De Schryver, A. Miyawaki, J. Hofkens, Journal of the American Chemical Society 2007, 129(16), 4870-4871, DOI 10.1021/ja069365v.

[31] A. Lukacs, A. Haigney, R. Brust, K. Addison, M. Towrie, G. M. Greetham, G. A. Jones, A. Miyawaki, P. J. Tonge, S. R. Meech, The Journal of Physical Chemistry B 2013, 117(40), 11954-11959, DOI 10.1021/ jp406142g.

[32] M. Andresen, J. Stiel, Andre C-amd Fölling, D. Wenzel, A. Schönle, A. Egner, C. Eggeling, S. W. Hell, S. Jakobs, Nature Biotechnology 2008, 26(9), 1035-1040, DOI 10.1038/nbt.1493.

[33] A. Regis Faro, P. Carpentier, G. Jonasson, G. Pompidor, D. Arcizet, I. Demachy, D. Bourgeois, Journal of the American Chemical Society 2011, 133(41), 16362-16365, DOI 10.1021/ja207001y.

[34] M. Vengris, I. H. M. van Stokkum, X. He, A. F. Bell, P. J. Tonge, R. van Grondelle, D. S. Larsen, The Journal of Physical Chemistry A 2004, 108(21), 4587-4598, DOI 10.1021/jp037902h.

[35] K. Addison, J. Conyard, T. Dixon, P. C. Bulman Page, K. M. Solntsev, S. R. Meech, The Journal of Physical Chemistry Letters 2012, 3(16), 2298-2302, DOI $10.1021 /$ jz3008408.

[36] J. Dong, K. M. Solntsev, L. M. Tolbert, Journal of the American Chemical Society 2006, 128(37), 12038-12039, DOI 10.1021/ja063128a.

[37] L. Andersen, A. Lapierre, S. Nielsen, I. Nielsen, S. Pedersen, U. Pedersen, S. Tomita, The European Physical Journal D 2002, 20(3), 597-600, DOI 10.1140/epjd/e2002-00141-0.

[38] L. Lammich, M. x. Petersen, M. B. Nielsen, L. Andersen, Biophysical Journal 2007, 92(1), 201-207, DOI 10.1529/biophysj.106.093674.

[39] X. He, A. F. Bell, P. J. Tonge, FEBS Letters 2003, 549(1-3), 35-38, DOI 10.1016/s0014-5793(03)00761-0. 
[40] H. Niwa, Y. Inoue, T. Hirano, T. Matsuno, S. Kojima, M. Kubota, M. Ohashi, F. I. Tsuji, Proc. Natl. Acad. Sci. USA 1996, 93, 13617-13622.

[41] N. M. Webber, K. L. Litvinenko, S. R. Meech, The Journal of Physical Chemistry B 2001, 105(33), 8036-8039, DOI 10.1021/jp011430u.

[42] D. Mandal, T. Tahara, S. R. Meech, The Journal of Physical Chemistry B 2004, 108(3), 1102-1108, DOI 10.1021/jp035816b.

[43] A. Usman, O. F. Mohammed, E. T. J. Nibbering, J. Dong, K. M. Solntsev, L. M. Tolbert, Journal of the American Chemical Society 2005, 127(32), 11214-11215, DOI 10.1021/ja0520520.

[44] S. L. Maddalo, M. Zimmer, Photochem Photobiol 2006, 82(2), 367-372, DOI 10.1562/2005-04-11-ra-485.

[45] L. Wu, K. Burgess, Journal of the American Chemical Society 2008, 130(12), 4089-4096, DOI 10.1021/ja710388h.

[46] C. L. D. Gibb, B. C. Gibb, Journal of the American Chemical Society 2004, 126(37), 11408-11409, DOI 10.1021/ja0475611.

[47] A. Baldridge, S. R. Samanta, N. Jayaraj, V. Ramamurthy, L. M. Tolbert, Journal of the American Chemical Society 2010, 132(5), 1498-1499, DOI 10.1021/ja908870k.

[48] M. Andresen, M. C. Wahl, A. Stiel, F. Gräter, L. V. Schäfer, S. Trowitzsch, G. Weber, C. Eggeling, H. Grubmüller, S. W. Hell, S. Jakobs, Proceedings of the National Academy of Sciences of the United States of America 2005, 102(37), 13070-13074, DOI 10.1073/pnas.0502772102.

[49] S. Pletnev, D. Shcherbo, D. M. Chudakov, N. Pletneva, E. M. Merzlyak, A. Wlodawer, Z. Dauter, V. Pletnev, Journal of Biological Chemistry 2008, 283(43), 28980-28987, DOI 10.1074/jbc.M800599200.

[50] S. Gayda, K. Nienhaus, G. U. Nienhaus, Biophysical Journal 2012, 103(12), 2521-2531, DOI 10.1016/j.bpj.2012.11.011.

[51] J. Bigeleisen, M. Wolfsberg, Advance in Chemical Physics 1958, 1, 15-76.

[52] F. H. Westheimer, Chem. Rev. 1961, 61, 265-273.

[53] L. I. Krishtalik, Biochimica et Biophysica Acta 2000, 1458, 6-27.

[54] T. Wilhelm, J. Piel, E. Riedle, Optics Letters 1997, 22(19), 1494-1496.

[55] W. Lauterborn, T. Kurz, Coherent Optics: fundamentals and applications, Springer, 2003. 
[56] J.-C. Diels, W. Rudolph, Ultrashort Laser Puls Phenomena, Elsevier, 2006.

[57] R. Alfano, S. Shapiro, Physical Review Letters 1970, 24(11), 584-587.

[58] A. Brodeur, S. Chin, J. Opt. Soc. Am. B 1999, 16(4), 637-650.

[59] S. L. Chin, S. Petit, F. Borne, K. Miyazaki, Jpn. J. Appl. Phys. 1999, 38, L126-L128.

[60] S. Kovalenko, A. Dobryakov, J. Ruthmann, N. Ernsting, Physical Review A 1999, 59(3), 2369-2384.

[61] L. De Boni, C. Toro, F. Hernández, Optical Society of America 2008.

[62] J. B. Ashcom, R. R. Gattass, C. B. Schaffer, E. Mazur, J. 2006, 23(11), 2317-2322.

[63] (Hrsg.: R. R. Alfano), The Supercontinuum Laser Source, (Hrsg.: R. R. Alfano), Springer, 2006.

[64] A. Zheltikov, Physics - Uspekhi 2006, 49(6), 605-628.

[65] E. Fron, M. Van der Auweraer, J. Hofkens, P. Dedecker, The Journal of Physical Chemistry B 2013, 131213083144001, DOI 10.1021/jp409654f.

[66] J. Schmidt, A. Penzkofer, Chemical Physics 1989, 133, 297-301.

[67] A. C. Stiel, S. Trowitzsch, G. Weber, M. Andresen, C. Eggeling, S. W. Hell, S. Jakobs, M. C. Wahl, Biochemical Journal 2007, 402(1), 35-42, DOI 10.1042/bj20061401.

[68] G. Orlandi, W. Siebrand, Chem. Phys. Lett. 1975, 30, 352-354.

[69] L. V. Schäfer, L. V.fer, G. Groenhof, A. R. Klingen, G. M. Ullmann, M. Boggio-Pasqua, M. A. Robb, H. Grubmüller, H.üller, Angewandte Chemie 2007, 119(4), 536-542, DOI 10.1002/ange.200602315.

[70] A. Vogt, C. D'Angelo, F. Oswald, A. Denzel, C. H. Mazel, M. V. Matz, S. Ivanchenko, G. U. Nienhaus, J. Wiedenmann, PLoS ONE 2008, 3(11), e3766, DOI 10.1371/journal.pone.0003766.

[71] H. Chang, M. Zhang, W. Ji, J. Chen, Y. Zhang, B. Liu, J. Lu, J. Zhang, P. Xu, T. Xu, Proceedings of the National Academy of Sciences of the United States of America 2011, 109(12), 4455-4460.

[72] J. N. Henderson, H.-w. Ai, R. E. Campbell, S. J. Remington, Proceedings of the National Academy of Sciences of the United States of America 2007, 104(16), 6672-6677, DOI 10.1073/pnas.0700059104. 
[73] A. C. Stiel, M. Andresen, H. Bock, M. Hilbert, J. Schilde, A. Schönle, C. Eggeling, A. Egner, S. W. Hell, S. Jakobs, Biophysical Journal 2008, 95(6), 2989-2997, DOI 10.1529/biophysj.108.130146.

[74] T. Grotjohann, I. Testa, M. Leutenegger, H. Bock, N. T. Urban, F. LavoieCardinal, K. I. Willig, C. Eggeling, S. Jakobs, S. W. Hell, Nature 2011, 478(7368), 204-208, DOI 10.1038/nature10497.

[75] T. Grotjohann, I. Testa, M. Reuss, T. Brakemann, C. Eggeling, S. Hell, S. Jakobs, eLife 2012, 1-14, DOI 10.7554/elife.00248.001.

[76] F. V. Subach, L. Zhang, T. W. Gadella, N. G. Gurskaya, K. A. Lukyanov, V. V. Verkhusha, Chemistry \& Biology 2010, 17(7), 745-755, DOI 10.1016/ j.chembiol.2010.05.022. 


\section{Abbildungsverzeichnis}

1.1 Struktur des GFP nach Brejc et al. [7] grün: $\beta$-Faltblatt, rot:

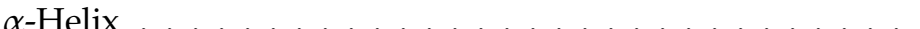

1.2 Reaktionspfad zur Bildung des Chromophors von GFP nach Reid et al. [8| Reaktionsschritte: 1. Zyklisierung, 2. Dehydrierung, 3. Oxidation . . . . . . . . . . . . . . . . . .

1.3 Umgebung und Koordination des GFP-Chromophors nach Ormö et al. |5| gestrichelte Linien: Wasserstoffbrücken, Länge in $\AA$ angegeben . . . . . . . . . . . . . . . . .

1.4 Absorption und Emission des GFP in wässriger Phosphatpufferlösung ( $\mathrm{pH} 7$ ) nach Winkler $|9| \ldots \ldots$. . . . . . . . 4

1.5 Zustandsmodell von GFP . . . . . . . . . . . . . 5

1.6 Pump-Probe und Pump-Dump-Probe Messungen an GFP [17] 6

1.7 Chromophorumgebung von Dronpa nach Andresen et al. [27] Atome und Wasser sind als farbige Kugeln gezeichnet (grau: $\mathrm{C}$, blau: $\mathrm{N}$, rot: $\mathrm{O} / \mathrm{OH}$, türkis: $\mathrm{H}_{2} \mathrm{O}$ Bindungen sind als Striche gezeichnet (grün gestrichelt: Wasserstoffbrücken, schwarze/lila/blau: Atombindung) . . . . . . . . 9

1.8 Spektren von Dronpa nach Ando et al. $\mid 26]$. . . . . . . . . . 10

1.9 Schaltspektren von Dronpa im Ensemble nach Ando et al. |26| 11

1.10 Zustandsmodelle von Dronpa . . . . . . . . . . . . . . 11

1.11 Stationäre Spektren von rsFastLime nach Andresen et al. [32] 13

1.12 Chromophorumgebung von Padron nach Brakemann et al. [23] Atome und Wasser sind als farbige Kugeln gezeichnet (grau: $\mathrm{C}$, blau: $\mathrm{N}$, rot: $\mathrm{O} / \mathrm{OH}$, türkis: $\mathrm{H}_{2} \mathrm{O}$ Bindungen sind als Striche gezeichnet (grün gestrichelt: Wasserstoffbrücken, schwarze/lila/blau: Atombindung) . . . . . . . . . .

1.13 Stationäre Spektren von Padron bei $\mathrm{pH} 7$ nach Brakemann et al. [23] orangene Linie: AN-Zustand, rote Linie: AUSZustand, blaue gestrichelte Linie: Fluoreszenzanregungsspektrum, grüne gestrichelte Linie: Fluoreszenzspektrum . . . . 
1.14 Absorptionszustände im Kryo-Experiment von Faro et al. [33] oben links: Umwandlung von $B_{\text {trans }} \mathrm{zu} I_{\text {cis }}$ durch Bestrahlung bei $523 \mathrm{~nm}$ vei $100 \mathrm{~K}$, Insert: zeitabhängige Maxima der Banden oben rechts: Spontane Umwandlung von $I_{c i s}$ nach $B_{c i s, L T}$ bei $100 \mathrm{~K}$, Insert: zeitabhängige Maxima der Banden unten links: Bildung des Protonierungsgleichgewichts $A_{c i s, R T} \rightleftharpoons B_{c i s, R T}$ bei $\mathrm{T}>180 \mathrm{~K}$ unten rechts: Emissionsspektren von $B_{\text {trans }}, I_{c i s}, B_{c i s, L T}$ und $B_{c i s, R T}$, Insert: reversible Isomerisierung zwischen $B_{\text {trans }}$ und $I_{\text {cis }}$ durch wechselnde Bestrahlung bei 405 und $523 \mathrm{~nm}$..........................

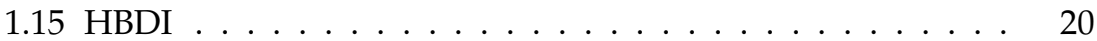

1.16 Photodynamik von HBDI nach Vengris et al. [34] . . . . . . 22

1.17 Erhöhung der Fluoreszenzquantenausbeute von GFP-Y66HChromophor-Analoga durch Fixierung nach Wu et al. [45] a: GFP-Tyr ${ }^{66}$ His-Chromophor-Analog, b: $\Phi_{F}=0.0005$, c: $\Phi_{F}=$

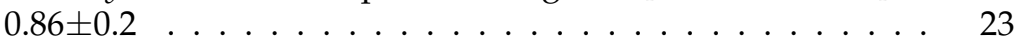

1.18 Torsionswinkel des Chromophors von Padron0.9 . . . . . . 24

1.19 Auswirkungen einer protonierenden Gruppe $X$ in der Umgebung des Chromophors $C$. Rote Kurven bezeichnen protonierte, blaue deprotonierte Chromophore. Gestrichelte Linien beschreiben unterschiedliche Subspezies, durchgezogene Linien jeweils die Summe aller protonierter bzw. deprotonierter Spezies. . . . . . . . . . . . . . . . . .

1.20 Kinetischer Isotopeneffekt am Beispiel von Wasserstoff und Deuterium . . . . . . . . . . . . . . . .

2.1 Schematischer Aufbau des verwendeten UV/Vis Lasersystems ST: Strahlteiler, VE: Verschiebeeinheit, PD: Photodiode, SK: Sapphir/CaF 2 -Kristall, SM: Spektrometer . . . . . . . . .

2.2 Schematischer Aufbau des nicht-kollinearen optisch-parametrischen Verstärkers (non-collinear optical parametric amplifier, NOPA) VE: Verschiebeeinheit, BBO: Beta-Bariomboratkristall, ST: Strahlteiler, LB: Lochblende, SK: Sapphirkristall . . . . . . . . . . 33

2.3 Schematischer Aufbau zur Erzeugung der zweiten Harmonischen (SHG) und Summenfrequenz (SFG) BBO: Beta-Bariumboratkristall, DS: Dielektrischer Spiegel, LH: $\lambda / 2$-Platte, BE: Verschiebeeinheit .................... 35

2.4 Schematischer Aufbau der Weisslichterzeugung LH: $\lambda / 2$-Platte, GF: Graufilter, LB: Lochblende, $\mathrm{CaF}_{2}-$ Kristall . . . . . . . 36

2.5 Das erzeugte Weißlichtkontinuum . . . . . . . . . . . 37 
2.6 Schematischer Aufbau des Interferometers S1,2: Planspiegel, S3,6: Konvexspiegel, S4,5: Konkavspiegel, ST: Strahlteiler, SM1,2: Spektrometer mit Diodenzeile, TF: Tiefpass-Kantenfilter

2.7 Auftretende Abbildungsfehler . . . . . . . . . . . . 39

2.8 Schematischer Aufbau des Probekreislaufs PP: Peristaltikpumpe, BK: Bestrahlungskammer, LED: Lichtemittierende Diode

2.9 Reaktionsschema und korrespondierende Differenz-Konzentrationsspektren der beteiligten Spezies mit und ohne Dumppuls nach Anregung durch einen Pumpuls . . . . . . . . . . . . 44

2.10 Elektrische Steuerung und Datenaufnahme. Signaleingang: links, Signalausgang: rechts DT: Steuerelektronik Pockelszelle, DS: Diodensteuerung, CS: Choppersteuerung, $\mathrm{CH}$ : Chopper, PD: Photodiode, DG: Delay-Generator, PG: Pulsgenerator, DC1: Diodentreiber, SM1,2: Spektrometer mit Diodenzeile, AD: Analog/Digitalwandler, GPIB: GPIB-Karte, PVE: Verschiebeeinheit ............... 45

2.11 Anpassung der wellenlängenabhängigen Nullpunkte . . . . 47

2.12 Darstellung der einzelnen Schritte bei der Erstellung der Funktion zur Anpassung transienter Daten. Die gepunktete Linie markiert $t_{0}$.

3.1 pH-Abhängige Absorptionsspektren des cis- (a) und transIsomers (b) von Padron0.9. Gemessene Spektren sind als offene Kreise dargestellt, die durchgezogenen Linien sind Anpassungen der gemessenen Spektren nach dem Modell 3.9a Die Spektren sind auf einen Absorptionspeak der Proteinumgebung bei $290 \mathrm{~nm}$ normiert. . . . . . . . . . . . . . . . . . . . .

3.2 Absorptionsspektren der Isomere von Padron0.9 bei $\mathrm{pH} 4$ (rote Linien) und nach anschließender Änderung des $\mathrm{pH}$ Wertes auf $\approx 7$ (grüne Linien) . . . . . . . . . . . .

3.3 Modell der Protonierung des Chromophors $C$ (respektive $T$ ) von Padron0.9 mit zwei protonierenden Gruppen $X$ und $Y$ in unmittelbarer Umgebung. Spezies mit identischen Absorptionsspektren sind mit der gleichen Farbe unterlegt. Die pK-Werte aus der Anpassung der Absorptionsspektren für cis- und trans-Isomer (in Klammern) sind angegeben. . . . .

3.4 Modell des Protonierungsgleichgewichtes von Padron0.9, pHabhängige Konzentrationen und ihre Absorptionsspektren . 
3.5 Emissionsspektren von Padron0.9. Punkte: gemessene Daten, durchgezogene Linie: Anpassung der Daten mit einer Summe von Gaußfunktionen, gestrichelte Linie: einzelne Gaußfunktionen . . . . . . . . . . . . . . . . 61

3.6 Vergleich der transienten Spektren von Padron $0.9, \lambda_{p}=505 \mathrm{~nm}$, bei pH 7 (orange) und pH 10 (blau) zu verschiedenen Verzögerungszeiten . . . . . . . . . . . . . . . . . . .

3.7 Transiente Spektren von Padron 0.9 bei $\mathrm{pH} 10$ nach Anregung bei $505 \mathrm{~nm}$ bei verschiedenen Verzögerungszeiten. $\circ$ : aufgenommenen Daten, $/$ : Anpassung durch das kinetische Modell in Fig 3.9a . . . . . . . . . . . . . . . . . . . .

3.8 Amplitudenspektren der exponentiellen Anpassung der transienten Daten von Padron0.9 bei pH 10 nach Anregung bei $505 \mathrm{~nm}$. . . . . . . . . . . . . . . . . . . . .

3.9 Modell der photoinduzierten Dynamik von Padron0.9 nach Anregung der $C^{-}$- und $T^{-}$-Spezies bei $\lambda_{p}=505 \mathrm{~nm}$, zeitabhängige Konzentrationen der beteiligten Spezies und ihre Absorptionsspektren . . . . . . . . . . . . . . . . . .

3.10 Vergleich der transienten Spektren von Padron0.9, cis-Isomer, $\lambda_{p}=387 \mathrm{~nm}$, bei $\mathrm{pH} 7$ (orange) und $\mathrm{pH} 10$ (blau) zu verschiedenen Verzögerungszeiten . . . . . . . . . . . . . . . . .

3.11 Transiente Spektren des cis-Isomers von Padron 0.9 bei $\mathrm{pH} 10$ nach Anregung bei $387 \mathrm{~nm}$ bei verschiedenen Verzögerungszeiten. $\circ$ : aufgenommenen Daten, $/$ : Anpassung durch das kinetische Modell in Fig 3.13a . . . . . . . . . . . . . . .

3.12 Amplitudenspektren der exponentiellen Anpassung der transienten Daten des cis-Isomers von Padron0.9 bei $\mathrm{pH} 10$ nach Anregung bei $387 \mathrm{~nm}$.

64

65

70

72

73

74

3.13 Modell der photoinduzierten Dynamik von Padron0.9 nach Anregung der $C^{H}$-Spezies durch $\lambda_{p}=387 \mathrm{~nm}$, zeitabhängige Konzentrationen der beteiligten Spezies und ihre Absorptionsspektren . . . . . . . . . . . . . .

3.14 Pump-Dump-Probe-Spektroskopie an Padron0.9 mit $\lambda_{p}=$ $387 \mathrm{~nm}$ und $\lambda_{d}=560 \mathrm{~nm}, \Delta \mathrm{t}_{d}=40 \mathrm{ps} \ldots \ldots \ldots \ldots$

3.15 Modell der photoinduzierten Dynamik von Padron0.9 nach Anregung der $C^{H}$-Spezies durch $\lambda_{p}=387 \mathrm{~nm}$ und Dumpen durch $\lambda_{d}=560 \mathrm{~nm} 40$ ps nach Anregung, zeitabhängige Konzentrationen der beteiligten Spezies und ihre Absorptionsspektren . . . . . . . . . . . . . . . .

3.16 Transiente Spektren von Padron 0.9 bei $\mathrm{pH} 4$ nach Anregung bei $387 \mathrm{~nm}$ bei verschiedenen Verzögerungszeiten . . . . . . 
3.17 Amplitudenspektren der exponentiellen Anpassung der transienten Daten von Padron0.9 bei pH 4 nach Anregung bei 387 nm. . . . . . . . . . . . . . . . .

3.18 Modell der photoinduzierten Dynamik von Padron0.9 nach Anregung der $C^{H+}$-Spezies durch $\lambda_{p}=387 \mathrm{~nm}$, zeitabhängige Konzentrationen der beteiligten Spezies und ihre Absorpti-

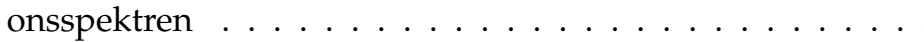

3.19 pH-abhängige Absorptionsspektren von rsFastlime. Gemessene Spektren sind als offene Kreise dargestellt, die durchgezogenen Linien sind Anpassungen der gemessenen Spektren nach dem Modell 3.9a. Die Spektren sind auf einen Absorptionspeak der Proteinumgebung bei 290 nm normiert. . . . . .

3.20 Modell der Protonierung des Chromophors $C$ von rsFastlime mit zwei protonierenden Gruppen $X$ und $Y$ in unmittelbarer Umgebung. Spezies mit identischen Absorptionsspektren sind mit der gleichen Farbe unterlegt. Die pK-Werte aus der Anpassung der Absorptionsspektren für das cis-Isomer sind

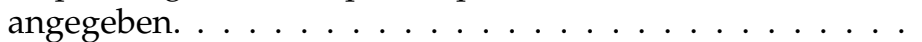

3.21 Modell des Protonierungsgleichgewichtes von rsFastlime, $\mathrm{pH}$-abhängige Konzentrationen und ihre Absorptionsspektren

3.22 Fluoreszenz- und stimuliertes Emisssionsspektrum nach Gl. 3.2. $\lambda_{p}=500 \mathrm{~nm}, \mathrm{pH} 7 \ldots \ldots . \ldots$

3.23 Transiente Spektren von rsFastlime bei pH 7 nach Anregung bei $505 \mathrm{~nm}$ bei verschiedenen Verzögerungszeiten. $\circ$ : aufgenommene Daten, / : Anpassung durch 2-Zustandsmodell. .

3.24 Amplitudenspektren der exponentiellen Anpassung der transienten Daten von rsFastlime bei pH 7 nach Anregung bei 505 nm.

3.25 Spektren der an der photoinduzierten Dynamik von rsFastlime nach Anregung der $C^{-}$-Spezies bei $\lambda_{p}=505 \mathrm{~nm}$ beteiligten

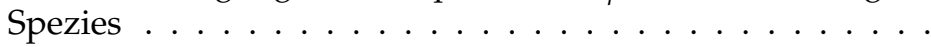

3.26 Transiente Spektren von rsFastlime bei pH 7 nach Anregung bei $387 \mathrm{~nm}$ bei verschiedenen Verzögerungszeiten. $\circ$ : aufgenommenen Daten, / : Anpassung durch die kinetischen Modelle in Abb. 3.28a und 3.29a. . . . . . . . . . . . .

3.27 Amplitudenspektren . . . . . . . . . . . . . . 96

3.28 Modell der an der photoinduzierten Dynamik von rsFastLime nach Anregung der $C^{H}$-Spezies durch $\lambda_{p}=387 \mathrm{~nm}$, zeitabhängige Konzentrationen der beteiligten Spezies und ihre Absorptionsspektren . . . . . . . . . . . . . . 100

3.29 Spektren der Spezies aus a . . . . . . . . . . . . 102 
3.30 Modell der photoinduzierten Dynamik von rsFastLime nach Anregung der $T^{H}$-Spezies durch $\lambda_{p}=387 \mathrm{~nm}$, zeitabhängige Konzentrationen der beteiligten Spezies und ihre Absorptionsspektren . . . . . . . . . . . . . . 102

3.31 Zusammenfassung der kinetischen Modelle zur Beschreibung der Dynamik nach Photoanregung der einzelnen Spezies. Vermutete Wege der Isomerisierung sind als gestrichelte Linien

3.32 Geschwindigkeitskoeffizienten der kinetischen Modelle zur Beschreibung der Dynamik nach Photoanregung der einzelnen Grundzustandsspezies . . . . . . . . . . . . . . . 106

3.33 Allgemeines Schaltmodell und Konzentrationsverlauf der Grundzustandspezies. $10<\mathrm{t}<50: \lambda_{e x}=400 \mathrm{~nm}, \mathrm{t}>=50: \lambda_{e x}=500 \mathrm{~nm}$ 108 


\section{Tabellenverzeichnis}

1.1 Lebensdauern von HBDI in verschiedenen Lösungsmitteln

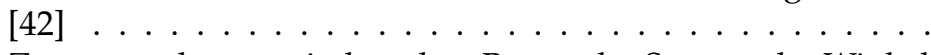

1.2 Zusammenhang zwischen dem Betrag der Summe der Winkel $\phi$ und $\tau$ und der Fluoreszenzquantenausbeute $\Phi_{F}$ für einige ausgewählte Proteine $[23] \ldots \ldots \ldots$. . . . . . . .

2.1 Verwendete Puffer-Lösungen für verschiedene $\mathrm{pH}$-Werte und Messungen. Die Angaben beziehen sich auf jeweils $100 \mathrm{~mL}$ Pufferlösung in zweifach destilliertem Wasser (Aqua bidest) .

3.1 Absorptionsmaxima $A b s_{\max }$ der AN- und AUS-Zustände einiger RSFPs und Schaltrichtung bei Bestrahlung derselben. Weitere wichtige Absorptionsbanden sind in Klammern angegeben. * Bestrahlung bei der angegebenen Wellenlänge schaltet das Protein ** die genaue Lage der Absorptionsbanden von rsCherry und rsCherryRev sind nicht angegeben, Bestrahlung bei der angegebenen Wellenlänge schaltet das Protein . . . .

A.1 Parameter zur Beschreibung der Speziesspektren von Padron0.9 im Grundzustand (Abb. 3.4) durch Gaussfunktionen

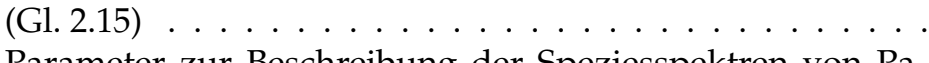

A.2 Parameter zur Beschreibung der Speziesspektren von Padron0.9 nach Anregung von $C^{-}$und $T^{-}$durch $\lambda_{p}=505 \mathrm{~nm}$ bei pH 10 (Abb. 3.9c) durch Gaussfunktionen (Gl. 2.15) . . . 115

A.3 Parameter zur Beschreibung der Speziesspektren von Padron0.9 nach Anregung von $\mathrm{C}^{\mathrm{H}}$ durch $\lambda_{p}=387 \mathrm{~nm}$ bei $\mathrm{pH} 10$ (Abb. 3.13c) durch Gaussfunktionen (Gl.2.15) . . . . . . . . . 116

A.4 Parameter zur Beschreibung der Speziesspektren von Padron0.9 nach Anregung von $C^{H}$ durch $\lambda_{p}=387 \mathrm{~nm}$ und Dumpen nach $40 \mathrm{ps}$ durch $\lambda_{d}=560 \mathrm{~nm}$ bei $\mathrm{pH} 10$ (Abb. 3.15c) durch Gaussfunktionen (G1.2.15) . . . . . . . . . . . . . .

A.5 Parameter zur Beschreibung der Speziesspektren von Padron0.9 nach Anregung von $C^{H}+$ durch $\lambda_{p}=387 \mathrm{~nm}$ bei pH 4 (Abb. 3.16) durch Gaussfunktionen (Gl.2.15) . . . . . . 
A.6 Parameter zur Beschreibung der Speziesspektren von rsFasLime im Grundzustand (Abb. 3.21) durch Gaussfunktionen (Gl. 2.15) . . . . . . . . . . . . . . . . . 119

A.7 Parameter zur Beschreibung der Speziesspektren von rsFasLime nach Anregung von $\mathrm{C}^{-}$durch $\lambda_{p}=505 \mathrm{~nm}$ bei $\mathrm{pH} 10$ (Abb. 3.25) durch Gaussfunktionen (Gl.2.15) . . . . . . . . . 120

A.8 Parameter zur Beschreibung der Speziesspektren von rsFasLime nach Anregung von $\mathrm{C}^{H}$ durch $\lambda_{p}=387 \mathrm{~nm}$ bei $\mathrm{pH} 10$ (Abb. 3.28c) durch Gaussfunktionen (Gl. 2.15) . . . . . . . . . 121

A.9 Parameter zur Beschreibung der Speziesspektren von rsFasLime nach Anregung von $T^{H}$ durch $\lambda_{p}=387 \mathrm{~nm}$ bei $\mathrm{pH} 10$ (Abb. 3.28c) durch Gaussfunktionen (Gl. 2.15) . . . . . . . . . 122 